$$
\begin{gathered}
\text { UNIVERSITY OF CALIFORNIA } \\
\text { COLLEGE OF AGRICULTURE } \\
\text { AGRICULTURAL EXPERIMENT STATION } \\
\text { BERKELEY, CALIFORNIA }
\end{gathered}
$$

\title{
Precooling Investigations With Deciduous Fruits
}

\author{
F. W. ALLEN AND L. R. McKINNON
}

\section{BULLETIN 590}

June, 1935 
Introduction

PAGE

Influence of temperature upon ripening _ . . . . . . . . . . . . 5

Effects of delayed cooling . . . . . . . . . . . . . . . . . . . . . 56

Meaning of precooling . . . . . . . . . . . . . . . . . . 7

Methods of precooling . . . . . . . . . . . . . . . . . . . . . 8

Heat in fruit . . . . . . . . . . . . . . . . . . . . . . 9

Removal of heat from fruit . . . . . . . . . . . . . . . . . . . . . . . . . . . . . . . . .

Refrigeration necessary for precooling . . . . . . . . . . . . . . . 11

Outline of experimental work . . . . . . . . . . . . . . . . . . . 14

Car-cooling equipment . . . . . . . . . . . . . . . 14

Methods of operating equipment . . . . . . . . . . . . . . 16

Securing temperatures during precooling . . . . . . . . . . . . . 17

Securing temperatures in transit . . . . . . . . . . . . 18

Temperature and condition of fruit on arrival . . . . . . . . . 18

Holding tests of precooled and nonprecooled fruit _ . . . . . 19

Tests with cherries . . . . . . . . . . . . . . . . 19

Tests with apricots . . . . . . . . . . . . . . . . . . . . . 39

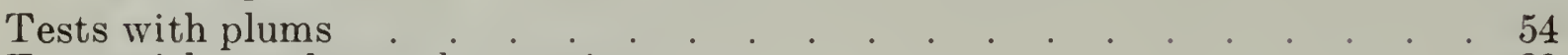

Tests with peaches and nectarines . . . . . . . . . . . . . . . . $\quad . \quad 80$

Tests with pears . . . . . . . . . . . . . . . . . . . . . . . . 86

Tests with apples

Tests with grapes . . . . . . . . . . . . . . . . . . . . . 114

General discussion of precooling in warehouse rooms . . . . . . . . 117

Type of rooms . . . . . . . . . . . . . . . . . . 117

Movement of air . . . . . . . . . . . . . . . . . . . . . . 120

Humidity . . . . . . . . . . . . . . . . . . . . 121

Commercial handling methods . . . . . . . . . . . . . . . 121

Air temperatures in precooling rooms . . . . . . . . . . . . . . 123

General discussion of precooling in refrigerator cars . . . . . . . . 123

Cooling equipment . . . . . . . . . . . . . . . . . 124

Quantities and methods of handling ice and salt . . . . . . . . . 124

Placing and reading thermometers . . . . . . . . . . . . . 128

Air temperatures during precooling . . . . . . . . . . . . . . . . 130

Fruit temperatures secured in precooling $\quad$. . . . . . . . . . . . . 132

Miscellaneous considerations . . . . . . . . . . . . . . . . 133

Car versus warehouse cooling . . . . . . . . . . . . . . . . . . . 134

Methods of shipping precooled fruit . . . . . . . . . . . . . . 135

Standard refrigeration . . . . . . . . . . . . . . . . . . . . 135

Rule 247: initial icing, and one re-icing in transit . . . . . . . 136

Rule 254: initial icing, ice replenished, and one re-icing in transit . . . 136

Rule 240: initial icing only . . . . . . . . . . . . . . . 137

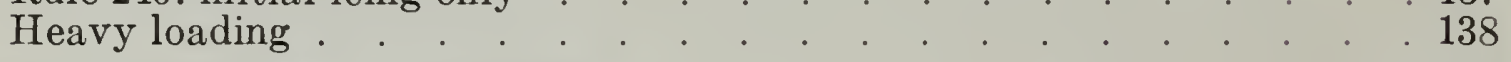

General summary and conclusions . . . . . . . . . . . . . . 139

Acknowledgments . . . . . . . . . . . . . . . . . 142 


\title{
PRECOOLING INVESTIGATIONS WITH DECIDUOUS FRUITS ${ }^{1}$
}

\author{
F. W. ALLEN ${ }^{2}$ AND L. R. MCKINNON ${ }^{3}$
}

\section{INTRODUCTION}

"From THE STANDPoINT of the keeping of fruit in transit, an economical, practical method is needed to reduce the temperature of the fruit more quickly after packing than is accomplished by the ordinary refrigerator car."

This statement, made thirty years ago by G. Harold Powell ${ }^{4}$ in pointing out the need of precooling, together with his successful cooling of a car of Georgia peaches, initiated a practice now extremely important to California fruit growers and shippers. The truth of Powell's statement was quickly recognized. The chief problem was to perfect the economical, practical method needed.

Space here does not permit even a brief review of the developments of this work in California. ${ }^{5}$ The expenditure of large sums for precooling plants and equipment, with extensive trials and investigations, has resulted in more efficient methods, identical, for the most part, with those suggested by Powell. Despite these improvements, precooling of deciduous fruits has in the past been confined largely to berries, cherries, a few apricots, and some of the late pears for export shipment. In most fruit-growing districts, cooling facilities were not available; and to build suitable plants for operation during only a short period each year was considered impracticable. The assemblying of cars of deciduous fruits at precooling plants resulted in congestion, delay in shipments, and considerable expense. Portable car-cooling outfits, until recently, proved more or less disappointing because of the limited cooling capacity and because they delayed bracing until precooling was com-

1 First received for publication June 14, 1934; withdrawn for insertion of 1934 data and resubmitted F'ebruary 15, 1935.

2 Associate Pomologist in the Experiment Station.

3 Refrigeration Technician.

4 Powell, G. Harold. The transportation of fruit in refrigeration. Amer. Soc. Refrig. Engin. Trans. 1:82-94. 1905. Also in : California Fruit Grower 33(919):1-3, Jan. 6. 1906; and 33(920):5. Jan. 13, 1906.

5 Covered in part by: Stubenrauch, A. V., and S. J. Dennis. The precooling of fruit. U. S. Dept. Agr. Yearbook 1910:437-448. 
pleted. Moreover, though precooled fruit requires less ice in transit than nonprecooled, this fact was not recognized by refrigeration tariffs; and the advantages of precooling usually seemed not to justify the extra expense. Precooling for deciduous fruits, as a general practice, had been retarded primarily because the economic problem had not been solved.

In 1932, however, shippers secured the coöperation of the carriers in permitting fruit to be shipped with only one re-icing in transit, at refrigeration charges materially lower than those for standard refrigeration, which calls for daily re-icing. This concession granted by the carriers, followed by still other modified icing services in 1933, has paved the way for the economic solution of the precooling problem; and, together with the recent development of more efficient car-precooling equipment than any previously used, has already changed fruit-handling methods in a manner which has been characterized as revolutionary. Definite data on the carloads of deciduous fruits cooled since 1932 are not available; but as some shipping companies report precooling from 60 to 100 per cent of their cherries, apricots, plums, peaches, pears, and grapes, in 1934, precooling is now evidently more extensive than at any previous time. Figures supplied by the Pacific Fruit Express alone show that on their lines north of the Tehachapi, 4,334 cars were precooled in 1932, 9,121 cars in 1933 , and 14,741 cars in $1934 .^{6}$

If good condition is to be guaranteed at destination, many boat lines now demand that export shipments, particularly pears, be precooled before loading. The refrigerated holds of most boats can carry a cool cargo satisfactorily but usually lack sufficient refrigeration for the initial cooling of large quantities of warm fruit within the desired period.

To a somewhat lesser extent the same condition exists in refrigerator cars, and with new types of car-cooling equipment, many shippers have been interested in the development of the most efficient operating methods, the rate and uniformity of cooling for different fruits after loading, the temperatures in precooled cars during transit, and the general condition of the fruit upon arrival. This report briefly describes precooling principles in general and covers three seasons' investigations with the more important deciduous fruits, under both refrigerator-car and warehouse conditions. Results of individual tests are first described and shown graphically, then the authors' observations are discussed as a whole.

In addition to a general discussion of precooling, this publication contains much detailed information with individual precooling tests. For ${ }^{6}$ Anonymous. Precooling deciduous fruits. Blue Anchor [California Fruit Exchange] $12(2): 12$. February, 1935. 
those to whom this technical detail is of little or no interest, the general results are summarized after discussing each fruit and more briefly in the general summary and conclusions.

\section{INFLUENCE OF TEMPERATURE UPON RIPENING}

Ripening changes, which begin before harvesting, are normally accelerated after picking. These changes, both chemical and plysical, can best be retarded by low temperature. Previous tests with plums ${ }^{7}$ showed that fruit harvested at the usual maturity for eastern shipment and held for 12 days at $43^{\circ}$ Fahrenheit softened approximately as much as did similar lots held for only 6 days at $52^{\circ}$; after 12 days at the higher temperature a considerable proportion liad softened and colored to such an extent as to be considered overripe. Fruit held at $43^{\circ}$ was usually in good market condition.

Similar results have been secured with apricots and Bartlett pears. The latter, held under temperatures of $65^{\circ}, 53^{\circ}$, and $43^{\circ} \mathrm{F}$, showed little softening until from 6 to 18 days after harvesting. ${ }^{8}$ The time required for ripening was, however, materially influenced by the temperature at which the pears were held. Under storage conditions the commercial life of the fruit was limited to 30 days at a temperature of $43^{\circ}$, 60 days at $36^{\circ}$, and 100 days at $31^{\circ}$.

Magness and others, ${ }^{9}$ measuring softening of several varieties of a ples, found that specimens held 1 day at $70^{\circ} \mathrm{F}$ softened approximately as much as they did in 2 days at $50^{\circ}, 4$ days at $40^{\circ}, 8-10$ days at $32^{\circ}$, or 12 days at $30^{\circ}$. The chemical changes at these temperatures, as measured by the rate of respiration, also differed markedly under different temperatures and were closely correlated with softening.

Haller and others, ${ }^{10}$ measuring the respiration rate of strawberries, peaches, and citrus fruits at different temperatures, found that Elberta peaches held at $40^{\circ} \mathrm{F}$ gave off carbon dioxide 1.5 times as rapidly as at $32^{\circ}$, while fruit held at $50^{\circ}$ respired 2.5 times as rapidly as at $40^{\circ}$. In the earlier work of Gore ${ }^{11}$ the average rate of respiration for forty different

i Allen, F. W., J. R. Magness, and M. H. Haller. The relation of maturiy of California plums to shipping and dessert quality. California Agr. Exp. Sta. Bul. 428:1-41. 1927.

8 Magness, J. R., H. C. Diehl, and F. W. Allen. Investigations on the handling of Bartlett pears from Pacific Coast districts. U. S. Dept. Agr. Tech. Bul. 140:1-27. 1929.

9 Magness, J. R., H. C. Diehl, and M. H. Haller, and others. The ripening, storage, and handling of apples. U. S. Dept. Agr. Dept. Bul. 1406:1-64. 1926.

10 Haller, M. H., P. L. Harding, J. M. Lutz, and D. H. Rose. Tle respiration of some fruits in relation to temperature. Amer. Soc. Hort. Sci. Proc. 1931:583-589. 1932.

11 Gore, H. C. Studies on fruit respiration. U. S. Dept. Agl'. Bur. of Chem. Bul. 142:1-40. 1911 . 
kinds of fruits was found to increase from 1.89 to 3.01 times, or an average of 2.3 times, for each $10^{\circ}$ Centigrade or $18^{\circ}$ Fahrenheit rise in temperature.

Overholser and Latimer, ${ }^{12}$ working with several varieties of late pears, found the average maximum keeping period of Anjou, Comice, Bose, and IIowell to be 143 days under a temperature of $30^{\circ} \mathrm{F}$ and only 37 days under a temperature of $45^{\circ}$.

Pentzer and others ${ }^{13}$ found the storage life of such varieties as Hardy and Comice to be one-half to one-third less at $36^{\circ} \mathrm{F}$ than at $31^{\circ}$. These varieties had a storage life of approximately 30 days at $43^{\circ}$ and about 15 days at $53^{\circ}$. As compared with nonprecooled pears, lower transit temperatures of precooled shipments were generally found to add 1 to 2 months to the life of the fruit subsequently stored.

\section{EFFECTS OF DELAYED COOLING}

The rapid ripening of fruit held at high temperatures after harvesting may be further emphasized by brief mention of a few experimental tests comparing the effects of immediate versus delayed cooling. The early work of Ramsey ${ }^{14}$ in the Northwest with red raspberries, cherries, and fresh prunes is outstanding. Raspberries cooled immediately after picking and held in a refrigerator car for 4 days showed 7 per cent decay, as ompared with 27 per cent decav where cooling was delayed some 24 hours. Cherries picked 2 days before loading into a refrigerator car showed 25 per cent decay after 10 days, whereas when cooled immediately after harvesting they developed only 13.5 per cent decay.

Brooks and Cooley, ${ }^{15}$ experimenting with the rotting of peaches, found that inoculating fruits with Rhizopus and holding for 24 hours at a temperature of $77^{\circ} \mathrm{F}$ before storing at $45^{\circ}$ gave the rots a 5 -day lead over similar inoculations where cooling was delayed only 12 hours. Lloyd and Newell ${ }^{16}$ found that Elberta peaches harvested at the ordinary stage of maturity for commercial shipment, but picked 4,24 , and 48 hours before loading into the top of a refrigerator car, showed marked differences

12 Overlolser, E. L., and L. P. Latimer. The cold storage of pears. California Agr. Exp. Sta. Bul. 377:1-56. 1924. (Out of print.)

13 Pentzer, W. T., J. R. Magness, H. C. Diehl, and M. H. Haller. Investigations in the harvesting and handling of fall and winter pears. U. S. Dept. Agr. Tech. Bul. 290:1-30. 1932.

14 Ramsey, H. J. Factors governing the successful shipment of red raspberries from the Puyallup Valley. U. S. Dept. Agr. Bul. 274:1-37. 1915.

Ramsey, H. J. The handling and shipping of fresh cherries and prunes from the Willamette Valley. U. S. Dept. Agr. Bul. 331:1-28. 1916.

15 Brooks, Charles, and J. S. Cooley. Time-temperature relations in different types of peach-rot infections. Jour. Agr. Research 37:507-543. 1928.

16 Lloyd, J. W., and H. M. Newell. Some factors influencing the keeping quality of fruit in transit. Illinois Agr. Exp. Sta. Bul. 330:451-484. 1930. 
in condition after a week's transit period. Similar results were obtained with strawberries and summer apples.

Morris ${ }^{1 \tau}$ found that Rome Beauty apples softened more rapidly in the first 24 hours at temperatures of $75^{\circ}-80^{\circ} \mathrm{F}$ than in any other succeeding 24-hour period.

Hartman and others ${ }^{18}$ found that holding Bose pears for a week at $66^{\circ} \mathrm{F}$ before placing them in cold storage reduced their storage life 2 months.

Mann ${ }^{19}$ reports that a delay of $24-48$ hours in handling and refrigeration greatly increased decay and deterioration in Malaga grapes after shipment.

\section{MEANING OF PRECOOLING}

Precooling is a form of refrigeration employed for the rapid removal of the field heat from fruit before shipping, mainly in order to reduce the temperature to a point where ripening will be materially arrested and mold growth prevented. For optimum results, especially with very perishable products, the heat must be removed as soon as possible after harvesting; and cooling must continue long enough to reduce the center of the packages to a suitable carrying temperature. This temperature varies with the product shipped, the type of container, the manner of shipping, and the period of transit. Berries, being more perishable, may require a lower temperature than pears or apples. Carrying temperatures considered satisfactory in refrigerator cars for a 10-day transcontinental shipment may not be satisfactory for a 30-day transoceanic voyage.

In the absence of definite precooling standards, the term "precooled" has sometimes been applied to fruit where only the "top" heat is removed and where at time of shipping the temperature in the center of the packages was between $50^{\circ}$ and $60^{\circ} \mathrm{F}$. Although such limited cooling has some value, most deciduous fruits will ripen rapidly at these temperatures, and fruit so treated should preferably not be labeled or advertised as precooled. When fruit in the center of packages is cooled to $40^{\circ}$ it can be transported in well-iced refrigerator cars for 10 days under maximum air temperatures gradually increasing from about $40^{\circ}$ to $48^{\circ}$. Such transit temperatures are sufficiently different from those in most nonprecooled cars that effects of precooling will be evident. Fruit cooled to

17 Morris, O. M. Studies in apple storage. Washington Agr. Exp. Sta. Bul. 193:1-44. 1925.

18 Hartman, Henry, J. R. Magness, F. C. Reimer, and M. H. Haller. Investigations on the harvesting and handling of Bose pears from the Rogue River Valley. Oregon Agr. Exp. Sta. Bul. 228:1-30. 1927.

19 Mann, C. W. The handling of California table grapes. U. S. Dept. Agr. Cir. $83: 1-14.1929$. 
$32^{\circ}-34^{\circ}$ will carry under a slightly lower air temperature during the first few days in transit and, in a well-constructed car in good repair and kept well iced, may even arrive at destination slightly colder than if precooled only to $40^{\circ}$. Since, however, the temperature of refrigerator cars at the time of loading is not generally below $45^{\circ}-50^{\circ}$, and the ice in the car does not maintain an average air temperature lower than $40^{\circ}-50^{\circ}$, the advantages gained by precooling car shipments to $32^{\circ}-34^{\circ}$ are not always so great as anticipated. Cooling to these temperatures is most effective when the car itself is precooled to a temperature approximating that of the fruit loaded, or in the case of heavy loads of tightly packed fruit, in which the fruit itself assists in maintaining a low air temperature; likewise boat shipments in which precooled temperatures may be maintained by mechanical refrigeration.

\section{METHODS OF PRECOOLING}

Fruit may be precooled either before or after loading in refrigerator cars. In the former case, precooling is usually carried out in a coldstorage warehouse under mechanical refrigeration and is spoken of as warehouse cooling. Car cooling, as the term indicates, takes place after loading; it may or may not be by mechanical refrigeration. Where cars are assembled for cooling, cold air from a precooling plant or cold storage may be circulated through them. At present, however, cooling of deciduous fruits in cars primarily depends upon ice as the refrigerant. Fans in the car circulate the air over and through the loat and back through the ice much more rapidly than occurs normally; and, by adding suitable quantities of salt to the ice during precooling, air temperatures can be lowered to any desired point.

A combination of these two methods of cooling now employed in several districts is that of a small precooling unit located in, or adjacent to, track side packing houses. Such units, usually of two rooms of 1 to 4 -car capacity, are equipped with an ice bunker-room and fans; the fruit being cooled by the usual car-cooling method. Where fruit deliveries are slow and irregular; where it is desirable to extend the precooling period longer than is feasible in refrigerator cars; or, where the installation of mechanical refrigerating equipment is not justified, such units serve a definite purpose and their use may increase.

Mechanical refrigerating units in cars and also the use of solid carbon dioxide as a refrigerant are still in the experimental stage and the writers have not conducted any tests on these cooling methods.

Under certain conditions, partial precooling may be accomplished by allowing fruit picked during the warmer part of the day to stand in an 
open shed overnight before packing or loading. As pointed out by Overholser and Moses, ${ }^{20}$ in some fruit-growing sections during harvesting there may be as much as $50^{\circ}$ difference between day and night temperature. Differences of $44^{\circ}$ were experienced by the writers at Placerville on September 7 and 8, 1933, when air temperatures during a 24 hour period ranged from $86^{\circ}$ to $42^{\circ} \mathrm{F}$.

\section{HEAT IN FRUIT}

The intensity of heat of a substance, or its thermal state, is known as its temperature. Since heat is a form of activity or energy consisting of molecular vibrations, the substance becomes warmer or colder as the molecular movement within increases or decreases in the presence of warmer or colder substances. The quantity of heat in any substance is the sum of the kinetic energy or random motion of its molecules and, since it cannot be perceived directly, can be measured only by its effects. In the United States and England the arbitrary unit of measurement is the British thermal unit (B.t.u.), representing the amount of heat required to raise the temperature of 1 pound of water $1^{\circ} \mathrm{F}$.

To be entire? $y$ devoid of heat a substance must be reduced to absolute zero $\left(-273^{\circ} \mathrm{C}\right.$ or $\left.-459.4^{\circ} \mathrm{F}\right)$. In commercial storage, however, or in precooling practice, the heat in fresh fruits is usually computed from the freezing point of pure water, or $32^{\circ} \mathrm{F}$. Substituting $32^{\circ} \mathrm{F}$ as a base instead of absolute zero, one ascertains the heat in fruit at $80^{\circ}$, for example, by multiplying the weight, in pounds, by the specific heat, ${ }^{21}$ and the result by the difference between the existing temperature and the base temperature to which the fruit is to be cooled. Thus,

$$
2,000 \times 0.9 \times 48=86,400 \text { B.t.u. }
$$

approximates the heat above $32^{\circ}$ which a ton of fruit may contain at a given moment.

In addition to the "field heat" which it contains, fruit is constantly producing heat as a result of respiration. This heat of respiration may be obtained either by comparing temperature differences between a fruit carrying on respiration and a nonliving substance of the same heat capacity; or by calculation based upon the rate of carbon dioxide evolved

20 Overholser, E. L., and B. D. Moses. Precooling of fresh fruits and temperatures of refrigerator cars and warehouse rooms. California Agr. Exp. Sta. Bul. 496:1-34. 1930 .

21 The B.t.u. required to raise the temperature of 1 pound of product $1^{\circ} \mathrm{F}$. For most fruits and vegetables the value of 0.9 B.t.u. per degree Fahrenheit is used. The specific heat for Bartlett pears calculated from data given by Rose, et al., would be 0.872 B.t.u. (Rose, Dean H., R. C. Wright, and T. M. Whiteman. The commercial storage of fruits, vegetables. and florists' stocks. U. S. Dept. Agr. Cir. 278:7. 1933.) 
(usually expressed in milligrams per kilogram of fruit per hour, or the $\mathrm{mg}$ of $\mathrm{CO}_{2}$ per $\mathrm{kg}$.-hr.) and the heat of combustion of the sugars consumed in respiration. Griffiths and Awberry, ${ }^{22}$ and Smith ${ }^{23}$ report that they calculated the approximate heat of respiration without actually measuring the $\mathrm{CO}_{2}$ output.

Hawkins, ${ }^{24}$ however, has compiled the respiration rates obtained by numerous investigations from $\mathrm{CO}_{2}$ output and has computed the heat of respiration in B.t.u. According to his data, a ton of peaches held for 24 hours at $32^{\circ} \mathrm{F}$ will liberate 1,540 B.t.u., whereas if held under a temperature of $80^{\circ}$ they will liberate 15,400 B.t.u. The heat of respiration from this fruit at $80^{\circ}$ thus amounts in 1 day to nearly 18 per cent of the 86,400 B.t.u. they originally contained above $32^{\circ}$. Aside from temperature differences, kinds of fruit vary widely in their respiration rate, the quickest-ripening, most perishable products having the highest rate, and citrus fruits the lowest.

\section{REMOVAL OF IIEAT FROM FRUIT}

Whether or not heating or cooling is desired, the molecular kinetic energy of heat always tends to equilibrium. A product that differs in temperature from the surrounding air will eventually, even though well insulated, come to air temperature, the rate of change per unit of time being proportional to the temperature difference, decreasing as the latter becomes less. ${ }^{25}$

This transfer or loss of heat from a warmer to a colder body may be by radiation, that is, by heat directly passing through the air from one body to another without perceptibly warming the air; by convection or circulation, which is the bodily moving of a cooled substance, such as air, coming in contact with a heated surface, such as a box of fruit or some of the exposed specimens that it contains; and by conduction, where the heat in order to escape must pass from molecule to molecule

22 Griffiths, Ezer, and J. H. Awberry. The heat generated by fruit. [Gr. Brit.] Dept. of Sci. and Indus. Research Food Invest. Bd. Ann. Rept. 1927:88-91. 1927.

23 Sinith, A. J. M. The generation of heat by respiring fruit. [Gt. Brit.] Dept. of Sci. and Indus. Research Food Invest. Bd. Ann. Rept. 1928:53-56. 1928.

Smith, A. J. M. Problems of biological engineering in the cold storage of fruit. First Imp. Hort. Conf. Part III [London] Proc. 1930:60-70. 1931.

24 Hawkins, Lon A. Governing factors in transportation of perishable commodities. Refrig. Engin. 18(5):130-131 and 135. Nov., 1929.

25 The cooling curves obtained by the writers in refrigerator cars and commercial cold-storage rooms usually show considerable variation from the theoretical cooling curves obtained under controlled laboratory conditions. Both the surrounding air temperature and the velocity with which air passes over the surface of the fruit are important factors in changing the rates of cooling. That the cooling of fruit only approximates a theoretical cooling curve has been pointed out by Rose, et al. (Rose, Dean H., R. C. Wright, and T. M. Whiteman. The commercial storage of fruits, vegetables, and florists' stocks. U. S. Dept. Agr. Cir. 278:7. 1933.) 
by heat vibration. The particles in contact with the colder air or colder substance cool first and, as part of their heat is liberated, in turn receive part of the heat from the particles next to them; and so on until the entire substance is cooled to the surrounding temperature.

From the standpoint of fruit cooling, only the heat losses by circulation and by conduction need be considered.Loosely packed fruit or fruit in direct contact with cold air is cooled by both these methods simultaneously. Wrapped and tightly packed fruit, especially in the center of relatively large containers, cools slowly because its heat loss is almost entirely by conduction (figs. 32-35, pp. 81, 88, 90, and 92). Even rapidly circulating air comes into direct contact with and directly removes the heat from only the outer specimens in a package. The heat from the center fruits must "work out" by the slower process of conduction.

\section{REFRIGERATION NECESSARY FOR PRECOOLING}

Refrigeration is usually measured in terms of the standard ton, or the quantity of heat (expressed in B.t.u.) required to melt a ton of pure ice at $32^{\circ} \mathrm{F}$ into water at $32^{\circ} \mathrm{F}$. Mechanical refrigeration capacity is expressed in tons per day, or a rate of heat removal equal to 288,000 B.t.u. per day, or 12,000 B.t.u. per hour.

To calculate the amount of refrigeration (or of ice) necessary to cool a 26,000-pound load of fruit from $80^{\circ}$ to $40^{\circ} \mathrm{F}$, the number of B.t.u. to be removed is divided by the number of B.t.u. absorbed by each pound or by each ton of ice. For example,

$$
26,000 \times 40 \times 0.9=936,000 \text { B.t.u. }
$$

Since, in melting, each pound of ice absorbs 144 B.t.u., or each ton 288,000 B.t.u., the ice required would be $\frac{936,000}{144}=6,500$ pounds, or the equivalent of 3.25 tons of refrigeration.

To cool a 36,000 -pound load from $80^{\circ}$ to $40^{\circ} \mathrm{F}$, a total of 9,000 pounds, or 4.5 tons, would be required, while to cool the same load to $32^{\circ}$ would necessitate 5.4 tons of refrigeration.

These calculations show only the amount of ice or mechanical refrigeration necessary to cool the fruit exclusive of the heat of respiration. Under most-favorable cooling conditions, small fruits in open packages require several hours of precooling, while tightly packed fruits in refrigerator cars or in storage rooms may require several days. During this period the heat of respiration is an item to be considered in estimating the amount of refrigeration required. According to Hawkins' calculation-that a ton of peaches held at $80^{\circ} \mathrm{F}$ for 24 hours will generate 15,400 B.t.u., or sufficient heat to melt 107 pounds of ice, and that 
at $32^{\circ}$ only one-tenth of this amount would be required-a 26,000-pound load of peaches held under these temperatures for 24 hours would melt 1,390 pounds and 139 pounds of ice respectively. If, instead of being held for 24 hours at either of these temperatures, this load of fruit is cooled from $80^{\circ}$ to $32^{\circ}$ over a 24 -hour period, it may be expected to give off approximately half the sum of the B.t.u. produced at $80^{\circ}$ and at $32^{\circ}$, or sufficient heat to melt about 770 pounds of ice. Any reduction or increase in the time required for cooling will have a corresponding effect upon the amount of refrigeration.

Because different fruits vary in their respiration rate, which is also influenced by their initial temperatures, by the temperatures to which they are to be precooled, and by their precooling rates, no general figure can be given for the amount of refrigeration necessary to overcome this source of heat. The example given, however, illustrates that respiration is a very important item to consider in large storage rooms or in holds of ships filled to capacity.

A second item which must be allowed for is leakage of refrigeration around openings, walls, ceilings, and roofs of rooms and of cars. Average loss from cars is obviously greater than from warehouse rooms. Assuming the heat leakage through the sides, ends, roof, and floor of a refrigerator car to be approximately 2 B.t.u. per square foot per day for each degree difference in temperature, Hawkins again calculates, under an average daily difference of $30^{\circ} \mathrm{F}$ between the inside and outside of a car, that the leakage would be 84,480 B.t.u., or sufficient to melt 587 pounds of ice. Again, this figure is based on assumption and is subject to wide variation, according to the design and condition of the car and the temperature to which it is exposed.

In precooling fruit, not only the product itself but the containers, the fruit wraps, the box pads, the battens, and, in car cooling, the brace in the doorways, must be cooled. Their total weight in a standard load of pears may be 2,000-2,500 pounds in addition to the 26,000 pounds of fruit. If this material has a specific heat of approximately 0.6 , some additional 375 pounds of ice would be required for its cooling. Even with the standard practice of pre-icing cars before loading, the walls, floor racks, and other interior surfaces are, by the time loading is completed, considerably above the temperature to which the fruit is to be precooled. Part of the refrigeration load, therefore, must go toward cooling the car. This factor, however, in a previously cooled car is not large and cannot be satisfactorily computed.

Additional heat to be overcome in precooling in refrigerator cars is generated by the fans and motors. These vary in type and design, in 
the power used, and in the heat generated. Table 1 gives data on several sizes of motors used and the approximate amount of heat input.

TABLE 1

Generation of Heat by Precooting Fans and Motors

\begin{tabular}{c|c|c|c|c|c}
\hline \hline $\begin{array}{c}\text { Number } \\
\text { of motors } \\
\text { and fans } \\
\text { used }\end{array}$ & $\begin{array}{c}\text { Rating of } \\
\text { motors }\end{array}$ & $\begin{array}{c}\text { Estimated } \\
\text { operating } \\
\text { efficiency } \\
\text { of motors }\end{array}$ & Input & \multicolumn{2}{|c}{ Refrigeration or ice required } \\
\cline { 4 - 6 } & per cent & B.t.u. per hour & pounds & Per 24 hours \\
\hline 2 & $1 / 4$ & 50 & 2,547 & 17.7 & pounds \\
2 & $1 / 2$ & 65 & 3,918 & 27.2 & 424 \\
4 & $3 / 4$ & 75 & 10,188 & 70.7 & 653 \\
1 & 5 & 85 & 14,980 & 104.0 & 2,696 \\
\hline
\end{tabular}

The 1/2-h.p. motors are perhaps most common, and the extra refrigeration to offset their heat would be about 30 pounds for each hour of operation.

The items included in cooling this theoretical car of fruit from $80^{\circ}$ to $40^{\circ} \mathrm{F}$ over a period of 24 hours would appear as follows :

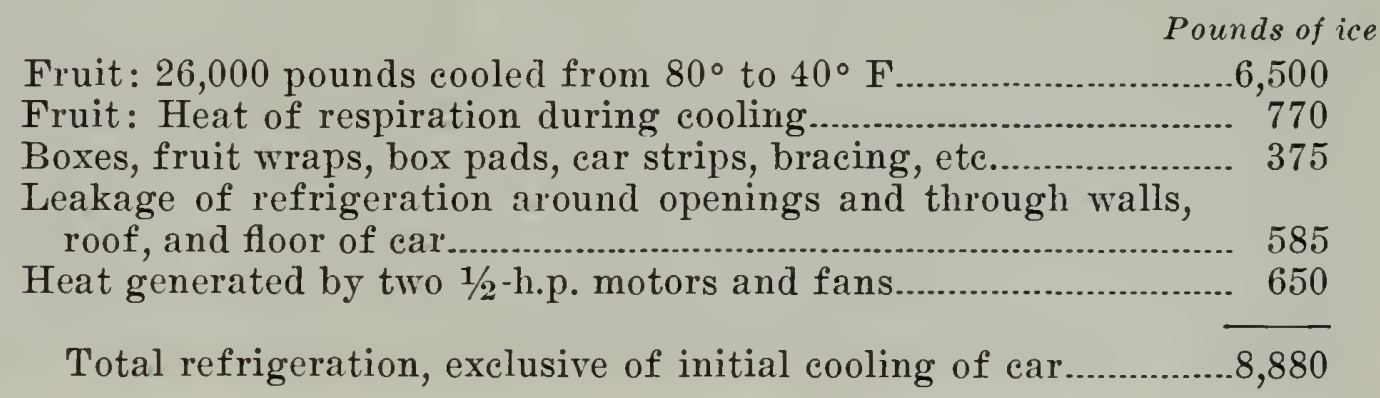

This calculation of refrigeration for cooling a car of warm fruit is within 100 pounds of the average amount of ice actually consumed in the precooling operation with ten different cars of pears precooled over a period of 24-36 hours (table 21, p. 125).

These figures represent the total estimated and actual amounts of refrigeration used for standard loads in 24-36 hours. With 722-box loads of pears from 10,000-14,000 pounds of ice have been used. In the rapid cooling of a product, much more refrigeration is required per hour at the beginning of the precooling period than at the end, or even after a few hours when the excess heat is largely removed from the packages and from the fruit near the outside. The time factor being especially important in car precooling, this extra refrigeration during the fore part of the precooling period is secured by heavy salting and more rapid melting of the ice. In warehouse rooms completely filled, a corresponding cooling rate can be secured only when the mechanical refrigeration units are of sufficient capacity to meet this extra requirement. For most 
rapid cooling, therefore, the quantity of refrigeration available must either exceed that ordinarily used or else be so flexible as to be supplied when and where most needed.

\section{OUTLINE OF EXPERIMENTAL WORK}

The precooling investigations with cherries, apricots, plums, peaches, nectarines, pears, apples, and grapes conducted during 1932 to 1934 inclusive are the outgrowth of similar work with asparagus. This report, covering only these fruits, discusses fruit and air temperatures during precooling in refrigerator cars and in warehouses, the car-precooling equipment and methods of commercial operators, the extent to which the fruit in different parts of individual packages is cooled within given periods, the air temperature at the top of the load of precooled cars in transit under standard and modified refrigeration, and the condition of the fruit upon arrival. Not only were reports made upon regular commercial shipments and, in some instances, upon especially selected and marked packages, but other packages were held in experimental storage for 10 days under transit temperatures and subsequently observed.

Data on warehouse cooling were secured both in commercial coldstorage rooms and in the experimental cold-storage rooms at the University Farm. Data on car precooling were secured in coöperation with cold-storage companies and individuals interested, and with shipping companies in connection with the movement of regular commercial shipments.

For those unfamiliar with standard containers for shipping California fruits, apricots and plums, unless otherwise noted, were shipped in standard crates containing 4 tin-top veneer baskets each holding approximately 5 pounds of fruit. All other fruits were shipped in boxes or "lugs" provided with ventilation at each of the top and bottom edges. Cherries were tightly packed in $8,12,14$, and 18-pound containers. Peaches were wrapped and packed in two layers in the standard peach box containing approximately 18 pounds. Pears and apples were wrapped and packed according to standard practice in standard western pear and apple boxes holding from 44 to 49 pounds. Grape lugs varying in the net weight of fruit from 24 to 30 pounds were used for grapes.

Car-Cooling Equipment.--Except in a few instances, the temperature records taken in cars were where the fruit was precooled by one of two similar types of portable car-cooling units, each consisting of a fan approximately 18 inches in diameter, placed with a slightly downward angle in each end of the car immediately before the grating at the top 
of the ice bunker. In the first type of equipment the fans, operating on 110 volts, were of the two and four-blade type turning at 3,450 and 1,740 r.p.m. respectively, designed to throw 5,000-6,000 cubic feet of free air a minute. Fins immediately in front of the blades appear useful in spreading and directing the air blast (fig. 1). The second type of equipment required 220 volts and consisted of multiblade fans turning at

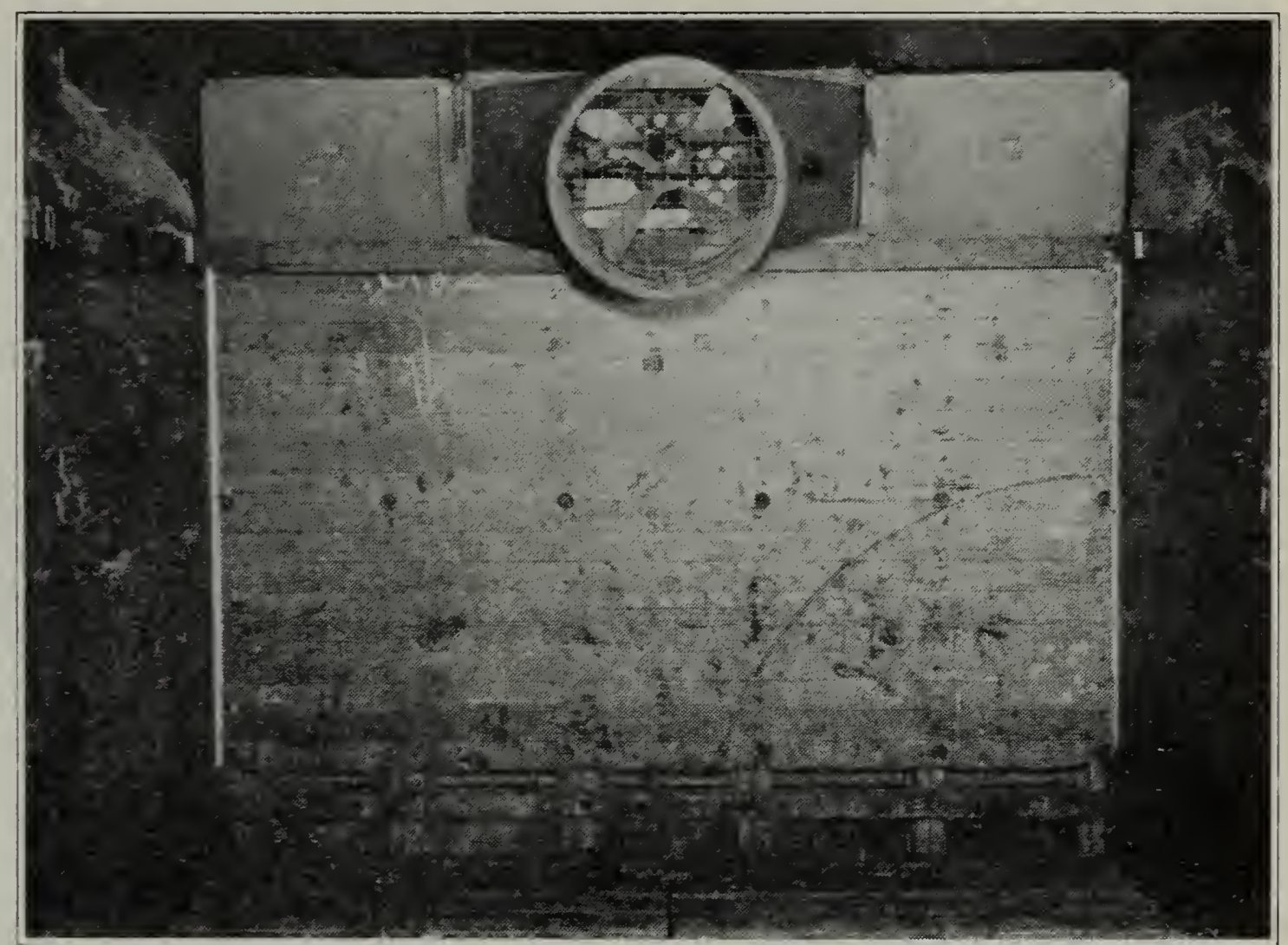

Fig. 1.-Four-bladed precooling fan placed before the grating at the top of the ice bunkers before loading the car. One vertical and two cross fins, attached to the fan screen, break up the whirling motion of the air and direct a larger portion of it to the center of the car. After filtering through the load the air is drawn back to the ice bunkers through the bottom grating, which extends beneath the false floor. The latter materially aids the circulation through the load.

1,725 r.p.m., rated to throw 6,000 cubic feet of air a minute (fig. 2 ). Both these types of equipment operated upon the same principle, drawing the cold air up through the ice and throwing it over and through the load toward the center of the car. The return air passes through the bottom of the load and beneath the false floor of the car back to the ice bunkers, in a reverse direction to the natural circulation.

Records were also taken in two cars (plum tests Nos. 3 and 6) cooled by the type of equipment illustrated and reported upon by Overholser and Moses. ${ }^{25}$ With this equipment the top opening of one ice bunker inside the car is closed; the air, by means of a large fan placed in one

25 Overholser, E. L., and B. D. Moses. Precooling of fresh fruits and temperatures of refrigerator cars and warehouse rooms. California Agr. Exp. Sta. Bul. 496:1-34. 1930. 
hatch opening, is drawn up through the ice, is carried over the top of the car in a heavy canvas duct and, after passing over and through the ice in the opposite bunker, is forced over and through the load. After several hours of precooling, the air flow is reversed.

In still another type of cooler, used in one car only, two strong electric fans, placed at the top of the load at the brace, forced the air back to the

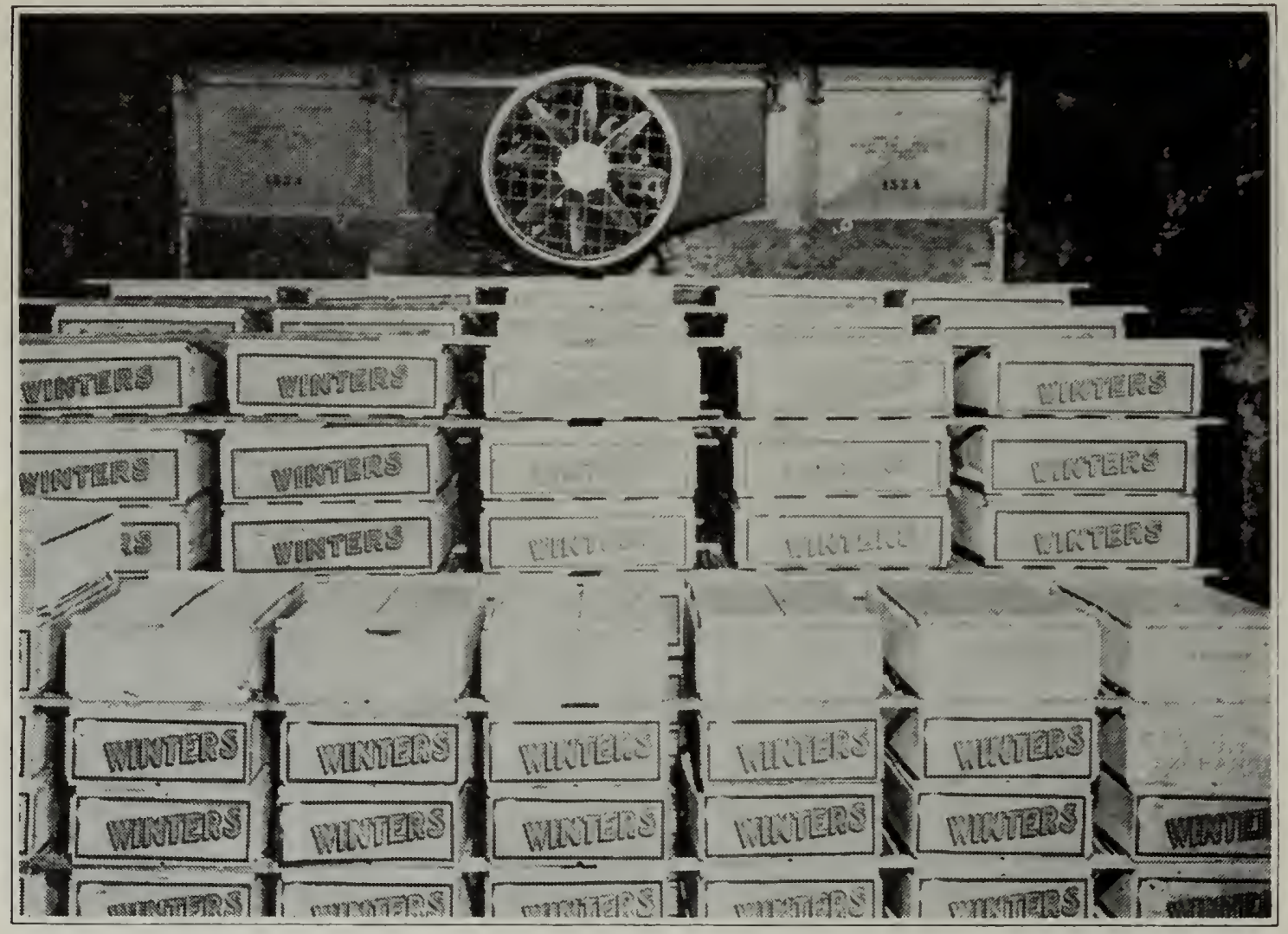

Fig. 2.-Multiblade type of precooling fan in place in one end of a refrigerator car and ready for precooling a load of apricots.

openings at the top of the bunkers. This equipment supplemented and increased the natural circulation. No tests were made on other types of fans, nor with other units suspended immediately under the bunker hatches.

Methods of Operating Equipment.-The precooling fans, usually in position previous to loading, were started when loading was completed and, except when "barring down" or adding ice or salt, were run continuously until time for the cars to move. Whenever the bunkers were less than 75 per cent full of ice when loading was completed, they were replenished before the precooling fans were started. Otherwise, the fans were stopped and ice was added after 2-4 hours of operation. In precooling heavy loads of pears for 24-30 hours, a second and third re-icing was given at 8-10 hour intervals. To reduce the air temperature quickly, 200-500 pounds of salt was added to the ice when the fans were first started and similar amounts at various intervals during the first half 
or two-thirds of the time allowed for precooling operations. Because of the rapid melting of the ice, especially in the lower part of the bunkers, frequent chopping or "barring down" with heavy ice forks was necessary in order to avoid large air pockets and to maintain a low air temperature (fig. 3). Variations from this procedure are shown on the graphs illustrating the individual tests.

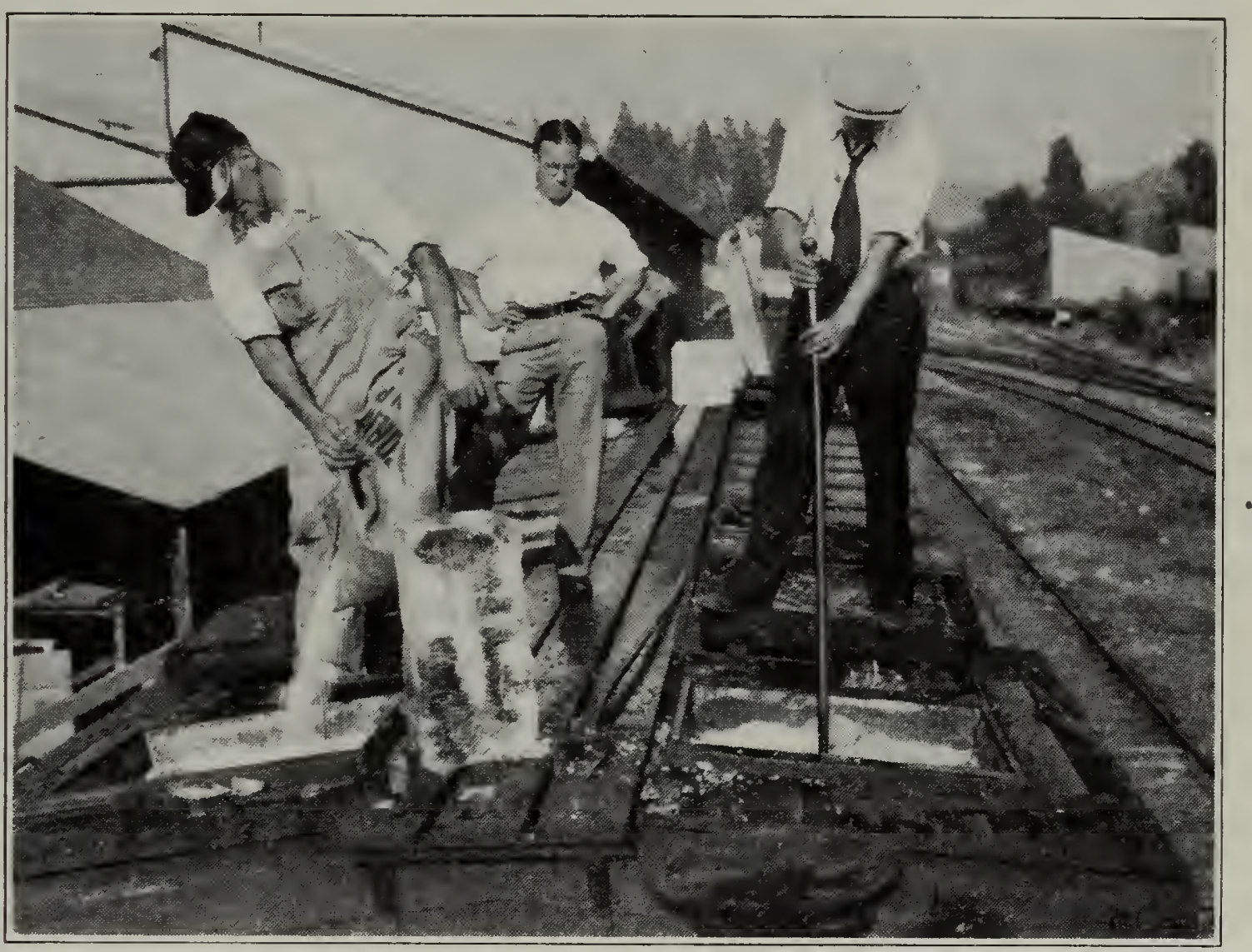

Fig. 3.-Barring down ice, filling the bunkers to capacity, and adding salt before starting the precooling fans. (Courtesy of California Fruit Exchange.)

In commercial cold-storage rooms where data on fruit temperatures were secured, air temperatures were controlled only by the methods usually employed.

Securing Temperatures During Precooling.-In both car and warehouse cooling, fruit and air temperatures were recorded in degrees Fahrenheit and were secured with electrical resistance thermometers having points reduced to 2.5 inches in length and $5 / 16$ inch in diameter for convenient insertion into individual fruits. Specially designed 10 inch thermographs with a bulb attachment similar to the points described above were also used for securing continuous fruit temperature records over either a 24 -hour or 7 -day period. These instruments were fully compensated for temperature differences existing between the bulb and the instrument itself.

Fruit temperatures in refrigerator cars were taken in 8-12 packages, 
situated in different tiers, numbered from each end of the car to the doorway, and at different heights of the load. As commercial precooling operators record fruit temperatures only by using an ordinary fruit thermometer placed in the fruit near the edge of a box or crate, and because the points of the electrical resistance thermometer could not have been removed from the center of boxes in the bottom and center of the load without removing most of the load, fruit temperatures recorded in cars were mostly taken within 3 to 4 inches of the edge of the boxes. Comparative differences in the rate of cooling of fruit in this position and that in the center of packages were determined in several instances where the packages were removed from the load after cooling. All resistance-thermometer points were placed in the packages as loading progressed. The individual leads were run over the top of the load to a master cable and brought out of the car at the top of the doorway, where connection was made with a Wilsen-Maeulen resistance indicator calibrated to read directly in degrees $\mathrm{F}$. Readings taken on this instrument were recorded at intervals of 15 minutes to 2 hours, according to the rapidity of cooling.

In placing each thermometer point in the fruit, an effort was made to avoid having even the nonrecording part of the bulb $(1.0-1.5 \mathrm{inch})$ exposed. This, however, was not always possible in such fruits as apricots and plums; and, to avoid undue influence of the circulating air upon a moist bulb, a small quantity of cotton was placed around each as it was put into position. Temperature readings of the air were usually taken in three positions of the car : immediately in front of the precooling fan as the air was drawn from the ice bunkers, at the doorway of the car after it had passed over the top of the load, and at the bottom of the load as it returned to the ice bunker.

In securing fruit and air temperatures in cold-storage rooms, longstemmed chemical thermometers were used in addition to the equipment mentioned above. All thermometers were first tested for accuracy, and the electric and recording equipment was calibrated frequently.

Securing Temperatures in Transit.-In some cars, air temperatures were secured with Ryan recording thermometers placed on the brace at the top of the load. Several records secured are reproduced in connection with the precooling test of the car.

Temperature and Condition of Fruit on Arrival.-Temperatures secured with fruit thermometers were taken in a number of cars, and the fruit was personally inspected by eastern representatives of the shippers at destination. Other reports of its condition upon arrival have been secured from the regular reports rendered the shippers. 
Holding Tests of Precooled and Nonprecooled Fruit.-Fruit held for 10 days (corresponding to the transit period in shipped fruit) in the experimental storage plant at Davis was kept under temperatures similar to those in the warmer parts of a precooled load. The air temperature surrounding precooled fruit, and subsequently the fruit temperature itself, was gradually raised from that to which the fruit was precooled to between $45^{\circ}$ and $53^{\circ} \mathrm{F}$. Nonprecooled fruit, $75^{\circ}-85^{\circ}$ when packed, was gradually reduced to the above temperatures. At the end of the 10 -day period all fruit was removed to $75^{\circ}-80^{\circ}$, where it was held as long as marketable.

\section{TESTS WITH CHERRIES}

During the precooling of cherries, air and fruit temperatures near the edges of packages were secured in three refrigerator cars. Similar data, and also center temperatures of packages, were secured in a small precooling plant using ice as a refrigerant, and in mechanically refrigerated rooms of three commercial plants and of the University Farm. The influence of air velocity upon rapidity of cooling was also studied, and some samples of precooled and nonprecooled fruit were held and observed after a 10-day shipping period.

Differences in the original temperature of the fruit, the type of package, the method of stacking or loading, the temperatures of air, and the rapidity of circulation, prevent the different tests from being closely compared with one another. The results obtained, however, were either from actual commercial shipments or from samples held under conditions similar to those encountered under present-day practices.

\section{CHERRY PRECOOLING TEST 1}

M. P. Exp. refrigerator 3115, Cordelia, April 30, 1932. Car loaded with 1,820 8-pound boxes 9 rows wide. Maximum height of load, 3 feet.

Purpose of Test.-To determine the general efficiency of car precooling units in reducing the temperature of cherries after loading in refrigerator cars.

Conditions of Loading and Precooling.-Loading extended over a portion of two days, with weather conditions cool and cloudy. Temperature of the fruit as received for loading was $65^{\circ}-68^{\circ} \mathrm{F}$. A delay in securing sufficient fruit to complete the load allowed that previously placed in the bottom of the car to cool to $55^{\circ}$ before the doors were closed and the initial temperatures read. Nevertheless, when precooling began, average temperatures, as recorded within 2-3 inches of the edge of top and bottom boxes in tiers $1,4,8$, and 12 , were only $10^{\circ}$ higher in the top of the load than in the bottom. The delay in loading reduced the 
precooling period from a normal 8 or 10 hours to 4 hours. Half an hour before the fans were started 1,800 pounds of ice and 250 pounds of salt were added to the bunkers; later, more was added (fig. 4).

Temperatures Secured from Precooling.-The reduction in fruit temperature during this 4-hour period is shown by figure 4 . Starting the fans immediately reversed the natural air circulation in the car and

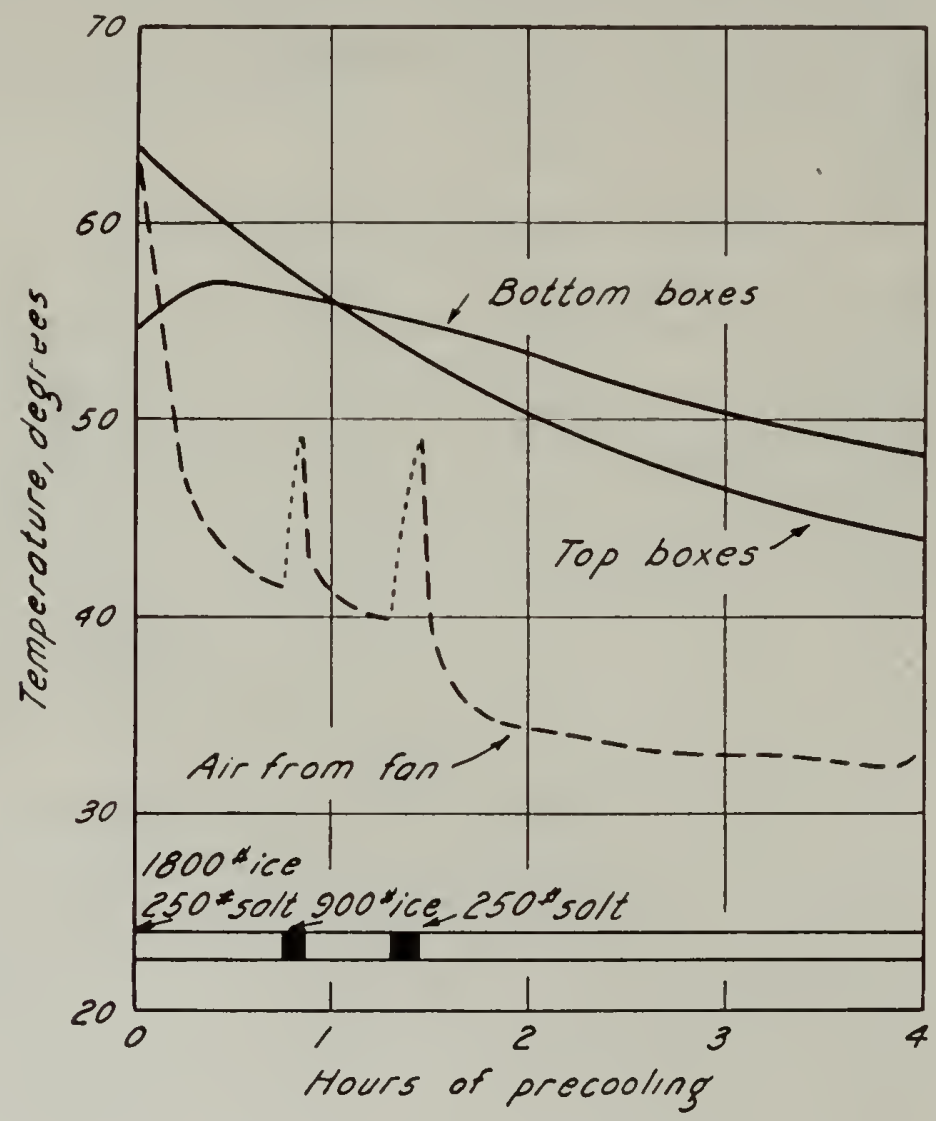

Fig. 4.-Precooling of cherries in refrigerator express car M. P. 3115, Cordelia, April 30, 1932 : average temperatures near the edge of the top and bottom boxes of tiers $1,4,8$, and 12 .

caused an immediate drop in temperature of the top fruit. After a drop of $8^{\circ} \mathrm{F}$ during the first hour, the average rate of cooling for the remaining 3 hours was $4^{\circ}$ an hour. Total cooling of the top boxes amounted to approximately $20^{\circ}$ in 4 hours. The temperature in the bottom of the load rose slightly during the first 30 minutes. Thereafter, cooling continued uniformly at approximately $2^{\circ}$ an hour, or half as rapidly as in the top of the load. The necessity of stopping the fans and supplying additional ice and salt during the first hour and a half of precooling kept the air above $35^{\circ}$ for nearly 2 hours. The two subsequent tests will show longer precooling, this one being presented to show the typical rapid cooling in the top of the load and the temperatures obtainable in a short period when the fruit is loaded at a relatively low temperature. 
Shipping Record and Condition of Fruit on Arrival.-This car was shipped to Chicago with 1-2 re-icings in transit, plus 3 per cent of salt. Being one of the first cars of the season, the load contained Chapman, Tartarian, and Burbank varieties, varying considerably in quality and general maturity. Upon arrival a few lots of Chapmans and Tartarians were described as pale and immature, while some Burbanks were softripe. Most of the fruit arrived in a firm to firm-ripe condition, and sold for slightly more than $\$ 2.00$ a box.

\section{CHERRY PRECOOLING TEST 2}

Refrigerator ear P. F. E. 27484, Neweastle, May 25-26, 1933. A mixed car of 8-pound boxes, 12-pound Lambert lugs, and 18-pound Calex lugs, loaded 6 to 9 boxes wide and 10 to 14 high, with one tier of peaches and plums at the doorway.

Purpose of Test.-(1) To secure additional cooling records over an 8-10 hour period and (2) to determine the temperature rise in the top half of the load after precooling.

Conditions of Loading and Precooling.-The method of loading presented cooling conditions typical of mixed cars in that many of the air channels running lengthwise of the car were blocked. The loading period extended over 7 to 8 hours, during which the outside air varied from $70^{\circ}$ to $85^{\circ} \mathrm{F}$. Before the fans were started, 375 pounds of salt were added to the ice; and the ice in the bunkers was replenished as indicated in figure 5. Average fruit temperatures in the top and bottom of the car when precooling began were $73^{\circ}$ and $57^{\circ}$ respectively, or a difference of $16^{\circ}$. Temperatures in edges of individual boxes, in the top and bottom of the load, located near the doorway in tiers 9 and 10, loaded shortly before the fans were started, varied $6^{\circ}-9^{\circ}$, whereas those in the top and bottom of tier 1 , having stood in the car nearly all day, varied from $25^{\circ}-30^{\circ}$. This wide difference is caused by the cold air surrounding the boxes near the bottom of the ice bunker and is materially lessened within 30 minutes after the natural air circulation is reversed.

After precooling for 8 hours, from 5:45 p.m. until 1:45 a.m., the fans in the car were stopped and remained off for a similar period. Precooling was then resumed for 2 hours. This interruption showed to what extent the fruit "warmed up" after precooling. Between the first and second precooling period the doors remained closed, and the car was well supplied with ice.

Temperatures Secured from Precooling.-With the top fruit in tiers $1,3,6$, and 9 of this load registering $72^{\circ} \mathrm{F}$ when the fans were started and with the air temperature reduced $30^{\circ}$ immediately, the top pack- 
ages cooled very rapidly during the first hour. Thereafter, cooling continued at approximately $3.5^{\circ}$ an hour for the next 3 hours and subsequently at approximately $1.5^{\circ}$ an hour (fig. 5). Aside from a slower initial rate of cooling for the first 2 hours, temperatures in the bottom and center were reduced much like those in the top. With the low load-
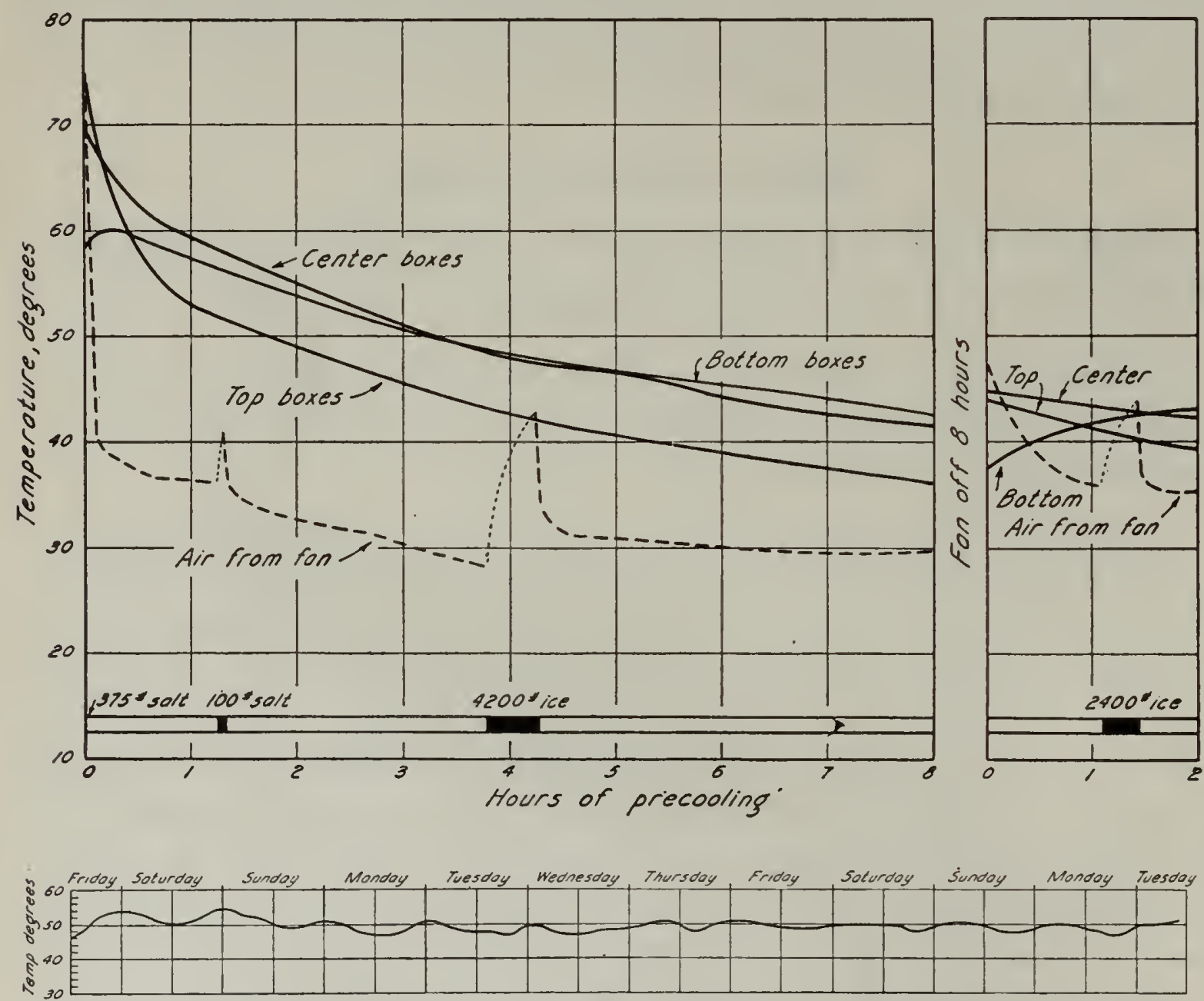

Fig. 5.-Precooling of cherries, P. F. E. 27484, Newcastle, May 25-26, 1933 : average fruit temperatures in the top, center, and bottom boxes of the load during and 8 hours after precooling. Temperatures were taken near the edges of top and bottom boxes in tiers $1,3,6$, and 9, and near the edge of center boxes in tiers 3 and 10 . The lower part of the figure represents a thermograph record of the air temperature at the top of the load while in transit to New York under standard refrigeration.

ing of cherries, actual temperatures in the center and at the bottom of stacks were similar. Center boxes cooled somewhat faster, being subjected to a slightly lower air temperature. Throughout most of the cooling period, temperatures in the top of the load averaged approximately $5^{\circ}$ lower than in the bottom. After 8 hours, the fruit in the lower part of the load was mostly $42^{\circ}$, whereas the top was $36.5^{\circ}$. Probably, 10 hours would have reduced the top fruit to $35^{\circ}$, whereas at least 15 hours would have been necessary to cool the center and bottom of the load to this temperature.

After cooling for 8 hours and then standing for the same time with 
only the natural air circulation in the car, temperatures were again recorded. Fruit in the top of the car, which recorded the lowest temperature while the fans were operating, had gained $8^{\circ} \mathrm{F}$, while that in the center of the stacks had increased only $3.5^{\circ}$. This increase was only slightly greater near the center of the car than near the end. Fruit in the bottom had cooled $5.5^{\circ}$, the decrease being largely confined to that loaded midway between the car door and the bunker. Fruit on the floor at the brace registered a slight gain. Air temperature over the top of the load, which was $30^{\circ} \mathrm{F}$ while the fans were operating, was now $47^{\circ}$.

When the temperatures at the bottom, center, and top of each of three tiers were averaged they were found, during the period of precooling, to be somewhat lower in tier 9, near the door, than in tier 1 , next to the ice bunkers. After 8 hours without the fans, this condition changed, the average temperature increasing gradually from the bunker to the doorway. As shown by this reversal of temperatures, fruit in the center of the package cools less rapidly than that 2 or 3 inches from the edge; and temperature readings in the latter position should not be misconstrued.

The second period of precooling, lasting only 2 hours, more than equalized the temperature differences near the edges of boxes in the different tiers, but scarcely equalized those in the top and hottom of the load. The lines in figure 5 clearly show, however, the trend in this direction.

Shipping Record and Condition of Fruit on Arrival.-This car of fruit was shipped under standard refrigeration to Boston, where it arrived June 6. A Ryan recording thermograph in the brace at the top of the load recorded very uniform air temperatures for the trip. Average maximum and minimum daily temperatures for the first two days in transit were $54^{\circ}$ and $49^{\circ} \mathrm{F}$. The average air temperature at the top of the load in the center of car was $50^{\circ}$. Upon arrival, air and fruit temperatures in different parts of the load were taken by a representative of the shipping company. Air temperatures were as follows:

\begin{tabular}{|c|c|c|c|}
\hline & At doorway & $\begin{array}{l}\text { Quarter way } \\
\text { of load }\end{array}$ & At bunker \\
\hline 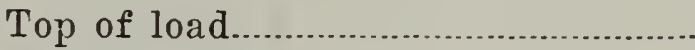 & $50^{\circ} \mathrm{F}$ & $48^{\circ} \mathrm{F}$ & $45^{\circ} \mathrm{F}$ \\
\hline & $48^{\circ}$ & $46^{\circ}$ & $42^{\circ}$ \\
\hline tom & $48^{\circ}$ & .... & $39^{\circ}$ \\
\hline
\end{tabular}

Fruit temperatures were taken in top boxes only and were the same as that of the surrounding air. Weather conditions for several days before the loading of this car impaired the carrying qualities of cherries, and some of the fruit showed considerable mold. 


\section{CHERRY PRECOOLING TEST 3}

Refrigerator car P. F. E. 50473, Newcastle, June 13-14, 1933. Mostly 12-pound Lambert lugs in one end, and 18-pound Calex lugs loaded 6 wide and 10 high in the other.

Purpose of Test.-To secure (1) further data on the uniformity or variability of cooling cherries and (2) data on the amount of cooling

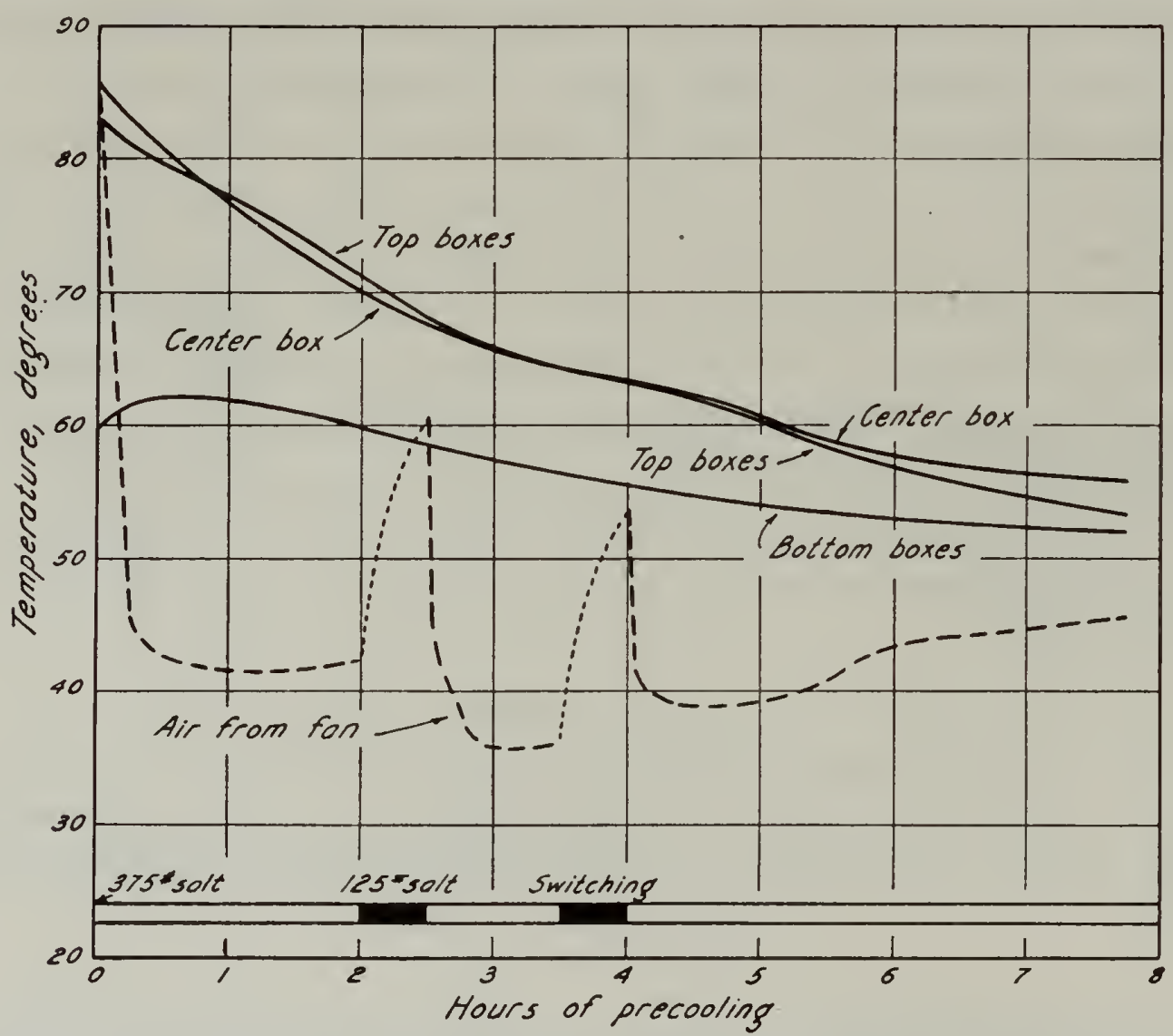

Fig. 6.-Precooling of cherries, P. F. E. 50473, Newcastle, June 13-14, 1933: average temperatures near the edge of the top, center, and bottom boxes of tiers $1,4,7$, and 10 .

possible in a car of warm fruit to which no additional ice was supplied during precooling.

Conditions of Loading and Precooling.-Loading and bracing extended from 1 to 8 p.m., with outside air temperatures ranging from $96^{\circ}$ to $89^{\circ} \mathrm{F}$. When precooling began, average fruit temperatures near the edges of the top and bottom 18-pound Calex lugs in tiers 1, 4, 7, and 10 were $83^{\circ}$ and $60^{\circ}$ respectively. The maximum difference between individual top and bottom boxes was $31^{\circ}\left(77.5^{\circ}\right.$ and $\left.46.5^{\circ}\right)$ at the bunkers. Air temperature in the top of the load was $85^{\circ}$ at the bunker and $86^{\circ}$ at the brace. About 30 minutes before cooling began, the ice was barred down, and 375 pounds of salt added, to be followed 2 hours later by an additional 125 pounds. Ice bunkers were approximately $2 / 3$ full at the outset, and no more ice was added during precooling. During precooling, the fans were off for a total of 1 hour, while adding salt 
and switching the car. Only 250-300 pounds remained in each bunker after 8 hours. Precooling began at $8: 15$ p.m. and continued until 4 a.m., or $73 / 4$ hours.

Temperatures Secured from Precooling.-Figure 6 shows that after precooling for essentially the same period, fruit temperatures in the bottom of this load were $9^{\circ} \mathrm{F}$ higher than in the previous test. Temperatures in the upper half of this load averaged some $10^{\circ}$ higher when precooling began. The additional degrees of heat maintained probably resulted largely from the fact that the air blast, during most of the precooling period, was $10^{\circ}-12^{\circ}$ higher than in the previous test. (Compare figs. 5 and 6 .) Somewhat larger packages, as well as possible differences in the air velocity in the car, may also be influencing factors.

Cooling in the outer portion of the center and bottom packages of the load practically ceased after 7 hours because the fruit in contact with the thermometer bulbs was as low as the returning air surrounding the boxes. The outer portion of the top boxes, exposed to air direct from the fan, would have continued to cool for several hours if precooling had continued and the air temperature not been allowed to rise. In the previous test (fig. 5) where the air blast was maintained at $30^{\circ}$ for the last 2 hours, all fruit temperatures continued to drop uniformly as long as the fans were operated.

The initial difference of $20^{\circ} \mathrm{F}$ between top and bottom boxes ${ }^{27}$ and the fact that the temperature of the air blast forced over the load was $40^{\circ}$ during most of the precooling period are responsible for the fact that average temperatures in the top remained above those in the bottom. If air-blast temperatures had been reduced and held $10^{\circ}$ lower than they were, the curves in figure 6 showing bottom and top temperatures would have crossed after 4-6 hours of precooling and would have resembled those in figures 4 and 5 .

When the temperature data recorded in the different boxes of each tier are averaged separately, the results resemble those of the previous test, in that fruit loaded in the tiers approximately half way between the doorway and the bumker cooled most slowly. In this car, however, the fruit in tier 10 at the doorway was not reduced to the same average temperature as that in tier 1 at the bunker until after 8 hours of precooling. The higher temperature of the air blast and possibly a slightly less rapid circulation of air probably explain the slower cooling in the center of this car.

This attempt to precool warm cherries without replenishing the ice in the bunkers was less successful than anticipated. Air temperatures

27 Some of the fruit in the bottom of the load was exposed to $33^{\circ}-35^{\circ}$ air from the bottom of the bunkers during the 7 hours of loading. 
remained above $40^{\circ} \mathrm{F}$ during most of the precooling period. Average fruit temperatures within 2 or 3 inches of the outside of the packages were from $52^{\circ}$ to $56^{\circ}$ after $73 / 4$ hours; and if temperature readings could have been secured 8 hours after stopping the fans, as in the previous test, they would most probably have been $10^{\circ}$ higher.

Shipping Record and Condition of Fruit on Arrival.-Because thorough precooling was lacking, this car was shipped standard refrigeration plus 3 per cent of salt at all icing stations. The fruit arrived in New York in good condition. Temperatures taken in top boxes at the brace were $48^{\circ} \mathrm{F}$; those in the bottom boxes $44^{\circ}$.

\section{CHERRY PRECOOLING TEST 4}

University Farm Cold Storage, May 20-21, 1933.

Purpose of T'est.-To determine (1) the difference in temperature of the fruit in the center and near the edge of 18-pound bulk-packed lugs, (2) the influence of air velocity upon the rate of cooling, and (3) the time required for cherries to reach the temperature of the surrounding air.

Conditions of Precooling.-Cooling was carried out in a small aircooled chamber $12 \times 14$ feet in size. Twelve boxes of fruit with an initial temperature of $65^{\circ} \mathrm{F}$ were divided into two adjacent stacks so situated that the normal circulation of air was very slight. One stack $(B)$ was allowed to cool under these conditions. The other $(A)$, separated from $B$ by a heavy paper screen, was subjected throughout the cooling period

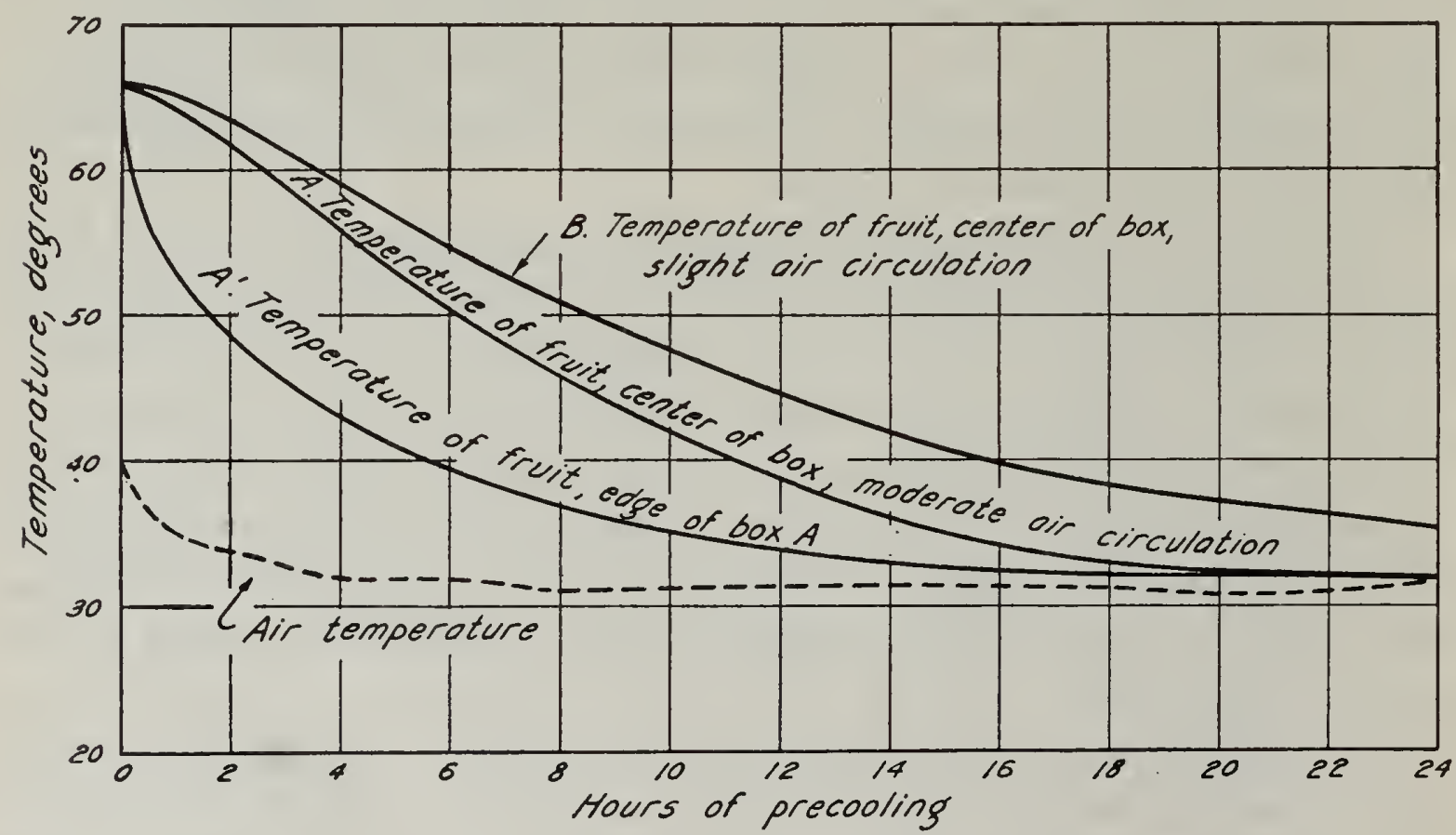

Fig. 7.-Precooling of cherries, University Farm cold storage, May 20-21, 1933, showing rate of cooling in 18-pound lugs as influenced by air velocity. 
to an air current moving approximately 250 feet a minute. During the first 4 hours, air temperature in the precooling room ranged from $40^{\circ}$ to $32^{\circ}$; thereafter it was held between $32^{\circ}$ and $31^{\circ}$.

Temperatures Secured from Precooling.-Figure 7 shows the results of the first 24 hours of precooling. Temperature of the fruit near the edge of the package dropped very rapidly during the first few hours; and continued to remain lower than that in the center for 18 hours. Centers of the packages cooled less rapidly but at a more uniform rate. After 12 hours, fruit in the center of boxes in slight circulation of air had cooled $21^{\circ} \mathrm{F}$, or at an average rate of $1.7^{\circ}$ an hour. A box cooled in a moderate breeze had dropped $28^{\circ}$. Fruit near the edge of this latter box, which cooled $16^{\circ}$ in the first 2 hours, was within $2.5^{\circ}$ of the circulating air at the end of 12 hours. Center temperatures of $35^{\circ}$ were reached in 15 hours where the fruit was cooled in a moderate circulation of air, while 24-26 hours was necessary where the air movement was very slight. The latter box would have required some 48 hours to reach $32^{\circ}$, which the former reached in half this time.

This test shows the importance of circulation of air in the rapid reduction of temperatures. Doubtless box $A$ cooled somewhat faster than is usual in a commercial storage room. On the other hand, box $A$ near the air intake in test 6 (fig. 9) shows even more cooling, and box $B$ in figure 9 shows as much as box $B$ in this test.

\section{CHERRY PRECOOLING TEST 5}

University Farm Cold Storage, June 27-28, 1933.

Purpose of Test.-To secure data on (1) the rate of cooling of cherries in 14-pound San Jose lugs as influenced by air velocity, (2) on the variability of cooling in individual packages, and (3) on the condition of precooled and nonprecooled fruit after 10 days.

Conditions of Precooling.-Five boxes of fruit were cooled in circulating air at 50-75 feet per minute and five at 250 feet. Temperatures were taken in the centers and near the edge of eight boxes out of the ten. Three nonprecooled boxes were held for the first 24 hours under a temperature of $60^{\circ}-50^{\circ} \mathrm{F}$.

Temperatures Secured from Precooling.-The results secured are illustrated in figure 8. On an average, fruit within the first 2 or 3 inches from the edge of the box, in moderately strong air, would have cooled from $73^{\circ}$ to $35^{\circ} \mathrm{F}$ in slightly less than 7 hours, whereas fruit in the center would have required 10 hours. (These packages were removed from the cooling room when the center temperatures were reduced to $40^{\circ}$.) Under a slower air circulation (50-75 feet a minute) 17 and 
24 hours respectively were required for the fruit at the edges and in the center of the boxes to cool to $35^{\circ}$. Characteristic differences of $5^{\circ}$ to $10^{\circ}$ between the edges and centers are shown during the first 6 to 10 hours of precooling.

The rate of cooling in this test was slightly more rapid than in the one previous. This was probably the result of colder air during the first 4 hours of cooling rather than of the somewhat smaller packages

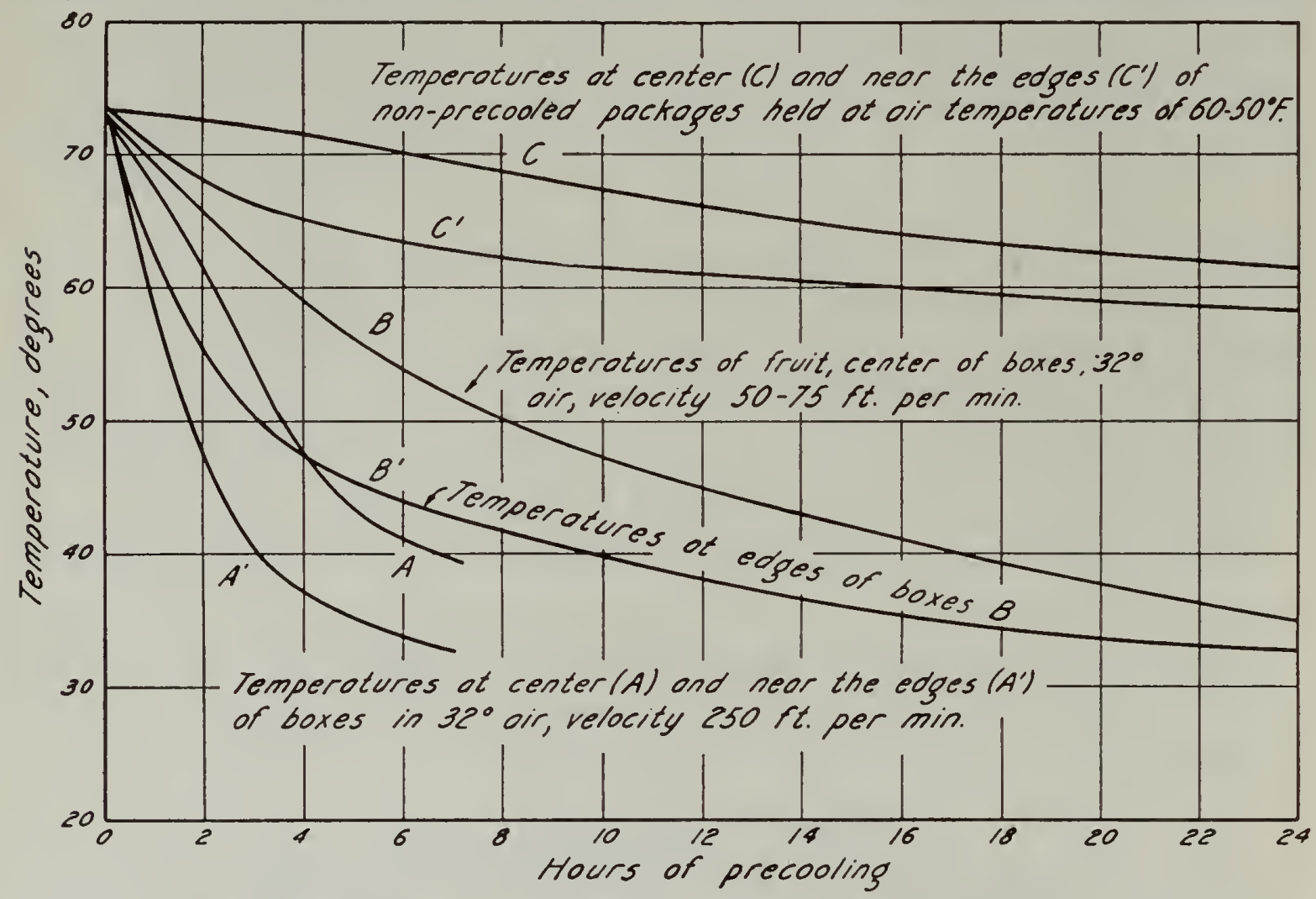

Fig. 8.-Precooling of cherries, Unirersity Farm cold storage, June 27-28, 1933: average fruit temperatures in the center and near the edge of 14-pound San Jose lugs precooled by $34^{\circ}-32^{\circ}$ air moving at 50-75 and at 250 feet a minute. Temperatures of nonprecooled lugs held at $60^{\circ}-50^{\circ}$ are shown for comparison.

which were more tightly packed. Differences in the cooling rate were not marked in individual packages, and no consistent differences existed in top and bottom packages in the stacks, which were limited to approximately 3 feet in height.

Temperatures of nonprecooled fruit after 24 hours remained from $8^{\circ}$ to $11^{\circ} \mathrm{F}$ higher than the surrounding air.

Conditions of Precooled and Nomprecooled Fruit.-See "Holding Tests with Precooled and Nonprecooled Cherries," page 36.

\section{CHERRY PRECOOLING TEST 6}

Commercial storage room, Stockton, May 31-June 1, 1933.

Purpose of Test.- To compare, in a commercial cold-storage room, the rapidity of cooling in bulk-packed 18-pound lugs and in 14-pound face-and-filled Campbell lugs as influenced by the rate of air circulation. 
Conditions of Precooling.-Cooling was in a large air-cooled room of approximately 36,000 cubic feet capacity with the cold air delivered through small openings at one end. Air flowed through the openings at about 600 feet a minute. Center temperatures were taken in three boxes. Box $A$, a bulk-packed, 18-pound lug, was placed immediately in front of an air intake. A comparable box, $B$, was placed 30 feet away where the air movement was too slight to be recorded on a small ane-

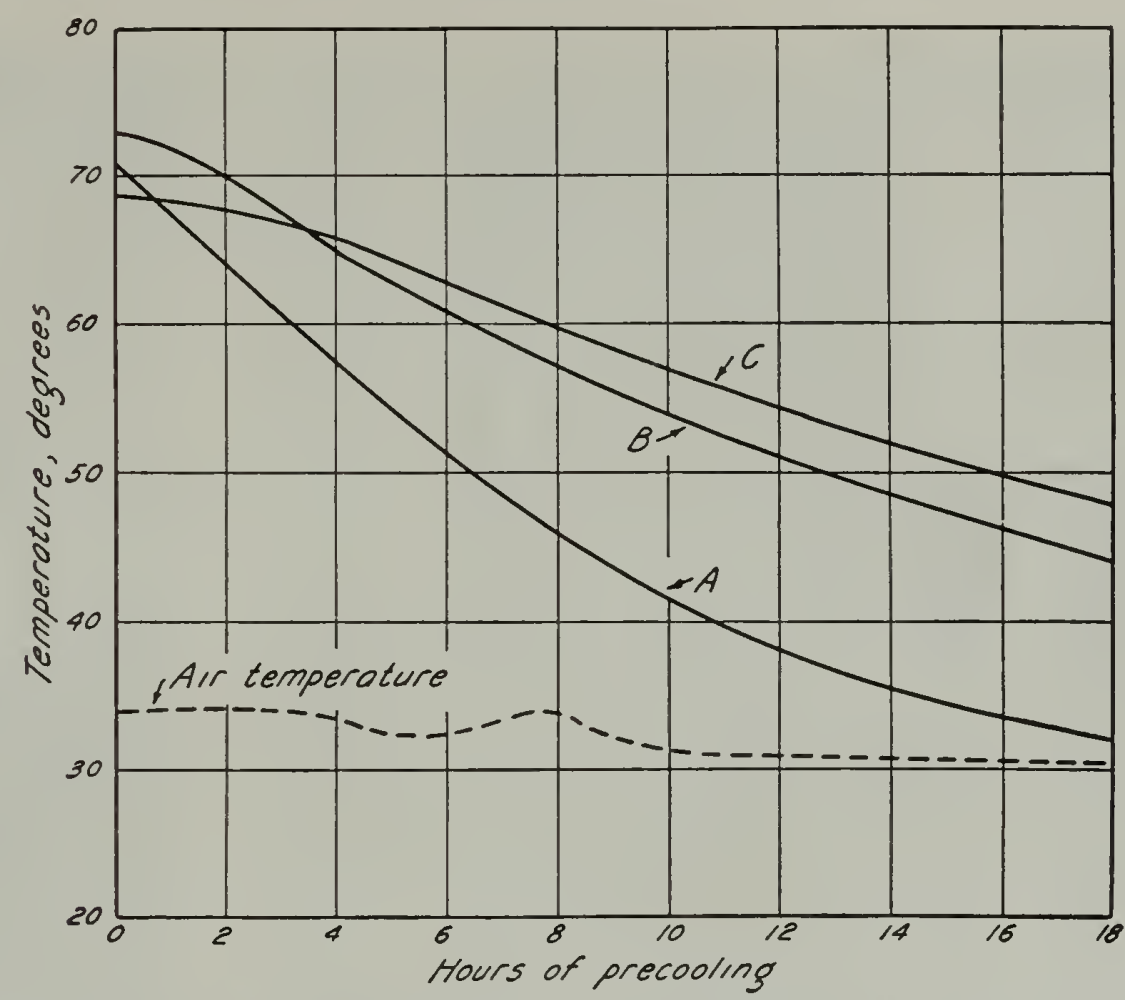

Fig. 9.-Precooling of cherries in commercial cold storage, Stockton, May 31-June 1, 1933 : fruit temperatures in center of packages- $A, 18$-pound bulk-packed lug next to cold-air intake; $B$, 18-pound bulk-packed lug 30 feet from cold-air intake; $C$, 14-pound Campbell lug 30 feet from cold-air intake.

mometer. A third box, $C$, placed in the same position as $B$, was a 14pound Campbell lug. All three boxes were approximately 4 feet from the floor and next to the top box of the stack. Not more than 15 to 20 per cent of the available floor space was occupied, and the individual stacks of fruit were well spaced for most rapid cooling.

Temperatures Secured from Precooling.--The results appear in figure 9. At the end of 18 hours, when all fruit was removed, the center of the bulk-packed box fully exposed to the incoming cold air had reached $32^{\circ} \mathrm{F}$, whereas the boxes 30 feet away in practically still air were $44^{\circ}$ and $48^{\circ}$. Box $C$, containing only 14 pounds of fruit but more tightly packed, cooled somewhat less rapidly than the bulk-packed lug containing 18 pounds. Had the room been filled with fruit during the precooling period, all temperatures would have been somewhat higher. Under the 
existing conditions, the rate of cooling was not dissimilar to that obtained with small lots in the cold-storage plant at the University Farm.

\section{CHERRY PRECOOLING TEST 7}

Commercial storage rooms, San Jose, June 29-30, 1933

Purpose of Test.-(1) To determine the difference in rate of cooling between boxes in the top, middle, and bottom of stacks and (2) to secure

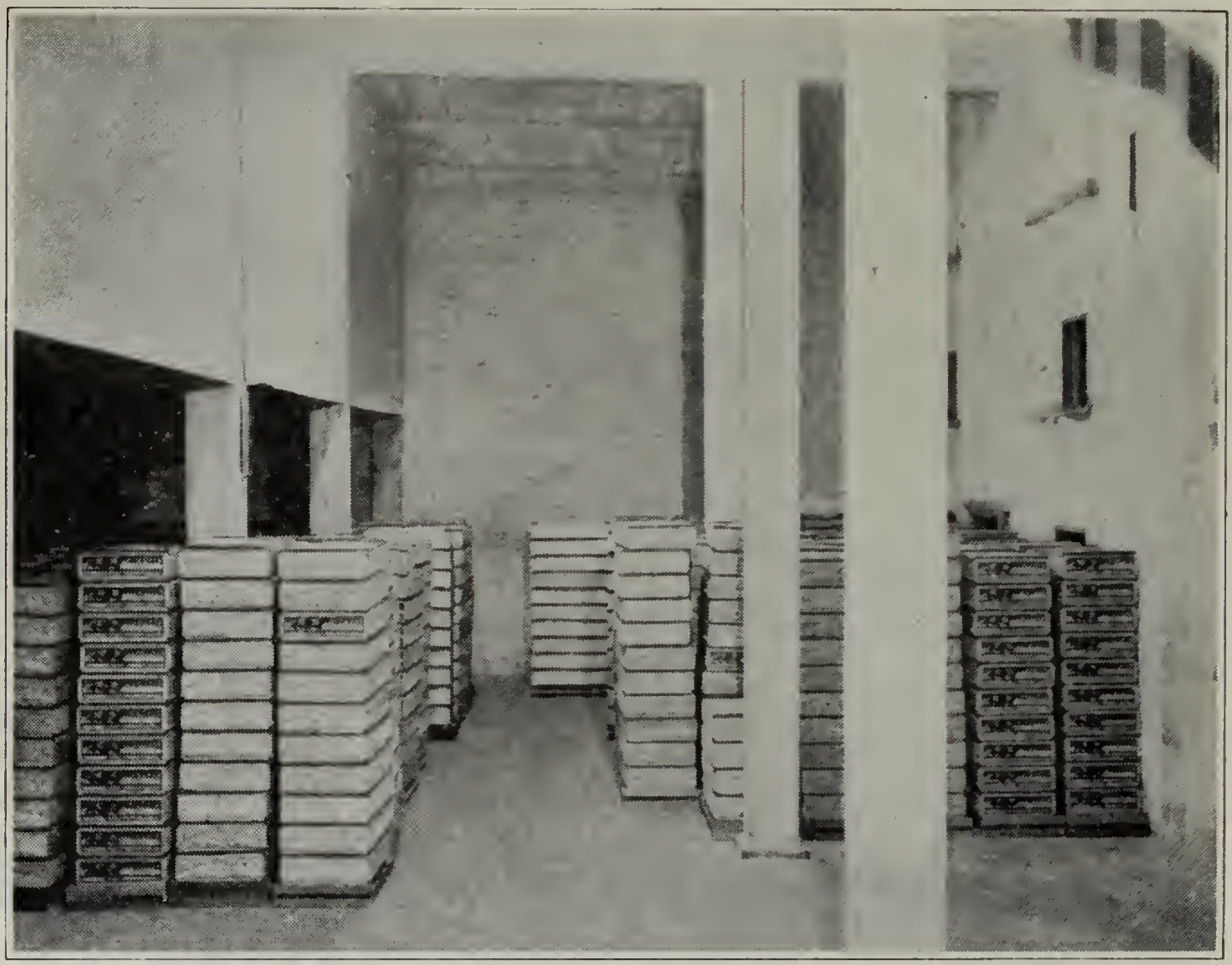

Fig. 10.-Boxes of cherries in a commercial cold-storage room, San Jose, June 29-30, 1933. The fruit is stacked on floor boards in open stacks. Circulating air enters at left and is drawn out through the openings in the false wall on the right. Upper vents are closed to force air through rather than over the stacks. Canvas baffle at left of aisle also forces incoming air downward.

data on the general cooling rate in a commercial cold-storage room containing considerable warm fruit.

Conditions of Precooling.-Cooling records were taken simultaneously in two air-cooled rooms each approximately, $20 \times 40$ feet, with a 15 -foot ceiling. Room 1 (fig. 10) had 15 air intakes $14 \times 14$ inches on one wall and a corresponding number of outlets on the opposite wall. Five of these openings were located approximately 4 feet from the floor, five about 8 feet, and five near the ceiling. On the outlet side of the room, only the lower vents were open. This arrangement reduced the volume of air across the room, but tended to force a greater proportion of cold air through the air channels between the stacks rather than 
over them. The incoming air was further directed downward by a canvas baffle ruming lengthwise of the room, located about 8 feet in front of the air intakes and hanging down from the ceiling to within 5 or 6 feet of the floor (fig. 10). In consequence the fruit in the bottom boxes cooled more rapidly than in the top (fig. 11).

At the time of this test the room was approximately half filled with cherries, some 20,000 pounds having been delivered during the 12 hours

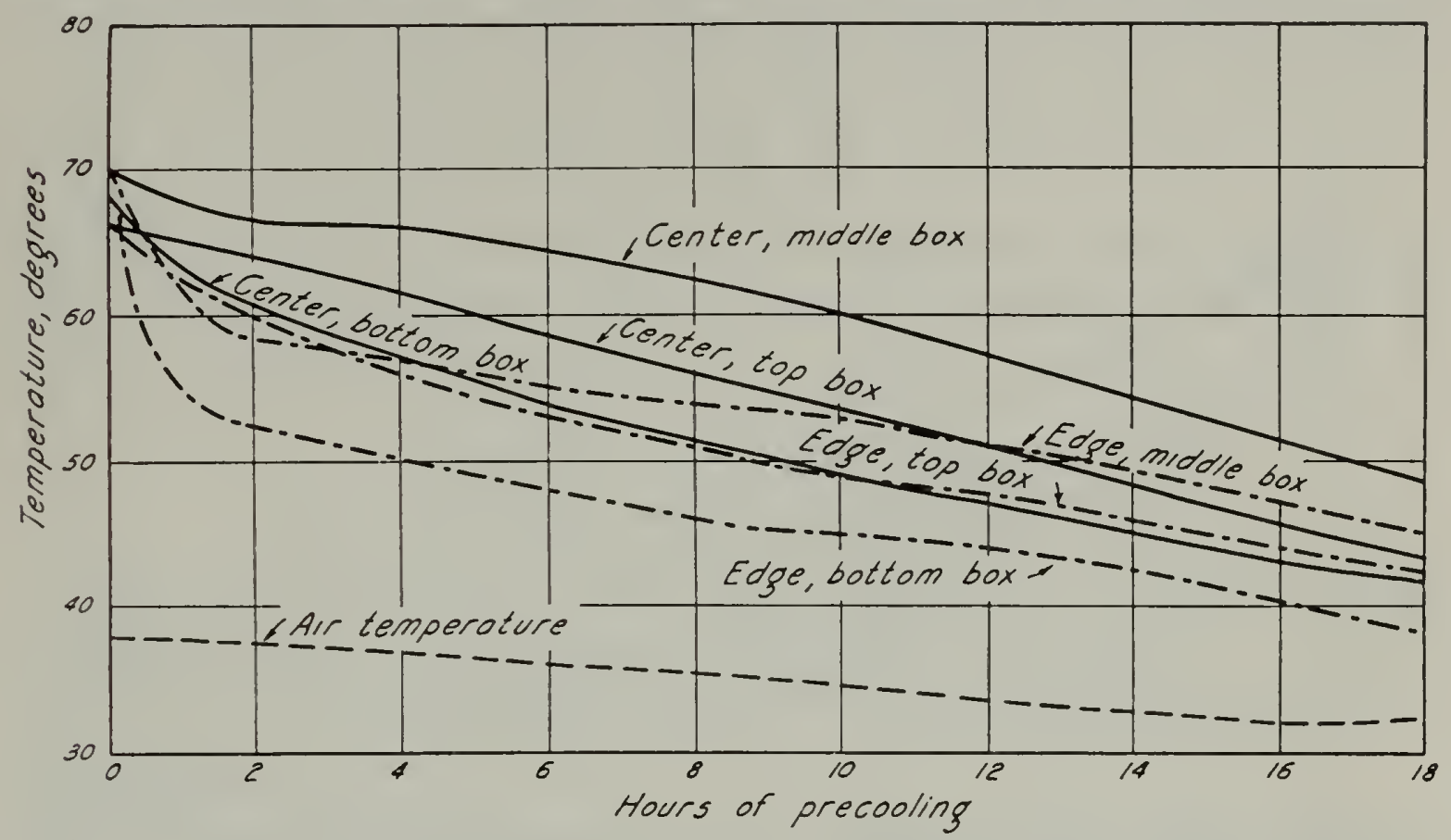

Fig. 11.-Precooling of cherries in room 1, commercial cold storage, San Jose, June 29-30, 1933: temperatures in the center and near the edge of individual Tozzi lugs (15 pounds) in the top, middle, and bottom of stacks. The boxes contained perforated paper liners.

preceding. Consequently the air temperatures were above $35^{\circ} \mathrm{F}$ during the first half of the precooling period. All fruit was stacked on floor boards. The individual stacks, 4 to 5 feet in height, were separated from each other by 1 to 4 -inch air spaces. Fruit temperatures were taken in 15-pound Tozzi lugs lined with perforated paper and placed 3 feet in front of the canvas baffle, where cooling would probably be most favorable.

Room 2, though the same size as room 1, had nine $18 \times 24$ inch air inlets in each end; a canvas baffle was placed crosswise of the room 8 feet in front of the intake openings. Only two of the nine air outlets were open. This room contained somewhat more fruit than room 1 , but less warm fruit. Air temperatures were reduced to $33^{\circ} \mathrm{F}$ in 4 hours and maintained between $33^{\circ}$ and $32^{\circ}$ until the fruit was removed. Temperatures were taken in packages of Campbell lugs 2 feet in front of the baffle, and in Lambert lugs near the center of the room. All fruit was stacked as in room 1, with ample spacing for optimum cooling.

Temperatures Secured from Precooling.-The results in room 1 with 
the Tozzi lugs are shown graphically in figure 11, where the rate of cooling is represented more nearly by a straight line than by a curve. Although the fruit was favorably placed for rapid cooling, the relatively high temperature of the air, together with its slow movement and the lining of the boxes, militated against a rapid reduction in temperature. Averages in three boxes at the end of 10 hours were $54^{\circ} \mathrm{F}$ in the center of the package and $49^{\circ}$ near the edge. All fruit was removed from the room after 18 hours, when center temperatures still averaged $44.5^{\circ}$.

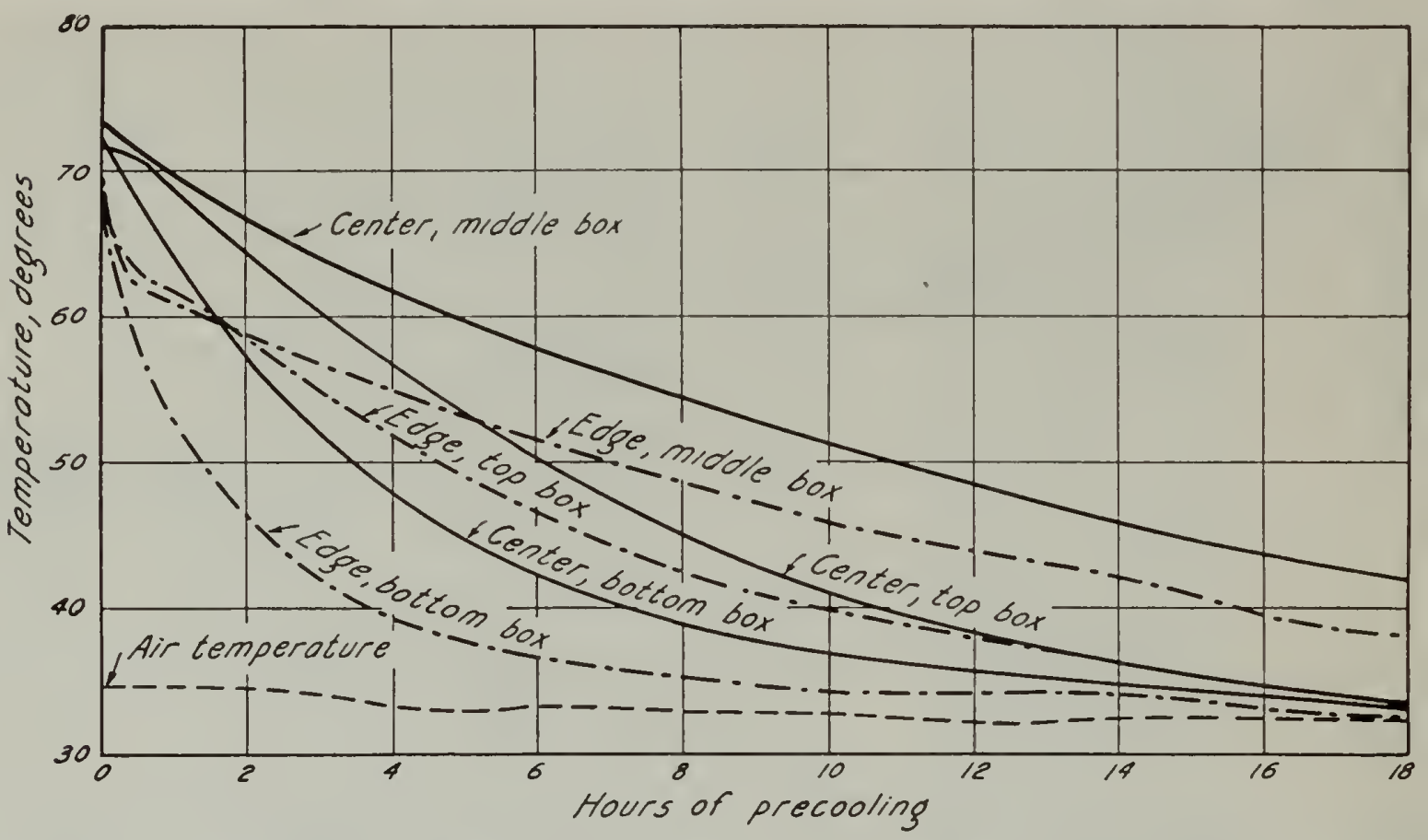

Fig. 12.-Precooling of cherries in room 2, commercial cold storage, San Jose June 29-30, 1933: temperatures in the center and near the edge of individual Campbell lugs in the top, middle, and bottom of stacks.

Cold-storage men have generally observed that fruit cools more slowly in the center of stacks than at the bottom or top. This observation is confirmed by the results presented in figures 11 and 12. In both these instances, the bottom packages cooled most rapidly. The position of the fruit with respect to the baffles, and the air circulation under the lower packages, doubtless explain the somewhat more rapid cooling in this position.

In the unlined San Jose lugs in room 2, which were situated like those in room 1 as to distance from air intakes and as to air currents, cooling was more rapid, especially during the first 6 or 8 hours (fig. 12). An air temperature $2^{\circ}-4^{\circ} \mathrm{F}$ lower during most of the precooling period, together with the fact that the San Jose lugs were unlined, undoubtedly explains the difference in cooling. After 10 hours, the average temperature in the centers of three boxes was $43^{\circ}$, or $11^{\circ}$ lower than in packages of similar size in room 1 . The average temperature near the edge of the boxes at this time was $40^{\circ}$, or $9^{\circ}$ lower than in room 1 . Here (room 
2 ) the fruit in the center of the bottom and top boxes was cooled to $35^{\circ}$ in 14 to 16 hours, while that in the center box was $42^{\circ}$ after 18 hours. Had cooling been continued, some 25 hours would have been required to bring the center of this latter box to $35^{\circ}$.

Fruit temperatures taken in 11-pound Lambert lugs in the center of room 2, cooled more rapidly during the first 6 or 8 hours than did the San Jose lugs closer to the air intake. After 8 hours, the rate of cooling was much less rapid, and the time required for the center of the packages to reach $35^{\circ} \mathrm{F}$ was 18 hours.

Since the fruit in the lined lugs was in a different room with slightly different air temperatures from the unlined packages, the exact influence of the liner in retarding cooling cannot be stated.

\section{CHERRY PRECOOLING TEST 8}

Commercial storage room, Stockton, May 7-8, 1934

Purpose of Test.-To further determine the rate of cooling in a large air-cooled room $58 \times 45 \times 20$ feet, containing 1,480 boxes of Campbell lugs, the room being equipped with two canvas baffles to direct the air flow.

Conditions of Precooling.-Fruit was received for precooling from $5: 00$ to $11: 30$ p.m. with an initial temperature of $58^{\circ}-71^{\circ} \mathrm{F}$. Cold air was delivered through 18 openings, $15 \times 19$ inches in size, at one end of the room at approximately 500 lineal feet, or a total of 17,800 cubic feet a minute. From the 20 -foot ceiling a canvas baffle placed crosswise of the room at approximately 25 feet from each end swung down to within 2-3 feet of the top of the stacks. Fruit temperatures were taken in the center of 10 packages in stacks located in different positions with reference to these baffles and to the air inlets and outlets.

Temperatures Secured from Precooling.-During the total precooling period of 20 hours, air temperatures recorded at the inlets varied between $31.5^{\circ}$ and $26.5^{\circ} \mathrm{F}$, being held at $31^{\circ}$ most of the time. Temperature of the outgoing air ranged from $39^{\circ}$ to $31.5^{\circ}$, the "split" between the incoming and outgoing air gradually declining from $9^{\circ}$ at the beginning of the precooling period to $2^{\circ}$ at the end.

After $16 \frac{1}{2}$ hours (as long as a part of the fruit was cooled) the average fruit temperature in the center of the different test boxes had been reduced from $70^{\circ}$ to $36.5^{\circ} \mathrm{F}$. As in test 6 of the previous year, the fruit located within a few feet of the air inlets again cooled somewhat more rapidly than that in the center or far end of the room near the air outlets. The average difference in fruit temperature in these positions after 12 hours was about $4^{\circ}$. As in test 7 , the baffles were again of ad- 
vantage in preventing the air from short-circuiting above the stacks of fruit. Anemometer readings showed a stronger air movement at the bottom of the baffles on the side from which the air current was coming than in the center of the room. The fruit close to the baffle on the windward side also showed a slight advantage in rate of cooling.

\section{CHERRY PRECOOLING TEST 9}

Small mechanical precooling plant, Willota, May 4-5, 1934

Purpose of T'est.-To secure the rate and variability of cooling in

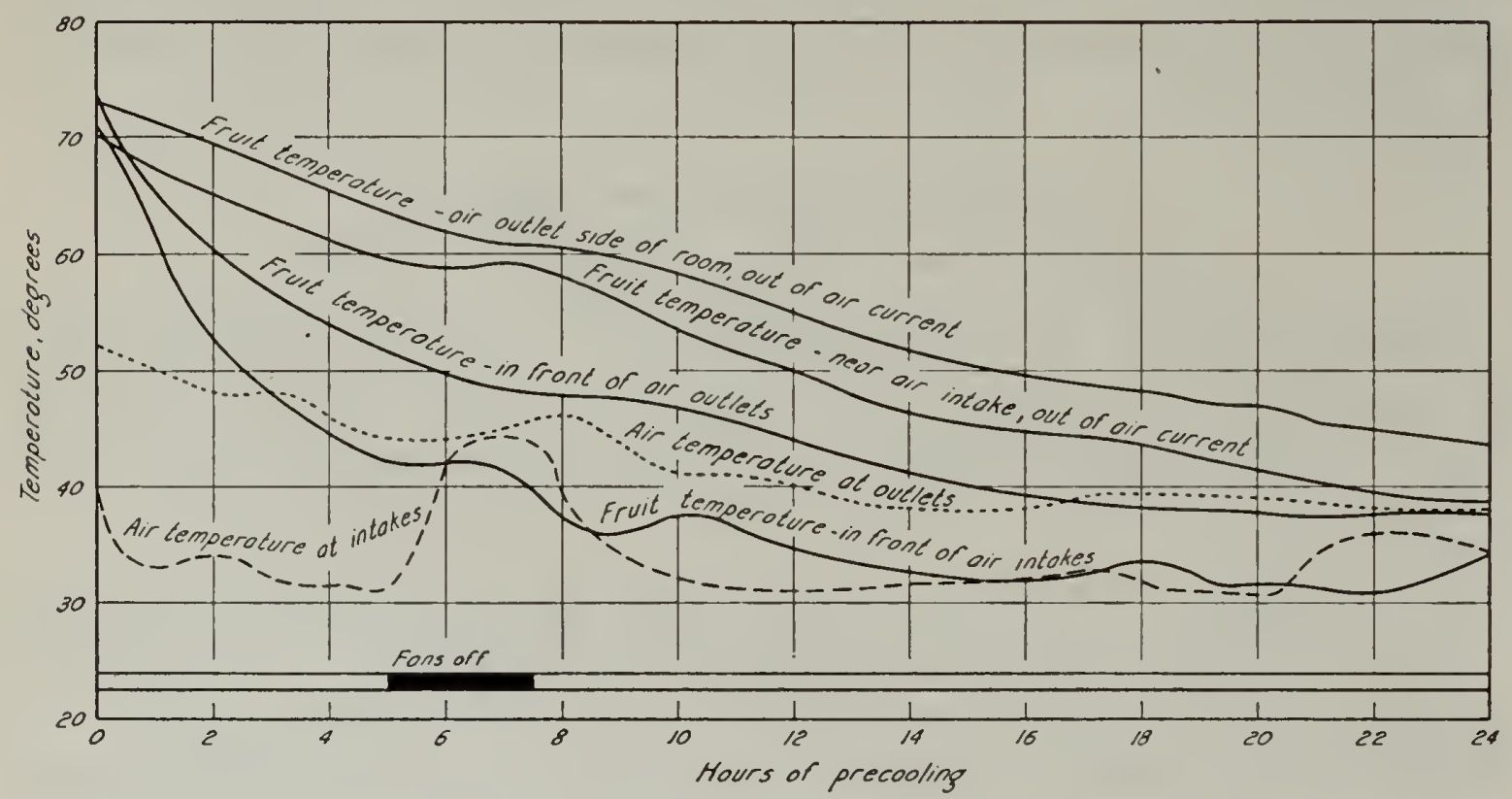

Fig. 13.- Precooling of cherries, two-car-capacity precooling room, Willotta, May 4-5, 1934: fruit temperatures in the center of Campbell lugs 3 feet from floor. The diagram illustrates the variability of cooling in different locations with reference to air intakes. (See fig. 49 , p. 118.)

14-pound Campbell lugs in a small room especially designed for precooling.

Conditions of Precooling.--Fruit was received from 5 to 8 p.m. at a temperature of $75^{\circ}-70^{\circ} \mathrm{F}$. The room was filled to $3 / 4$ capacity (11/2 cars).

Temperatures Secured from Precooling.-All fruit temperatures were recorded in the center of boxes in the center of stacks. Air temperatures were recorded at air intakes, outlets, and in the center of the room over the stacks. Fruit stacked immediately in front of the air intakes in a circulation of approximately 600 feet a minute cooled more rapidly than that immediately in front of the air outlets, owing to the lower air temperature in the former position (fig. 13). Fruit in both these positions cooled more rapidly during the first 12-16 hours than that which was not in such a direct air current. More numerous open- 
ings in the walls would have been conducive to greater uniformity in cooling.

The average reduction in temperature in the center of packages in this test, where the refrigerating mechanism during the 24-hour run was off for $21 / 2$ hours, was $34^{\circ} \mathrm{F}$, or approximately $1.5^{\circ}$ an hour.

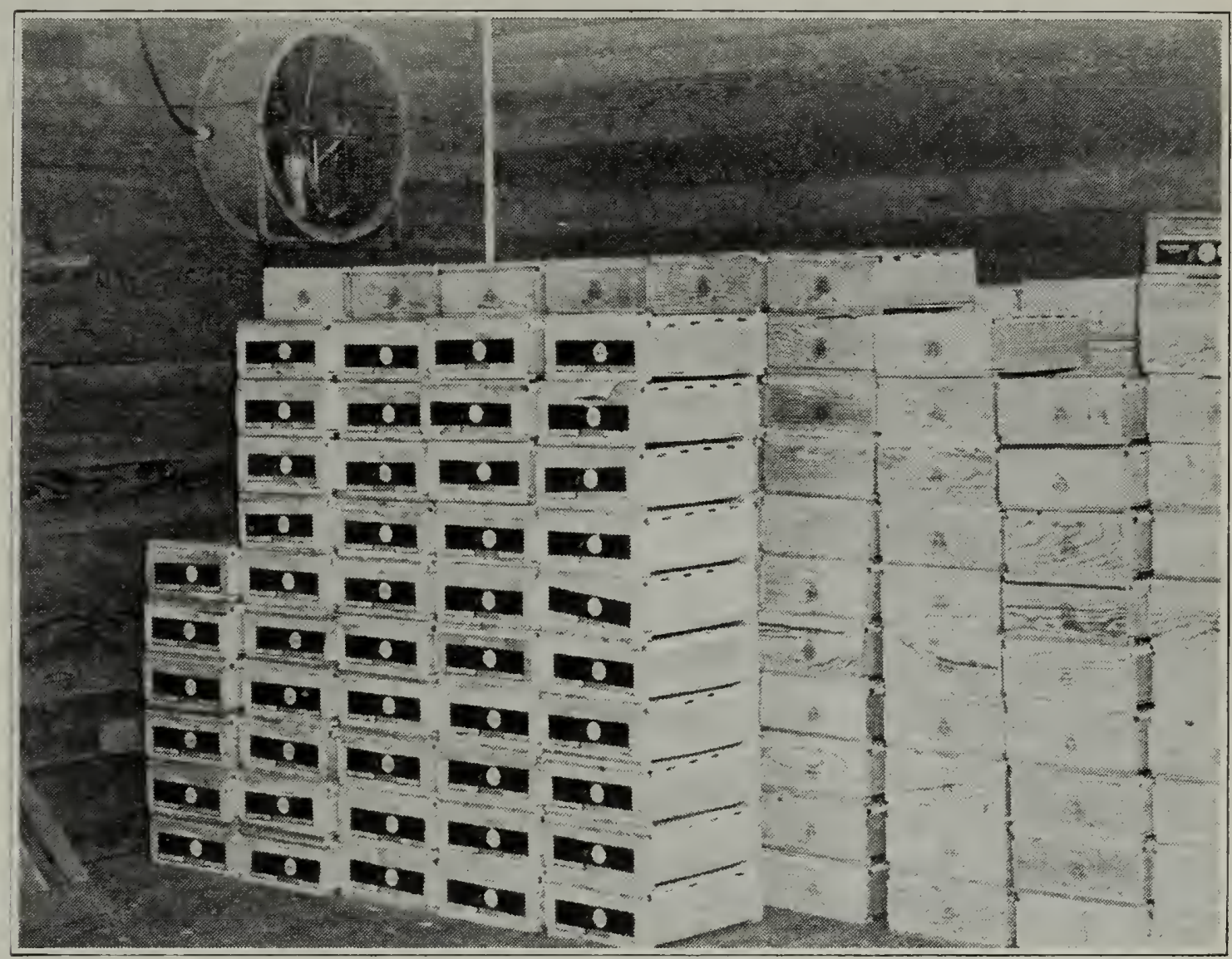

Fig. 14.-Precooling of cherries: corner view of one room in ice precooling unit, Linden, May 7, 1934. Precooling fans (only one shown), one placed before each of two openings in the ice bunker wall near the corners of the room direct the cold air over and through the stacks of fruit. A slatted opening in the center of the wall at the floor serves as a return air duct (lower left).

\section{CHERRY PRECOOLING TEST 10}

Small ice precooling unit, Linden, May 7-9, 1934. Fruit in 15-pound Campbell lugs. Stacks $4-4 \frac{1}{2}$ feet high

Description of Precooling Unit and Method of Operation.-This icecooled, track-side precooling unit, constructed during the past year, consists of two small, well insulated, low-ceilinged rooms, each holding $1-1 \frac{1}{2}$ cars of fruit, when the stacks are well spaced for rapid cooling. Between the two rooms is a smaller compartment or bunker-room holding approximately 20,000 pounds of ice. As originally designed and operated, this space was kept well filled with block ice to which was added various amounts of salt. The resulting brine was caught and sprayed over the ice, additional salt being added from time to time as the brine became diluted. 
Cooling of the fruit was accomplished by two fans located in one end of each precooling room drawing the cold air from the bunker room and directing it over the top of the fruit stacks. After preliminary tests with brine sprayed over the block ice, this method was discarded in favor of pulling the air through salted ice broken up, as in the bunkers of a refrigerator car. In fact, the latter method of operation was similar to car cooling, differing only in having but a single ice bunker between the two rooms and in that the precooling fans and the return air outlet were in the same end of the room. The fans were located at a height of about 5 feet and near the corners of the wall between the precooling rooms and the ice bunker, while the return air was drawn out at the floor near the center of the same wall (fig. 14). Cold air was thus blown over the tops of the stacks near the two sides of the room and returned through the center.

Temperatures Secured from Precooling.-With an initial fruit temperature of $68^{\circ}-70^{\circ} \mathrm{F}$ and an air-blast temperature maintained between $38^{\circ}$ and $30^{\circ}$, the center of the boxes were reduced only to $49^{\circ}$ in 11 hours. During the same period of time, but with an air-blast temperature after the second hour of between $32^{\circ}$ and $26^{\circ}$, the average fruit temperature in the center of the boxes was reduced to $41^{\circ} \mathrm{F}$. This latter cooling rate was similar to that in mechanically cooled rooms.

Individual packages varied slightly in their rate of cooling, those in the direct path of the incoming air tending to cool more rapidly than those in the path of return air, which was of a higher temperature. In this instance, however, the difference in rate of cooling in these two positions was largely offset by the relatively small amount of fruit in the room and by more open stacking in the warmer positions. Differences in the temperature between the incoming and outgoing air varied from $15^{\circ} \mathrm{F}$ during the first few hours of precooling with a $26^{\circ}$ air blast to only $3^{\circ}-5^{\circ}$ after 11 hours with a $32^{\circ}$ air blast. The greater split with the colder air indicates its value for rapid removal of heat.

\section{HOLDING TESTS WITH PRECOOLED AND NONPRECOOLED CHERRIES}

Two holding tests were made with cherries: the first with Bing and Royal Ann varieties; the second with Bing, Royal Ann, and Lambert. The maturity was that usually selected for eastern shipment.

Test 1.-After precooling the fruit in the center of the boxes to temperatures of $36^{\circ}-40^{\circ} \mathrm{F}$ in the University Farm cold storage, several lug boxes were removed and held for 10 days in air temperatures gradually increasing from $38^{\circ}$ to $45^{\circ}$. These temperatures simulate those in the warmer part of a precooled car while in transit. Comparable boxes 
of nonprecooled fruit were held for the same period under air temperatures declining gradually from $65^{\circ}$ to $55^{\circ}$. After the 10-day holding period (corresponding to "arrival" in shipped fruit), the boxes were opened, and the condition of the fruit was noted. Subsequent holding at room temperature yielded data as to the period of marketability. Since the fruit in this test was not of the best quality and the non-

TABLE 2

Comparative Condition and Period of Marketability of Precooled and Nonprecooled Cherries AfTER Holding For 10 Days UNDER TRANSIT TEMPERATURES

\begin{tabular}{c|c|c|c|c}
\hline Variety & Precooled to & Held at & $\begin{array}{c}\text { Condition after 10 days under } \\
\text { transit conditions }\end{array}$ & $\begin{array}{c}\text { Number of } \\
\text { days } \\
\text { marketable }\end{array}$ \\
\hline Royal Ann............ & $\left\{\begin{array}{c}\text { degrees } F \\
36-40\end{array}\right.$ & $\begin{array}{c}\text { degrees } F \\
38-45\end{array}$ & $\begin{array}{c}\text { Satisfactory: 75-85 per cent firm, } \\
\text { balance slightly soft; no mold } \\
\text { Unmarketable, generally soft and } \\
\text { moldy }\end{array}$ & 4 \\
$36-40$ & $65-55$ & $38-45$ & $\begin{array}{c}\text { Fair, firm to slightly spongy; slight } \\
\text { traces of mold } \\
\text { Bing }\end{array}$ & 5 \\
\hline
\end{tabular}

precooled boxes were held under rather high temperatures, the results are not considered typical of most commercial shipments. The data, however, as shown in table 2, emphasize the value of precooling and of holding at a lower temperature.

Test 2.- In this test, the fruit was of better quality when packed than in test 1 , although the Bing cherries were considered to be of maximum ripeness for eastern markets. Holding temperature of the nonprecooled fruit was kept slightly lower than in the previous test in order to correspond more nearly to car temperatures. The results as shown in table 3 are therefore more typical of commercial shipments than those in the previous test.

These data further indicate the beneficial results of precooling, but only repeated tests can establish the value of precooling to $34^{\circ} \mathrm{F}$ rather than to $40^{\circ}$.

\section{SUMMARY OF CHERRY PRECOOLING AND HOLDING TESTS}

From the limited precooling period in refrigerator cars recorded in tests 1 and 2, where the air temperature was reduced to $33^{\circ}$ and $30^{\circ} \mathrm{F}$, from 10 to 15 hours are required for cherries near the outside of the 
packages to cool from a temperature of $65^{\circ}-70^{\circ} \mathrm{F}$ to one of $35^{\circ}$. Tests in storage rooms under temperature and air conditions similar to those in refrigerator cars indicate that the temperature of the fruit in the center of the boxes differs from that near the edge by $10^{\circ}-13^{\circ}$ at the end of the first 4 hours and $1^{\circ}-5^{\circ}$ after 18 hours. Unless, therefore, cooling has extended over 10 to 15 hours (with favorable cooling conditions),

\section{TABLE 3}

Comparative Condition and Period of Marketability of Precooled and NonPrecooled CHerries AFter HOLding For 10 DAYS UNDER TRANSIT TeMPERATURE

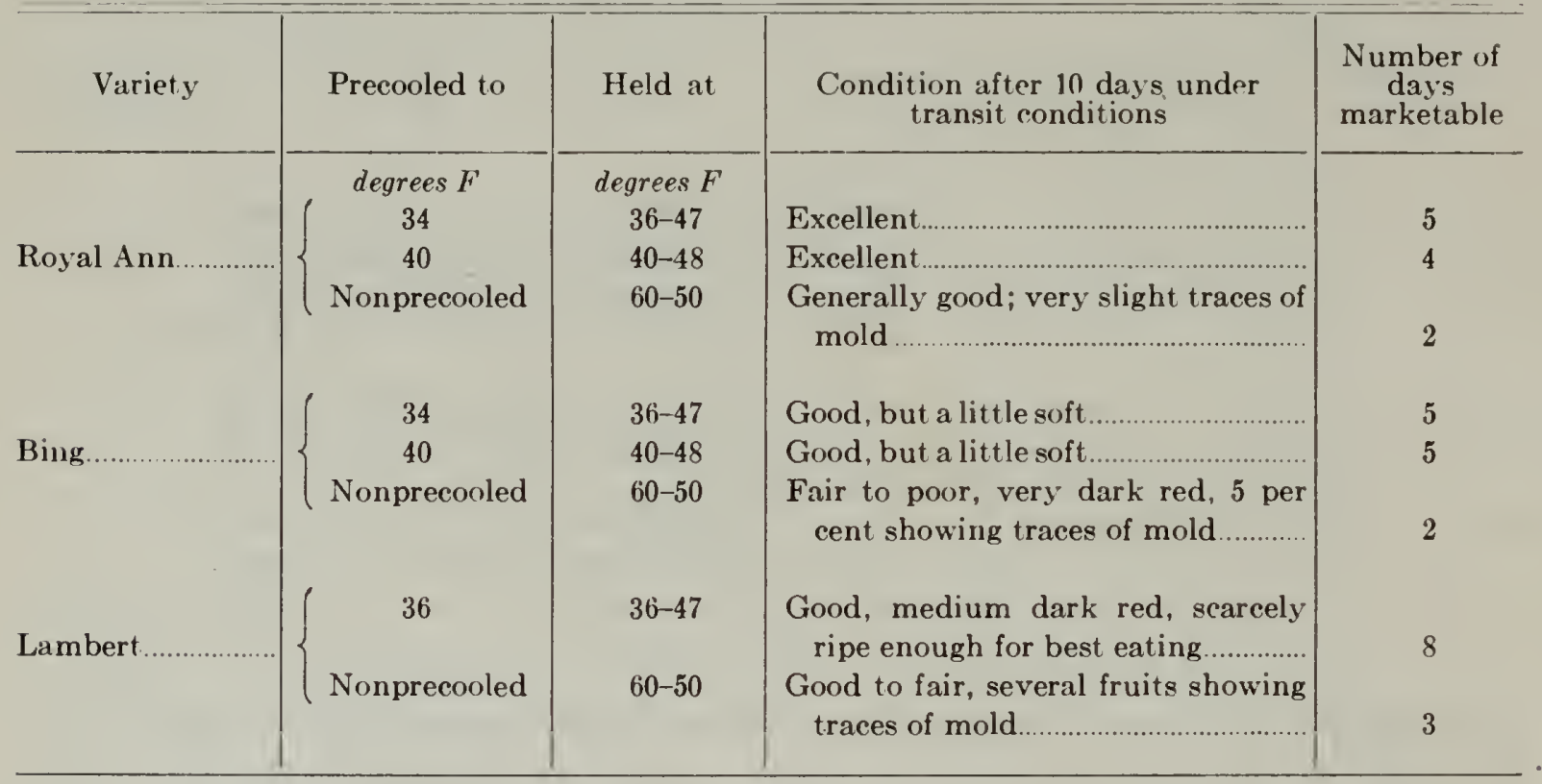

fruit temperatures in the top of refrigerator cars will increase considerably after the precooling period. For complete cooling in the center of packages approximately a 24 -hour period is necessary.

From the different tests made, both in refrigerator cars and in storage rooms, the most usual rate of cooling for cherries over a period of $8-10$ hours is $2.0^{\circ}-3.5^{\circ} \mathrm{F}$ an hour in the center of the package and $3.0^{\circ}-4.0^{\circ}$ an hour for the fruit near the edge. Over a 16 to 20 -hour period the average rate was found to be slightly less than $2^{\circ}$ an hour for both center and edge of the box.

Nonprecooled fruit $\left(70^{\circ}-75^{\circ} \mathrm{F}\right)$, held in still air at a temperature varying between $65^{\circ}$ and $50^{\circ}$ (representing car temperatures to which the upper part of the load might be subjected), cooled at an average rate of from $0.5^{\circ}$ to $1.0^{\circ}$ an hour during the first 24 hours.

Tests 4 to 7 show the rate of cooling to be influenced materially by the velocity of the air. Under the conditions of these tests, fruit temperatures in the center of packages in a moderate air circulation were $5^{\circ}$ to $13^{\circ} \mathrm{F}$ lower than in comparable packages in slowly moving air. 
In most instances, these packages were cooled in adjacent stacks where the air coming in contact with them was of the same temperature.

In commercial cold-storage rooms, fruit stacked immediately before the air intakes may be subjected during the first few hours of cooling to air which is $10^{\circ}-15^{\circ} \mathrm{F}$ colder than that surrounding the fruit 25 or 50 feet away, the difference in temperature depending largely upon the amount of warm fruit in the room. In large storage rooms with high ceilings, a greater volume of cold air may be forced through the stacks of fruit if baffles are used to prevent its passing directly across the room overhead.

Data secured on cooling rate as influenced by size of package, by liners, and by the general tightness of the pack are too meager to be conclusive. Apparently, however, in the smaller packages in which the fruit is tightly packed, cooling under comparable conditions is little if any more rapid than in the larger lugs that are packed more loosely. In addition, liners probably have some retarding influence on cooling.

Precooling is highly desirable for long-distance shipments of cherries, and the two holding tests show marked differences in the condition of fruit precooled and held under maximum transit temperatures of $45^{\circ} \mathrm{F}$ and that nonprecooled and held at temperatures from $60^{\circ}$ to $50^{\circ}$. The period of marketability of the former was also over twice as long.

\section{TESTS WITH APRICOTS}

The results in precooling apricots comprise those secured from four precooling tests in cars and five in storage rooms. As with cherries, the chief points investigated were the uniformity and general rate of cooling as affected by the location of the packages, the air temperature, and the velocity. Temperatures in transit and brief reports of the condition of the fruit upon arrival were secured in two of the car tests. Samples of nonprecooled fruit and of fruit precooled in a storage room to $40^{\circ}$ and to $34^{\circ} \mathrm{F}$ were also held for the transit period under average nonprecooled and precooled car temperatures and then examined for differences in color and firmness.

\section{APRICOT PRECOOLING TEST 1}

Refrigerator car P.F.E. 30255, Brentwood, June 12-13, 1932. Loaded with 1,008 18-pound lugs, face-and-fill pack

Purpose of T'est.-To ascertain the cooling rate of apricots in lug boxes.

Conditions of Loading and Precooling.-The fruit was loaded in stacks 6 boxes wide and 8 high throughout the afternoon with air tem- 
peratures varying between $78^{\circ}$ and $72^{\circ} \mathrm{F}$. Precooling started at $6: 00$ p.m. and was continued until 3:00 a.m. During this 9-hour period the fans were off $1 \frac{1}{2}$ hours because of icing. Salting and icing records appear in figure 15.

Temperatures Secured from Precooling.-The temperatures secured in relatively the same position at both ends of this car were very similar; hence the graphs in figure 15 are averages for the entire car. Under the conditions of this test, the fruit in the top of the load was reduced from

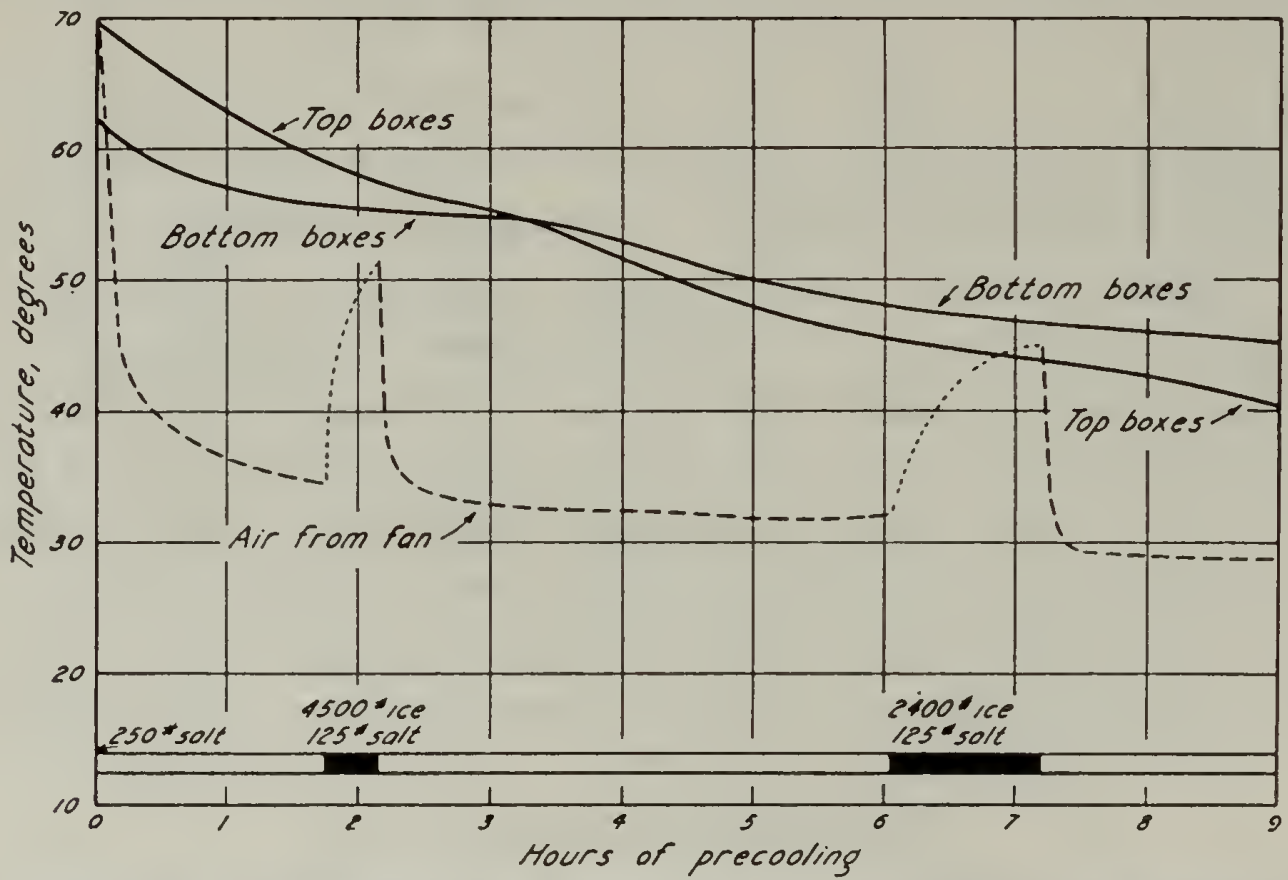

Fig. 15.-Precooling of apricots in P. F. E. 30255, Brentwood, June 12-13, 1932: average fruit temperatures in 18-pound lug boxes during precooling. Temperatures were taken in top and bottom boxes in tiers $1,4,7$, and 10 of " $\mathrm{A}$ " end and tiers $2,5,7$, and 10 of "B" end of car.

$70^{\circ}$ to $40^{\circ} \mathrm{F}$ in 9 hours, or an average of $3.3^{\circ}$ an hour, while that in the bottom, $7^{\circ}-8^{\circ}$ colder at the outset, was reduced to $45^{\circ}$, or $2.1^{\circ}$ an hour. Cooling was relatively uniform over the 9 -hour period, because of the differences in air temperature during the first and last two hours of precooling.

Fruit temperatures in the bottom and top of the load were averaged by tiers. Those in tier 10, the last fruit to be loaded, dropped rapidly during the first hour and remained slightly lower than in any of the other tiers throughout the precooling period (fig. 16). Tiers 4 and 7 , quarter way of the load, remained the highest. The maximum difference between tiers after 9 hours was $6.5^{\circ} \mathrm{F}$.

\section{APRICOT PRECOOLING TEST 2}

Refrigerator car S.F.R.D. 23062, Bixler, June 11, 1932

Except that initial fruit temperatures in this load were $5^{\circ}-8^{\circ}$ higher 
$\left(74^{\circ} \mathrm{F}\right.$ in the top and $70^{\circ}$ in the bottom) than in test 1 , all conditions of loading and cooling were essentially the same. The results differed only slightly. In contrast to test 1 , however, the top and bottom cooled at a very similar rate. For the first 4 hours of cooling, the average temperatures of the top remained some $3^{\circ}$ above those of the bottom. After 6 hours, this difference disappeared; and the final fruit temperatures at the end of 9 hours were $44^{\circ}$ for both top and bottom.

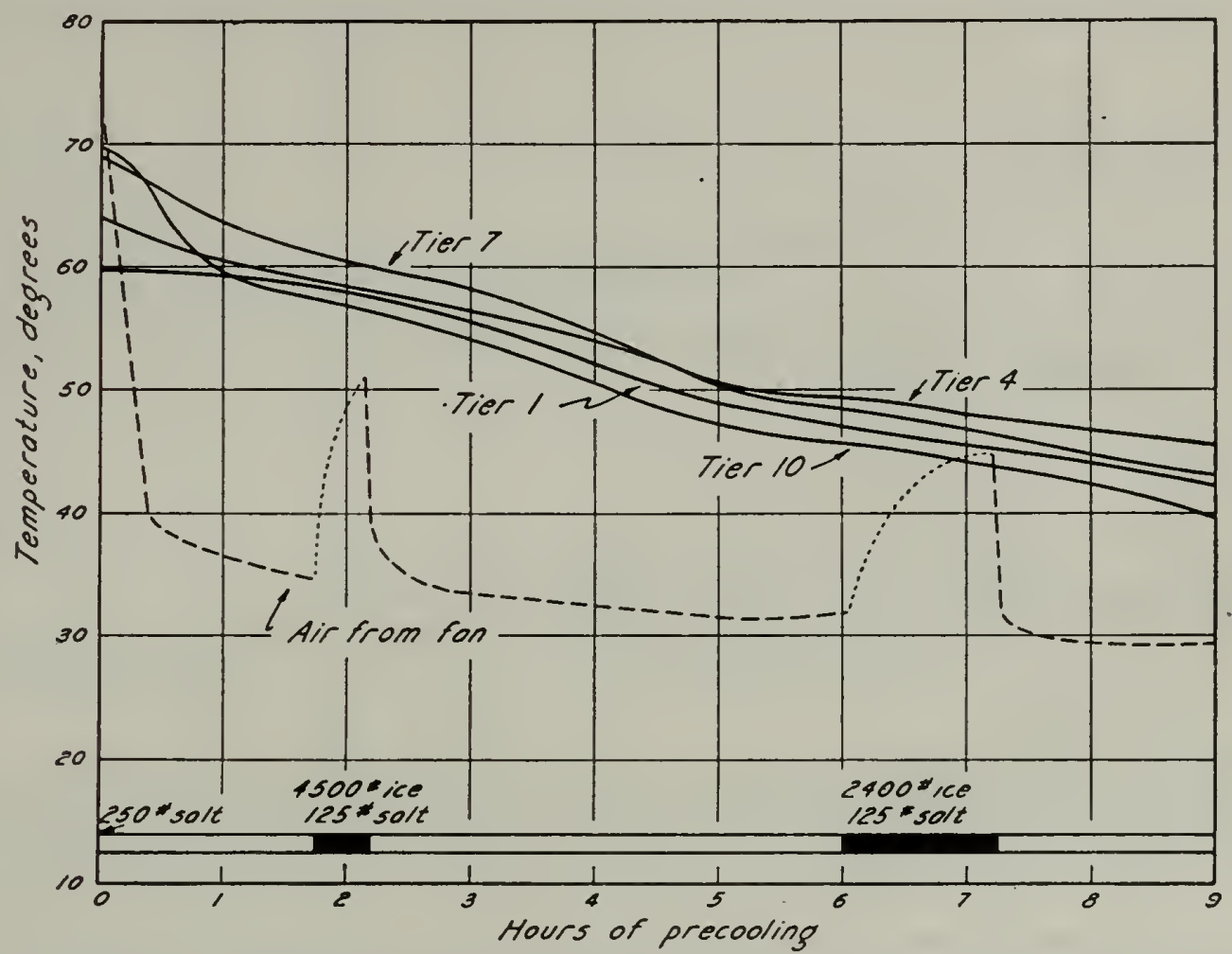

Fig. 16.-Precooling of apricots in P. F. E. 30255, Brentwood, June 12-13, 1932: average fruit temperatures in different tiers of the load during precooling. Temperatures were taken near the edge of top and bottom boxes of tiers 1, 4, 7, and 10 of "A" end and tiers 2, 5,7 , and 10 of " $\mathrm{B}$ " end of car. (Tiers 1 and 2 combined as tier 1, and tiers 4 and 5 as tier 4.)

\section{APRICOT PRECOOLING TEST 3}

Refrigerator cars P.F.E. 33160 and P.F.E. 34296, Winters, June 15-16, 1933. Standard loads of 1,000 4-basket crates

Purpose of Test.-(1) To determine rate and extent of cooling in 10 hours and (2) to compare air temperatures in transit and the condition of fruit on arrival when shipped $(a)$ under "standard" refrigeration and (b) with only one re-icing in transit (Rule 254).

Conditions of Loading and Precooling.-The fruit was loaded between 1 and $6 \mathrm{p} . \mathrm{m}$. with air temperatures varying from $96^{\circ}$ to $86^{\circ} \mathrm{F}$. The precooling period extended from $6: 15$ p.m., June 15, to $4: 45$ a.m., June 16. No additional ice was supplied the cars during this period and most of the time minimum air temperatures were above $40^{\circ}$. From 5 to 10 a.m., June 16, the cars were in transit from Winters to Roseville. 
Temperatures Secured from Precooling.-Precooling of these two cars was carried out simultaneously and in similar manner, and the results were essentially the same. The data secured from temperatures recorded near the edges of crates in the top and bottom of tiers $1,4,7$, and 10 in P.F.E. 33160 are presented in figures 17 and 18. The former illustrates the characteristic "crossing over" of the top and bottom lines, resulting from the more rapid reduction in temperature in the top of
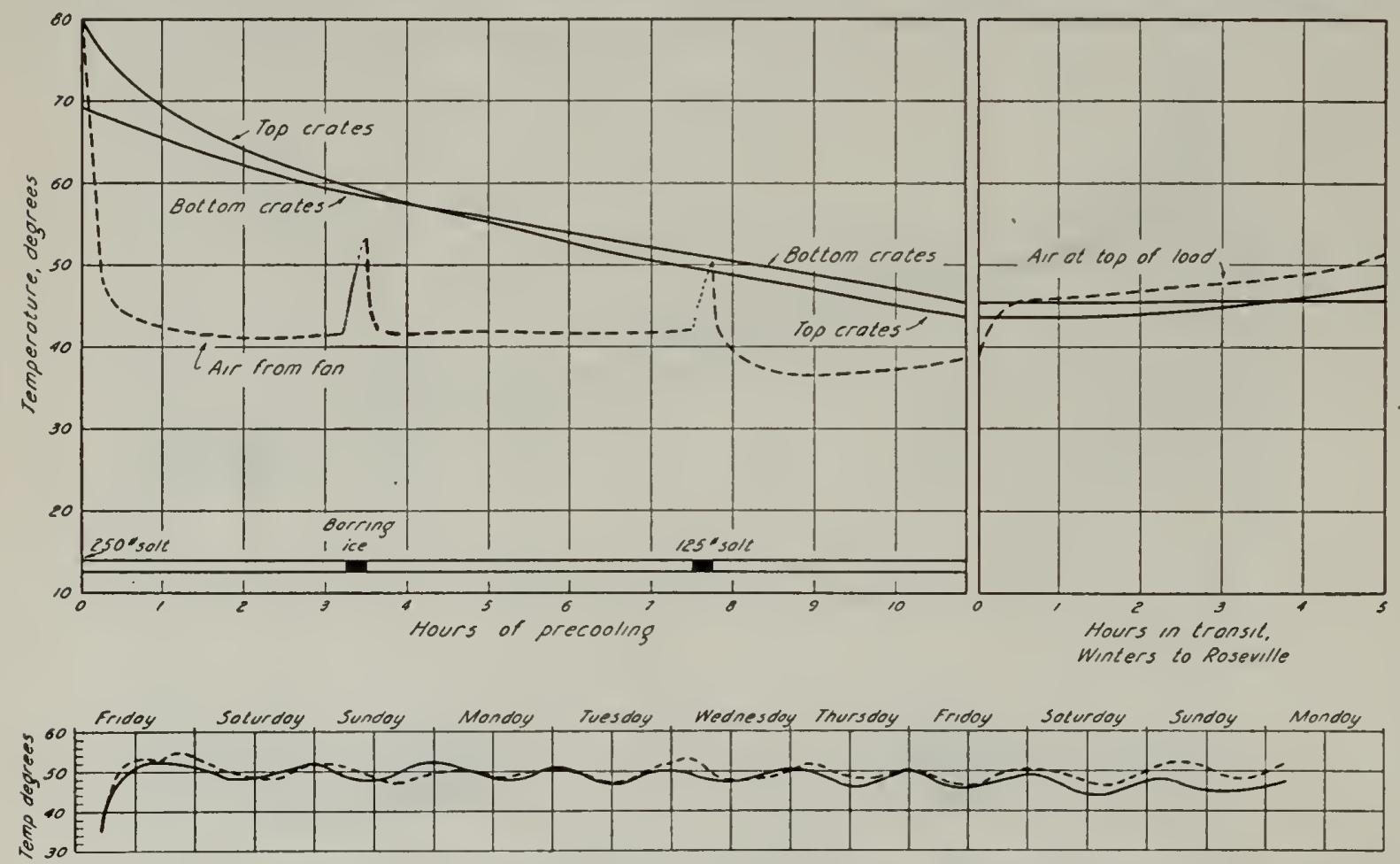

Fig. 17.-Precooling of apricots in P. F. E. 33160, Winters, June 15-16, 1933 : average fruit temperatures in crates during precooling and after 5 hours in transit, from Winters to Roseville. Temperatures were taken in bottom and top of stacks in tiers $1,4,7$, and 10. The solid line in the lower part of the figure represents a thermograph record of air temperature at the top of the load in transit to New York under standard refrigeration. The broken line represents the air temperature in a companion car shipped with only one re-icing in transit.

the load during the first 4 hours. During this period the top crates were reduced $22.5^{\circ}$ (from $80^{\circ} \mathrm{F}$ to $57.5^{\circ}$ ) ; the bottom crates, only $12^{\circ}$ (from $69^{\circ}$ to $57^{\circ}$ ). Thereafter, both top and bottom cooled very uniformly; and after $10^{3} / 4$ hours they were $44^{\circ}$ and $46^{\circ}$ respectively. Cooling would have been more rapid had the air temperature in the car during the first 7 hours been $10^{\circ}$ lower. The "straight line" rate of cooling during the latter half of the precooling period doubtless results from a slight reduction in air temperature after 7 hours.

The uniformity of cooling in this car is further shown by figure 18, illustrating the average temperatures in the top and bottom crates of the different tiers. Tier 7 , intermediate between the doorway and the bunker, remained only $2^{\circ}$ higher during the precooling period than tier 10 at the doorway. Tier 1 remained $2^{\circ}-5^{\circ} \mathrm{F}$ colder than tier 10 for the 
first 7 hours. After this time, the temperatures were all uniform within $2^{\circ}-5^{\circ}$.

For reasons previously mentioned, fruit temperatures could not well be taken in the center of the crates. However, some indication of center temperatures was ascertained by noting the extent to which temperatures near the edge of the package increased after the precooling period. The resistance thermometer bulbs were therefore left in place, and fruit temperatures again recorded at Roseville after 5 hours in transit. Those
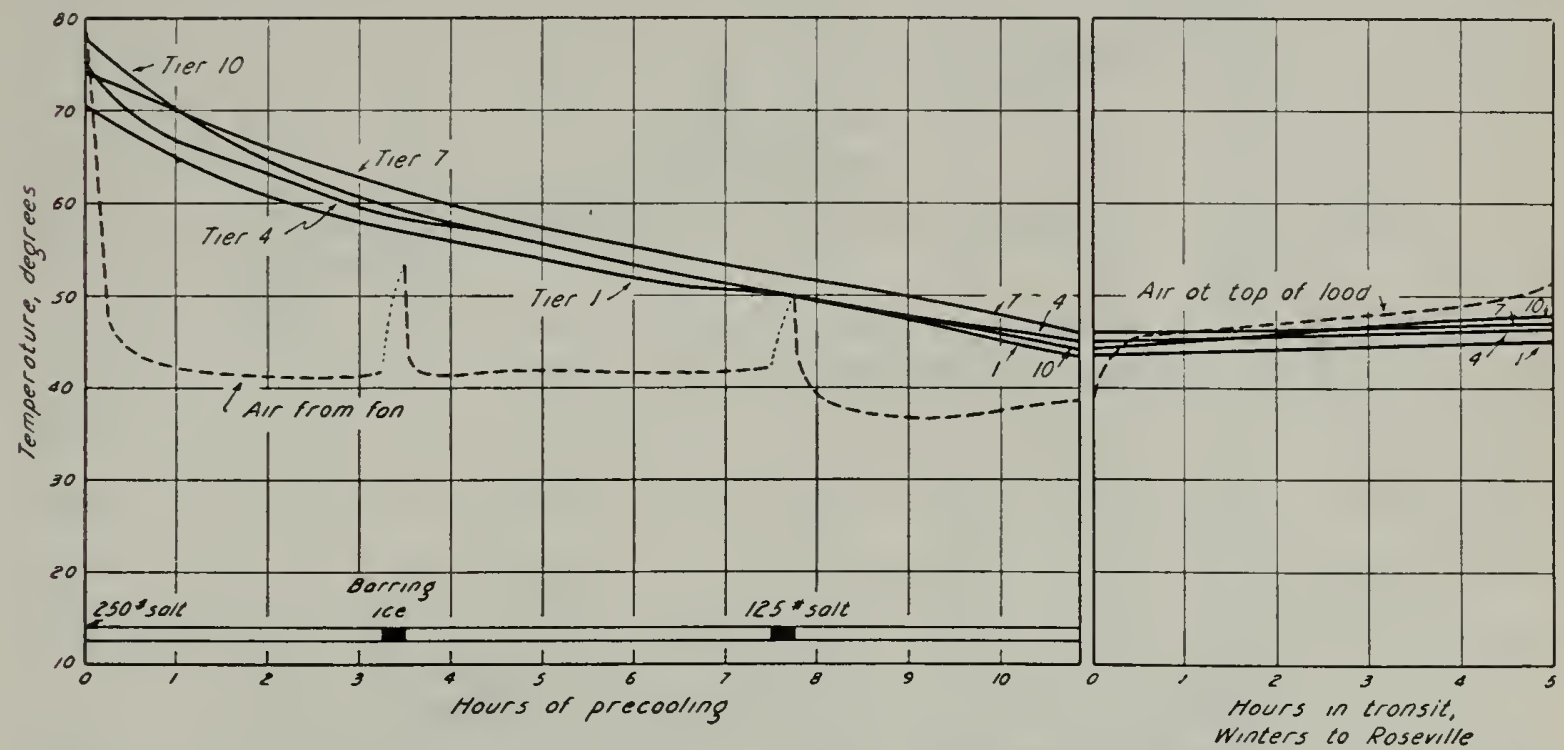

Fig. 18.-Precooling of apricots in P. F. E. 33160, Winters, June 15-16, 1933 : average fruit temperatures in different tiers of the load during and for 5 hours after precooling. Temperatures were taken in the top and bottom of tiers 1, 4, 7, and 10 .

in the bottom of the car were unchanged. Those in the top had risen from $44^{\circ}$ to $48^{\circ} \mathrm{F}$ (fig. 17). Judging from this increase of only $4^{\circ}$, the temperature in the center of the package after 10 hours of precooling was not markedly different from that $3-4$ inches from the outside.

Shipping Record and Condition of Fruit on Arrival.-Maximum air temperatures in the car at Roseville were $51.5^{\circ} \mathrm{F}$, or only $3.5^{\circ}$ higher than that of the fruit in the top of the load. This air temperature, if maintained under daily re-icing, would definitely limit further increases in fruit temperatures. Although the latter were not taken in transit, a recording thermometer on the brace of the car registered the air temperature at the top of the load. The maximum, $52^{\circ}$, occurred during the first 24 hours en route and gradually declined to a minimum of $44^{\circ}$ over the 10-day shipping period (fig. 17). The temperature in top crates at the brace upon arrival in New York was reported as $46^{\circ}$.

Car P.F.E. 34296, loaded and cooled, and moved simultaneously to the same market as P.F.E. 33160, was shipped under Rule 254. Refrigeration was replenished at Roseville, as with P.F.E. 33160; but only one subsequent re-icing (at Council Bluffs) was given in transit. Air in this 
car, shipped under limited refrigeration, was not more than $2^{\circ}$ warmer than that in the car shipped standard refrigeration until the last 24-36 hours in transit, when insufficient ice permitted the air to reach $54^{\circ} \mathrm{F}$. Daily temperatures fluctuated from $2^{\circ}-^{\circ}$, usually being highest near
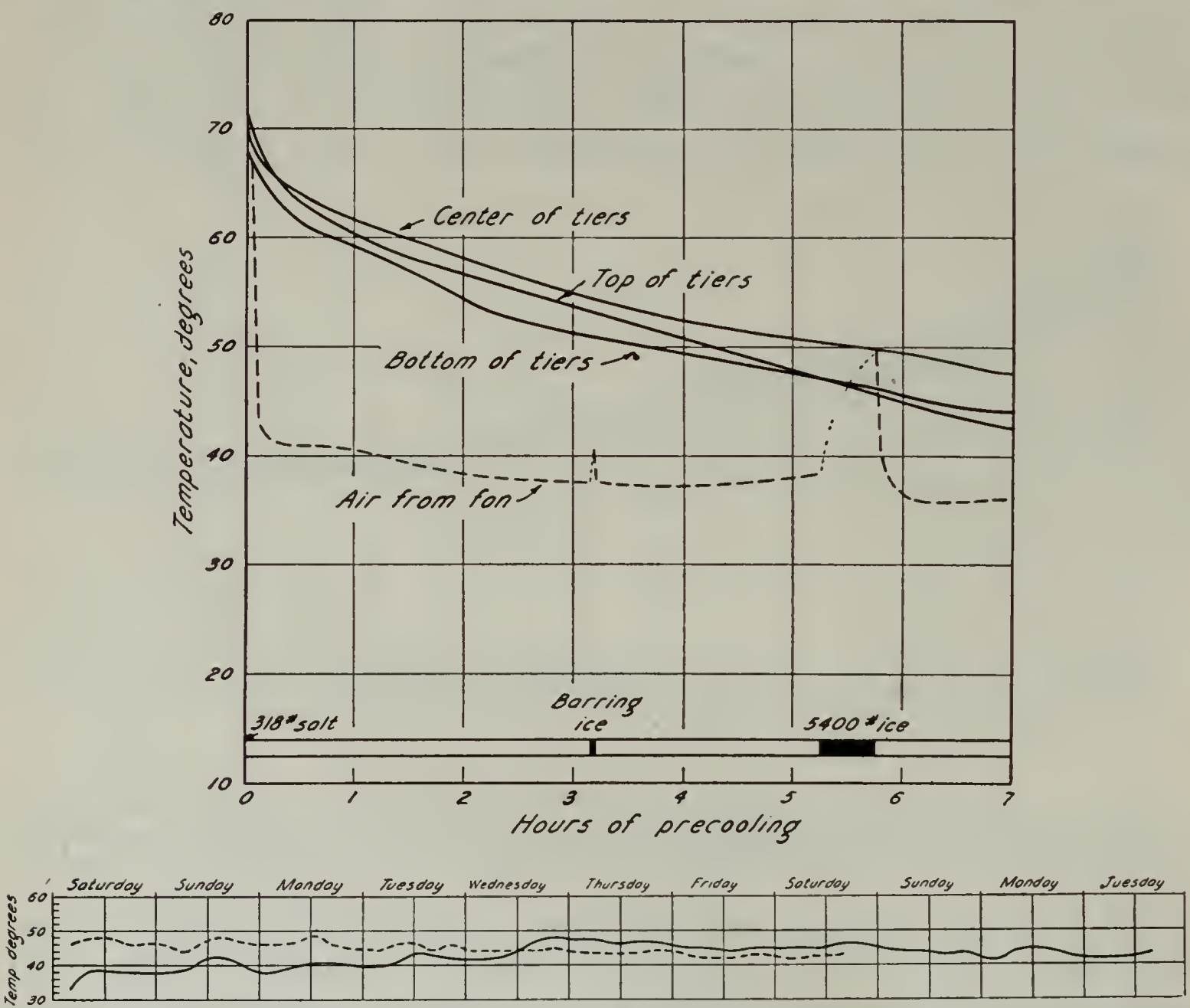

Fig. 19.-Precooling of apricots in P. F. E. 38444, Santa Clara, July 14-15, 1933 : average fruit temperatures in the center of baskets in crates packed in the top, center, and bottom of tiers 2, 6, and 10. The broken line in the lower part of the figure is a thermograph record of the air temperature at the top of the load while in transit to Cincinnati. The solid line represents the air temperature in a companion car shipped the same day to New York. Fruit in this car was precooled to $34^{\circ}$ before loading, that in P. F. E. 38444 to approximately $46^{\circ}$. Both cars moved under standard refrigeration plus salt.

midnight. Fruit temperatures taken at the brace upon arrival were recorded as $54^{\circ}$ in the top of the load and $48^{\circ}$ in the bottom. In general, however, transit temperatures of the two cars differed but slightly.

The shipments were of the Royal variety and the fruit in both cars arrived in practically the same condition-all firm, 75 per cent greenish yellow, and 25 per cent light yellow in color.

\section{APRICOT PRECOOLING TEST 4}

Refrigerator cars P.F.E. 38444 and 37549, Santa Clara, July 14-15, 1933.

Standard load of 1,000 4-basket crates

Purpose of Test.-To ascertain (1) rate of cooling in the center of 
packages precooled in a refrigerator car, (2) the air temperatures in transit of car-cooled and warehouse-cooled fruit, and (3) the condition of the fruit after ten days in transit.

Conditions of Loading and Precooling.-Fruit precooled in P.F.E. 38444 was assembled during the afternoon and loaded between $7: 30$ and $8: 30 \mathrm{p} . \mathrm{m}$. at average temperatures of $68^{\circ}-70^{\circ} \mathrm{F}$. Fruit loaded in P.F.E. 37549 was precooled to $34^{\circ}$ in a cold-storage room and placed in the car without being exposed to the outside air. In this test the thermometer points were placed in the center fruit of individual baskets in crates at the top, center, and bottom of tiers 2, 6, and 10. (These thermometer bulbs were placed in the fruit before loading the crates, and the car was subsequently unloaded in order to extract them.)

Temperatures Secured from Precooling.-Figure 19 illustrates the results of cooling the fruit in the refrigerator car. With the precooling period covering only 7 hours, the average temperature in the center crates was reduced only to $47^{\circ} \mathrm{F}$. The cooling rate, however, resembled those of the two previous tests. With initial fruit temperatures in the bottom of the load averaging only $3^{\circ}-4^{\circ}$ below those of the top (because of the rapidity of loading) the general cooling rate during the first 2 hours was between $6^{\circ}$ and $7^{\circ}$ an hour. Thereafter, bottom and center crates cooled at approximately $2^{\circ}$ an hour; those in the top, $3^{\circ}$. According to vertical averages of temperatures in top, center, and bottom crates of tiers 2,6 , and 10 , the fruit in tiers 6 and 10 cooled very uniformly and at the end of 7 hours averaged $42^{\circ}$ and $43^{\circ}$ respectively. Tier 2 , subjected to a slower rate of air circulation, averaged $50^{\circ}$ at this time.

No records were available as to the precooling rate of the fruit taken from the warehouse room and loaded into P.F.E. 37549. Before removal from the storage room, several packages gave a uniform reading of $34^{\circ} \mathrm{F}$.

Shipping Record and Condition of Fruit on Arrival.-Both P.F.E. 38444 , in which precooling was carried out after loading, and P.F.E. 37549 , loaded with precooled fruit at $34^{\circ} \mathrm{F}$, were shipped under standard refrigeration plus 3 per cent of salt at the first re-icing and 1 per cent at the second. Air temperatures just above the loads at the brace of the two cars in transit are shown in the lower part of figure 19. In the car-cooled load, they averaged $46^{\circ}-47^{\circ}$ during the first 24 hours and fell fractionally each day until they reached $44^{\circ}-43^{\circ}$ after $71 / 2$ days. Air in the car loaded with precooled fruit averaged $37^{\circ}-38^{\circ}$ for the first 24 hours. Thereafter, it rose in $4 \frac{1}{2} 2$ days to $48^{\circ}$, or slightly 
higher than in the car loaded with warm fruit. This difference of approximately $2^{\circ}$ was maintained as long as the temperature record in the latter car was taken.

Although both these cars were originally destined for New York, P.F.E. 38444 was diverted to Cincinnati, where it arrived after $71 / 2$ days. The diverting of this car to Cincinnati made impossible comparison of differences in the ripeness of the fruit in the two cars on arrival. Judging from the condition of the fruit when loaded, and the temperatures in the two cars in transit, the fruit in the two loads probably differed little when examined, one in Cincinnati after $71 / 2$ days, the other

TABLE 4

Percentage of Apricots Ripe Upon and After Arrival in New York; Shipped in P.F.E. 37549 from SAN'ta Clara, California, July 15, 1933

\begin{tabular}{|c|c|c|c|c|c|}
\hline & & $\begin{array}{l}\text { Top } \\
\text { crates }\end{array}$ & $\begin{array}{l}\text { Center } \\
\text { crates }\end{array}$ & $\begin{array}{l}\text { Bottom } \\
\text { crates }\end{array}$ & $\begin{array}{c}\text { A verage for } \\
9 \text { crates }\end{array}$ \\
\hline \multicolumn{2}{|c|}{ On arrival...... } & $0-6$ & 0 & 0 & 2 \\
\hline & 1 day & $20-30$ & $4-6$ & $4-25$ & $10-20$ \\
\hline \multirow[t]{3}{*}{ After } & 2 days.... & $35-45$ & $10-15$ & $8-30$ & $18-30$ \\
\hline & 3 days.... & & & & \\
\hline & 4 days.... & 85 & 80 & $70-85$ & $80-85$ \\
\hline
\end{tabular}

in New York after 101/2 days. Had both cars gone to New York, as originally planned, the apricots (Royal) in the warehouse-cooled load would probably have been somewhat superior. Fruit in this ear, loaded in a hard condition-50 per cent greenish yellow and 50 per cent light yellow-arrived 75 to 90 per cent firm and 60 to 80 per cent yellowish orange. The top crates arrived with 2.5 to 25 per cent of the fruit full color, and one bottom crate with 5 per cent. Thorough precooling largely eliminated color differences although, in 9 crates held for observation, the fruit in the top crates appeared slightly riper on the second day after arrival than that in the center or bottom crates. Four days after arrival all fruit was considered 80-85 per cent ripe (table 4).

\section{APRICOT PRECOOLING TEST 5}

University Farm cold storage, July 6-7, 1932

Purpose of Test.-To secure the cooling rate of fruit in the center of an individual 18-pound lug pack.

Conditions of Precooling.-The lug on all sides except the top was fully exposed to a constant temperature of $33^{\circ}-32^{\circ} \mathrm{F}$, but in air having only a slight movement.

Temperatures Secured from Precooling.-With $82^{\circ} \mathrm{F}$ as the initial temperature, 22 hours were required to reduce the center of the pack- 
age to $40^{\circ}$, and 40 hours to reduce it to $34^{\circ}$ (fig. 20). Although the fruit was cooled in air having little movement, the fact that the air temperature was uniformly low and that the box was not surrounded by warm fruit doubtless explains the similarity of cooling to that with the crates in air moving at 75 feet a minute in test 7 (fig. 22).

Had the lug box been cooled under the same conditions as those to which the crates were exposed, it would probably have cooled slightly more slowly than it did. On the other hand, a strong circulation of air would have tended toward more rapid cooling. The rate of cooling in this test, therefore, probably represents a fair average for lug packs

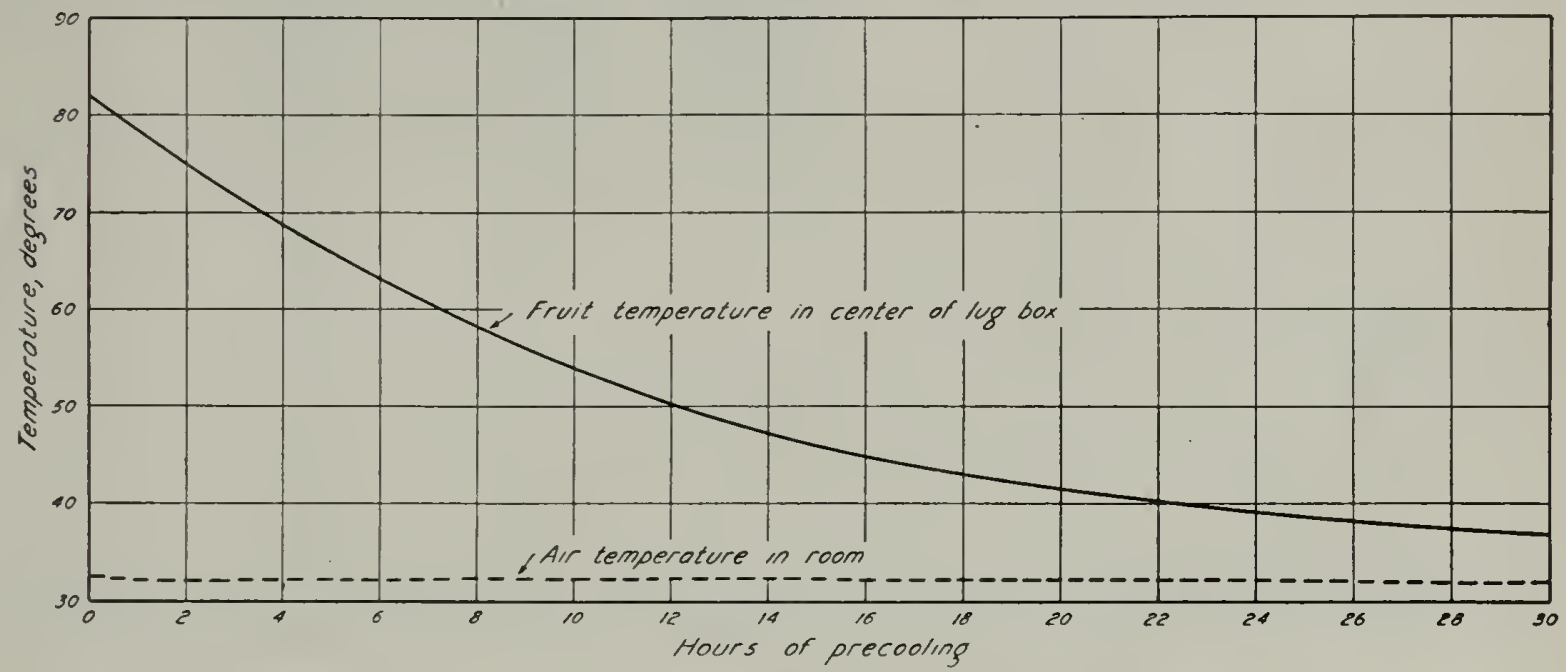

Fig. 20.-Precooling of apricots in University Farm cold storage, July 6-7, 1932 : rate of cooling in the center of an 18-pound tug box in $33^{\circ}-32^{\circ}$ air circulating only slightly. Forty hours were necessary to reduce the temperature to $34^{\circ}$, and 48 hours to bring it to $33^{\circ}$.

in most storage rooms where the natural circulation of air is not supplemented with booster fans.

\section{APRICOT PRECOOLING TEST 6}

University Farm cold storage, July 19-20, 1933

Purpose of T'est.-(1) To ascertain the cooling rate in the center and near the edge of crates under different velocities of air and (2) to compare the shipping qualities of precooled and nonprecooled fruit.

Conditions of Precooling.-Standard crates were placed on shelves with $33^{\circ}-32^{\circ}$ air circulating freely on all sides. The fruit was cooled only to $40^{\circ} \mathrm{F}$.

Temperatures Secured from Precooling.-The cooling rate is shown in table 5 . Center of packages in air moving at 250 feet a minute cooled to $40^{\circ} \mathrm{F}$ in 8 hours while 10 hours were necessary to secure the same results in air moving at 75 feet a minute.

These data are almost identical to those secured with cherries under the same conditions. The cooling rate as influenced by air velocity is 
less marked than when a relatively large number of packages are stacked together. Characteristic differences of $6^{\circ}-8^{\circ} \mathrm{F}$ between the center and near the edge of packages are noted during the first 4-6 hours.

Condition of Precooled and Nonprecooled Fruit.-See "Holding Tests with Precooled and Nonprecooled Apricots," page 52.

TABLE 5

The Rate of Cooling Apricots in AIr at $32^{\circ} \mathrm{F}$

\begin{tabular}{|c|c|c|c|}
\hline \multirow[b]{2}{*}{ Hours of cooling } & \multirow{2}{*}{$\begin{array}{c}\text { Air velocity } \\
75 \text { feet } \\
\text { a minute; } \\
\text { temperature } \\
\text { at center of } \\
\text { package }\end{array}$} & \multicolumn{2}{|c|}{ Air velocity 250 feet a minute } \\
\hline & & $\begin{array}{l}\text { Temperature } \\
\text { at center of } \\
\text { package }\end{array}$ & $\begin{array}{l}\text { Temperature } \\
\text { at edge of } \\
\text { package }\end{array}$ \\
\hline 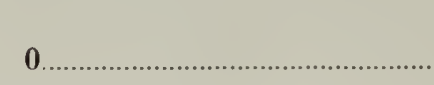 & $\begin{array}{c}\text { degrees } F \\
70\end{array}$ & $\begin{array}{c}\text { degrees } F \\
72\end{array}$ & $\begin{array}{c}\text { degrees } F \\
73\end{array}$ \\
\hline 1 & 67 & 69 & 64 \\
\hline 2 & 64 & 64 & 56 \\
\hline $3 \ldots \ldots \ldots \ldots$ & 59 & 57 & 50 \\
\hline 4 & 55 & 52 & 46 \\
\hline $5 \ldots \ldots \ldots$ & 52 & 49 & 43 \\
\hline $6 \ldots \ldots \ldots \ldots$ & 49 & 45 & 40 \\
\hline $7 \ldots \ldots \ldots \ldots \ldots \ldots$ & 46 & 42 & 38 \\
\hline $8 \ldots \ldots \ldots \ldots \ldots \ldots \ldots \ldots \ldots \ldots \ldots$ & 44 & 39 & 36 \\
\hline $9 \ldots \ldots \ldots \ldots \ldots$ & 41 & .... & .... \\
\hline $10 \ldots \ldots \ldots \ldots \ldots \ldots \ldots \ldots \ldots \ldots$ & 40 & .... & $\cdots$. \\
\hline
\end{tabular}

APRICOT PRECCOOLING TEST 7

University Farm cold storage, July 3-4, 1933

Purpose of Test.-(1) To ascertain (a) the cooling rate in the center of baskets in standard crates at the top, center, and bottom of stacks 6 crates high and $(b)$ the time required to reach $40^{\circ} \mathrm{F}$ when the fruit, starting at $80^{\circ}$, is cooled in a slight and in a moderately strong circulation of air. (2) To observe the shipping quality of precooled and nonprecooled fruit.

Conditions of Precooling.-Temperatures were taken in two stacks of fruit placed on floor boards, separated from each other by 3 -inch air channels, and completely surrounded by other crates of warm fruit. An air temperature of $32^{\circ} \mathrm{F}$ was maintained after the first 4 hours.

Temperatures Secured from Precooling.-Figure 21 illustrates the precooling rate of fruit in the center of packages in air moving at only 75 feet a minute. Center crates exposed to minimum air circulation lost heat somewhat more slowly than either the bottom crates or those next to the top. Bottom crates exposed to a free circulation of air underneath cooled most rapidly for 10 to 11 hours, after which the rate declined and was exceeded by that of the crates next to the top. In both instances, 
$40^{\circ} \mathrm{F}$ was reached after 19 hours of cooling. Center crates required 23 hours to reach this temperature.

Comparable crates placed in the same position, but cooled in air circulating at 250 feet a minute, again show that center crates are slowest to cool. The data are not presented, but when plotted differ from figure

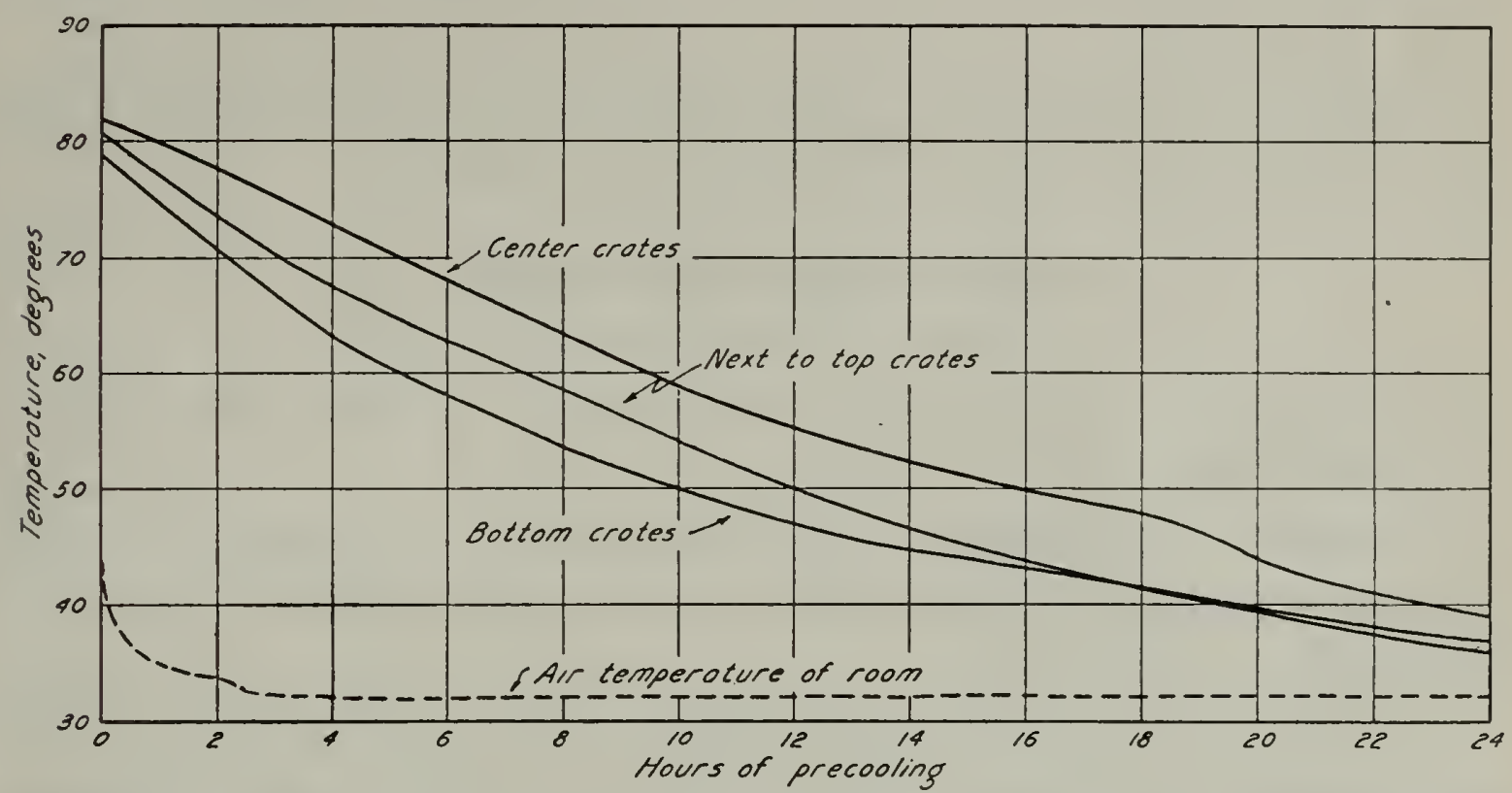

Fig. 21.-Precooling of apricots in University Farm cold storage, July 3-4, 1933: temperature of fruit in centers of baskets in next-to-top, center, and bottom crates in stacks. The fruit was cooled in air circulating 75 feet a minute.

21 only in that the general cooling rate is more rapid and that the temperature differences between the crates are less. Stronger air velocity was conducive to more uniform cooling.

Figure 22 shows the general cooling rate and the time required for

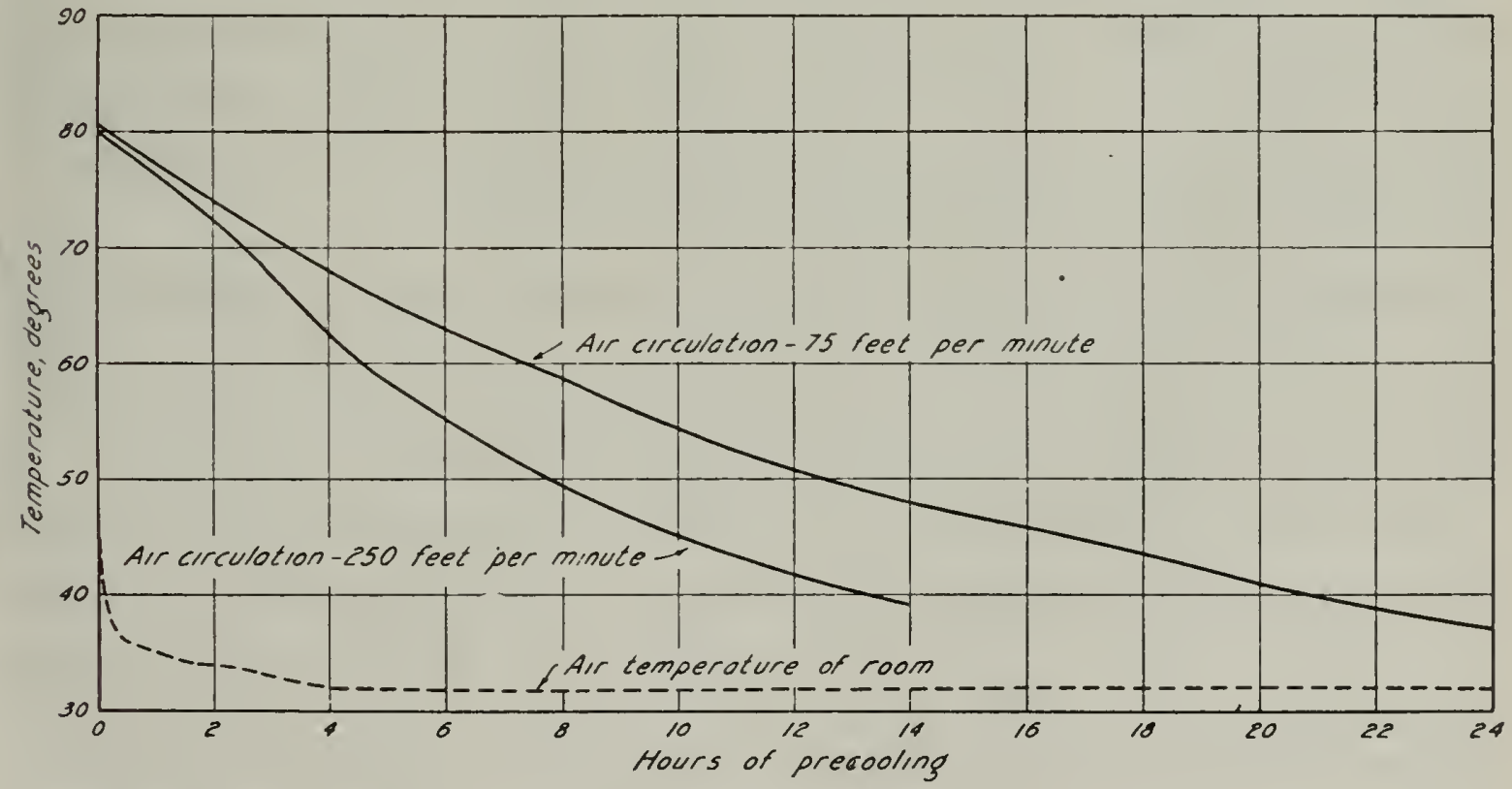

Fig. 22.-Precooling of apricots in University Farm cold storage, July 3-4, 1933 : average fruit temperatures in the center of baskets in top, center, and bottom crates cooled in air circulating at 75 and at 250 feet a minute. 
the center of the crates to reach an average of $40^{\circ} \mathrm{F}$ when cooled in a slight and in a moderately strong current of air. The stronger air velocity of 250 feet a minute reduced the time almost 50 per cent.

The temperature of nomprecooled fruit, held for 10 days at $60^{\circ}-50^{\circ}$ $\mathrm{F}$, dropped from $80^{\circ}$ to $60^{\circ}$ in the first 24 hours and from $60^{\circ}$ to $50^{\circ}$ in the next 9 days.

Condition of Precooled and Nonprecooled F'ruit.-See "Iolding 'Tests with Precooled and Nonprecooled Apricots," page 52.

\section{APRICOT PRECOOLING TEST 8}

University Farm cold storage, June 27-28, 1934

Purpose of Test.-T'o ascertain the influence of air temperature upon the cooling rate of fruit.

Conditions of Precooling.- - Small lots of fruit were placed in rooms where air temperatures were maintained close to $25^{\circ}$ and $35^{\circ} \mathrm{F}$ throughout the entire cooling period.

Temperatures Secured from Precooling.-Apricots in the center of crates exposed to $25^{\circ}$ air cooled to $32^{\circ} \mathrm{F}$ in slightly under 10 hours. Indications of slight freezing were noted in the most exposed fruits, which had been cooled to between $27^{\circ}$ and $28^{\circ}$. Ten hours cooling in $35^{\circ}$ air reduced the temperature of the center and outer fruit to $37^{\circ}$ and $38^{\circ}$ respectively.

\section{APRICOT PRECOOLING TEST 9}

Commercial storage room, Santa Clara, July 10-11, 1933

Purpose of Test.-To ascertain, under commercial conditions, the general cooling rate and the time required for apricots to reach $32^{\circ} \mathrm{F}$ in the center and near the edge of packages, together with the variability of cooling in crates in different parts of the stack.

Conditions of Preciooling.- Standard crates and Los Angeles lugs were stacked 8-10 high. The stacks were spaced a minimum of $4-6$ inches apart, with 12-inch space between each two. All fruit was handled on floor boards permitting free circulation under the stacks.

Precooling was carried out in a room $46 \times 70$ feet with a 15 -foot ceiling. On one side, 75 per cent of the floor was occupied with fruit; the other side was empty. Cold air was brought through the center air duct running lengthwise along the ceiling. Warm air was drawn out through similar ducts at each side. The natural air flow was augmented by an 18-inch portable booster fan in the center aisleway, forcing the incoming cold air through the stacks with greater velocity. (The air moved 
approximately 800 feet a minute, 6 feet in front of the fan.) To aid further in cooling and to prevent "short circuiting" of the air above the fruit rather than through the stacks, a canvas baffle was suspended from the ceiling in front of the intakes. This reached the top of the stacks or slightly below.

Special long-stemmed mercury thermometers were placed in fruit in the center and near the edges of the baskets in the crates and in the centers of the lug boxes. Crates in which temperatures were recorded were located (1) in the top and bottom of the second stack in front of the fan, (2) in the same positions in the second stack from the side

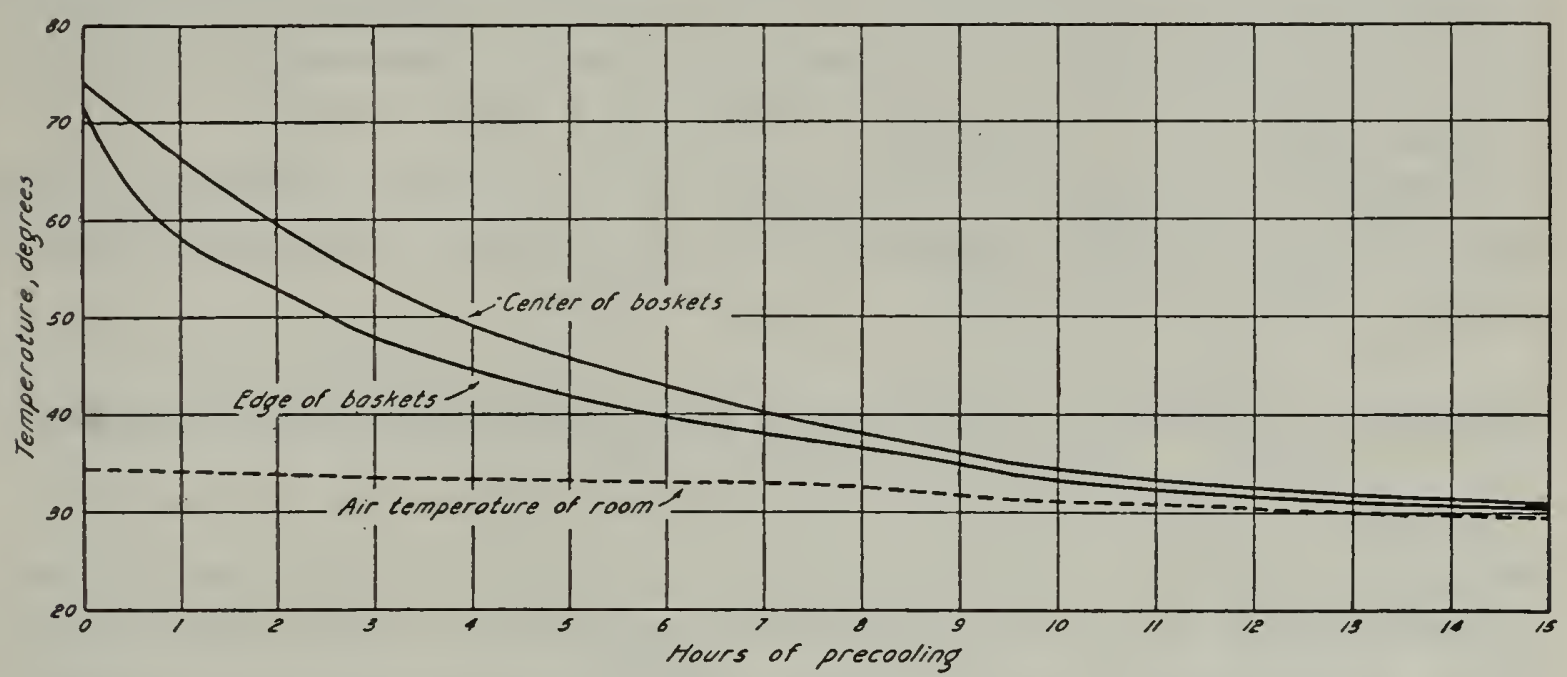

Fig. 23.--Precooling of apricots in a commercial cold-storage room, Santa Clara, July 10-11, 1933: average cooling rate in the center and at the edge of baskets in five crates. Natural air circulation was augmented by a portable precooling fan.

wall, and (3) in the center of the stack situated half way between the fan and the wall. Lug boxes were placed in nearby stacks in similar positions. Air temperature in the room during precooling ranged from $34^{\circ}$ to $29^{\circ} \mathrm{F}$.

Temperatures Secured from Precooling.-The average cooling rate of five crates located in the positions indicated above is presented in figure 23 . With a temperature of $74^{\circ} \mathrm{F}$ when placed in the room, fruit in the center of the baskets required an average of $131 / 2$ hours to reach $32^{\circ}$. The second row of fruits in the top layer of the baskets reached this temperature after approximately 12 hours. During the first 2 or 3 hours, temperatures in the center and near the edge of the baskets differed as much as $8^{\circ}$. The difference gradually lessened, and disappeared after 15 hours.

The cooling rate is represented by a broad curve, the temperature in the center of the baskets dropping $8^{\circ}$ during the first hour and only $1^{\circ}$ an hour or less after 11 hours, when the difference between fruit and air temperature became very small. Temperatures in the center of lug 
boxes, doubtless because of the rapid air circulation and the somewhat more open stacking, were reduced as rapidly as in the basket crates and considerably more rapidly than the fruit in the center of an individual lug box cooled in test 5 with only a slight movement of air (fig. 20).

The cooling rate was influenced somewhat both by the position of the fruit in the stacks and by the position of the stacks with reference to the air currents. Fruit at the bottom of the stacks cooled as rapidly as that at the top, or slightly more so. Fruit in the center cooled most slowly, lagging about $4^{\circ} \mathrm{F}$ after 10 hours. A similar lag existed between the stacks near the wall and those immediately in front of the booster fan. Fruit in the center of the stack intermediate between the fan and the wall cooled more slowly than that in any other location.

Attempts to measure the air velocity at different positions in the stacks were not entirely successful, but apparently most rapid cooling occurred where the circulation was most rapid.

\section{HOLDING TESTS WITH PRECOOLED AND NONPRECOOLED APRICOTS}

Subsequent to precooling as carried out in tests 6 and 7, Royal apricots grown at Winters and at Davis were held at car temperatures and examined after 10 days, a period corresponding to the usual transit period. Additional lots of the Tilton variety from Davis and the Blenheim variety from Los Altos were also held under these conditions.

In each of the samples, the value of precooling was generally noticeable in both the color and the general condition of the fruit. Nonprecooled apricots held at a temperature gradually declining from $60^{\circ}$ to $50^{\circ} \mathrm{F}$ were generally full ripe after 10 days and were considered marketable for 1 or 2 days less than the comparable precooled samples. Fruit precooled to $40^{\circ}$ was distinctly firmer, usually with less color development, and was in better condition for handling than the nonprecooled. Samples precooled to $34^{\circ}$ exhibited greater firmness and usually somewhat less color "upon arrival" than those precooled to only $40^{\circ}$; and, though they failed to show a longer period of marketability after removal from car temperatures, they would have been considered preferable for commercial rehandling on the eastern markets. The observations on the different lots are shown in table 6 .

\section{SUMMARY OF APRICOT PRECOOLING AND HOLDING TESTS}

In these precooling tests with apricots, the general cooling rate, where air temperatures of $35^{\circ}-40^{\circ} \mathrm{F}$ were maintained, averaged $2.5^{\circ}$ to $3.0^{\circ}$ per hour over an 8 to 10 -hour period. Fruit temperatures in the outer 
TABLE 6

Comparative Condition and Period of Marketability of Precooled and NONPRECOOLED APRICOTS AFTER HOLDING FOR 10 DAYS

Under Transit Temperatures

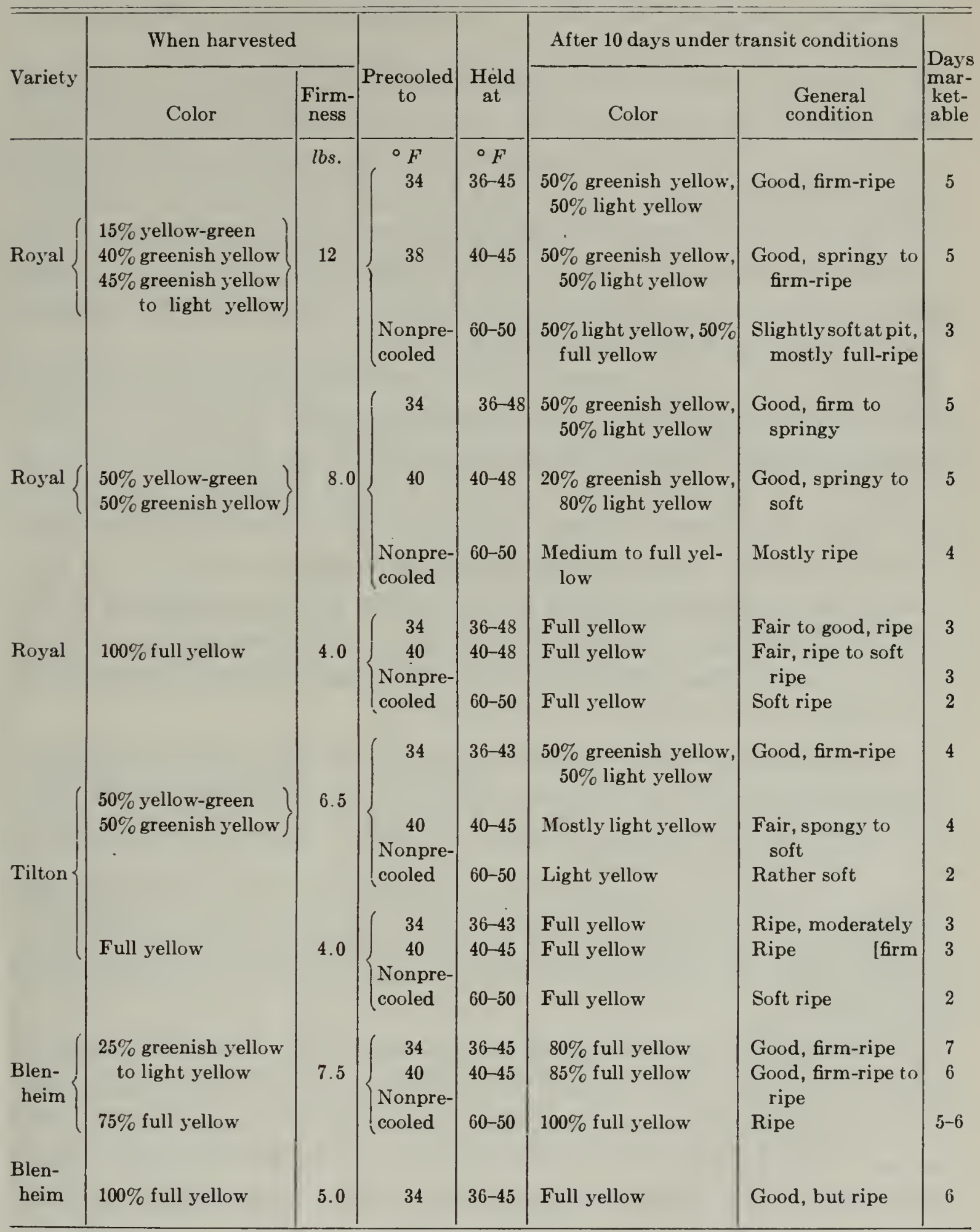

part of the packages were usually reduced to $40^{\circ}$ in 10 to 12 hours. (The temperature of the fruit in the center of baskets may be $2^{\circ}-5^{\circ}$ higher after this period of cooling.)

Temperatures near the edge of crates in the top of the load, higher at the beginning of precooling, were after 3 to 5 hours usually lower 
than those in the bottom. Fruit in the different tiers cooled at a comparatively uniform rate, tiers 4-7, quarter way of the load from the door to the bunker, being usually slightly higher than either tier 1, next to the bunker, or tier 10, exposed to the circulation of air in the center of the car.

In warehouse rooms with temperatures of $35^{\circ}-32^{\circ} \mathrm{F}$, the average hourly cooling rate over a 10 -hour period was slightly more rapid than that in the cars under test. Over an 18 to 20 -hour period, the average cooling rate in the center of packages was $2^{\circ}$ to $2.5^{\circ}$ per hour. Packages in the center of stacks cooled somewhat less rapidly than those at the top or bottom, when the stacks were placed on floor boards. The comparative cooling rate in the top and bottom of stacks largely depends upon how the air currents are directed.

Both the velocity and temperature of the air influenced the rate of cooling. Fruit in the center of crates which cooled to $40^{\circ} \mathrm{F}$ in 7 hours under a strong air blast required 9 hours under a moderate circulation; that taking 14 hours to cool under the former condition required 21 hours under the latter. Apricots requiring close to 24 hours to cool to $32^{\circ}$ under average storage-room conditions may be cooled to this temperature in approximately half the time by a strong circulation of $30^{\circ}$ air. With $25^{\circ}$ air fruit may be cooled to $32^{\circ}$ in 10 hours or less, but such fruit must be watched closely for signs of freezing of the exposed fruits at the edges of the crates.

In most cooling tests, the temperature of the fruit near the edge of the baskets and that in the center differed $6^{\circ}-8^{\circ} \mathrm{F}$ in temperature during the first few hours of precooling, but after 10-12 hours the difference was usually not more than $2^{\circ}$.

Fruit in 18-pound lug boxes, face-and-fill pack, may, under rapidly circulating air, cool at essentially the same rate as apricots in the 4-basket crate. Under a slight movement of air they lose their heat somewhat less rapidly.

After holding under shipping temperatures for 10 days, precooled samples of apricots were usually of greener color and distinctly firmer than the nonprecooled samples; they also kept 1-2 days longer after ripening. Although fruit precooled to $34^{\circ} \mathrm{F}$ did not hold up any better after becoming ripe than that precooled only to $40^{\circ}$, that which received the more thorough cooling would have been considered preferable for commercial rehandling.

TESTS WITH PLUMS

Cooling of plums in refrigerator cars included two tests with mixed loads, one with the fruit wrapped and packed in peach boxes, and three 
with "heavy," or 30,000-pound loads cooled with different types of equipment and shipped under standard and under limited refrigeration.

In addition to the general condition of the shipments upon arrival as reported by receivers, special test crates were included in different parts of one load. Upon arrival in New York, these were examined by eastern representatives of the shipping firm for color and firmness changes in transit and were then held for observation of the subsequent ripening changes and the period of marketability.

Further first-hand data on ripening under transit conditions were secured by holding selected precooled and nonprecooled crates of 15 varieties in the University Farm cold-storage plant for 10 days at temperatures usually found in precooled and nonprecooled cars. These results are presented under "Holding Tests of Precooled and Nonprecooled Plums," page 71.

The comparative cooling rate of fruit exposed to different air temperatures and velocities was also determined by tests conducted in the University Farm experimental rooms.

\section{PLUM PRECOOLING TEST 1}

Refrigerator car P.F.E. 36088, Placerville, July 27-28, 1932.

A mixed load of plums and pears consisting of 183 plum erates, 353 plum lugs, and 259 standard pear boxes-the latter loaded in the four center tiers of the car

Purpose of Test.-To determine (1) the cooling rate of plums in a mixed load, (2) the air temperatures in the car during transit, and (3) the condition on arrival (since the shippers reported that these plums were the most mature they had ever shipped).

Conditions of Loading and Precooling.-Loading was in progress from 11:30 a.m. to 4:30 p.m., with the temperature of the outside air $96^{\circ}-92^{\circ} \mathrm{F}$. Bunkers were replenished with 4,200 pounds of ice before loading. With these kept well filled and with the operator giving close attention to temperatures, cooling conditions were favorable for a mixed load where the air channels were broken. Fruit in the bottom part of the car cooled $15^{\circ}-20^{\circ}$ before the precooling fans were started.

Temperatures Secured from Precooling.-Figure 24 illustrates again the typical "crossing over" of the top and bottom temperatures, as recorded near the edge of plum crates and pear boxes, even when these differ widely at the beginning of precooling. At the end of 10 hours the fruit in the top, center, and bottom of the load had cooled $37^{\circ}, 22^{\circ}$, and $14^{\circ} \mathrm{F}$ respectively. At this time, fruit in the center was $8^{\circ}-9^{\circ}$ higher than on the top. Judging from the average temperatures, the plums in 
tiers 1 and 4 (averaging top, center, and bottom crates) had cooled in 10 hours from $59^{\circ}$ to $38^{\circ}$ and from $64^{\circ}$ to $43^{\circ}$ respectively. The fruit in tiers 7 and 10 averaged $69^{\circ}$ and $75^{\circ}$ respectively at the beginning of precooling and cooled to $41^{\circ}$ and $44^{\circ}$. Tier 1 therefore remained the coldest throughout precooling, while tier 10, where the thermometer points were in pears, remained only $1^{\circ}-2^{\circ}$ higher than tier 4 . Tier 7 ,

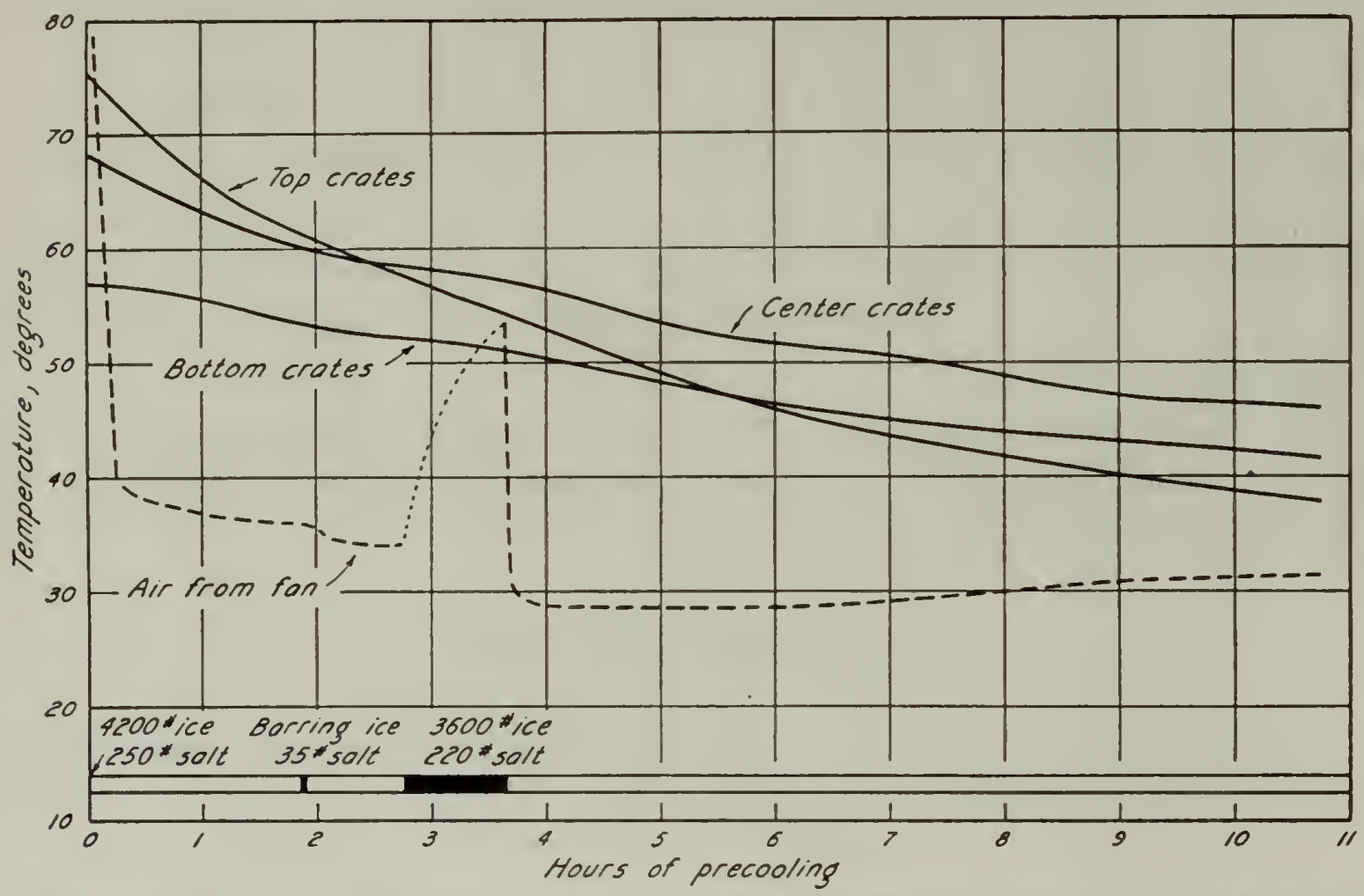

Fig. 24.-Precooling of plums and pears in P. F. E. 36088, Placerville, July 2728, 1932: average fruit temperatures in top, center, and bottom crates in tiers 1, 4, and 7 , and in top and bottom pear boxes in tier 10 .

originally $5^{\circ}$ warmer than tier 4 , cooled slightly faster, probably because of a stronger air current. The air temperature over the top of the load during precooling was immediately reduced to $40^{\circ}$ and, after the car was re-iced at the end of 3 hours, averaged slightly below $30^{\circ}$.

Shipping Record and Condition of Fruit on Arrival.-This car was forwarded to New York under standard refrigeration. When opened at Erie pier the air temperature at the top of the load at the brace was $52^{\circ} \mathrm{F}$. Fruit temperatures in the top and bottom of the load at the doorway were $50^{\circ}$ and $46^{\circ}$ respectively; midway between the door and the ice bunkers they were $49^{\circ}$ and $44^{\circ}$.

The receivers reported:

This fruit was examined very carefully and found to be generally in excellent condition. Plums were in a good, firm, healthy condition with the exception of $4 \times 4$ Duartes, Burbanks, and Wicksons, which showed up hard-ripe to slightly soft. [Some of this fruit was practically ripe when shipped.] Pears were all hard-green to an occasional box showing very slight color. 


\section{PLUM PRECOOLING TEST 2}

Refrigerator car P.F.E. 38819, Vacaville, August 5-6, 1933. A mixed car of 60 per cent plums and 40 per cent pears. Temperatures recorded in plum crates only

Purpose of Test.-To secure additional data on (1) the cooling of mixed cars, (2) the ripening changes in test crates of precooled plums in transit, and (3) the period of time such fruit remained marketable after its arrival.

Conditions of Loading and Precooling.-Except for two tiers of

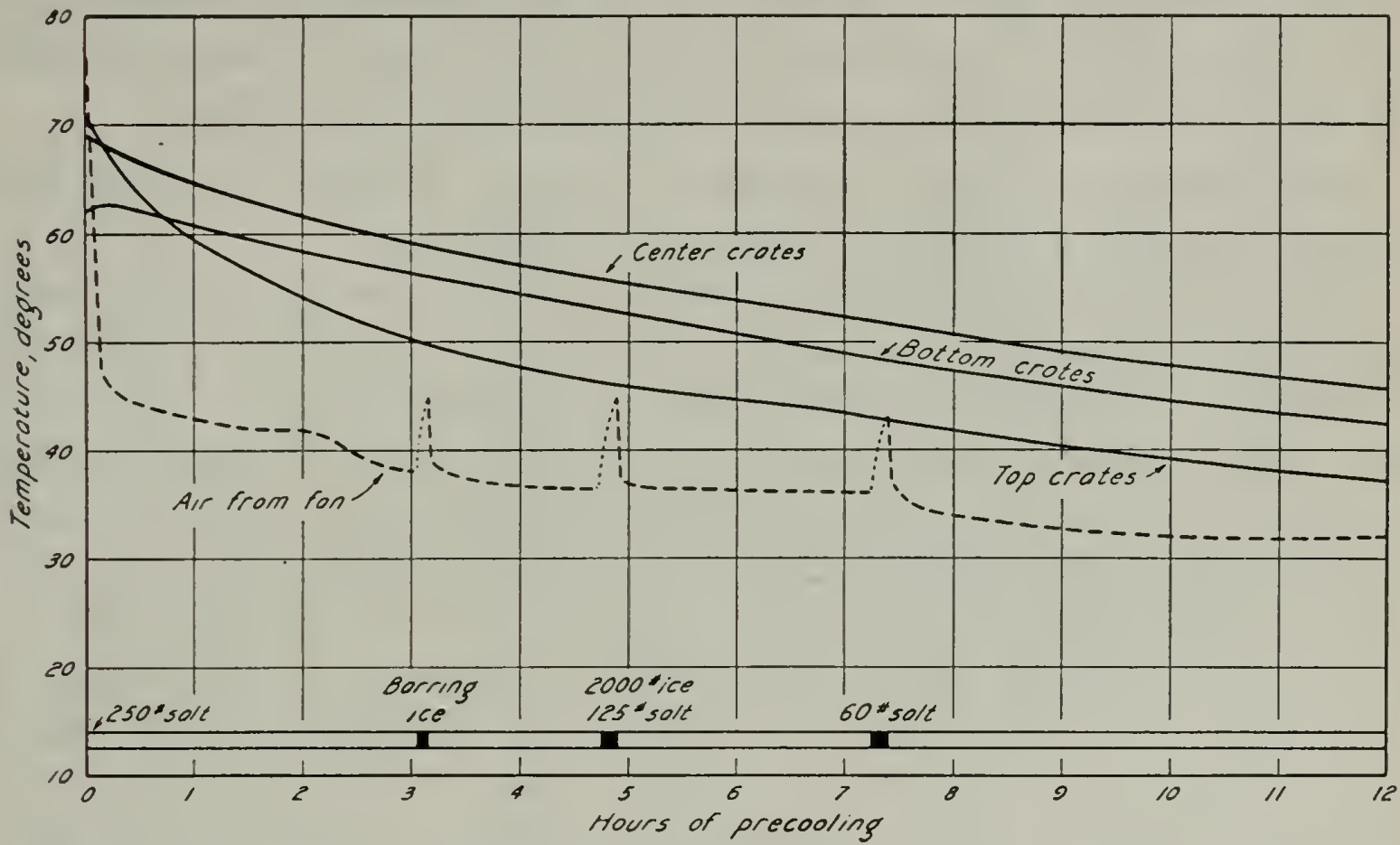

Fig. 25.-Precooling of plums and pears in P.F.E. 38819, Vacaville, August 5-6, 1933: average fruit temperatures in top, center, and bottom plum crates in tiers 1 , 5 , and 10.

plums at the brace, the "A" end of the car contained a standard load of pears. These were loaded in the forenoon after standing exposed to outside air overnight. The " $\mathrm{B}$ " end of the car, containing the thermometers, was loaded between $1: 30$ and $3: 30$ p.m. with standard plum crates, 5 wide and 9 and 10 high, with an average fruit temperature of $75^{\circ} \mathrm{F}$. Loading was completed 2 hours before starting the fans, which operated, except during four short periods, for 12 hours-from $5: 30$ p.m. to $5: 30$ a.m. During precooling, 6,700 pounds of ice and 435 pounds of salt were used.

Temperatures Secured from Precooling.-Average temperatures near the edges of top, center, and bottom crates in tiers 1, 5, and 10 after 11 hours of precooling (fig. 25) were within $2^{\circ} \mathrm{F}$ of those in the mixed car cooled at Placerville (test 1, fig. 24). In this Vacaville car, however, the initial fruit temperatures in the top of the load differed from those in the bottom only by $7.5^{\circ}$; and throughout most of the precooling period 
the line representing bottom temperatures was therefore slightly higher than the one in figure 24. Air temperatures were also slightly higher.

Fruit in the top and center of the load cooled in 10 hours from $71^{\circ}$ and $69^{\circ} \mathrm{F}$ to $39^{\circ}$ and $48^{\circ}$ respectively, or an arerage of $2.0^{\circ}$ an hour for the center. The temperature of the bottom, though somewhat lower, dropped at the same rate as that of the center. The different tiers of plums also cooled in essentially the same way, tier 1 remaining $4^{\circ}-5^{\circ}$ below tier 10. Except for the rapid reduction in temperature of the top crates during the first 2-3 hours, the entire load cooled uniformly over the 12-hour period. The temperature of the air from the fans was gradually lowered from the beginning until the end of precooling.

Shipping Record and Condition of Fruit on Arrival.-This car was shipped to New York under standard refrigeration.

The general condition upon arrival was reported as very satisfactory. Individual crates were specially observed as to color and firmness at loading, upon arriving in New York, and thereafter for 4 days, when the fruit was held under temperatures of $70^{\circ}-80^{\circ}$. All samples were subsequently sold. The condition of Grand Duke, Giant, and President varieties was reported as especially fine. Table 7 presents the color and firmness changes in transit and the general rate of ripening after arrival. In the Grand Duke and Diamond varieties, the two stages of maturity show differences in ripening. The two crates each of Giant and President were selected for similar maturity but were carried at different heights in the load. The differences in color between crates of these latter varieties are considerably smaller than those usually found in cars of nonprecooled fruit, but probably greater than if the fruit in the top and center of the load had been thoroughly precooled to $40^{\circ} \mathrm{F}$ or below.

\section{PLUM PRECOOLING TEST 3}

Refrigerator car P.F.E. 36224, Colfax, July 16, 1933. Fruit wrapped, in peach boxes. A standard 26,000-pound load

Purpose of Test.-To determine (1) the amount of cooling of nonprecooled wrapped plums during the first 12 hours in transit, (2) the rate and uniformity of cooling of the fruit when subsequently precooled for 10 hours with the overhead type of equipment described on pages 15 and 16 , and (3) the condition upon arrival.

Conditions of Loading and Precooling.-Both the conditions of cooling and the type of cooling equipment used in this car differed from those in previous tests. The fruits were large, individually wrapped, and packed in peach boxes. The car was loaded and in transit or standing for 12 hours before precooling. 


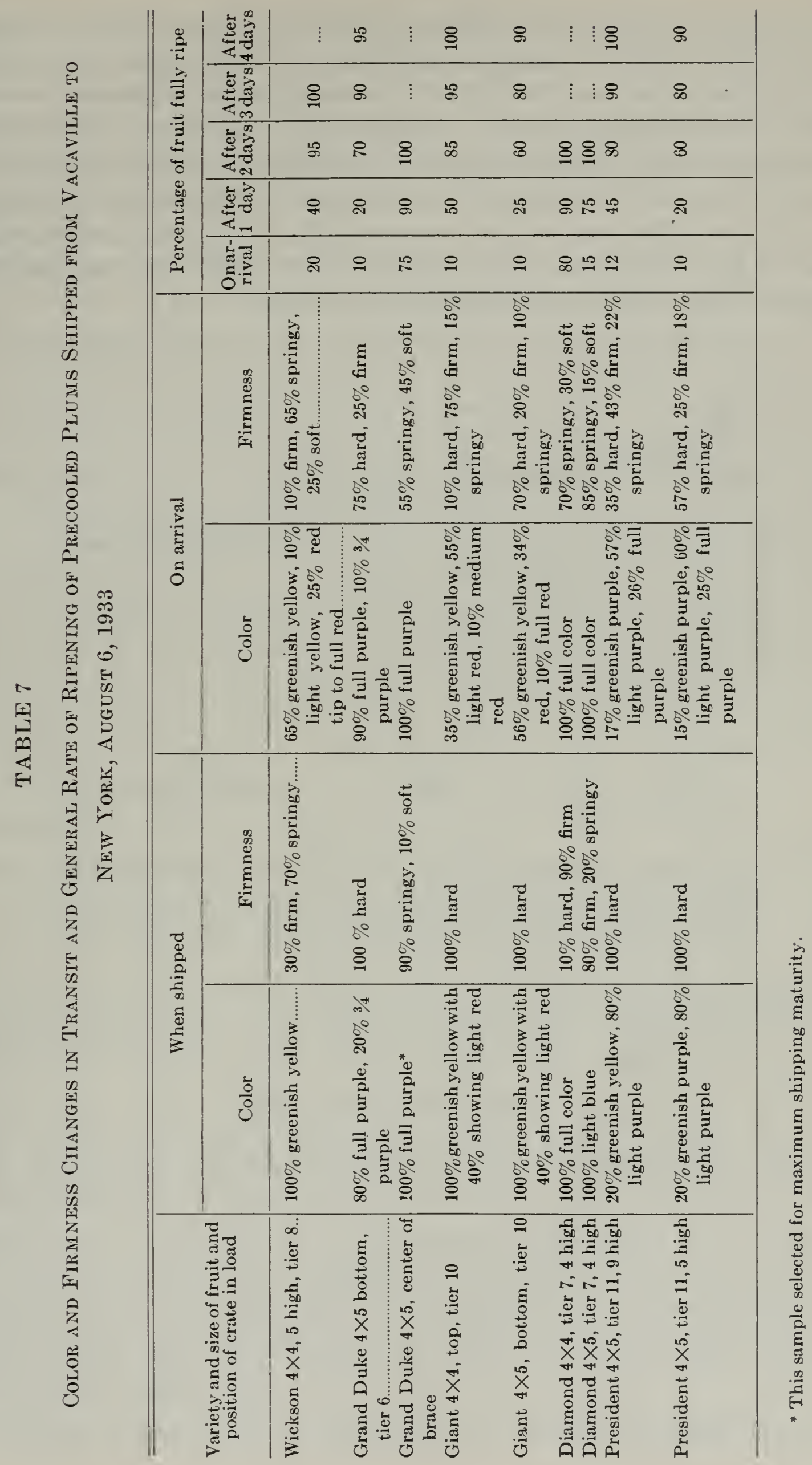


Loading continued from 8:30 a.m. until 5:00 p.m., July 15. Fruit was loaded in the " $\mathrm{B}$ " end from 1:30 p.m. to 5:00 p.m. Its temperature during this period was $88^{\circ}-90^{\circ} \mathrm{F}$. The car, braced and sealed, was in transit from Penryn to Colfax (by Roseville for re-icing) until the following morning. Precooling started at 7:00 a.m. Cold air, entering from both the top and the bottom of the bunkers, was blown for 4 hours in the " $B$ " end of the car and then reversed. The ice bunkers at the beginning of precooling were full and were three-eighths to one-half full after 10 hours. No ice was added during cooling.

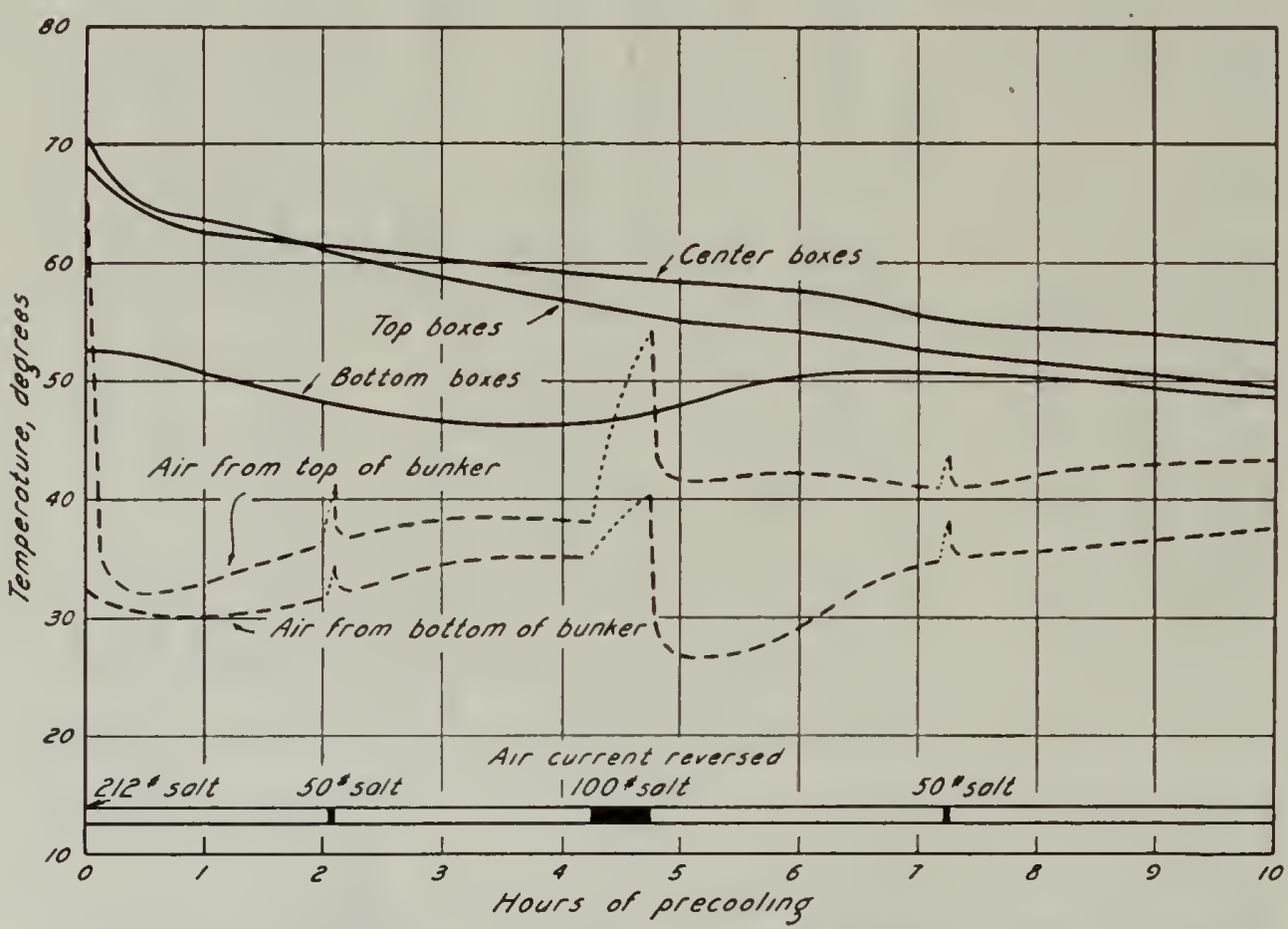

Fig. 26.-Precooling of plums in P.F.E. 36224, Colfax, July 16, 1933: average fruit temperatures in top, center, and bottom crates of tiers 1, 4, 7, and 9 when cold air passes in at one end of the car and out at the other, the direction being reversed after $43 / 4$ hours.

Temperatures Secured from Precooling.-Fruit temperatures recorded in the second fruit from the edge of the boxes in top, center, and bottom of tiers $1,4,7$, and 9 in the " $\mathrm{B}$ " end of the car (the last end loaded) at $6: 50$ a.m., July 16, just before starting the fan, were as follows : top of load $70^{\circ} \mathrm{F}$, center $68^{\circ}$, and bottom $52^{\circ} \mathrm{F}$. Air temperatures at the top and bottom of the bunker were $66^{\circ}$ and $32^{\circ}$ respectively. The fruit, loaded at $88^{\circ}-90^{\circ}$, had cooled $20^{\circ}$ in the outer part of the packages in the top and center of the load and $35^{\circ}$ in the bottom. This cooling in the upper part was equal to that which occurred during the next 10 hours, when the fans were in operation. Cooling under a wide temperature difference between fruit and air is always more rapid at first than it is later when this difference grows smaller. Figure 26 will also show that during precooling the incoming air from the top of the bunker was not kept sufficiently cold for rapid cooling. During the first 4 hours, the 
fruit at the "B" end cooled approximately as fast as that in the top and center of the load. After the fans were changed and the air current was reversed, bottom temperatures rose, till at the end of the precooling period they were only $4^{\circ}$ below what they were 12 hours after loading the car and before precooling. Fruit in the top boxes had cooled $20^{\circ}$ during precooling, or $2.0^{\circ}$ an hour; in the center of the load $15^{\circ}$, or $1.5^{\circ}$ an hour.

According to the fruit temperatures in the top, center, and bottom boxes of each of the four tiers in which temperatures were recorded, cooling averaged about $1.3^{\circ} \mathrm{F}$ an hour over the 10 -hour period. At the beginning of precooling, after the car had been in transit 12 hours, tier 10 at the door averaged $66^{\circ}$; tier 1 at the bunker, $62^{\circ}$; and tiers 4 and $7,64^{\circ}$. After the fans had been in operation 3 hours, tier 10 became the coldest, and tier 7 the warmest. At the end of 10 hours, the temperatures were $48^{\circ}$ and $53^{\circ}$ respectively. Tier 1 was only $2^{\circ}$ above tier 10 , while tier 4 was only $2^{\circ}$ above tier 1 , or $1^{\circ}$ below tier 7 . The data indicate, therefore, that cooling was somewhat more uniform (during the first 6 hours at least) in the different tiers than in the top and bottom of the load. After 10 hours, temperatures throughout the car were relatively uniform, but still slightly above $50^{\circ}$. Wrapped fruit and relatively high air temperatures prevented more rapid cooling. Comparative rates between the different tiers resembled those in figure 15 for apricots shipped from Brentwood.

Shipping Record and Condition of Fruit on Arrival.-This car was forwarded to New York under standard refrigeration. The fruit arrived in good, firm condition and was stored for 2 weeks awaiting better markets. At the end of this period, the following report was rendered: "The fruit came out of storage [26 days after loading] showing good condition; and, while there was considerable color throughout, these plums were firm and strong." The average price exceeded $\$ 1.00$ a box.

\section{PLUM PRECOOLING TEST 4}

Refrigerator cars P.F.E. 70021 and P.F.E. 71405 loaded Newcastle, June 13, 1934, and precooled at Roseville 8 hours after loading. Crates stacked 11 high30,000-pound loads.

Purpose of Test.-(1) To determine the cooling rate in a "heavy" or 30,000-pound load, (2) to ascertain the temperature rise of the fruit 18 hours after precooling, and (3) to compare the air temperature in the cars while in transit to New York under $(a)$ modified and $(b)$ under standard refrigeration.

Conditions of Loading and Precooling.-Loading occurred between 
$3: 00$ and $7: 30$ p.m. of June 13 with the fruit temperature varying between $70^{\circ}$ and $75^{\circ} \mathrm{F}$. At 1:00 a. m. June 14 the cars were received at Roseville, where the ice bunkers were refilled and 300 pounds of salt added. Precooling began at 4:00 a.m. and continued for 12 hours. After 6 hours the bunkers were again replenished with $3,200-3,600$ pounds of ice.

Temperatures Secured from Precooling.-With the same methods of loading and cooling, the results obtained in the two cars were similar.
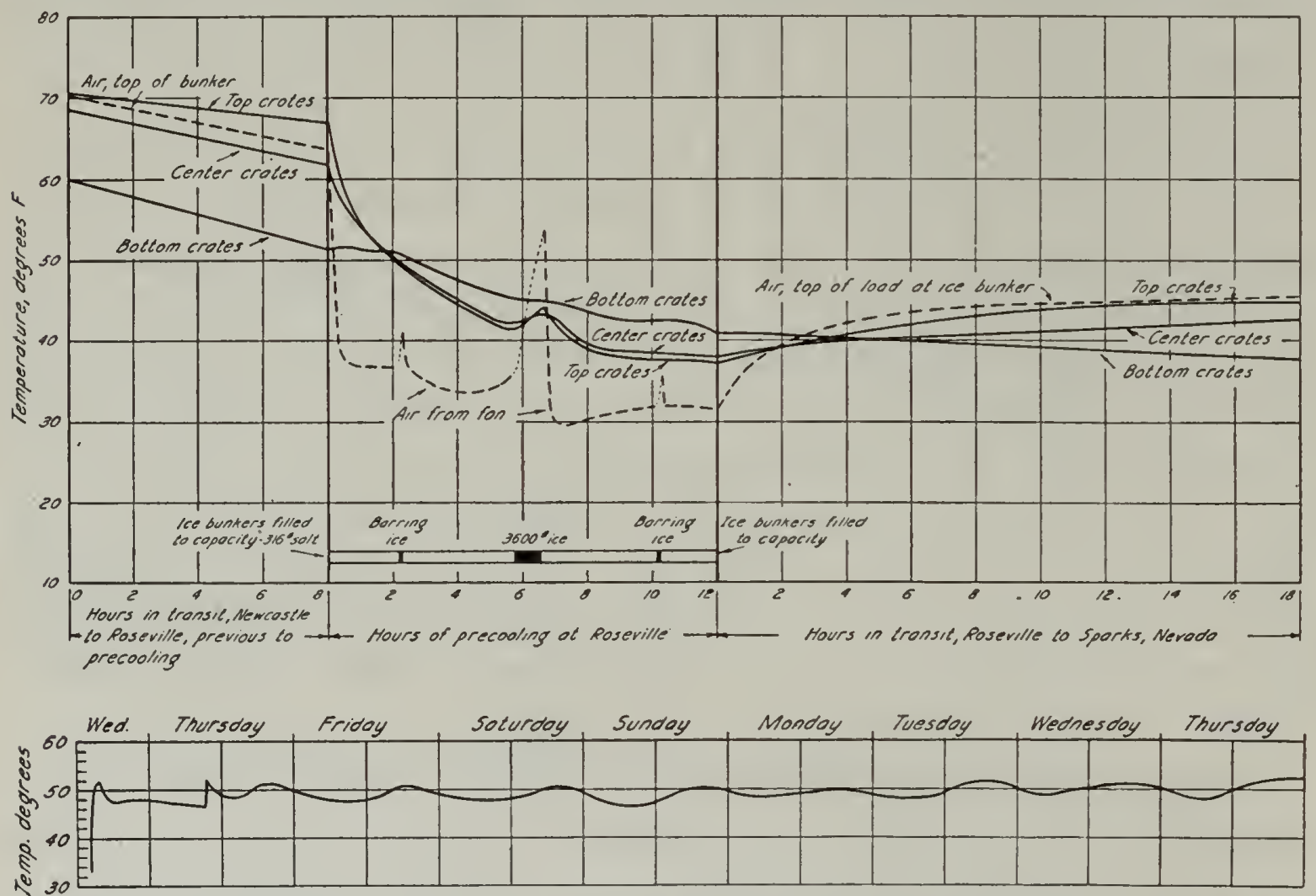

Fig. 27.-Precooling of a 30,000-pound load of plums in refrigerator car P. F. E. 70021, Roseville, California, June 14, 1934, together with air and fruit temperatures during 18 hours in transit from Roseville to Sparks, Nevada. The fruit was loaded at Newcastle (stacks 11 high) and precooled at Roseville for 12 hours with portable precooling fans. Air temperature was recorded at the top of the ice bunker immediately in front of the precooling fan. Fruit temperatures taken near the edge of crates in the top, middle, and bottom of tiers 1, 5, and 10. Below, air temperature at top of load at doorway while in transit from Roseville to New York; car re-iced at Council Bluffs, Iowa, only.

Figure 27 illustrates graphically the air temperature at the fans and the fruit temperatures near the edges of top, middle, and bottom crates in tiers 1,5 , and 10 of P.F.E. 70021.

After loading was completed the average temperature of the top fruit was $70^{\circ} \mathrm{F}$ while that in the bottom of the car had cooled to $60^{\circ}$. During the 8-hour interval between loading and starting of the precooling fans at Roseville, fruit temperatures in the bottom of the load had further declined $9^{\circ}$; those in the top only $4^{\circ}$. This temperature difference between the outer fruits in top and bottom crates of the load 
was equalized after 2 hours of precooling and throughout the subsequent 10 hours of cooling was lower than those in the bottom. 'T'welve hours' operation of the precooling fans, following 8 hours of cooling occasioned by the natural circulation of air in the car, had reduced the temperature of the fruit in the top and center crates to $36^{\circ}$ and $38^{\circ}$ respectively and that in the bottom crates to $41^{\circ}$.

These temperatures are rather similar to those obtained in tests 1 and 2 with 26,000-pound mixed loads. This 30,000-pound load, however, had the advantage of 8 hours natural cooling previous to the precooling period proper. The fruit was therefore colder to begin with.

After completion of precooling at Roseville, the thermometer points were left in place and the temperatures again secured 18 hours later after the car arrived at Sparks, Nevada. With the air temperatures at the bottom of the load becoming colder and those over the top warmer, a similar change occurred in the fruit temperatures. Fruit in the bottom crates continued to cool about $4^{\circ} \mathrm{F}$ while that in the center and top of the load showed an increase of $4^{\circ}$ to $8^{\circ}$. Upon opening the doors and entering the cars at Sparks the air temperature at the top of the load near the door rose to $52^{\circ}$ and varied between this temperature and $46^{\circ}$ throughout the transit period. Fruit in the top of the load would naturally assume the same temperature as the surrounding air.

Shipping Record and Condition of Fruit on Arrival.-Billing on P.F.E. 70021 called for only one re-icing (at Council Bluffs, Iowa) in transit while P.F.E. 71405 was forwarded under standard refrigeration calling for daily re-icing. The air temperature at the top of the load near the doorway was recorded by a Ryan recording thermometer and is shown in the lower part of figure 27.

The temperature recorded at the corresponding place in P.F.E. 71405 , sent standard refrigeration, was not more than $2^{\circ}$ lower, and during most of the trip the two records were nearly identical. Upon arrival in New York the ice bunkers of this car were seven-eighths full with the fruit temperatures varying from $40^{\circ}$ in the bottom of the load to $46^{\circ}$ in the top. Fruit temperatures in P.F.E. 70021, which arrived with the ice bunkers three-eighths full, varied from $44^{\circ}$ to $50^{\circ} \mathrm{F}$. A detailed description and report upon the color and firmness of the fruit in various crates examined from each car upon arrival fails to show any essential difference in maturity of the two loads. The district manager of the receiving company states, however, that the fruit shipped under standard refrigeration showed less evidence of ripening or softening. In general, both loads arrived in a very firm condition, indicating that there was no excessive ripening in either of the high loads. 


\section{PLUM PRECOOLING TEST 5}

Refrigerator cars P.F.F. 13565, P.F.E. 24696, and P.F.E. 32502, Newcastle, June 21-22, 1934. Crates stacked 11 high-30,000-pound loads

Purpose of Test.-(1) To secure additional data on the rate of cooling 30,000-pound loads where precooling immediately followed loading and (2) to compare the efficiency of two 18-inch 1-fan units with two 16-inch 2-fan units.

Conditions of Loading and Precooling.-Loading was not completed until late in the afternoon, at which time the fruit temperature was from $75^{\circ}$ to $80^{\circ} \mathrm{F}$. The car bunkers were refilled to capacity and from 250 to 375 pounds of salt added before starting the precooling fans. Precooling, including interruptions due to switching and re-icing, continued from 10 to 15 hours. From 500 to 800 pounds of salt were used in an effort to secure low air temperatures and to expedite cooling. The value of the additional salt was largely nullified by more or less continuous switching of the cars over a 2 -hour period.

Temperatures Secured from Precooling.-In P.F.E. 13565, containing the two 18 -inch fans, the air. blast was reduced to $35^{\circ} \mathrm{F}$ in 1 hour and maintained between $32.5^{\circ}$ and $30.0^{\circ}$, except when switching. Fruit temperatures in the outer part of top and bottom crates in tiers 1,5 , and 10 were reduced in 10 hours from $80^{\circ}$ and $65^{\circ}$ respectively to $42^{\circ}$. Crates in the center of the load were reduced only to $47^{\circ}$. Very similar results were secured in the same period of time in P.F.E. 24696 and P.F.E. 32502 equipped with two 2-fan precooling units. At the end of 15 hours the highest fruit temperature recorded was $37.5^{\circ}$.

\section{PLUM PRECOOLING TEST 6}

Refrigerator Cars P.F.E. 19709 and P.F.E. 2489, Auburn, July 5-6, 1934. Crates stacked 11 high-30,000-pound loads

Purpose of Test.-(1) To compare the cooling secured in 18 hours from the use of inside precooling fans (in P.F.E. 19709) and the canvas duct overhead system (P.F.E. 2489) used in test 3 and described on pages 15 and 16. (2) To determine the carrying qualities of plums in a 30,000-pound load.

Conditions of Loading and Precooling.-Loading occupied the afternoon and fore part of the night, cooling of P.F.E. 2489 starting at $10: 00$ p.m. and P.F.E. 19709 at midnight. Each car was re-iced to capacity and 250 pounds of salt added just prior to starting the precooling fans. Subsequent ice and salt was added as indicated in figures 28 and 29. Cooling of both cars was carried out by representatives of the companies concerned without any suggestions from the writers. 


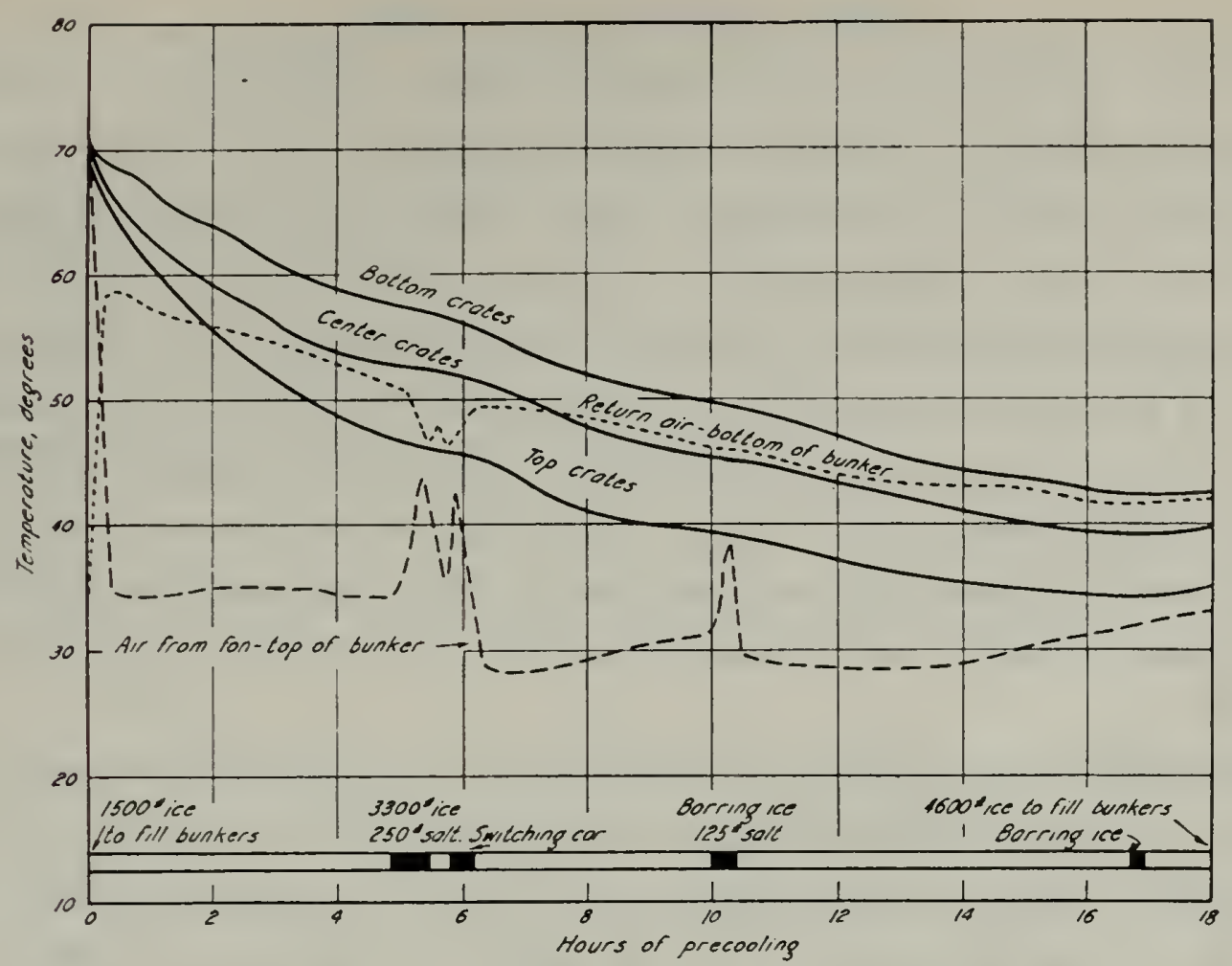

Fig. 28.-Precooling of plums in P. F. E. 19709, Auburn, July $5-6,1934$ : cooling rate of a 30,000 -pound load of plums over an 18 hour period when precooled with inside fans at the top of the ice bunkers. The temperature of the air returning to the ice bunkers, after passing over and through the load, is shown as well as that blown over the top of the load.

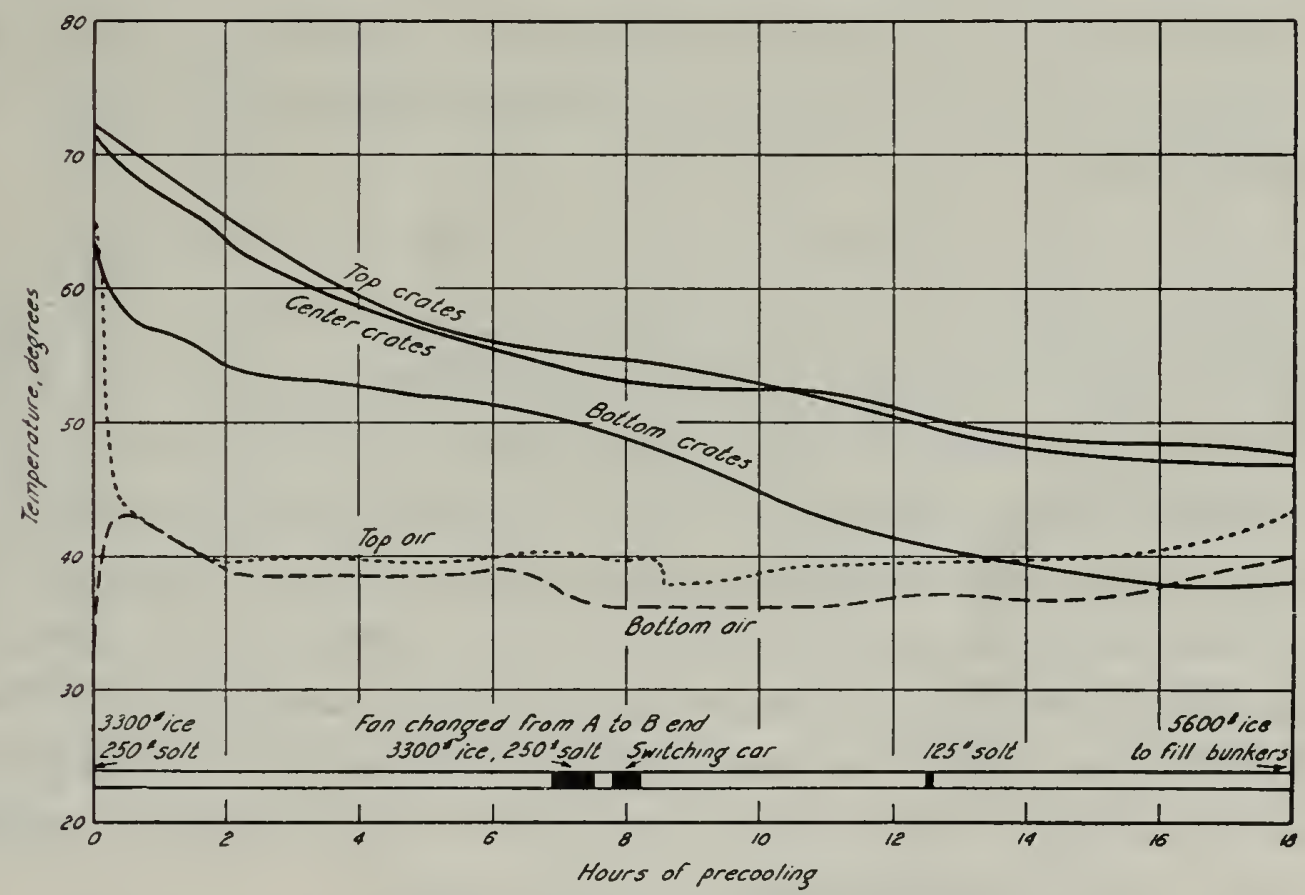

Fig. 29.-Precooling of plums in P. F. E. 2489, Auburn, July 5-6, 1934: cooling rate of a 30,000-pound load of plums over an 18-hour period when precooled with the outside-canvas-duct method carrying the cold air from one ice bunker over the top of the car and blowing it into the car through both the top and bottom openings of the opposite bunker. Both air temperatures shown are those of incoming air. (Compare with fig. 28.) 
Temperatures Secured from Precooling.-Temperatures recorded in both cars in the outer parts of crates in tiers 1, 5, and 10 show that in 18 hours the fruit in P.F.E. 19709, equipped with inside fans, was cooled from $72^{\circ} \mathrm{F}$ to an average (top, center, and bottom crates) of $39^{\circ}$. The average temperature in comparable crates in P.F.E. 2489 with the large single fan in the hatch opening forcing the cold air over the top of the car and then into it at the opposite end was $44^{\circ}$. To accomplish this result required 8,900 pounds of ice as compared with 7,900 pounds in the former car. Thus, not only was less ice consumed in the former car but also the top fruit in it, being exposed to colder air, cooled more rapidly and remained colder than that at the bottom of the load.

Wide differences existed in temperature of the air blast and the return air, owing to the amount of heat it removed from the fruit and to the high load, which partially covered the fan and retarded air circulation. In the second car (P.F.E. 2489), where the air was forced through the load in one direction from the top and bottom of the bunker simultaneously, the fruit on the bottom of the load was subjected to somewhat colder air than that at the top. Fruit in the top crates therefore remained $10^{\circ}-14^{\circ} \mathrm{F}$ higher, and that in the center crates, $4^{\circ}-8^{\circ}$ higher than in P.F.E. 19709. In both instances cooling would probably have been more rapid if the ice bunkers had been kept well filled and the ice had received both a heavier initial salting and a larger total quantity of salt.

Temperature and Condition of Fruit on Arrival.-Both cars of fruit were shipped under standard refrigeration and arrived with full ice bunkers. P.F.E. 19709 was inspected in Cleveland on July 18, 12 days after loading. The average fruit temperature recorded in the top and in the center of the load was $52^{\circ}$; that in the bottom tiers $46^{\circ} \mathrm{F}$. The plums, consisting of the Wickson, Giant, Diamond, Gaviota, and Sharkey varieties were characterized as "green to turning and hard ripe."

P.F.E. 2489, loaded with the same varieties, arrived in Buffalo 10 days after loading with the temperature of top and center fruit averaging $47^{\circ}$ and that of the bottom fruit $42^{\circ} \mathrm{F}$. The condition was hard ripe to firm-very few soft ripe.

The fruit in both of these cars arrived in very good condition. The fruit in the first car which received better precooling than the second, had a slightly higher temperature but was at least as firm after 12 days as the fruit in the second car after 10 days. 


\section{PLUM PRECOOLING TEST 7}

University Farm cold storage, July 11-12, 1933

Purpose of Test.-To ascertain under controlled conditions the cooling rate in the center of baskets packed in standard plum crates exposed to different air velocities.

Conditions of Loading and Precooling.-Fruit in standard crates located in the center of stacks 5 crates high was cooled in $32^{\circ} \mathrm{F}$ air moving at 75 and at 250 feet a minute.

Temperatures Secured from Precooling.-The advantage of rapidly circulating air for quick cooling is shown in figure 30 . Crate $A$ cooled

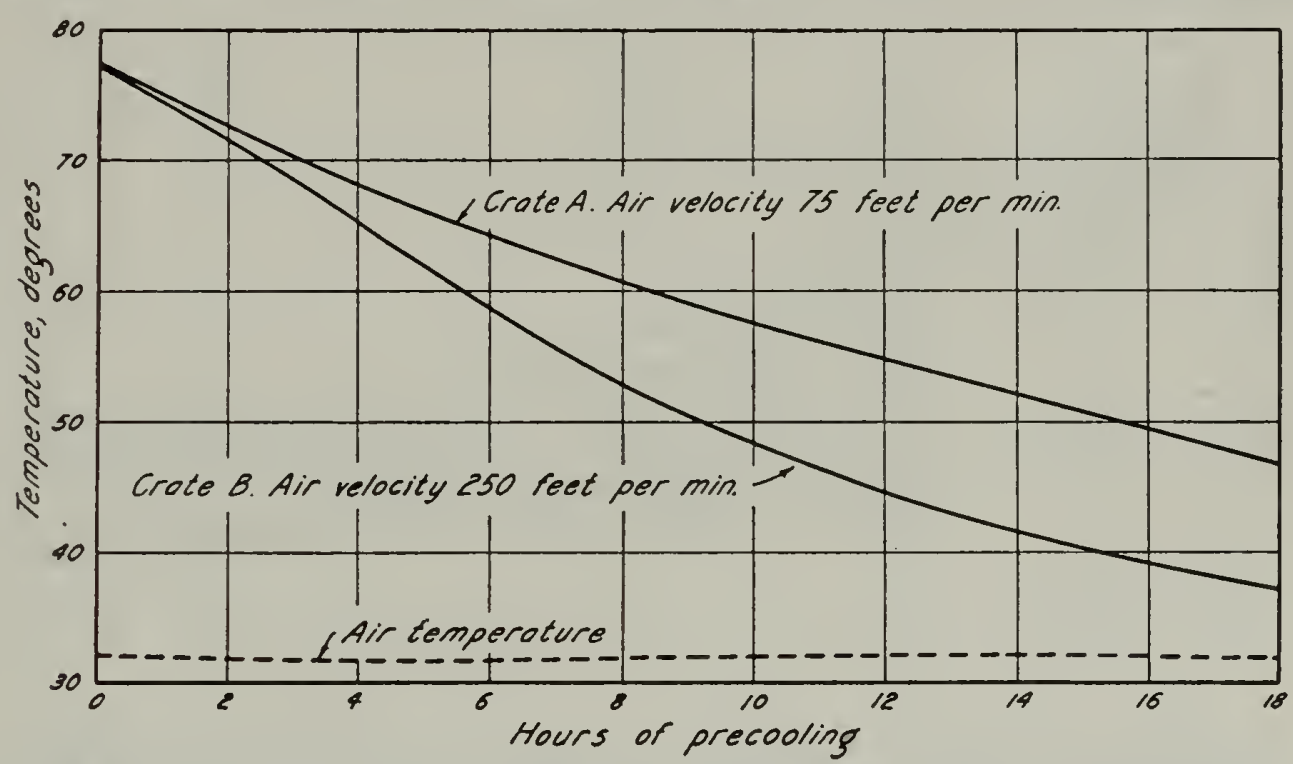

Fig. 30.-Precooling of plums in University Farm cold storage, July $3-4$ and 11-12, 1933: fruit temperature in center of baskets with crates placed in center of stack, 5 high. The $32^{\circ}$ air which cooled crate $A$ moved at about 75 feet and that which cooled crate $B$ at about 250 feet a minute.

only to $47^{\circ} \mathrm{F}$ in 18 hours, while crate $B$, in a stronger circulation, cooled to $38^{\circ}$. These graphs indicate that very warm plums, under somewhat more favorable conditions than usually exist in a commercial storage room, need 18 to 20 hours for precooling the center of the packages to $35^{\circ}$. Under favorable air temperature, but with slow circulation, some 28 to 30 hours would be required. The average hourly rate of cooling over the 18 hours covered by this test was about $1.7^{\circ}$ for the fruit in the slowly circulating air and $2.5^{\circ}$ for that in the air moving more rapidly.

\section{PLUM PRECOOLING TEST 8}

University Farm cold storage, June 2-21, 1934

Purpose of Test.-To compare the relative cooling rate of plums when two comparable lots were simultaneously exposed to two temperatures differing between $4^{\circ}$ and $10^{\circ} \mathrm{F}$. 
Conditions of Precooling.-Although this test was conducted in small experimental storage rooms, the rooms contained a relatively large quantity of fruit and the rate of cooling was similar to that which may be expected in larger rooms heavily loaded with fruit at a temperature of $75^{\circ} \mathrm{F}$. During the first 12-16 hours, air temperatures between the stacks of fruit were high, averaging approximately $38^{\circ}$ in one room and $33^{\circ}$ in the other. Differences in the air temperatures, however, gradually became wider and after the above period, temperatures close to $35^{\circ}$ and $26^{\circ}$ were maintained. Cooling was continued until the fruit both at the edge and in the center of the packages was within $1^{\circ}$ of the surrounding air.

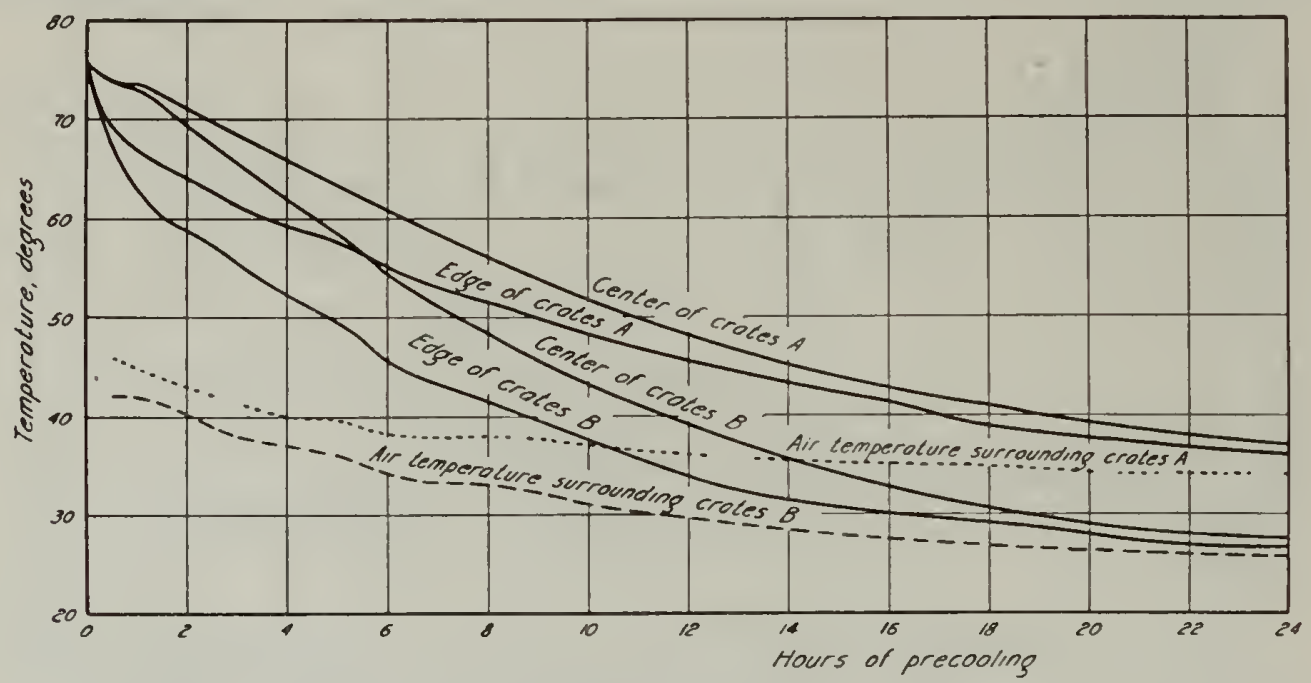

Fig. 31.-Precooling of plums in University Farm cold storage, June 20-21, 1934: comparative cooling rate of fruit near the edge and at the center of baskets in standard crates exposed to two different air temperatures.

Temperatures Secured from Precooling.-Cooling was necessarily slow on account of the high initial air temperatures. Figure 31 illustrates, however, that even with an average difference in air temperature of only $4^{\circ}-6^{\circ} \mathrm{F}$ in the two rooms during the first 10 hours of cooling, 50 per cent more time was required to cool the centers of the baskets in the crates to $40^{\circ}$ when the fruit was exposed to the higher temperature $\left(45^{\circ}-38^{\circ}\right)$ than was necessary in the colder air $\left(42^{\circ}-31^{\circ}\right)$. At the end of 10 hours, average center temperatures were $52^{\circ}$ and $43^{\circ}$ and a corresponding temperature difference existed throughout the cooling period. As the fruit temperatures approach those of the surrounding air the cooling rate must gradually diminish.

PLUM PRECOOLING TESTS 9 AND 10

University Farm cold storage, June 27-28 and July 3-4, 1934

Purpose of Tests.-To determine the relative time required to cool plums when exposed to uniform temperatures of $35^{\circ}$ and of $25^{\circ} \mathrm{F}$. 
Conditions of Precooling.-In these tests the quantity of fruit placed in each of two rooms was sufficiently limited that the above air temperatures could be maintained from the beginning of the precooling period. All fruit was placed 8 feet in front of a 16 -inch electric fan which operated continuously. This promoted relatively rapid cooling of the fruit exposed to $35^{\circ}$ air while the combination of $25^{\circ}$ air moving past

\section{TABLE 8}

Rate of Cooling Plums Under Constant Air Temperatures of $25^{\circ}$ and $35^{\circ} \mathrm{F}$ University Farm Cold Storage, July 3-4, 1934

\begin{tabular}{|c|c|c|c|c|}
\hline \multirow[b]{2}{*}{ Period of cooling } & \multicolumn{2}{|c|}{ Air temperature $25^{\circ} \mathrm{F}$} & \multicolumn{2}{|c|}{ Air temperature $35^{\circ} \mathrm{F}$} \\
\hline & $\begin{array}{l}\text { Fruit } \\
\text { in center of } \\
\text { baskets }\end{array}$ & $\begin{array}{l}\text { Fruit } \\
\text { in edge of } \\
\text { baskets }\end{array}$ & $\begin{array}{c}\text { Fruit } \\
\text { in center of } \\
\text { baskets }\end{array}$ & $\begin{array}{l}\text { Fruit } \\
\text { in edge of } \\
\text { baskets }\end{array}$ \\
\hline hours & degrees $F$ & degrees $F$ & degrees $F$ & degrees $F$ \\
\hline $0 \ldots \ldots$ & 78 & 76 & 78 & 76 \\
\hline $1 \ldots$ & 74 & 57 & 74 & 64 \\
\hline $2 \ldots$ & 67 & 49 & 69 & 55 \\
\hline 3. & 61 & 47 & 64 & 49 \\
\hline 4 & 54 & 42 & 58 & 45 \\
\hline 5 & 48 & 38 & 53 & 43 \\
\hline 6 & 43 & 35 & 48 & 39 \\
\hline $7 .$. & 39 & 33 & 45 & 37 \\
\hline | & 36 & 32 & 42 & 36 \\
\hline $9 .$. & 34 & 30 & 40 & 36 \\
\hline $10 \ldots$ & 33 & 29 & 39 & 36 \\
\hline
\end{tabular}

the stacks rapidly furnished more favorable conditions for cooling than is usually found in commercial cooling plants.

Temperatures Secured from Precooling.-The comparative merits of the two air temperatures of $35^{\circ}$ and of $25^{\circ} \mathrm{F}$ may best be shown by noting the average time required to cool the fruit in the center of packages in the two rooms from $78^{\circ}$ to $40^{\circ}$. As shown by table 8 , this was 7 hours under the latter temperature and 9 hours under the former. In relative terms, approximately 30 per cent longer was necessary to accomplish the same result under an air temperature of $35^{\circ}$ than was required with air at $25^{\circ} \mathrm{F}$.

In this test cooling was exceedingly rapid, the temperature of the center fruit being reduced to $40^{\circ}$ in 7 and 9 hours, or approximately half the time required under the conditions of test 8 . The relative difference in rates of cooling in $25^{\circ}$ and $35^{\circ}$ air was somewhat less, the $35^{\circ}$ air requiring 30 per cent longer time to reduce center temperatures to $40^{\circ}$ than did $25^{\circ}$ air.

A week after the above results were secured a second test was made under the same conditions and results were practically identical. Actual 
temperatures at the end of 10 hours' cooling did not differ more than $2^{\circ} \mathrm{F}$.

\section{PLUM PRECOOLING AND FREEZING TESTS}

University Farm cold storage, June and July, 1934

Purpose of Tests.-To determine the approximate time at which fruit placed in rapidly circulating air at $25^{\circ} \mathrm{F}$ will freeze.

Conditions of Tests.-The conditions under which these tests were conducted were the same as those outlined for cooling in the $25^{\circ} \mathrm{F}$

TABLE 9

Rate of Cooling, Temperatures and Time of Freezing Plums* in $25^{\circ}$ Air;

University Farm Cold Storage, July 3-4 and July 21-22, 1934

\begin{tabular}{|c|c|c|c|}
\hline \multirow{2}{*}{$\begin{array}{l}\text { Period of } \\
\text { precooling }\end{array}$} & \multicolumn{2}{|c|}{ Temperature of fruit } & \multirow[b]{2}{*}{ Observations on freezing } \\
\hline & $\begin{array}{l}\text { Center } \\
\text { of baskets in } \\
\text { crates }\end{array}$ & $\begin{array}{l}\text { Edge } \\
\text { of baskets in } \\
\text { crates }\end{array}$ & \\
\hline hours & degrees $F$ & degrees $F$ & \\
\hline 12 & 29 & 27 & No apparent injury \\
\hline 14 & 27 & 27 & $\begin{array}{l}\text { Very slight spotting on the surface of } 6-8 \text { specinnens on the } \\
\text { top of the baskets }\end{array}$ \\
\hline 18 & 27 & 26 & Spotting more noticeable \\
\hline 23 & 26 & 26 & $\begin{array}{l}\text { Most fruits showing spotting, the frozen areas extending } \\
\text { into the flesh } 1 / 8 \text { to } 1 / 4 \text { of an inch }\end{array}$ \\
\hline
\end{tabular}

* Climax, Wickson, Burbank, Gaviota, and Kelsey varieties were included

room in the previous tests. Several crates of plums (as well as boxes of peaches and pears mentioned in subsequent tests) taken from shipments being loaded into refrigerator cars, and having an initial temperature of $75^{\circ}-80^{\circ} \mathrm{F}$, were placed $6-8$ feet in front of a 16 -inch electric fan which furnished a strong circulation of $25^{\circ}$ air past the crates. These conditions were designed to cool the fruit as rapidly as would be secured in any commercial storage room even when it was stacked immediately in front of the air intakes. Cooling was allowed to continue until the fruit was frozen, As freezing temperatures were approached, close observation was made of the exposed fruits at the edges of the crates for the first signs of freezing.

Results Secured.-The results of cooling and of freezing different lots of fruit are summarized and presented in table 9. The initial fruit temperature and cooling rate for the first 10 hours was similar to that shown in the previous table.

The exact temperature at which plums, or other fruits, will freeze will vary considerably with the degree of ripeness, mature or fully ripe 
fruit freezing at a lower temperature than green fruit. Wright and Taylor ${ }^{28}$ as a result of their extensive work give the average freezing point of plums at $28.5^{\circ} \mathrm{F}$. From the results in table 9 it appears that the plums tested possessed a slightly lower temperature before freezing could be noticed and that, with good shipping maturity and a temperature of $75^{\circ}-80^{\circ}$ when starting to precool, they may be submitted to $25^{\circ}$ air for some 10-12 hours without injury. President plums of full light-purple color were held in $25^{\circ}$ air for 60 hours before showing any signs of injury and were not frozen after holding for 7 days under a temperature of $28^{\circ} \mathrm{F}$.

\section{HOLDING TESTS OF PRECOOLED AND NONPRECOOLED PLUMS}

Supplementing the reports received from New York on the general condition of plums shipped from Placerville and Penryn and on the test crates included in the car from Vacaville, observations were made on selected crates of fruit grown at Davis, Vacaville, and Newcastle, and held at Davis under temperatures similar to those existing in transit of precooled and nonprecooled cars. These holding tests included 15 varieties at different stages of maturity. In most instances each picking of fruit was divided into three lots, one lot being precooled to $34^{\circ} \mathrm{F}$ and held for 10 days at a temperature gradually rising from $36^{\circ}$ to $45^{\circ}$, another precooled to $40^{\circ}$ only and held at a temperature increasing from $40^{\circ}$ to $50^{\circ}$, and a third not precooled and held at a temperature declining from $60^{\circ}$ to $52^{\circ}$. At the end of the 10 days, each sample was removed from the holding rooms, observed for general condition and comparative color, and tested for firmness. It was then kept at $75^{\circ}-80^{\circ}$ to determine the time required to ripen (unless ripe when removed from the holding room) and the period of marketability. This information is summarized in table 10.

28 Wright, R. C., and Geo. F. Taylor. The freezing temperatures of some fruits, regetables, and cut flowers. U. S. Dept. Agr. Dept. Bul. 1133:1-8. 1929. 
응ㅇㅇ

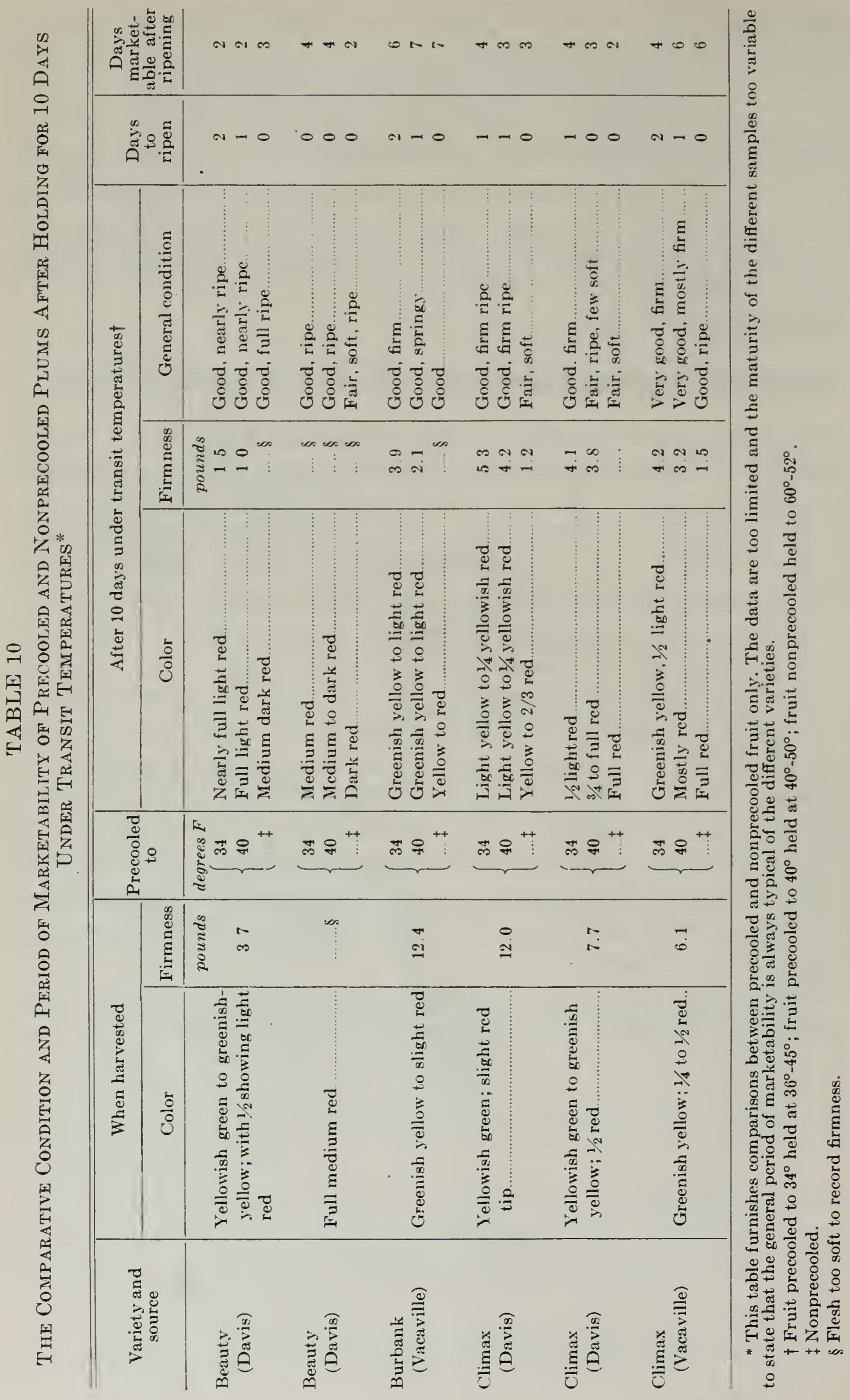




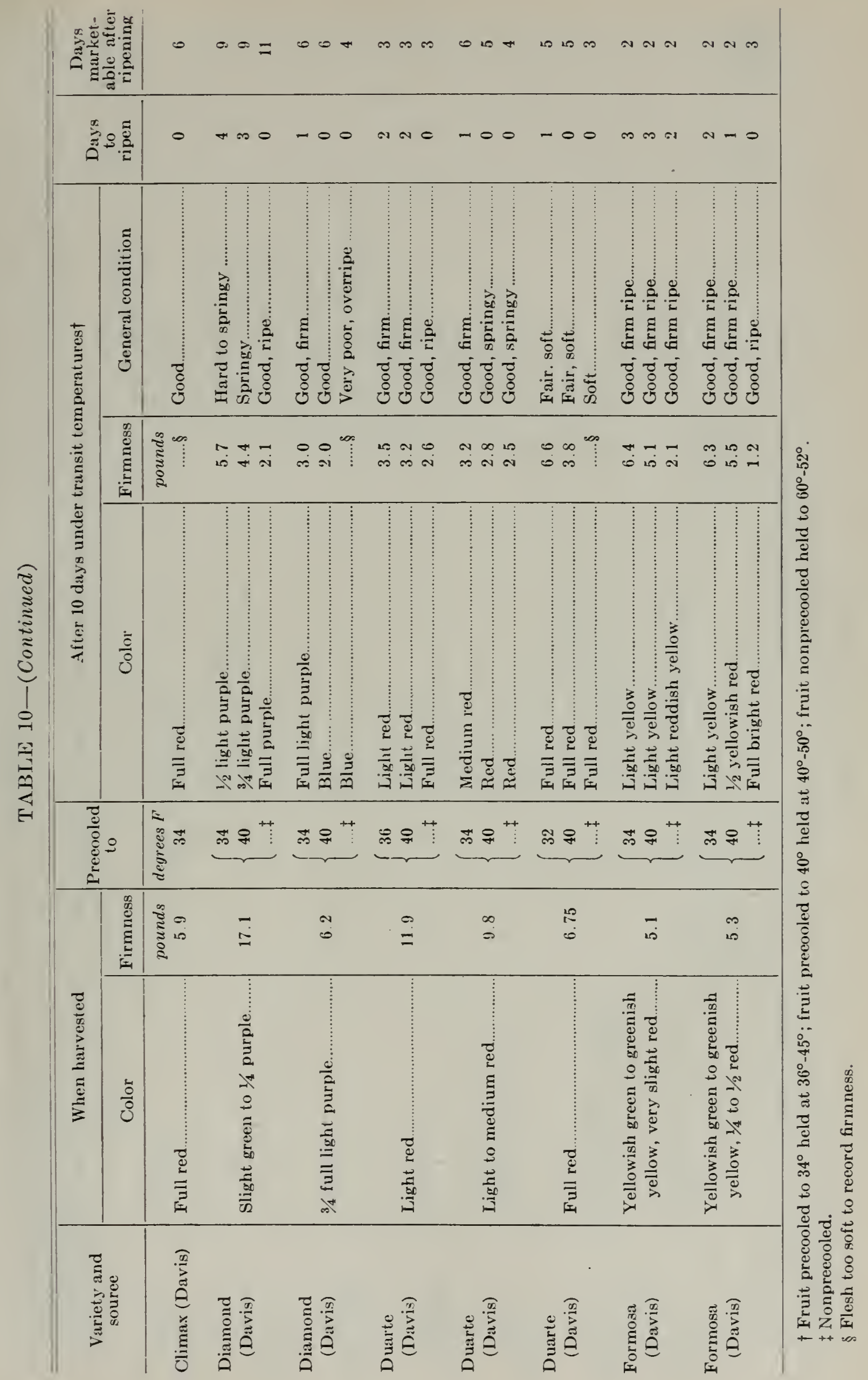




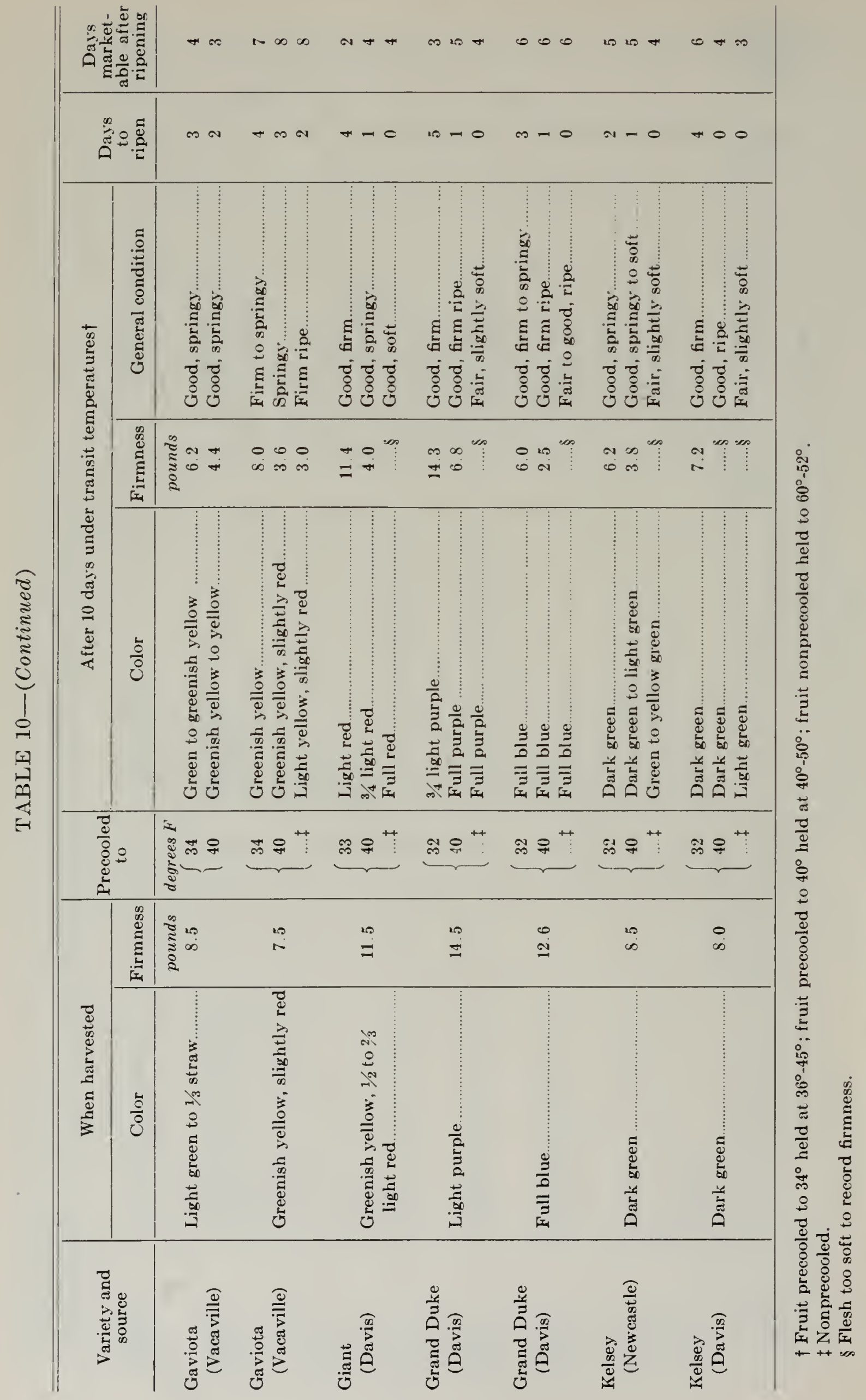




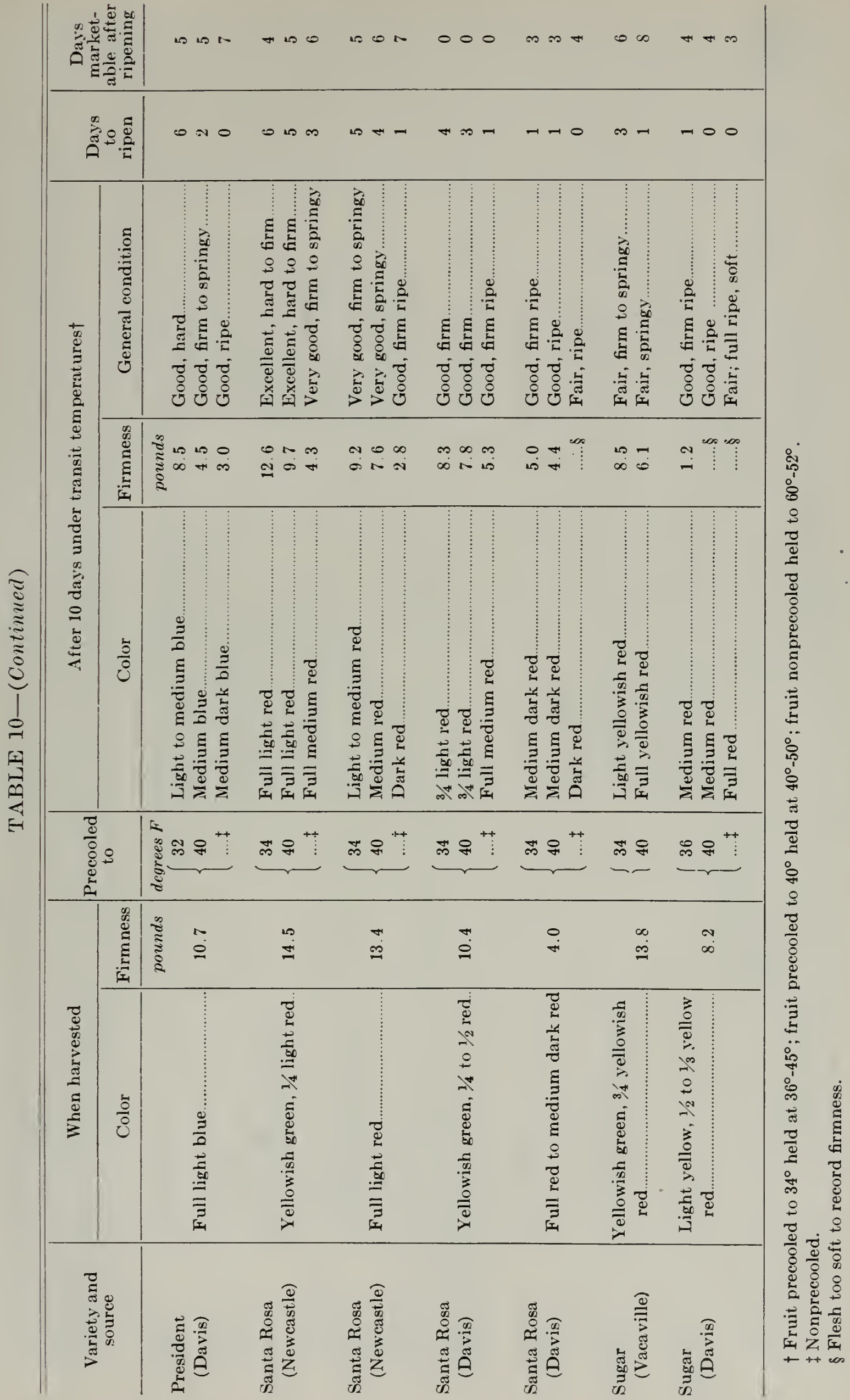




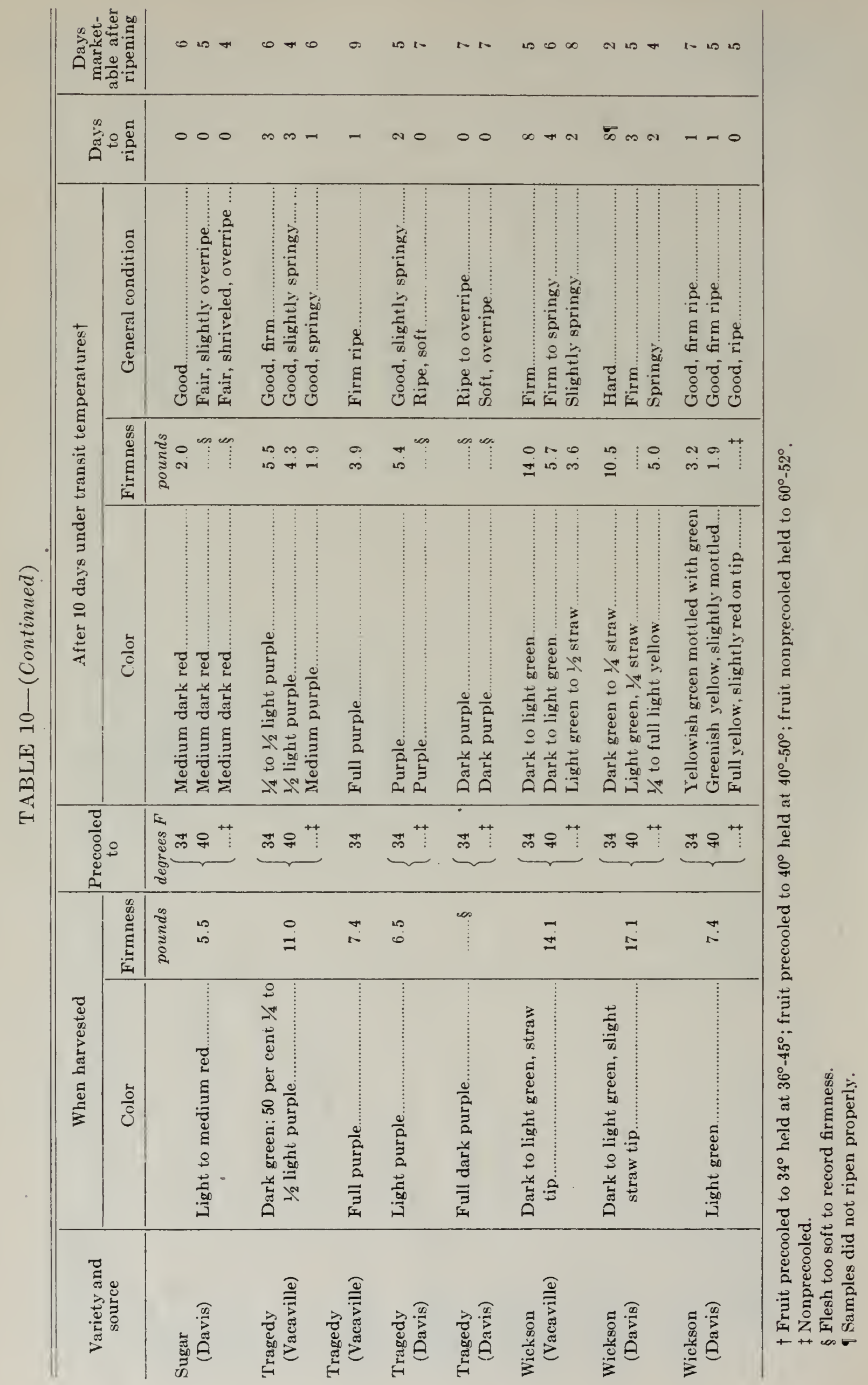




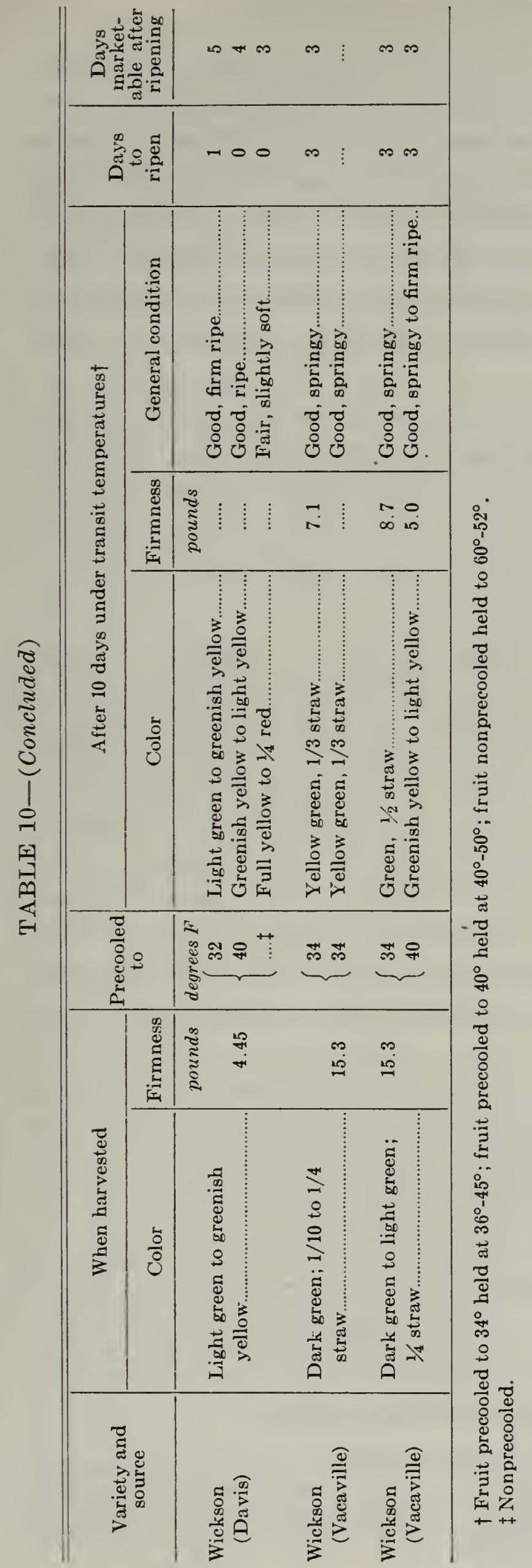


Unless the fruit was of full color when picked, the amount of color development in the various samples differed in a few cases slightly, but in most rather markedly. Beauty, Climax, Santa Rosa, Formosa, and Giant were among the varieties showing the most decided color change. The general ripeness of the different samples was noted, and attempts were made to measure the firmness with a pressure tester. Although the instrument used was not designed to measure accurately fruits testing below 3-4 pounds, most of the data secured do show a slight difference in firmness in favor of the fruit precooled to $34^{\circ} \mathrm{F}$ and held at the lower temperatures. ${ }^{29}$

When removed from the holding room, after 10 days at transit temperatures, most nonprecooled samples were fully ripe. A few individual samples of rather green fruit required 2 additional days to ripen. The average time for all lots was 0.5 day; for samples precooled to $40^{\circ} \mathrm{F}$, 1.5 days; for those precooled to $34^{\circ}, 2.7$. Precooling therefore did materially check the ripening process.

After the different samples had been judged as ripe, their further keeping quality was noted. The number of days they remained in good condition was essentially the same, though nonprecooled fruit averaged fractionally higher. The total period of marketability, however, should be computed from the time of reaching the wholesale market until the fruit is too soft or otherwise undesirable for sale. It includes the time necessary for ripening. Obviously, therefore, the total period of marketability of the precooled samples is usually longer than that of the nonprecooled because of the additional time necessary for the precooled samples to ripen. The different varieties shown in table 10 had an average total marketable period of 7.3 days when precooled to $34^{\circ} \mathrm{F}, 5.8$ days.when precooled to $40^{\circ}$, and 5.2 days when nonprecooled. The relatively small difference in the total period of marketability again indicates that the chief value in precooling plums or apricots is not to make them hold longer after ripening, but to delay ripening.

The fact that the less mature Wickson plums precooled to $34^{\circ} \mathrm{F}$ ripened irregularly and rather imperfectly after 8 days is regarded as significant. This same observation has been made by commercial shippers. Storage tests have also shown repeatedly that immature fruit can best be ripened under relatively high holding temperatures.

29 In three or four instances the precooled fruit held for 10 days under comparatively low temperatures registered firmer than when picked. This has frequently been noted in fruit out of storage. The higher readings represent a slight toughening or sponginess of the flesh rather than actual firmness. 


\section{SUMMARY OF PLUM PRECOOLING TEST}

Plums of like size and shipped in the same containers, cooled at a similar rate to apricots. When exposed to an air temperature of $35^{\circ} \mathrm{F}$ or below in refrigerator cars precooled with the inside type of bunker fans, fruit in the center parts of the crate cooled from $70^{\circ}$ or $80^{\circ}$ to $40^{\circ}$ in from 10 to 15 hours. After this period of cooling, fruit in the center of the haskets will usually be from $2^{\circ}-5^{\circ}$ higher than is shown by the temperatures recorded in the outer fruits.

Under the conditions of these tests, the cooling rate of the 26,000pound mixed loads of plums and that where the fruit was wrapped was similar to that of the straight unwrapped 30,000-pound loads. It is reasonable, however, to assume that under strictly comparable conditions both of these loads would contain more heat to be removed than a straight 26,000-pound plum load. With the mixed type of loading there is also less opportunity for rapid air circulation.

Wrapped plums precooled 12 hours after loading with the overheadcanvas-duct system cooled more slowly in the top of the load and more ice was consumed during cooling than with unwrapped fruit cooled by the system of inside fans placed in front of the bunker openings.

Tests in storage rooms have shown the value of rapid air circulation as well as low temperatures for rapid cooling. Fruit in the center of baskets in $32^{\circ}$ air moving at approximately 250 feet a minute cooled from $75^{\circ}$ to $40^{\circ} \mathrm{F}$ in 15 hours; that cooled in slowly moving air was $51^{\circ}$ after this period. Approximately 22 hours would have been required under the more favorable conditions to have cooled the fruit to $32^{\circ} \mathrm{F}$.

In two similar lots of fruit cooled for 24 hours under a good circulation of air, liaving average temperatures about the crates of $37^{\circ}$ and $31^{\circ} \mathrm{F}$, the fruit temperatures in the center of the crates were reduced from $76^{\circ}$ to $42^{\circ}$ and to $32^{\circ}$ respectively. Small lots of plums cooled in air at relatively uniform temperatures of $35^{\circ}$ and of $25^{\circ}$ cooled to $42^{\circ}$ and $32^{\circ}$ in the center of the boxes in 10 hours. With large lots of fruit, however, from 18-30 hours will usually be necessary to secure a temperature of $32^{\circ}$. Although the time required for cooling may be reduced 30 to 50 per cent by the use of $25^{\circ}$ air for $8-10$ hours, air at $29^{\circ}-30^{\circ}$ is recommended for commercial use. Plums of suitable maturity for shipping are unlikely to freeze above $30^{\circ} \mathrm{F}$.

Unless of full color when picked, most varieties of plums precooled to $34^{\circ} \mathrm{F}$, to $40^{\circ}$, and nonprecooled showed rather marked color differences after a 10-day holding period at car temperatures. The average time required for the different samples to be judged as fully ripe after the holding period was $2.7,1.5$, and 0.5 days respectively. The chief 
value in precooling is in delaying the ripening process rather than extending the period of marketability after the fruit becomes ripe. The time, however, which would have elapsed between the arrival of the fruit on the eastern markets and that at which it would have been discarded as unmarketable was 7.3 days for fruit precooled to $34^{\circ}, 5.8$ days for that precooled to $40^{\circ}$, and 5.2 days for that nonprecooled.

The results of test 1 in which riper plums were shipped than ordinarily, indicate the possibility of shipping riper fruit even when precooled only for 11 hours.

\section{TESTS WITH PEACHES AND NECTARINES}

No car-precooling tests were made with peaches, but their cooling rate as influenced by air velocity and air temperature was determined by several tests in the experimental storage rooms at the University Farm. As with plums, data were also secured on the length of time peaches could be precooled in $25^{\circ}$ air without freezing injury. Limited holding tests were also made of several lots of Elberta peaches picked at different degrees of maturity to determine the influence of precooling upon their subsequent rate of ripening. A car-precooling test was made with nectarines and a comparison made as to ripening of precooled and nonprecooled fruit.

TABLE 11

Rate of Precooling Peaches as Influenced by Air Velocity; Univerisity FarM Cold Storage July 3-4, 1933

\begin{tabular}{|c|c|c|c|c|c|}
\hline \multirow{3}{*}{ Period of precooling } & \multirow{3}{*}{$\begin{array}{l}\text { Air temper- } \\
\text { ature }\end{array}$} & \multicolumn{4}{|c|}{ Fruit temperatures } \\
\hline & & \multicolumn{2}{|c|}{$\begin{array}{l}\text { Crate } A \text {; air velocity } 250 \\
\text { feet a minute }\end{array}$} & \multicolumn{2}{|c|}{$\begin{array}{l}\text { Crate B; air velocity } 75 \\
\text { feet a minute }\end{array}$} \\
\hline & & Center of box & Edge of box & Center of box & Edge of box \\
\hline hours & degrees $F$ & degrees $F$ & degrees $F$ & degrees $F$ & degrees $F$ \\
\hline $0 \ldots \ldots$ & $\begin{array}{l}40 \\
36\end{array}$ & $\begin{array}{l}84 \\
83\end{array}$ & $\begin{array}{l}77 \\
73\end{array}$ & $\begin{array}{l}88 \\
88\end{array}$ & $\begin{array}{l}81 \\
78\end{array}$ \\
\hline $\begin{array}{l}1 / 2 \ldots \\
1 \ldots\end{array}$ & $\begin{array}{l}36 \\
35\end{array}$ & 80 & 70 & 87 & 75 \\
\hline $2 \ldots$ & 34 & 77 & 64 & 85 & 72 \\
\hline $3 \ldots \ldots$ & 33 & 72 & 59 & 83 & 68 \\
\hline $4 \ldots$. & 32 & 69 & 54 & 80 & 64 \\
\hline 6. & 32 & 62 & 48 & 77 & 60 \\
\hline $8 \ldots$ & 32 & 56 & 44 & 72 & 56 \\
\hline $10 \ldots$ & 32 & 52 & 42 & 68 & 54 \\
\hline $12 \ldots$ & 32 & 47 & 39 & 64 & 51 \\
\hline 14 & 32 & 44 & 38 & 60 & 48 \\
\hline 16 . & 32 & 42 & 37 & 57 & 47 \\
\hline $18 \ldots$ & 32 & 40 & 36 & 54 & 44 \\
\hline $24 \ldots$ & 32 & 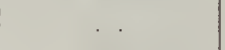 & 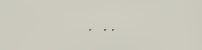 & 46 & 39 \\
\hline 30 & 32 & & $\ldots$ & 40 & 37 \\
\hline 36 & 32 & $\ldots$ & $\ldots$ & 38 & 35 \\
\hline . & 32 & & & 34 & 34 \\
\hline
\end{tabular}




\section{PEACH PRECOOLING TEST 1}

University Farm cold storage, July 3-4, 1933.

Purpose of Test.-To determine the influence of air velocity upon the cooling rate of peaches.

Conditions of Precooling.-Two adjacent stacks of fruit with a temporary partition between were arranged in the same room, one being in front of a small fan throwing approximately 75 feet of air a minute and the other in front of a larger fan supplying approximately 250 feet a minute.

Temperatures Secured from Precooling.-The temperatures secured from precooling are shown in table 11 . Cooled in $32^{\circ}$ air circulating at

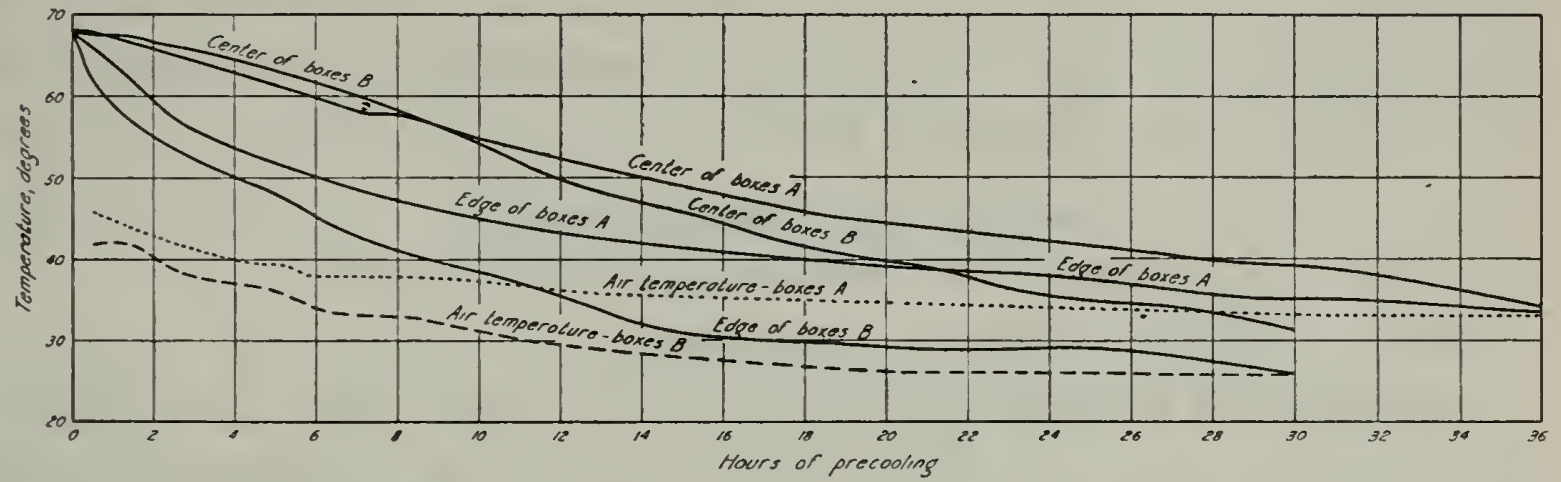

Fig. 32.-Precooling of peaches in University Farm cold storage, June 20-22, 1934: comparative cooling rate in the center and at the edges of boxes over a 30 to 36 -hour period when the fruit was held under average air temperatures of $30^{\circ}$ and $36^{\circ} \mathrm{F}$ and an air movement of $200-250$ feet a minute.

250 feet a minute, the fruit in the centers of boxes was reduced to $40^{\circ} \mathrm{F}$ in 18 hours, and a temperature of $34^{\circ}-32^{\circ}$ could undoubtedly have been obtained in 25-30 hours. In the slower-moving air 30 hours were required to reduce the fruit in the center of the boxes to $40^{\circ}$ and 48 hours to cool it to $34^{\circ}$. The higher velocity of air reduced the time of cooling about 40 per cent. The results presented in the table also show the relative cooling rates of the fruit in the center and near the edge of the boxes. After 10 hours' precooling this difference was $10^{\circ}-14^{\circ}$.

\section{PEACH PRECOOLING TEST 2}

University Farm cold storage, June 20-21, 1934

Purpose of Test.-To determine the influence of air temperature upon the cooling rate of peaches.

Conditions of Precooling. - The conditions of this test were the same as with plum test 8 -air temperatures declining from $42^{\circ} \mathrm{F}$ to $25^{\circ}$ (averaging $30^{\circ}$ ) and from $46^{\circ}$ to $33^{\circ}$ (averaging $36^{\circ}$ ).

Temperatures Secured from Precooling.-Figure 32 illustrates the general rate of cooling under the two air temperatures and also the lag in cooling of the center fruits over those at the edges of the box. 
Fruit near the edges of the boxes was reduced from $68^{\circ} \mathrm{F}$ to $40^{\circ}$ in 9 hours under an air temperature declining from $42^{\circ}$ to $32^{\circ}$, and to a temperature of $32^{\circ}$ in 14 hours with the air, temperature declining from $42^{\circ}$ to $28^{\circ} \mathrm{F}$. Center fruits in the same boxes required 20 hours to reach $40^{\circ}$ and 30 hours to cool to $32^{\circ}$. This rate of cooling is similar to that of the fruit cooled in the previous test where the air was moving at 250 feet a minute. As may be seen by comparing the above rate of cooling for boxes $B$ in figure 32 with boxes $A$, the center of the boxes required approximately 30 per cent longer time to cool under the ligher temperature. After 10 hours of cooling, when the outside fruits had been reduced to $38^{\circ}$ and to $45^{\circ}$ under the two air temperatures, the center fruits in the packages were still close to $55^{\circ}$. Twenty hours of cooling under the more favorable air temperature was necessary to reduce center temperatures to $40^{\circ} \mathrm{F}$.

\section{PEACH PRECOOLING TEST 3}

University Farm cold storage, July 3-4, 1934.

Purpose of Test.-The same as in test 2.

Conditions of Precooling.-The fruit was held under air temperatures of $35^{\circ} \mathrm{F}$ and of $25^{\circ}$ from the beginning of the precooling period.

Temperatures Secured from Precooling.-The results are presented in table 12. Fruit in the center of boxes exposed to a constant air temperature of $25^{\circ} \mathrm{F}$ was reduced from $78^{\circ}$ to $40^{\circ}$ in $81 / 2$ hours and to $32^{\circ}$ in 13 hours. In $35^{\circ}$ air the center of the boxes were not reduced to $40^{\circ}$ until after 14 liours. When this test is compared with the first 8 to 14 hours of precooling test 2, where higher air temperatures prevailed, some of the fruit temperatures are similar. Cooling may at first appear

TABLE 12

Rate of Cooling Peaches Under Constant Air Temperatures of $25^{\circ}$ and of $35^{\circ} \mathrm{F}$; University Farm Cold Storage, July 3-4, 1934

\begin{tabular}{|c|c|c|c|c|}
\hline \multirow[b]{2}{*}{ Period of cooling } & \multicolumn{2}{|c|}{ Air temperature, $25^{\circ} \mathrm{F}$} & \multicolumn{2}{|c|}{ Air temperature, $35^{\circ} \mathrm{F}$} \\
\hline & $\begin{array}{l}\text { Fruit } \\
\text { in center of } \\
\text { box }\end{array}$ & $\begin{array}{l}\text { Fruit } \\
\text { at edge of } \\
\text { box }\end{array}$ & $\begin{array}{l}\text { Fruit } \\
\text { in center of } \\
\text { box }\end{array}$ & $\begin{array}{l}\text { Fruit } \\
\text { at edge of } \\
\text { box }\end{array}$ \\
\hline hours & degrees $F$ & degrees $F$ & degrees $F$ & degrees $F$ \\
\hline $0 \ldots \ldots \ldots \ldots$ & 78 & 75 & 78 & 76 \\
\hline $1 \ldots$ & 71 & 60 & 74 & 68 \\
\hline $2 \ldots$ & 65 & 51 & 69 & 62 \\
\hline $4 \ldots$ & 55 & 42 & 62 & 55 \\
\hline $6 \ldots \ldots \ldots$ & 47 & 37 & 55 & 48 \\
\hline $8 \ldots \ldots \ldots . .$. & 41 & 33 & 49 & 44 \\
\hline $10 \ldots$ & 37 & 31 & 46 & 41 \\
\hline $12 \ldots$ & 33 & 29 & 43 & 40 \\
\hline $14 \ldots$ & 31 & 27 & 40 & 38 \\
\hline $16 \ldots$ & 29 & 26 & 39 & 37 \\
\hline
\end{tabular}


to have been as rapid in the previous test as in this one. As a matter of fact, however, cooling in this test, where the desired air temperatures were maintained from the beginning, was $30-35$ per cent more rapid, owing to the fact that the original temperature of the fruit was $10^{\circ}$ higher.

\section{PEACH PRECOOLING AND FREEZING TESTS}

University Farm cold storage, July 8-August 15, 1934

Purpose of Tests.-To determine the length of time fruit may be precooled in $25^{\circ}$ air without injury.

Conditions of Precooling.-All fruit was wrapped and packed in standard peach boxes and placed in a strong blast of air having a temperature of $25^{\circ} \mathrm{F}$. Fruit of the J. H. Hale and Orange Cling varieties was well colored. The Elberta peaches varied in color from a light yellowish green to greenish yellow with some red blush.

Results of Tests.-According to the data secured and presented in table 13 , no injury occurred to peaches from $25^{\circ}$ air until after the

TABLE 13

Precooling and Frefing of Peaches in 25 Air; University Farm Storage, July 8-August 15, 1934

\begin{tabular}{|c|c|c|c|c|}
\hline \multirow[b]{2}{*}{ Variety } & \multirow[b]{2}{*}{$\begin{array}{l}\text { Period of } \\
\text { cooling }\end{array}$} & \multicolumn{2}{|c|}{ Fruit temperatures } & \multirow[b]{2}{*}{ Observations on freezing } \\
\hline & & $\begin{array}{l}\text { Center of } \\
\text { boxes }\end{array}$ & $\begin{array}{l}\text { Edge of } \\
\text { boxes }\end{array}$ & \\
\hline J. H. Hale... & $\begin{array}{c}\text { hours } \\
0 \\
8 \\
15 \\
18 \\
22\end{array}$ & $\begin{array}{c}\text { degrees } F \\
76 \\
47 \\
35 \\
32 \\
29\end{array}$ & $\begin{array}{c}\text { degrees } F \\
75 \\
32 \\
28 \\
27 \\
27\end{array}$ & $\begin{array}{l}\text { No injury } \\
\text { First signs of freezing injury; a few } \\
\text { fruits showed a slight spotting on } \\
\text { the surface } \\
30 \text { to } 40 \text { per cent of fruit showing spot- } \\
\text { ting and having the flesh slightly } \\
\text { frozen; several fruits in each box } \\
\text { frozen solid }\end{array}$ \\
\hline Elberta...... & $\begin{array}{r}0 \\
10 \\
14 \\
19\end{array}$ & $\begin{array}{c}70 \\
34 \\
29 \\
27-30^{*}\end{array}$ & $\begin{array}{c}70 \\
27 \\
26-29 \\
28-30^{*}\end{array}$ & $\begin{array}{l}\text { No injury } \\
\text { Slight spotting on a few specimens } \\
\text { Slight to bad spotting on } 50 \text { to } 75 \text { per } \\
\text { cent of specimens according to ma- } \\
\text { turity }\end{array}$ \\
\hline Orange Cling. & $\begin{array}{r}0 \\
16 \\
20 \\
26 \\
\\
\\
72\end{array}$ & $\begin{array}{l}\ldots . \\
\ldots . \\
\cdots \\
\cdots\end{array}$ & $\begin{array}{l}78 \\
26 \\
26 \\
25 \\
25\end{array}$ & $\begin{array}{l}\text { No injury } \\
50 \text { per cent of fruit at edges of boxes } \\
\text { slightly frozen } \\
90 \text { per cent of fruit at edges of boxes } \\
\text { frozen } \\
\text { All fruit frozen hard }\end{array}$ \\
\hline
\end{tabular}

* Rise in temperat ure due to ice formation. 
fruit in the center of the boxes had been reduced to $29^{\circ} \mathrm{F}$. The outside fruit at this time (after 14-22 hours) varied in temperature between $29^{\circ}$ and $26^{\circ}$. Individual peaches will usually freeze at between $29^{\circ}$ and $30^{\circ}$ but when wrapped and packed they may withstand somewhat lower temperatures. When held at a temperature of $28^{\circ}$, only a few of the Orange Cling peaches (the only variety tested) showed any signs of freezing after 72 hours and only 50 per cent of the specimens (those of least color) were frozen after 7 days.

\section{NECTARINE PRECOOLING TEST 1}

Refrigerator car P.F.E. 7146, Vina, July 31, 1933. A 26,000-pound load containing 1,211 boxes stacked 9 and 10 high.

Purpose of T'est.-To determine (1) the temperature to which unwrapped nectarines could be reduced in 14 hours and (2) the condition of the fruit on arrival in New York.

Conditions of Loading and Precooling.-This fruit was placed unwrapped two layers deep in peach boxes in individual cardboard compartments, an arrangement favorable to rapid cooling. The fruit temperature as loaded was between $75^{\circ}$ and $80^{\circ} \mathrm{F}$. Cooling started at $3: 30$ p.m. with the temperature of the top of the load $75^{\circ}$ and that of the bottom $60^{\circ}$. Inability to secure a good circulation of air through the ice bunkers and an interruption of an hour in the operation of the precooling fans made it impossible to reduce the air temperature in the car to $30^{\circ}$ until after 7 hours. Cooling was therefore materially slower than it would have been under a more favorable air temperature.

Temperatures Secured from Precooling.-During the 14 hours of cooling under the above conditions, the average fruit temperatures in the top and in the center of tiers 1,5 , and 9 were reduced from $75^{\circ}$ and $70^{\circ} \mathrm{F}$, respectively, to $36^{\circ}$ and $37^{\circ}$, the top fruit cooling slightly more rapidly than that in the middle. Fruit in the bottom of the load, only $60^{\circ}$ at the outset, cooled to the same temperature as the top. In general, therefore, the center of the load cooled approximately $35^{\circ}$ in 14 hours, or at a fairly uniform rate of $2.5^{\circ}$ an hour.

Maximum air temperatures in the car while in transit to New York were $45^{\circ} \mathrm{F}$ for the first day and $48^{\circ}$ on subsequent days. The fruit carried at an average of $45^{\circ}$ and arrived in good condition.

\section{HOLDING TESTS OF PRECOOLED AND NONPRECOOLED PEACHES AND NECTARINES}

Holding tests with three samples of precooled and nonprecooled Elberta peaches picked in different stages of maturity and with two 


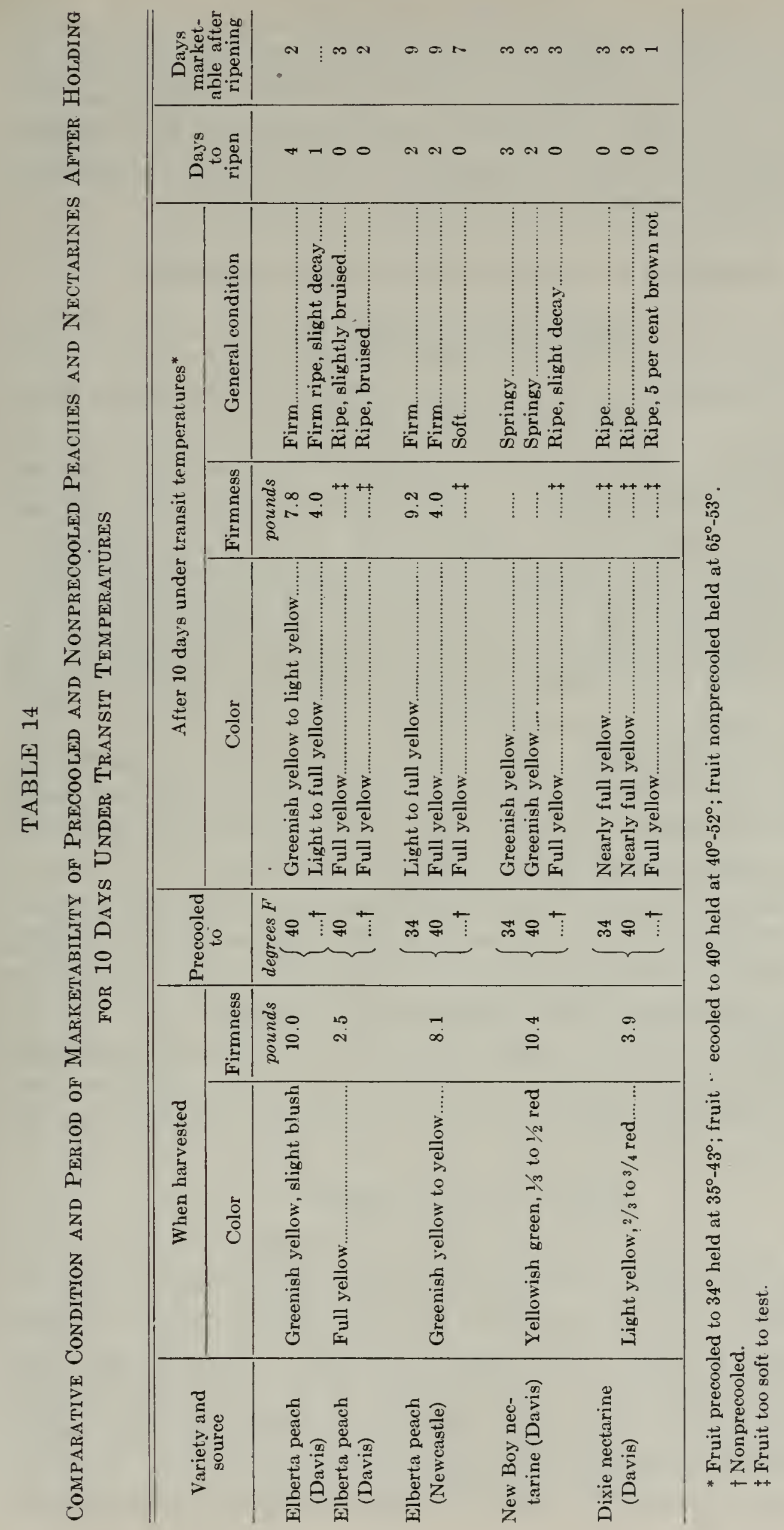


samples of nectarines are shown in table 14. The fruit in one of the peach and nectarine samples was riper than would be shipped any distance, so that precooling showed little benefit after holding the fruit for 10 days. In the other two samples, representing about the maximum maturity possible for eastern shipment, the influence of precooling is shown in the color, firmness, and period of marketability.

\section{SUMMARY OF PEACH AND NECTARINE TESTS}

The results of precooling peaches in storage rooms show that the time necessary to cool the fruit in the center of the boxes to $40^{\circ} \mathrm{F}$ varied from 8 to 30 hours; and to $34^{\circ}$ from 10 to 48 hours, according to the air temperature and its velocity. With a good circulation of air having a temperature close to $32^{\circ}$, fruit will cool to $40^{\circ}$ in about 14 hours and will approach $32^{\circ}$ in 24-30 hours. This time, however, was reduced approximately one-third by the use of $25^{\circ}$ air. Such an air temperature was employed with warm packed fruit for a period of 14 hours before freezing injury occurred. At this time the fruit in the center of the package had been reduced to a temperature of $29^{\circ}$. Increasing the velocity of the air from 75 feet a minute to 250 feet a minute reduced the time of cooling approximately 40 per cent.

Unwrapped nectarines in peach boxes in individual compartments cool rapidly under favorable cooling conditions, but in the test made cooling was retarded by high air temperatures. Fourteen hours were necessary to reduce the temperature from $75^{\circ}$ to $35^{\circ} \mathrm{F}$.

The several precooled and nonprecooled samples of peaches and nectarines observed for their condition and period of marketability after 10 days under transit temperatures were too limited in number to more than indicate something of the advantage of precooling.

The condition on arrival of the precooled car of nectarines was typical of most other commercial shipments. All arrived in good condition. Previously, considerable difficulty had been experienced in shipping this fruit.

\section{TESTS WITH PEARS}

Precooling experiments were conducted in 15 cars of packed pears, in 3 cars of loose pears in lug boxes, and in commercial and experimental storage rooms. As pears lose heat more slowly from the center of the package than the other fruits previously discussed, data were secured on the comparative rate of cooling in the center and near the edges of packages in various parts of the load or stack; also the cooling rate under different air temperatures and velocities.

Because of the extensive interest in heavier loading and in the pos- 
sibility of shipping under limited refrigeration, shipping organizations coöperated in securing air-temperature records in different cars during transit, and in providing inspection of different types of shipments, including precooled and nonprecooled Bartlett pears, upon arrival in New York. Precooled and nonprecooled fruit was also held at Davis for a 10-day period under refrigerator-car temperatures and then compared for changes in color and firmness, and for their general period of marketability.

\section{PEAR PRECOOLING TEST 1}

Refrigerator car P.E.E. 26014, Walnut Grove, August 4, 1932. A 520-box load with tiers only 3 and 4 high

Purpose of Test.-To determine the uniformity of cooling and the precooling rate of pears when cooled in refrigerator cars after loading.

Conditions of Loading and Precooling.-This car was one of the first cooled with portable precooling fans. Loading extended over a period of approximately 6 hours with the fruit at a temperature of $75^{\circ}-80^{\circ} \mathrm{F}$. Boxes were stacked 8 wide with most of the tiers 4 high. Those in the center of the car were only 3 boxes high.

Temperatures Secured from Precooling.-At the end of 14 hours, which was the total period of cooling, temperatures taken in the second pear from the edge of top boxes in tiers $1,4,7$, and 10 averaged $40^{\circ} \mathrm{F}$; those in the bottom boxes averaged $37.5^{\circ}$. Top and bottom boxes cooled at essentially the same rate during most of the above period, the temperature of the outside fruits being reduced approximately $35^{\circ}$. As some 6 hours were required for loading, the average temperature in the center of the boxes in tier 1 , when precooling began, was $60^{\circ}$; in tier $10,80^{\circ}$. After 14 hours the temperatures were $36^{\circ}$ and $42.5^{\circ}$ respectively, showing that tier 10 , more freely exposed to the circulating air, cooled somewhat more rapidly than tier 1 . Although only 3,300 pounds of ice and 290 pounds of salt were used in this car, a satisfactory air temperature of $30^{\circ}$ was easily maintained after 4 hours. No temperatures were taken in the center of the pear boxes.

Shipping Record and Condition of Fruit on Arrival.-The cars were shipped standard refrigeration to Chicago. Air temperatures near the top of the load at the brace of the car during transit showed a maximum daily fluctuation between $48^{\circ}$ and $56^{\circ} \mathrm{F}$, or slightly higher than in other cars containing similar or heavier loads but precooled for a longer period. When loaded, the fruit was considered somewhat too mature; but it arrived in Chicago in satisfactory condition. 


\section{PEAR PRECOOLING TEST 2}

Refrigerator cars 9023 (precooled), 36463 (nonprecooled), Placerville, September 13-14, 1932. Standard loads of 532 boxes-19 tiers, 7 wide and 4 high

Purpose of Test.-To compare a precooled and a nonprecooled car as to (1) the rate of cooling, (2) comparative temperatures during precooling and during transit, and (3) the condition of the fruit upon arrival in New York.
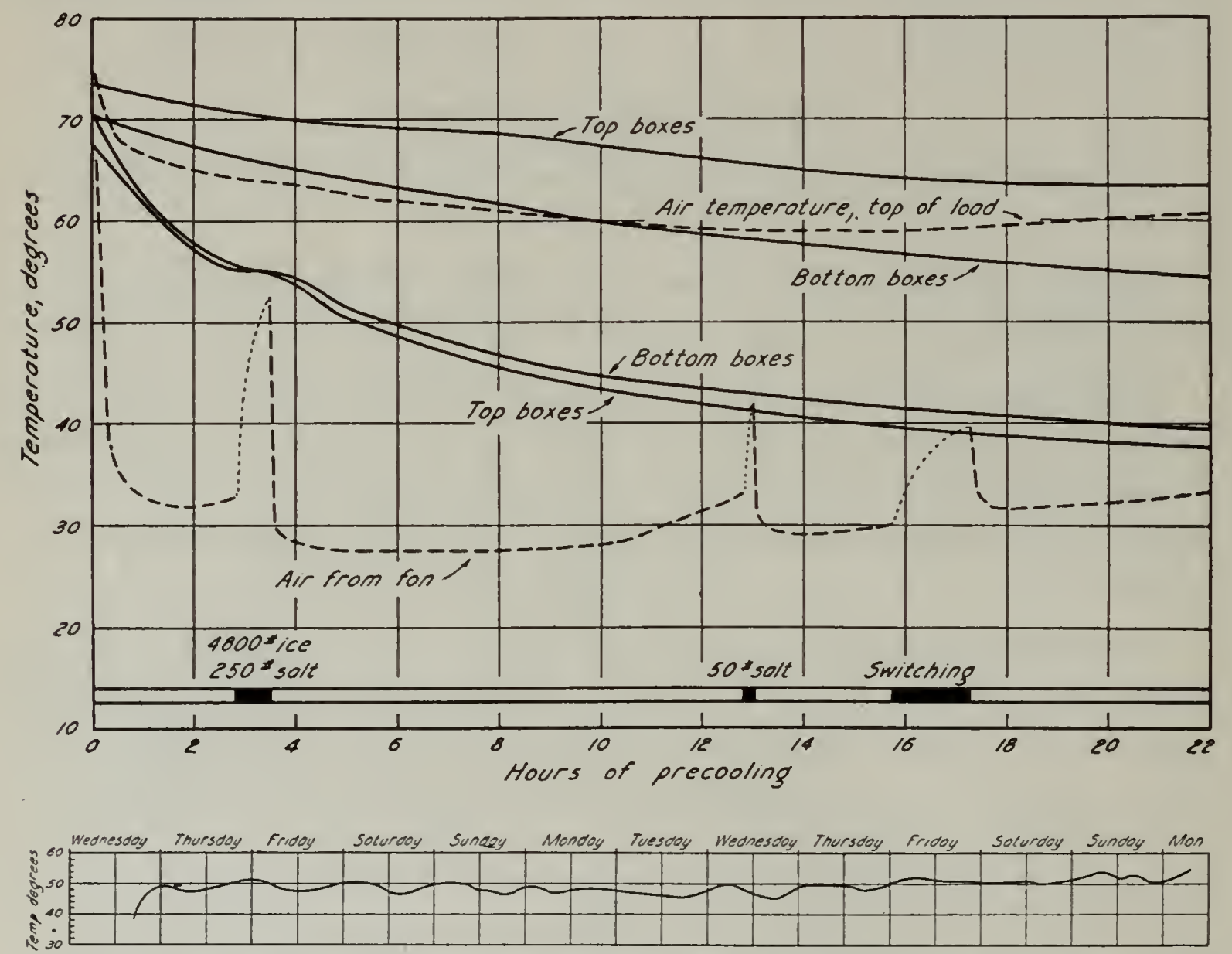

Fig. 33.-Precooling of pears in P.F.E. 9023 below, and a comparable car (P.F.E. 36463 ) of nonprecooled pears above; Placerville, September 13-14, 1932 ; average fruit temperatures in top and bottom boxes in tiers $1,4,7$, and 10 of the two loads. The lower part of the figure shows a thermograph record of air temperature in P.F.E. 9023 at top of load in transit to New York with only one re-icing.

Conditions of Loading and Precooling.-The fruit was loaded in both cars at $70^{\circ}-75^{\circ} \mathrm{F}$. Precooling in P.F.E. 9023 started within $21 / 2$ hours after the first boxes were loaded, and continued for 22 hours. Meanwhile, P.F.E. 36463 stood on the track, and its fruit was allowed to cool under normal air circulation. No salt was added to the ice in the latter car.

Temperatures Secured from Precooling.-As in the previous test, temperatures were recorded in the second pear from the edges of top and bottom boxes in tiers 1, 4, 7, and 10. Top and bottom boxes of the precooled car cooled similarly, remaining within $4^{\circ}$ of each other 
throughout precooling (fig. 33). During the first 10 hours of cooling, the temperature fell from $70^{\circ}$ to $45^{\circ} \mathrm{F}$, averaging $3.5^{\circ}$ an hour. During the following 12 hours, it reached $39^{\circ}$, with an average cooling rate of $1.4^{\circ}$ an hour for the 22-hour period. Except when necessary to disconnect the precooling fans, an air-blast temperature of $30^{\circ}$ was maintained. Tiers 1 and 4 were $4^{\circ}-5^{\circ}$ colder than tiers 7 and 10 at the end of 10 hours, but each averaged within $2^{\circ}$ of the other after 22 hours. After this period of cooling, the car was allowed to stand 6 hours, during which time the warmer fruit in the center of the boxes caused the temperature of that near the edge to rise $3^{\circ}$.

In the nonprecooled car, with the air temperature (at the top of tier 9) dropping only to $60^{\circ} \mathrm{F}$, the fruit in the top of the load after 22 hours was $63.5^{\circ}$; that in the bottom, $55^{\circ}$. Fruit in the outer part of the top boxes had cooled only $10^{\circ}$, as compared with $31^{\circ}$ for the precooled car (fig. 33).

Shipping Record and Condition of Fruit on Arrival.-P.F.E. 9023 (precooled) was shipped to New York under initial icing (Rule 240) while P.F.E. 36463 (nonprecooled) was forwarded under standard refrigeration plus 3 per cent of salt at all re-icings. During transit, air temperature above the load at the brace in the precooled car fluctuated between $46^{\circ}$ and $50^{\circ} \mathrm{F}$ for the first 7 days, and between $50^{\circ}$ and $54^{\circ}$ during the last 3 . Unfortunately the record for the corresponding position in the nonprecooled car was never received. The following quotation regarding the condition of the fruit on arrival is from the receivers in New York:

Both of these cars arrived in Croxton Yards late in the afternoon of September 23.... Ice tanks in P.F.E. 9023, precooled shipment, were $1 / 8$ full... When shipments were unloaded on Erie pier a very careful inspection of the fruit was made and the advantage insofar as condition of the fruit was concerned, was all in favor of P.F.E. 9023, precooled. Fruit in this shipment was mostly fairly well colored, slight traces of green tinge, but all stock very firm.... In P.F.E. 36463, standard refrigeration, all of the fruit was fully colored, firm to an occasional pear softripe. The comparative condition of these two shipments was very noticeable as reflected in the price realized.

\section{PEAR PRECOOLING TEST 3}

Refrigerator car P.F.E. 36550, San Jose, August 12, 1933. A standard load of 532 boxes - 19 tiers, 7 wide and 4 high

Purpose of Test.-(1) T'o secure additional data on the rate and extent of cooling in different parts of the load after 30 hours and (2) to determine the condition of Santa Clara Valley Bartlett pears upon arrival. 
Conditions of Loading and Precooling.-The " $B$ " end of the car was loaded 12 hours before precooling, while the " $A$ " end, in which thermometers were placed in the second pear from the edge of top, center, and bottom boxes of tiers 1, 5, and 10, was loaded between 8:00 a.m. and $12 \mathrm{~m}$. Ice bunkers were refilled to capacity, 212 pounds of salt added, and fans started at 12:15 p.m. Precooling continued for 30 hours, 8,000 pounds of ice and 550 pounds of salt being used.

T'emperatures Secured from Precooling.-Temperature of the air as delivered by the fan was reduced to $33^{\circ}$ in 4 hours, held from $33^{\circ}$ to

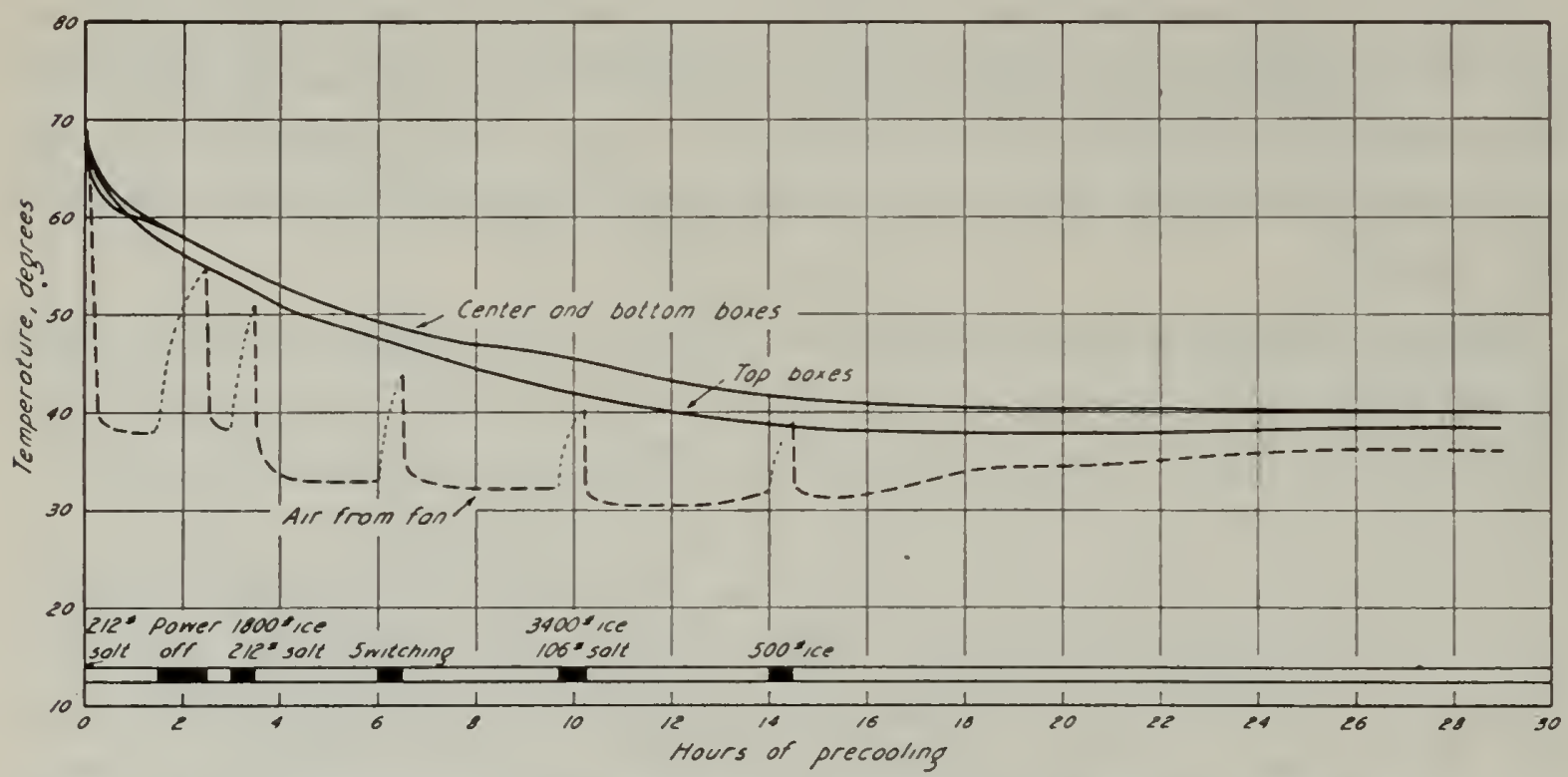

Fig. 34.--Precooling of pears in P. F. E. 36550, San Jose, August 12, 1933 : average fruit temperatures near the edge of boxes at the top, center, and bottom of tiers 1,5 , and 10 .

$30^{\circ}$ for 12 hours, and then gradually permitted to rise to $36^{\circ}$. Temperatures recorded for this car and the general rate of cooling were, during the first 22 hours, practically identical with those of the previous test. The bottom and top boxes remained within $2^{\circ}-3^{\circ}$ of each other, while no difference existed in the center and bottom boxes. With a gradually rising air temperature after 16 hours of precooling, the outside pears in the boxes could cool no further (fig. 34). Temperatures in the center of the boxes, though not recorded, probably continued to drop gradually, as shown by later tests.

Shipping Record and Condition of Fruit on Arrival.-This car was forwarded to Chicago under standard refrigeration. The fruit was reported as arriving "in a hard-ripe condition, greenish color with 5-25 per cent showing a slight blush." Other precooled lots forwarded by the same company arrived in good condition. Shippers of Santa Clara Bartlett pears add, "We would not ship without precooling." 


\section{PEAR PRECOOLING TEST 4}

Refrigerator car P.F.E. 36612, Suisun, August 15-16, 1933. A standard load of 532 boxes -19 tiers, 7 wide and 4 high.

Purpose of Test.-To determine (1) the cooling rate with heavy initial salting. (2) the difference in temperature between fruit at the edge and at the center of the box. (3) the car temperature during transit. and (4) the condition of the fruit upon arrival.

Conditions of Loading and Precooling.-Loading continued throughout the afternoon, with an average fruit temperature of $78^{\circ} \mathrm{F}$. Cooling started at $7: 15$ p.m. and continued for 24 hours. Adding 500 pounds of salt to the ice after 1 hour and an additional 125 pounds after 4 hours lowered the air temperature to $30^{\circ}$. As this temperature was maintained for the first 18 hours, air conditions were favorable for precooling.

Temperatures Secured from Precooling.-Temperatures were recorded in the second pear from the edge of top, center, and bottom boxes of tiers 1,5 , and 9 , and in the edge and center of a single box in the brace of the car, as shown in figure 35 . The precooling record illustrates the rather rapid drop in temperature of the fruit near the edges of the box during the first 10 hours. Top and bottom boxes cooled at essentially the same rate, having been reduced to approximately $45^{\circ} \mathrm{F}$ in 10 hours. Those in the center of the load showed approximately a 6 -hour lag in reaching the same temperature. At the end of 24 hours. top and bottom boxes had cooled to $38^{\circ} \mathrm{F}$, with the center boxes $46^{\circ}$. A box in the brace of the load containing fruit having an initial temperature $8^{\circ}$ higher than in other boxes, had reached $35^{\circ}$ near the edge of the box while that in the center of the box had cooled only to $46^{\circ}$. Pears in the center of the box were therefore $11^{\circ}$ warmer than those near the edge, even after being precooled for 24 hours. At the end of 10-12 hours' precooling, this difference was as much as $25^{\circ}$. The results also show that even though the edges of the box may cease to cool as their temperature approaches that of the surrounding air, the center continues to lose its heat. In this test, as in the previous one, the fruit temperature in the outer part of the package remained practically constant after 16 hours, a continued reduction being prevented both by the air temperature, approximating that of the outside fruit, and the conduction of heat from the center of the box.

During the 24-hour precooling period the outer part of all boxes lost $30^{\circ}-35^{\circ} \mathrm{F}$. The box cooled in the brace, a very favorable location, lost $44^{\circ}$ at the outer edge, while its center cooled only $33^{\circ}$.

Shipping Record and Condition of Fruit on Arrival.-This car of fruit was forwarded to New York under standard refrigeration with 
air temperature at the top of the load at the brace varying, after the first 12-15 hours, between $45^{\circ}$ and $52^{\circ} \mathrm{F}$. Upon arrival, the receivers recorded the actual fruit temperatures in 18 boxes in different posi-
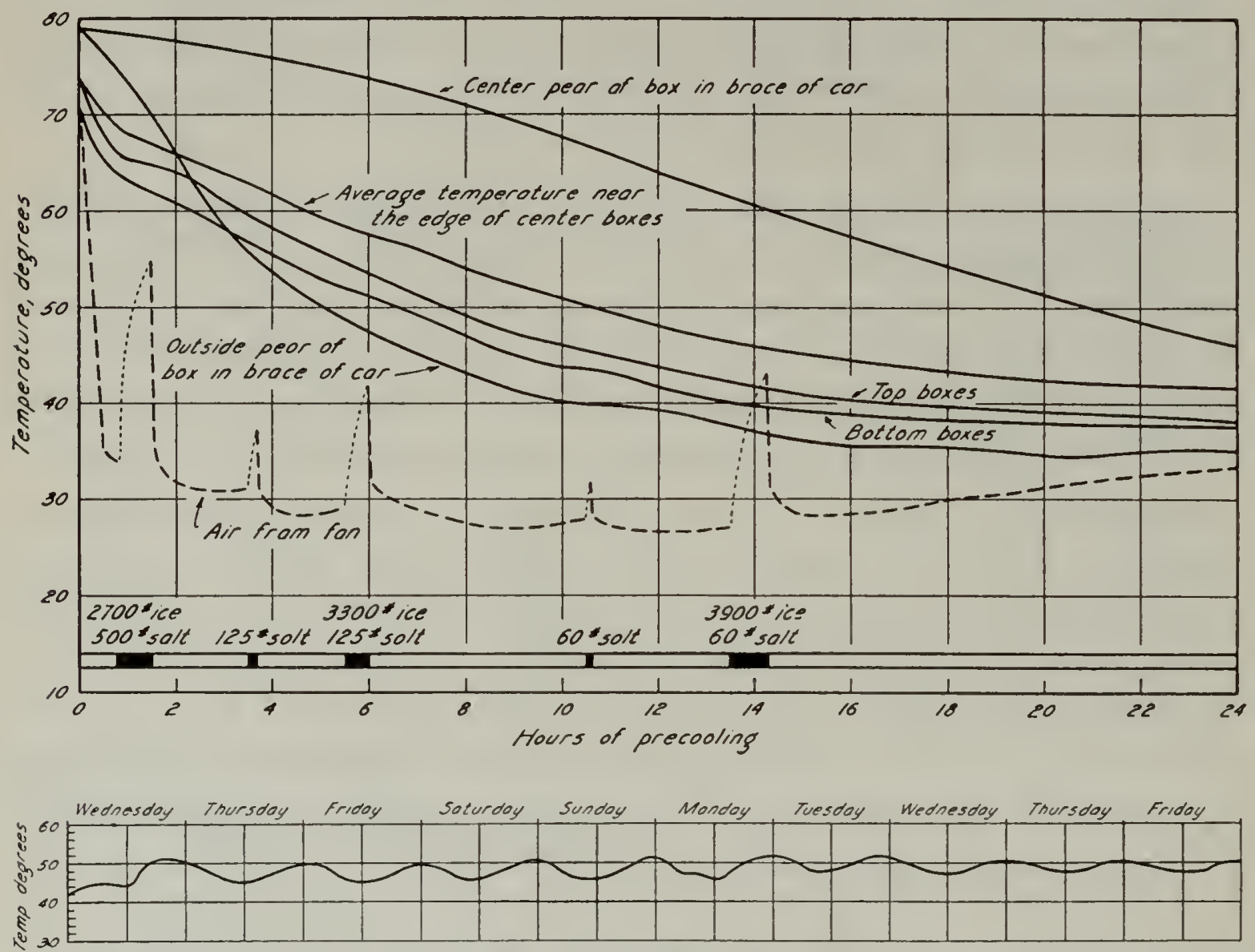

Fig. 35.-Precooling of pears in P.F.E. 36612, Suisun, August 15-16, 1933 : average fruit temperatures near the edges of boxes at the top, center, and bottom of tiers 1,5 , and 9 , and near the edge in the center of a single box cooled in the brace of the car. The lower part of the figure represents a thermograph record of air temperature at the top of the load in transit to New York under standard refrigeration.

tions of the load and reported the fruit "firm, mostly green, a few light green." Fruit temperatures found upon opening the car were as follows :

\begin{tabular}{|c|c|c|c|}
\hline & At doorway & $\begin{array}{l}\text { Quarter way } \\
\text { of load }\end{array}$ & At bunker \\
\hline Top boxes............... & $50^{\circ} \mathrm{F}^{\top}$ & $46^{\circ} \mathrm{F}$ & $43^{\circ} \mathrm{F}$ \\
\hline 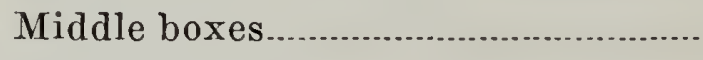 & $48^{\circ}$ & $45^{\circ}$ & $40^{\circ}$ \\
\hline Bottom boxes......... & $46^{\circ}$ & $42^{\circ}$ & $36^{\circ}$ \\
\hline
\end{tabular}

These data, together with the air temperature in the top of the load during transit and the precooling record, appear to indicate (1) that although fruit in the outer part of the package is precooled to below $40^{\circ} \mathrm{F}$, center temperatures after 24 hours of cooling may be at least $50^{\circ}$ and (2) that further cooling is limited by the air temperatures in the different parts of the car during transit. 


\section{PEAR PRECOOLING TEST 5}

Refrigerator car P.F.E. 22693, Placerville, August 23-24, 1933. A "heavy" load of 722 boxes-19 tiers, 8 wide, and 5 high, omitting the 2 center boxes on the top of each tier.

Purpose of Test.-To determine the efficiency of car precooling in a "heavy" load of pears, (2) to record air temperatures in transit, and (3) to determine the condition of the fruit upon arrival when shipped under only one re-icing.

Conditions of Loading and Precooling.-Temperatures in this car were taken in the second pear from the edge of boxes in tiers 1,5 , and 10 , and in the same position and at the center of a box on the top of tier 8 , second from the side of the car. Loading was in progress between $10: 00 \mathrm{a}$. m. and $2: 00$ p.m., with fruit temperatures of $68^{\circ}-75^{\circ} \mathrm{F}$. Reicing was done between $2: 00$ and $3: 40$ p.m. Precooling started at $3: 45$ p.m., with an outside air temperature of $97^{\circ}$.

Temperatures Secured from Precooling.-At the end of 24 hours the fruit temperature near the edge of the top, center, and bottom boxes varied only between $39.5^{\circ}$ and $41^{\circ} \mathrm{F}$. The bottom boxes, $7^{\circ}$ colder than top and center boxes when precooling began, soon lost the lead; and after 5 hours the average cooling rate in top, center, and bottom boxes was practically identical. When the temperatures in these three positions were averaged by tiers, however, cooling was not so uniform (fig. $36)$. Tier 10 at the doorway cooled less rapidly than either tier 5 or tier 1 , and after 4 hours remained some $15^{\circ}$ higher than the latter. The general cooling rate after 4-5 hours and until the sixteenth hour was slower than in former tests, primarily because of relatively high air temperature from the fans. After the re-icing and the addition of salt after 15 hours, both air and fruit temperatures declined. Had this second 250 pounds of salt been added at the first re-icing after 2 hours' precooling, colder air and more rapid cooling would have been obtained. If the fans had been set at a slightly higher angle, or equipped with fins to direct the current slightly upward, cooling in the different tiers would probably have been more uniform.

The temperatures of the fruit near the edge of the box and in the center are further compared by the curves representing temperatures in these positions in a top box in tier 8 . Starting with a temperature of $76^{\circ} \mathrm{F}$, fruit near the edge of this box cooled in 24 hours to $38^{\circ}$, while that in the center registered $55^{\circ}$. This difference of $17^{\circ}$ is greater than that in the previous test, where the box was not an integral part of the load.

Shipping Record and Condition of Fruit on Arrival.-This car was 
shipped under Rule 254 (only one re-icing in transit) and arrived witl the ice tanks one-fourth full. The air temperature recorded just above the load at the brace (fig. 36 ) is very similar to that in the Suisun car shipped under standard refrigeration.

Upon arrival in New York, the air temperature at the top of the load
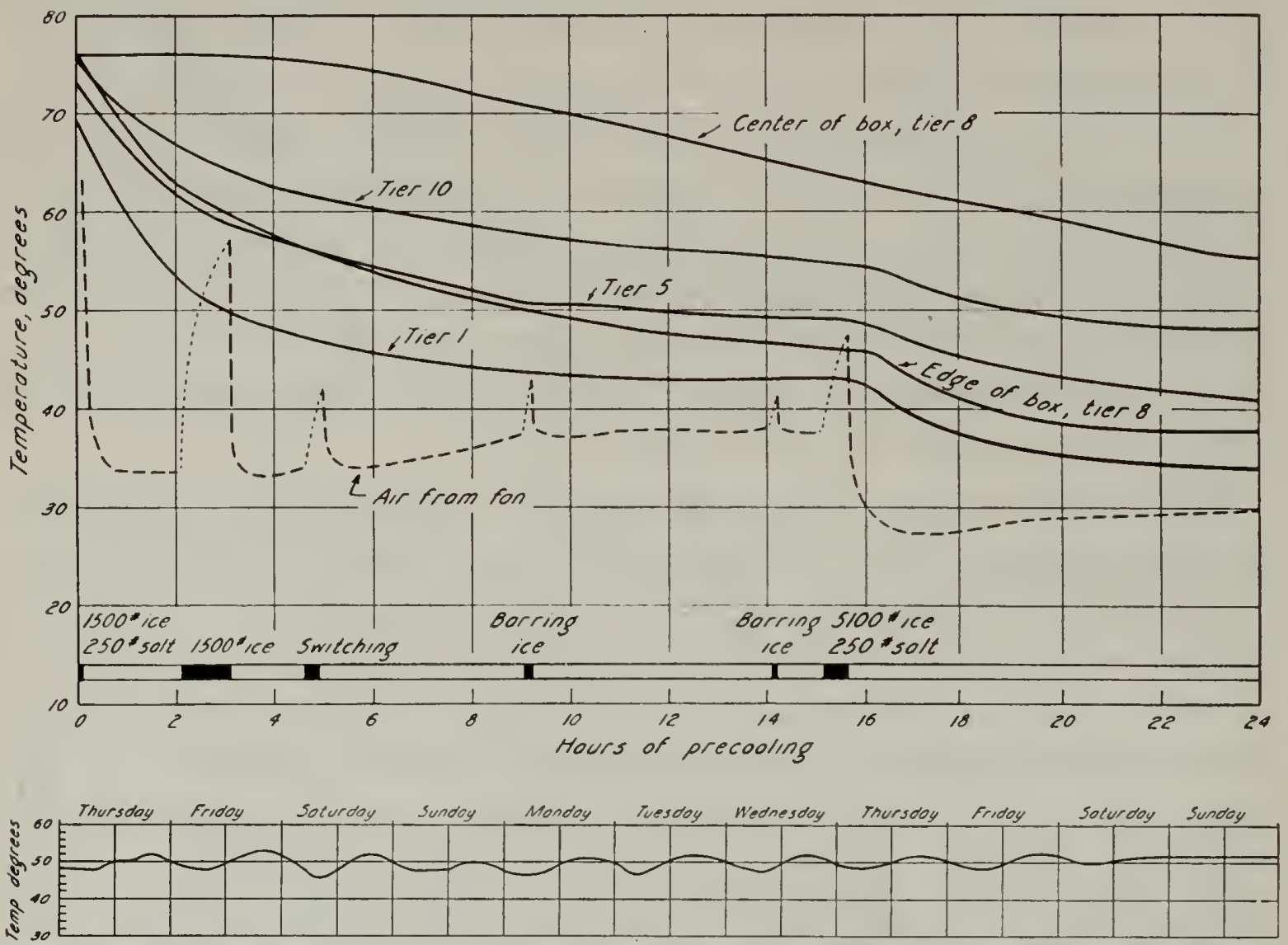

Fig. 36.-Precooling of pears in P. F. E. 22693, Placerville, August 23-24, 1933 : average fruit temperatures near the edge of the top, center, and bottom boxes in tiers 1, 5, and 10, and the temperature in the center and near the edge of a top box in tier 8. The lower part of the figure represents a thermograph record of air temperature at the top of the load in transit to New York with only one re-icing.

at the doorway was $55^{\circ} \mathrm{F}$. Fruit temperatures taken in six boxes of the load were as follows:

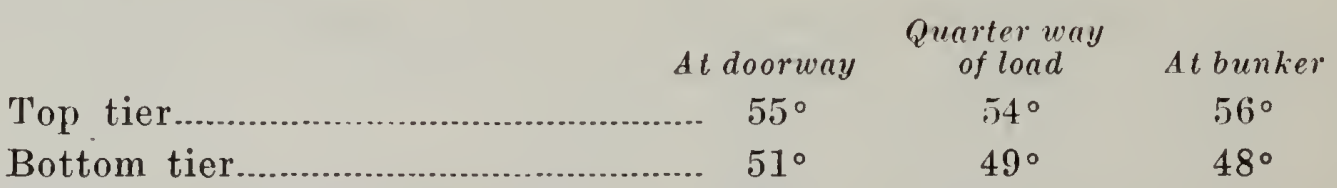

In comparing these temperatures with those recorded in the previous test, where the car was shipped standard refrigeration, they are noted to be more uniform, but $5^{\circ}-13^{\circ} \mathrm{F}$ higher in the top of the load. The greatest difference was found in the ends of the car near the ice bunkers.

Fruits in the boxes in the bottom were described as "mostly light green," while those in the top of the load were "light green to considerable slight color but firm." 


\section{PEAR PRECOOLING TEST 6}

Refrigerator cars P.F.E. 35403 and 7476, Placerville, September 7-9, 1933. "Heavy" loads of 722 boxes.

Purpose of Test.-To secure (1) colder air temperatures and more rapid cooling with a heavy load of pears than previously obtained, (2) further data on the cooling of fruit in the center of boxes, and (3) condition on arrival with only one re-icing in transit.
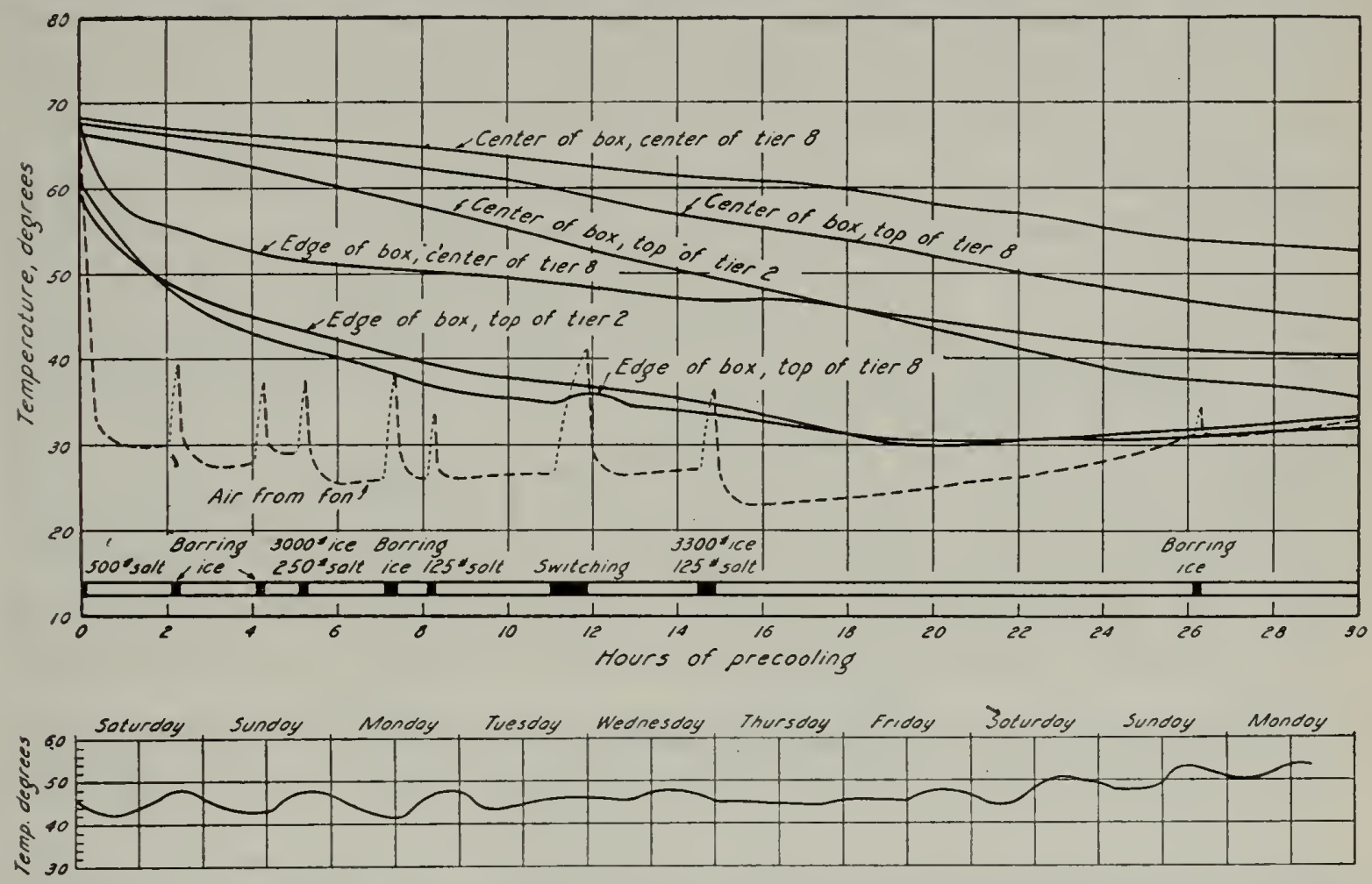

Fig. 37.-Precooling of pears in P. F. E. 35403, Placerville, September 7-9, 1933 : fruit temperatures at the center and near the edge of boxes at the top of tier 2 and at the top and center of tier 8. The lower part of the figure represents a thermograph record of air temperature at the top of the load while in transit to New York with only one re-icing.

Conditions of Loading and Precooling.-Loading was in the same manner as test 5 and was in progress from $7: 00$ to $11: 00 \mathrm{a} . \mathrm{m}$., with the fruit temperature $70^{\circ}-72^{\circ} \mathrm{F}$. When precooling began, 500 pounds of salt were added to the ice in P.F.E. 35403 ; and 500 pounds more were supplied later. Ice was barred down or salt added during the first half of the precooling period whenever the air temperatures in the car tended to rise. The ice consumed in precooling totaled $6,500-7,000$ pounds.

P.F.E. 7476 received, in all, only 500 pounds of salt; and air temperatures were not reduced so rapidly nor quite so low as in the other car.

Temperatures Secured from Precooling.-Figure 37 shows fruit temperatures in the center and near the edge of the individual boxes in different parts of P.F.E. 35403. Edges of the top boxes cooled very rapidly during the first 3-4 hours, cooled as fast as the centers of the 
same boxes during the next 14-15 hours, and then ceased to cool. Edge temperatures in the box buried in the load cooled much more slowly, the rate even being exceeded after 17 hours by the center fruit in the top box near the ice bunker. The center temperature of all boxes declined gradually and uniformly throughout the 30 hours of precooling, the actual amount of heat lost from each depending largely upon its position in the load. After 30 hours the average difference in temperature between the edges and center of the boxes was $9^{\circ} \mathrm{F}$. The extreme

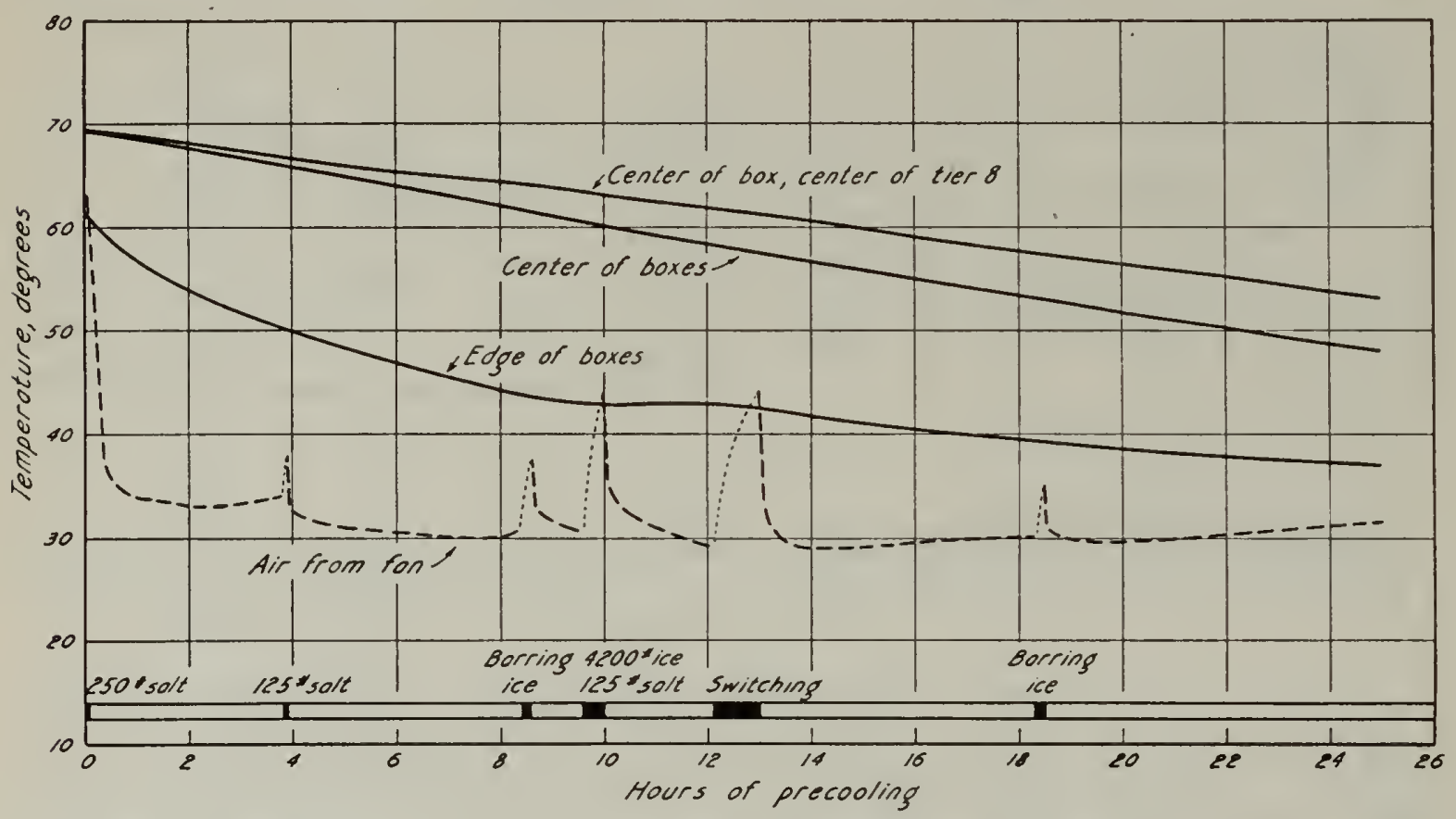

Fig. 38. Precooling of pears in P. F. E. 7476, Placerville, September 7-9, 1933 : average fruit temperatures in the center and near the edge of boxes at the top of tier 2 and in the top and center of tier 8 and in the middle of the center box in tier 8 .

difference, between the center of the box in the center of the load and the edge of a box in tier 6 (a very favorable position for rapid cooling), was $20^{\circ}$. Fruit temperatures are usually taken in the outer fruits of packages during precooling; but the records for this car show that while the outer fruit was precooled to between $33^{\circ}$ and $40^{\circ}$, or about $25^{\circ}$ in 30 hours, the temperature in the center of the boxes was $33^{\circ}-52^{\circ}$, mostly $45^{\circ}-50^{\circ}$.

Very similar results were obtained with P.F.E. 7476. Average temperatures at the center and near the edge of the three boxes, together with the air temperature maintained in the car during 26 hours of precooling, are shown in figure 38 . The air temperature, though $3^{\circ}-4^{\circ}$ higher than in P.F.E. 35403, remained very close to $30^{\circ} \mathrm{F}$ after the first 6 hours of precooling; and very satisfactory cooling resulted.

Shipping Record and Condition of the Fruit on Arrival.-Both of these cars were shipped to New York with only one re-icing. The lower part of figure 37 shows the air-temperature record in transit for P.F.E. 
35403. Because of longer and more thorough precooling, the air temperature for the first $7-8$ days was $4^{\circ}-6^{\circ}$ lower than in P.F.E. 22693 (fig. 36).

Both cars arrived with the ice bunkers $1 / 4-3 / 8$ full. Fruit temperatures in the top and center of the two loads were $50^{\circ}-52^{\circ} \mathrm{F}$; in the bottom, $44^{\circ}$. In P.F.E. 35403 , cooled with air below $30^{\circ}$, the fruit was described as "dark to generally light green, only an occasional box showing slight color." Pears in P.F.E. 7476 were described as "varying from light green to generally slight traces of color, with an occasional box fully colored but firm." The receivers add, "There was quite a little difference in the maturity of the fruit in these two shipments." (Observations during packing and loading in these two cars had indicated that the fruit was uniformly mature at the outset.)

After the precooling of car P.F.E. 35403, three boxes in which fruit temperatures were taken were removed with the resistance thermometer points still in place, carefully wrapped in heavy paper, and brought to Davis (between 9:00 and 11:00 p.m.) to be held for 10 days under refrigerator-car conditions. A fourth box, nonprecooled, was used as a check. The condition of this fruit 10 days later is reported upon under "Holding Tests of Precooled and Nonprecooled Pears," page 108.

\section{PEAR PRECOOLING TEST 7}

Refrigerator ears 24943, 34286, and 34215, Walnut Grove, August 4-5, 1933. Loads of 60050 -pound lug boxes, 6 wide and 6 high "squeeze pack"

Purpose of Test.-To ascertain (1) the time required to cool unwrapped fruit in the center of the boxes to $35^{\circ} \mathrm{F}$ or below and (2) the increase in fruit temperature during $5-6$ days while the cars were held on track in Sacramento with outside air temperatures between $45^{\circ}$ and $107^{\circ}$ on 2 consecutive days.

Conditions of Precooling.-P.F.E. 24943 (car A) received 8,400 pounds of ice and 600 pounds of salt during precooling. After 1 hour of precooling an additional 500 pounds of salt was added. Upon completion of precooling, bunkers were filled to capacity with 2,400 pounds of ice. No additional salt or ice was added during the $5 \frac{1}{2} 2$ days of standing on track.

P.F.E. 34286 (car B) received 8,100 pounds of ice and 812 pounds of salt during precooling and no salt thereafter. Ice (500-850 pounds) was added daily. The total amount of ice supplied was 11,550 pounds.

P.F.E. 34215 (car C) received 9,150 pounds of ice and 875 pounds of salt during precooling, and was re-iced and salted with 2 per cent salt daily thereafter. The total amount of ice and salt supplied was 12,350 and 1,029 pounds respectiveiy. 
Temperatures Secured from Precooling.-Air temperatures were reduced to $30^{\circ} \mathrm{F}$ in 8 hours in car A, 4 hours in car B, and 6 hours in car C. Fruit in the center of the top, middle, and bottom of tiers 1, 4, and 9 reached $35^{\circ}$ in 18 hours in car $\mathrm{A},{ }^{30} 13$ hours in car $\mathrm{B}$, and 18 hours in car C. This rate of cooling unwrapped fruit in the center of loose lug boxes is as rapid or slightly more rapid than that found for the outer pears when wrapped and packed for eastern shipment.

Shipping Record and Holding Temperatures.-These three cars were shipped only to Sacramento, where they were held on track for 5-6 days before being unloaded at a cannery. With the ice replenished in car A and no further icing, and with cars $\mathrm{B}$ and $\mathrm{C}$ re-iced as indicated above, average fruit temperatures rose in $51 / 2$ days to $43^{\circ} \mathrm{F}$ in car $\mathrm{A}, 41^{\circ}$ in car $\mathrm{B}$, and $40^{\circ}$ in car $\mathrm{C}$. During this holding period outside temperatures were probably higher than under actual transit conditions. The fruit temperatures, however, indicate the temperature of thoroughly precooled fruit shipped as far east as Omaha under initial icing (car A), standard refrigeration (car B), and standard refrigeration plus 2 per cent salt (car C).

\section{PEAR PRECOOLING TEST 8}

P.F.E. 2774 and P.F.E. 28246, Placerville, July 16-17, 1934. Heavy loads of 722 boxes

Purpose of Test.-To determine (1) possible differences in the cooling rate and ice consumption in two 3,600-pound loads of pears precooled for 26 hours with 2 and with 4 fans, and (2) the possibility of shipping such precooled loads without re-icing in transit.

Conditions of Loading and Precooling.-The fruit was loaded over a period of several hours, the car doors being open from 8:30 a.m. to $3: 30$ p.m. The precooling fans were started at $3: 20$ p.m. and, except for several 15-minute periods when adding salt and ice, were in continuous operation for 26 hours. Air-blast temperatures were reduced to $32^{\circ}$ in $31 / 2$ hours and maintained between $25^{\circ}$ and $30^{\circ}$ until the last 2 to 4 hours. With the ice bunkers three-quarters full at the beginning of precooling, the first re-icing was given after $2 \frac{1}{2}$ hours, the second after 12 hours of cooling. Air-blast temperatures were watched closely; salt was added and attention given to barring the ice whenever the air temperature tended to rise.

Temperatures Secured from Precooling.-With close attention given to air temperatures, the general cooling rate of the fruit in the edge and in the center of boxes in tiers $3,5,8$, and 10 were very similar to those

30 Temperatures in top and bottom boxes only. 
of the previous test. Temperatures after 26 hours averaged $38^{\circ}$ in the edges of the boxes and $49^{\circ}$ in the center (fig. 39). With slightly warmer fruit than in the previous test more ice and salt was used. P.F.E. 27246, containing the two 2 -fan units, melted 13,800 pounds of ice and P.F.E. 2774 , containing the two 1-fan units, melted 10,800 pounds in cooling.

Both cars were operated in a similar manner and the final results differed only $2^{\circ}$. This difference was in favor of the car containing the
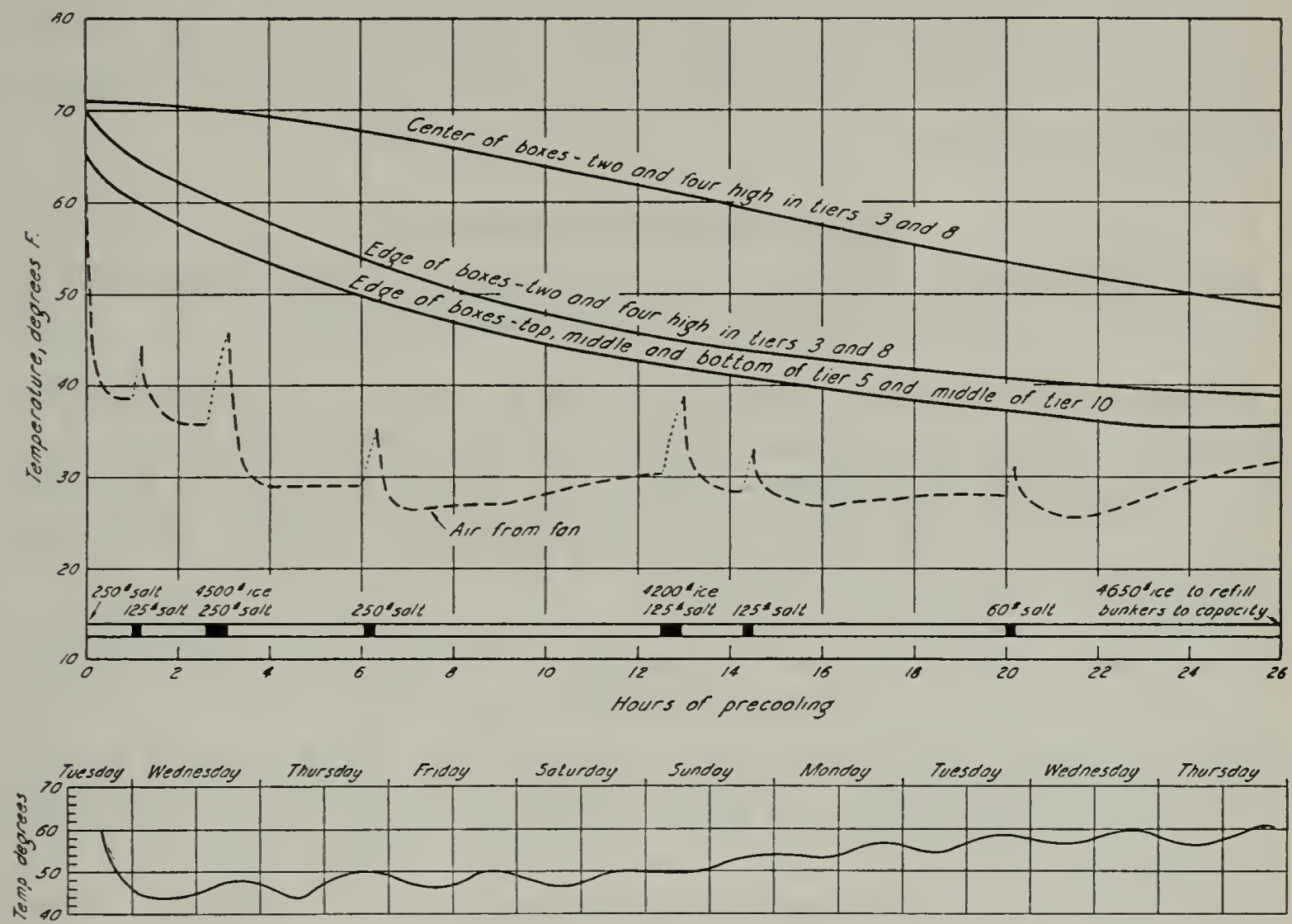

Fig. 39.-Precooling of a 36,000-pound load of Bartlett pears in refrigerator car P. F. E. 2774, Placerville, California, July 16-17, 1934: air-blast temperature and average fruit temperatures near the edge and in the center of boxes in different positions of the load. The fruit was precooled with portable precooling fans for 26 hours. The base line shows the complete icing and salting record. Ice bunkers were approximately three-fourths full at the beginning of the precooling period. Ice melted during cooling totaled 10,850 pounds; salt, 1,180 pounds.

Below, air temperature at the top of the load at the doorway while in transit from Placerville to New York. Ice bunkers were not replenished after leaving Placerville.

1-fan unit, shown in figure 39. As evidenced by a smaller "split" or difference between the air blast and the return air, the rate of circulation in the car containing 4 fans appeared more rapid than in the one equipped with only 2 fans. Air-blast temperatures in the 4 -fan car, however, showed more fluctuation and could not be maintained at quite so low a level. An earlier comparison between the relative efficiency of two 19-inch fans and four 16-inch fans likewise failed to show that the latter cooled the fruit any more rapidly. 
Shipping Record and Condition of Fruit on Arrival.-With slightly less cooling in these cars than in the previous test, with no re-icing in transit, and with warm outside temperature, air temperatures at the top of the load in P.F.E. 2774 were consistently $6^{\circ}-8^{\circ} \mathrm{F}$ higher after the first two days than those in the car shipped the previous September under one re-icing. With daily fluctuations of several degrees, the air gradually increased from $44^{\circ}$ to $60^{\circ}$ over a 10 -day period. Upon arrival in New York the temperature of the fruit in the top of the load at the brace was $56^{\circ}$; that in the bottom of the load $50^{\circ} \mathrm{F}$. The fruit was described as all very firm to hard but with a slight tinge of color in many boxes of the top tier.

\section{PEAR PRECOOLING TEST 9}

P.F.E. 22907 and P.F.E. 70595, Placerville, August 14-15, 1934. Loads of 608 boxes, 4 tiers high, and 722 boxes 5 tiers high

Purpose of Test.-To determine (1) if by the use of extra amounts of salt and ice a 722-box load of pears can be cooled in 26 hours to as low a temperature as a 608-box load under the more ordinary methods employed in car cooling and (2) to compare the condition of the two loads upon arrival in New York.

Conditions of Loading and Precooling.-Both cars were loaded simultaneously with fruit having an average temperature of $80^{\circ}$ F. P.F.E. 22907 was loaded only 4 tiers high with a total of 608 boxes and P.F.E. 70595 was loaded with tiers 5 high (except down the center of the car) and contained 722 boxes. In the first car the air-blast temperature was reduced to $35^{\circ}$ in one hour and maintained at $30^{\circ}$ or slightly below. In the second car it was hoped to reduce the temperature below $32^{\circ}$ within the first two hours and to maintain it between $30^{\circ}$ and $25^{\circ}$ throughout the remainder of the cooling period. During the 26 hours of cooling 1,625 pounds of salt were added and 12,450 pounds of ice melted. In the 608-box load only 875 pounds of salt were added and 10,500 pounds of ice melted.

Temperatures Secured from Precooling.-Despite the extra-large quantities of salt and ice used, efforts to reduce the air-blast temperature in the heavy load quickly were not so successful as on several previous occasions with cooler fruit. Only after 6 hours was it possible to secure an air blast of $30^{\circ} \mathrm{F}$ and only after 11 hours (after the third re-icing) was a $25^{\circ}$ temperature secured (fig. 40). Air temperatures in the smaller load were therefore lower during the first 7 hours than they were in the higher load. Only after 11 hours was it possible to secure colder air in the heavier load. Even with this delay, however, the $22^{\circ}$ 
air finally secured caused the fruit in this load to cool more rapidly, and at the end of the 26-hour cooling period fruit in the heavy load was slightly colder than that in the lighter load. 'The average rate of cooling for the lighter load is not shown but was very similar to the heavier load illustrated in figure 40.

Shipping Record and Condition of Fruit on Arrival.-Both of the loads were shipped to New York without re-icing. Air-temperature records taken at the top of the loads near the brace were similar. Dur-

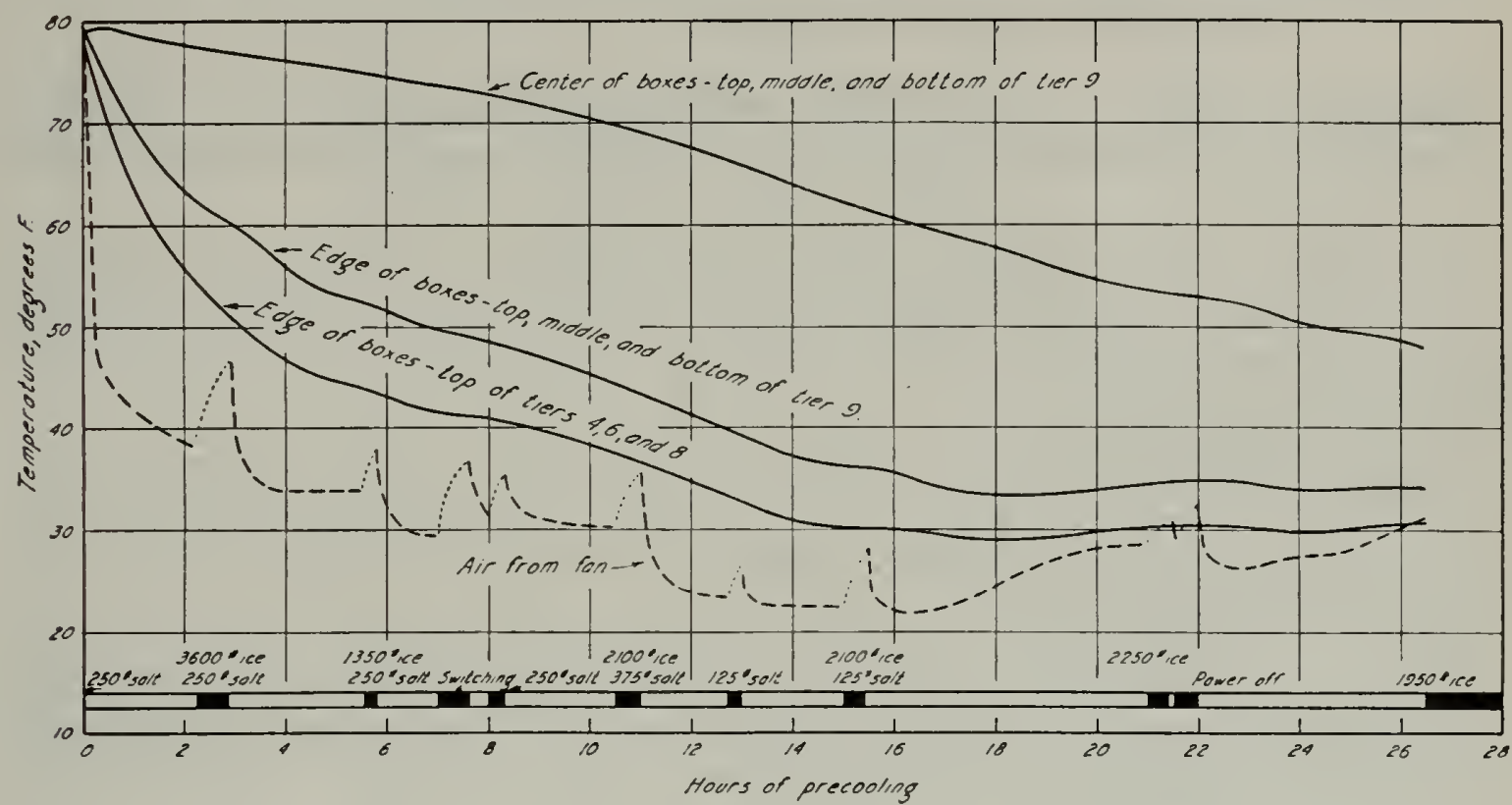

Fig. 40.-Precooling of pears in P. F. E. 70595, August 14-15, 1934: air-blast temperature and cooling rate in a 722-box load (tiers 5 high) of pears cooled for 26 hours with the use of 12,450 pounds of ice and 1,625 pounds of salt.

ing the first 5 days the air temperature in the light load varied between $45^{\circ}$ and $55^{\circ} \mathrm{F}$; during the second 5 days between $55^{\circ}$ and $62^{\circ}$. In the heavy load air temperatures were $52^{\circ}$ or below until the last 4 days, when the thermograph record indicated $58^{\circ}$. Upon arrival in New York the ice bunkers were one-fourth full and the air temperature was recorded as $56^{\circ}$. Fruit temperatures were:

$\begin{array}{llll} & \text { At doorway } & \begin{array}{c}\text { Quarterway } \\ \text { of load }\end{array} & \text { At bunker } \\ \text { Top boxes.............................................. } & 54^{\circ} \mathrm{F} & 54^{\circ} \mathrm{F} & 55^{\circ} \mathrm{F} \\ \text { Bottom boxes } & 47^{\circ} & 47^{\circ} & 46^{\circ}\end{array}$

Ice tanks of the car containing the smaller load were only one-eighth full and the air in the top of the car was $63^{\circ} \mathrm{F}$. Fruit temperatures were:

\begin{tabular}{|c|c|c|c|}
\hline & At doorway & $\begin{array}{l}\text { uarter way } \\
\text { of load }\end{array}$ & At bunker \\
\hline Top boxes...... & $\ldots \quad 59^{\circ} \mathrm{F}$ & $61^{\circ} \mathrm{F}$ & $62^{\circ} \mathrm{F}$ \\
\hline Bottom boxes & $52^{\circ}$ & $51^{\circ}$ & $52^{\circ}$ \\
\hline
\end{tabular}


The fruit in both cars was described as firm. That in the heavy load was characterized as 20 per cent slight color while that in the lighter load was fully colored in the top and 20 per cent colored in the bottom. The extra effort in cooling the heavy load therefore seemed of some value; once cooled the larger amount of fruit in the car helped to maintain a lower temperature.

\section{PEAR PRECOOLING TEST 10}

Shipping tests of precooled and nonprecooled cars under different types of refrigeration, Placerville, August 12, 1934. 608-box loads

Purpose of Test.-To determine air temperatures in the top of loads and the temperature and condition of the fruit on arrival in New York

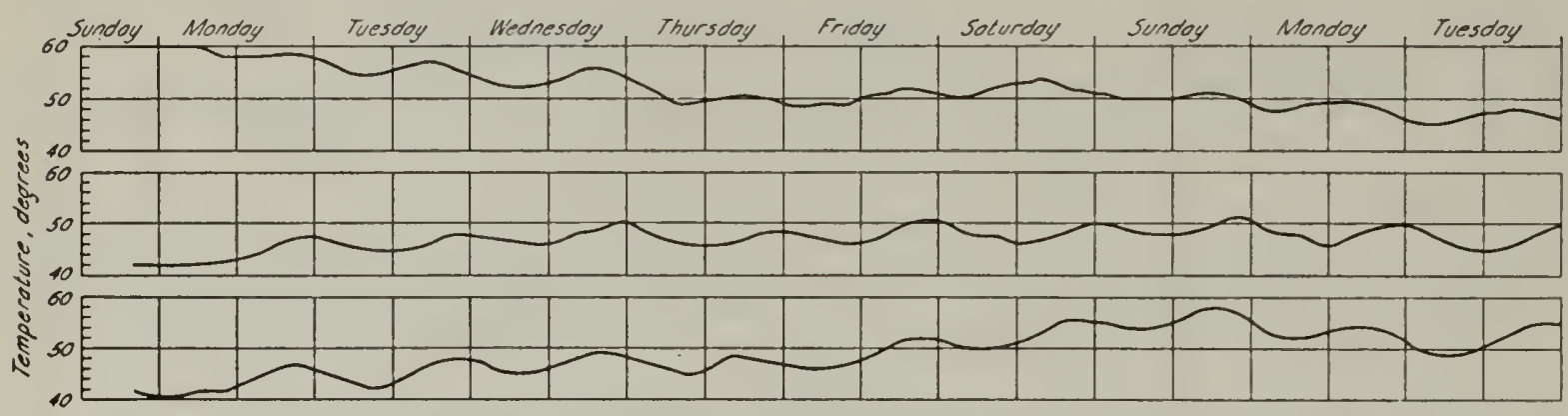

Fig. 41.-Air temperature at tops of 608-box loads of Bartlett pears in transit from Placerville, California, to New York, August 12-21, 1934: top, P. F. E. 34954, a nonprecooled load shipped standard refrigeration plus 3 per cent salt at each icing; center P. F. E. 26322, a precooled load shipped with one re-icing in transit; bottom, P. F. E. 28472, a precooled load shipped with no re-icing in transit.

of precooled and nonprecooled pears, shipped under different types of refrigeration.

Conditions of Test.-Three cars of pears, each containing 608 boxes, were shipped as follows:

P.F.E. 34954 loaded with nonprecooled fruit and shipped under standard refrigeration plus 3 per cent salt.

P.F.E. 26322 loaded with precooled fruit and shipped with one re-icing in transit (Rule 254).

P.F.E. 28472 loaded with precooled fruit and shipped with initial icing only (Rule 240).

Shipping Record and Condition of Fruit on Arrival.-The comparative air temperatures in the top of the three cars during the 10-day transit period is shown in figure 41 . In the precooled cars the initial maximum air temperature was $42^{\circ} \mathrm{F}$. For 5 days, temperatures in both cars fluctuated between $46^{\circ}$ and $52^{\circ}$. During the second 5 days in transit the temperature in the car receiving no re-icing gradually climbed about $6^{\circ}$, or to $58^{\circ}$, while the car which was re-iced at Council Bluffs maintained a $50^{\circ}$ average. The initial temperature in the car loaded 
with nonprecooled fruit, but receiving daily icing plus salt, was $62^{\circ}$, or $20^{\circ}$ warmer than that in the precooled cars. For the first 5 days the air in this car was higher than in the other two, and did not go below $50^{\circ}$ until the eighth day. Upon arrival of the car in New York it was slightly below that of the other cars.

TABLE 15

The Temperature and Generai. Condition of Precooled and Nonprecoolfid Pears ON ARrival IN NEW York WHEN SHIPPEd UNDER StaNdard Refrigeration and UNDer Modified Icing

\begin{tabular}{|c|c|c|c|c|c|}
\hline \multirow{2}{*}{ Wethod of shipment } & \multirow{2}{*}{$\begin{array}{l}\text { Relative } \\
\text { amount of } \\
\text { ice re- } \\
\text { maining in } \\
\text { bunkers }\end{array}$} & \multirow{2}{*}{$\begin{array}{l}\text { Air tem- } \\
\text { perature } \\
\text { at top } \\
\text { of load }\end{array}$} & \multicolumn{2}{|c|}{ Fruit temperature } & \multirow{2}{*}{ General condition and color of fruit } \\
\hline & & & $\begin{array}{l}\text { Top } \\
\text { boxes }\end{array}$ & $\begin{array}{c}\text { Bottom } \\
\text { boxes }\end{array}$ & \\
\hline Precooled, no re-icing & $1 / 16$ full & $\begin{array}{c}\text { degrees } F \\
59\end{array}$ & $\begin{array}{c}\text { degrees } F \\
56-58\end{array}$ & $\begin{array}{c}\text { degrees } F \\
46-47\end{array}$ & $\begin{array}{l}\text { Generally good condition; } 15 \text { per } \\
\text { cent full green, } 50 \text { per cent light } \\
\text { green, } 25 \text { per cent slightly colored } \\
\text { but firm, } 10 \text { per cent fairly well } \\
\text { colored though mostly firm }\end{array}$ \\
\hline Precooled, one re-icing & $3 / 8$ full & 55 & $52-54$ & $43-45$ & $\begin{array}{l}\text { Good condition; } 20 \text { per cent full } \\
\text { green, } 50 \text { per cent light green, } 20 \\
\text { per cent showing slight color but } \\
\text { firm }\end{array}$ \\
\hline $\begin{array}{l}\text { Nonprecooled, daily } \\
\text { re-icing and salt }\end{array}$ & $\pi / 8$ full & 48 & $47-48$ & $41-42$ & $\begin{array}{l}\text { Top tier fully colored and soft-ripe } \\
\text { to generally firm; lower tiers } 10 \\
\text { per cent full green, } 40 \text { per cent } \\
\text { light green, } 50 \text { per cent slight to } \\
\text { fairly well colored though gener- } \\
\text { ally firm }\end{array}$ \\
\hline
\end{tabular}

Throughout the 10-day transit period average temperatures were similar, but the lower temperatures which existed during the first 5 days in the precooled cars show their value in retarding maturity. The temperatures recorded on arrival and the condition of the fruit in the different loads is summarized in table 15.

\section{PEAR PRECOOLING TEST 11}

Commercial cold-storage room, San Jose, August 12-13, 1933.

Purpose of Test.-To compare cooling rates in the center and near the edge of boxes in different positions in the stack in a commercial cold-storage room.

Methods of Stacking and Conditions for Precooling.-Boxes stacked 9 high in a room approximately $27 \times 54$ feet with a 10 -foot ceiling. The room was filled to only 10-15 per cent of its capacity. The stack was approximately 10 feet from the cold air intakes, with two stacks of precooled fruit between the test stack and the intakes. Open stacking, 
however, permitted unobstructed passage of the incoming air, which registered $33^{\circ}-31^{\circ} \mathrm{F}$; and general conditions favored rapid cooling. Fruit temperatures were taken in the first, fifth, and ninth boxes from the floor.

Temperatures Secured from Precooling.-The results (fig. 42) show that sufficient cold air came in contact with the pears near the edges of the boxes so that the cooling rate for this part of the box was essentially the same in the center of the stack as in the top and bottom. In the center of the boxes, on the other hand, fruit temperatures in the

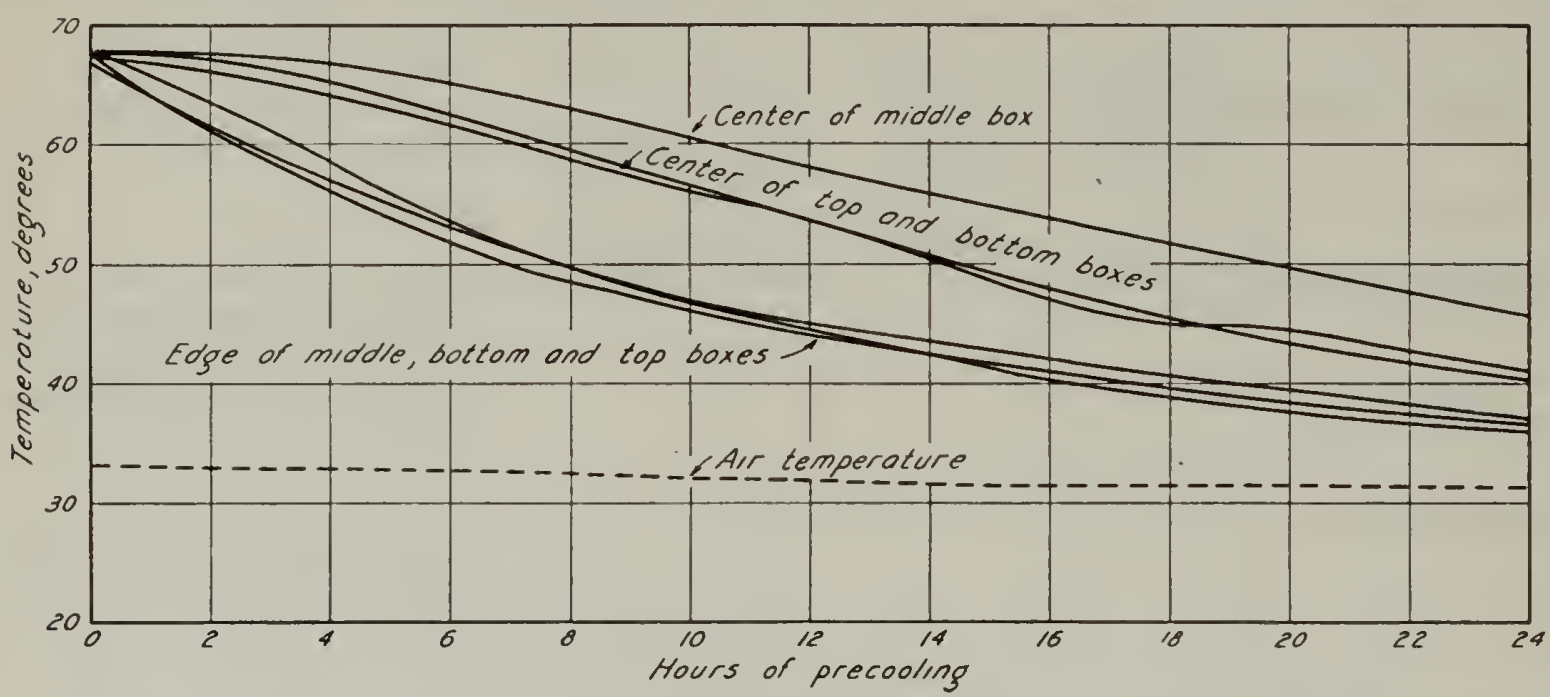

Fig. 42.- Precooling of pears in a commercial cold-storage room, San Jose, August 12-13, 1933: comparative cooling rate near the edge and in the center of boxes in the top, center, and bottom of a stack 9 ligh situated within 10 feet of the cold-air intake.

top and bottom of the stack registered $41^{\circ} \mathrm{F}$ as compared with $46^{\circ}$ for the center of the middle boxes after 24 hours of precooling. Temperatures in the outer parts of all packages were $36^{\circ}-37^{\circ}$. While, therefore, fruit temperatures as ordinarily taken may indicate that pears precooled for 24 hours under very favorable conditions were below $40^{\circ}$, the center of the boxes in the middle of stacks of large blocks of fruit would probably be nearer $50^{\circ}$. (See succeeding tests.)

\section{PEAR PRECOOLING TEST 12}

University Farm cold storage, June 27-28, 1934.

Purpose of Test.-To secure the cooling rate of pears near the edges and in the center of packed boxes when precooled in air temperatures of $25^{\circ}$ and of $35^{\circ} \mathrm{F}$.

Conditions of Precooling.-Boxes of fruit were placed under temperatures of $25^{\circ}$ and of $35^{\circ} \mathrm{F}$ and in a direct air current of $200-250$ feet a minute.

Temperatures Secured from Precooling.-The general rate of pre.. 
cooling as influenced by position of the fruit in the box and the air temperature is illustrated in figure 43. After 16 hours of cooling the fruit at the edges of the box cooled in $25^{\circ}$ air had been reduced to $32^{\circ}$ $\mathrm{F}$; that in the $35^{\circ}$ air to $39^{\circ}$. After this period of cooling, however, the temperature of the center of the boxes was $10^{\circ}$ higher than the edge in the boxes cooled in $25^{\circ}$ air and $15^{\circ}$ higher than edges in the boxes cooled in $35^{\circ}$ air. Only 26 hours were necessary to cool the center of the box to $32^{\circ}$ in the colder air, while approximately 52 hours or twice this period was necessary to secure a center temperature of $36^{\circ} \mathrm{F}$. Fruit cooled in $25^{\circ}-28^{\circ}$ air had been uniformly cooled to below $30^{\circ}$ after 36

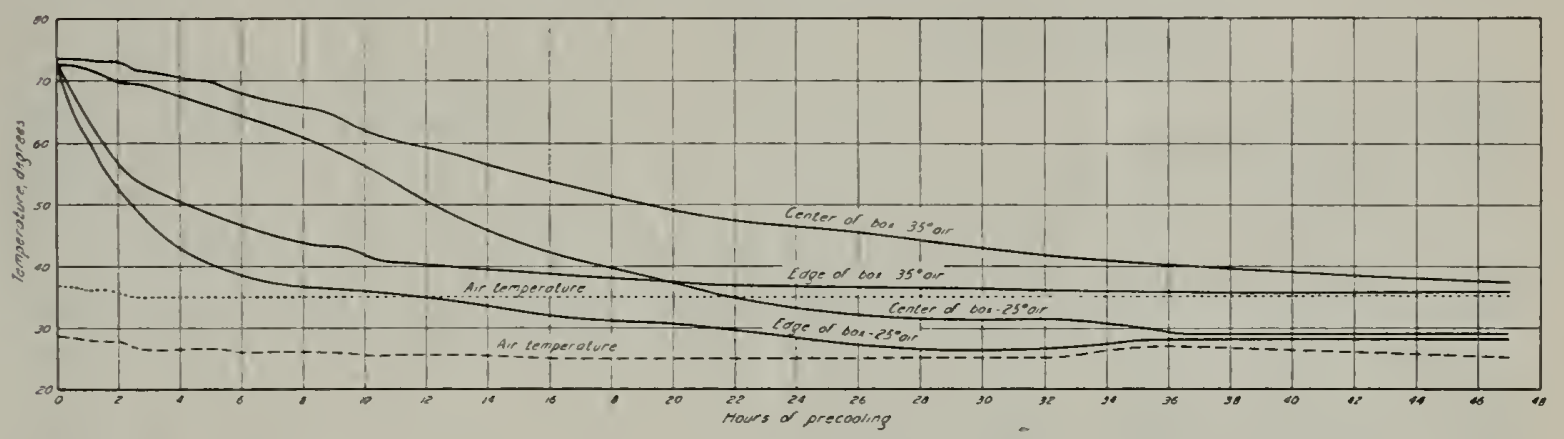

Fig. 43.-Precooling of pears in University Farm cold storage, June 27-28, 1934: a verage cooling rate in the center and near the edges of boxes cooled in $25^{\circ}$ and in $35^{\circ}$ air moving at 200-250 feet a minute.

hours. Data on cooling in $32^{\circ}$ air secured in an earlier test, is shown in table 16 for comparison. The advantage of the $25^{\circ}$ air is obvious.

TABLE 16

Rate of Heat Loss from the Center and Outer Pears in a Packed Box Precooled in $32^{\circ}$ Atr Moving at 200-250 Feet a Minute

\begin{tabular}{|c|c|c|c|c|c|c|}
\hline \multirow{2}{*}{ Temperature position } & \multirow{2}{*}{$\begin{array}{l}\text { Original } \\
\text { temper- } \\
\text { ature } \\
\text { of fruit }\end{array}$} & \multicolumn{5}{|c|}{ Temperature readings after } \\
\hline & & 18 hours & 21 hours & 37 hours & 46 hours & 64 hours \\
\hline Outside pear & $\begin{array}{c}\text { degrees } F \\
70\end{array}$ & $\begin{array}{c}\text { degrees } F \\
37\end{array}$ & $\begin{array}{c}\text { degrees } F \\
36\end{array}$ & $\begin{array}{c}\text { degrees } F \\
33\end{array}$ & $\begin{array}{c}\text { degrees } F \\
33\end{array}$ & $\begin{array}{c}\text { degrees } F \\
33\end{array}$ \\
\hline Second pear from edge of box... & 72 & 42 & 40 & 35 & 35 & 33 \\
\hline 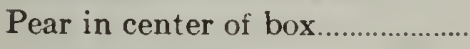 & 78 & 53 & 49 & 38 & 36 & 33 \\
\hline
\end{tabular}

\section{PEAR PRECOOLING AND FREEZING TESTS}

University Farm cold storage, July 8-30, 1934.

Purpose of Tests.-To determine the period of time packed Bartlett and Hardy pears may be precooled in rapidly moving air with a temperature of $25^{\circ} \mathrm{F}$ without showing freezing injury.

Conditions of Tests.-The conditions of the test were the same or similar to those of the freezing tests with plums and peaches, with the fruit cooled in $25^{\circ} \mathrm{F}$ air. Fruit temperatures were taken and ob- 
servations made of the fruit in each of three boxes cooled simultaneously. After the fruit had cooled to the average freezing point for Bartlett pears $\left(28.5^{\circ}\right)$, as given by Wright and Taylor, ${ }^{31}$ the lids of the boxes were pried open at various intervals and the pears examined for freezing.

Results.-The general rate of cooling in this test, as is shown in table 17, was slightly less rapid in the center of the boxes than in test 12 .

TABLE 17

Precooling and Freezing of Bartlett Pears in 25 Air; University Farm Cold Storage, July 8-15, 1934

\begin{tabular}{|c|c|c|c|c|c|}
\hline \multirow{3}{*}{$\begin{array}{l}\text { Period } \\
\text { of pre- } \\
\text { cooling }\end{array}$} & \multicolumn{4}{|c|}{ Fruit temperatures } & \multirow{3}{*}{ Observations on freezing } \\
\hline & \multicolumn{2}{|c|}{ Center of boxes } & \multicolumn{2}{|c|}{ Edge of boxes } & \\
\hline & Max. & Min. & Max. & Min. & \\
\hline hours & degrees $F$ & degrees $F$ & degrees $F$ & degrees $F$ & \\
\hline 0 & 75 & 74 & 75 & 75 & \\
\hline 6 & 70 & 69 & 49 & 42 & .......................... \\
\hline 12 & 61 & 59 & 41 & 34 & \\
\hline 18 & 53 & 50 & 36 & 31 & \\
\hline 24 & 45 & 43 & 33 & 29 & \\
\hline 36 & 36 & 32 & 30 & 27 & No signs of freezing injury \\
\hline 48 & 30 & 27 & 28 & 27 & $\begin{array}{l}40 \text { per cent of the exposed fruit with a temperature } \\
\text { of } 27^{\circ} \text { for } 17 \text { hours showed spotting and some } \\
\text { slight freezing of the flesh }\end{array}$ \\
\hline 72 & 27 & 27 & 27 & 27 & $\begin{array}{l}40 \text { to } 50 \text { per cent of all fruit showed spotting and } \\
\text { slight freezing of the flesh }\end{array}$ \\
\hline 120 & 27 & 26 & 26 & 26 & Most fruits $1 / 2$ to completely frozen \\
\hline 144 & 27 & 26 & 26 & 25 & Several fruits still uninjured \\
\hline 168 & 25 & 25 & 25 & 25 & $\begin{array}{l}\text { All fruits frozen solid. (Previous removal of sam- } \\
\text { ples had nearly emptied the boxes of fruit.) }\end{array}$ \\
\hline
\end{tabular}

Center temperatures after 36 hours were $32^{\circ}-36^{\circ}$, or $5^{\circ}-6^{\circ}$ higher than that of the exposed fruits. Although a $27^{\circ}$ temperature was recorded in one box, no freezing was noticeable at this time. After 48 hours, however, when the fruit in the center of one of the boxes had been reduced to $27^{\circ}$ and this temperature had existed in the exposed part of the box for some 17 hours, slight freezing was observed. After 72 hours, with uniform temperatures of $27^{\circ}$ throughout the boxes, approximately half of the pears showed some spotting on the surface and a slight freezing of the flesh. After 120 hours, or 5 days, most fruits were either partially or completely frozen, but not until after 7 days were all fruits frozen solid.

From this trial it was evident that packed boxes of Bartlett pears having a temperature of $75^{\circ}$ could be precooled in $25^{\circ}$ air rapidly cir-

31 Wright, R. C., and Geo. F. Taylor. The freezing temperatures of some fruits, vegetables, and cut flowers. U. S. Dept. Agr. Dept. Bul. 1133:1-8. 1929 
culating about the boxes for 48 hours before any injury occurred. To check these results, however, a second test was carried out under the same conditions.

Both Bartlett and Hardy pears were used in this second test and the rate of cooling, time, and amount of freezing were practically identical. The results from the two varieties were therefore combined and are briefly summarized in table 18. After 24 hours the individual fruits at

\section{TABLE 18}

Pear Precooling and Freezing of Bartlett and Hardy Pears in $25^{\circ}$ Air; University Farac Cold Storage, July 22-30, 1934

\begin{tabular}{|c|c|c|c|c|c|}
\hline \multirow{3}{*}{$\begin{array}{l}\text { Period } \\
\text { of pre- } \\
\text { cooling }\end{array}$} & \multicolumn{4}{|c|}{ Fruit temperatures } & \multirow{3}{*}{ Observations on freezing } \\
\hline & \multicolumn{2}{|c|}{ Center of boxes } & \multicolumn{2}{|c|}{ Edge of boxes } & \\
\hline & Max. & Min. & Max. & Min. & \\
\hline $\begin{array}{c}\text { hours } \\
0\end{array}$ & $\begin{array}{l}\text { degrees } F \\
\quad 73\end{array}$ & $\begin{array}{c}\text { degrees } F \\
67\end{array}$ & $\begin{array}{l}\text { degrees } F \\
\quad 72\end{array}$ & $\begin{array}{l}\text { degrees } F \\
\quad 67\end{array}$ & …................ \\
\hline 24 & 40 & 35 & 27 & $26^{*}$ & $\begin{array}{l}\text { Two pears at the edge of the box (exclusive of } \\
\text { those in which temperatures were recorded) } \\
\text { beginning to show signs of freezing }\end{array}$ \\
\hline 30 & 35 & 32 & 28 & $27 \dagger$ & $\ldots \ldots \ldots \ldots \ldots \ldots$ \\
\hline 48 & 28 & 27 & 29 & $28 \dagger$ & $\begin{array}{l}\text { Considerable spotting and some freezing of the } \\
\text { flesh in exposed pears }\end{array}$ \\
\hline 72 & 27 & 27 & 28 & 27 & $\begin{array}{l}\text { No injury to nearly solid freezing; most fruit } \\
\text { showing some injury }\end{array}$ \\
\hline 120 & 27 & 27 & 27 & 26 & Some fruits frozen solid, others uninjured \\
\hline 192 & 26 & 26 & 26 & 25 & All fruits frozen solid \\
\hline
\end{tabular}

* After approximately 24 hours of cooling, the individual pear in which the metal bulb of the recording instrument was placed supercooled to $25.5^{\circ}$ and was slightly frozen.

$\dagger$ Slight increase in temperature, probably due to ice formation.

the edge of the boxes in which metal thermograph points were inserted had supercooled to $25.5^{\circ} \mathrm{F}$ and had subsequently frozen. One or two other adjacent fruits showed a very slight spotting. In general, however, freezing was again not noticeable until after 48 hours, when the temperature in the center of the boxes had dropped to $27^{\circ}-28^{\circ}$. After this period, freezing was very similar to that in the first trial. Some fruits remained uninjured after 5 days. In connection with both of these trials, individual fruits were exposed to the same conditions as the packed boxes. These were frozen in approximately half the time required for packed fruit.

Damage to Pears from Freezing.-At various time intervals after the beginning of freezing in these tests, small samples of fruit were removed from the boxes and placed in $32^{\circ}$ air and also in $50^{\circ}$ air in order to determine the extent of the injury after thawing. Regardless of the rate of thawing (whether in air at $32^{\circ} \mathrm{F}$ or at $50^{\circ}$ ) all Bartlett pears re- 
moved from the boxes during the first 7 days thawed without any indication of freezing and ripened with good flavor in a perfectly normal manner. Fruit which had been exposed to $25^{\circ}$ for 103 hours was perfectly normal after 48 hours at temperatures above freezing; that held for 120 hours or 5 days at $25^{\circ}$ required 60 hours to appear normal again.

Fruit thawed after 8 days' exposure to $25^{\circ}$ air showed some slight injury or browning of the vascular system. This condition remained after ripening. After 10 days under subfreezing temperature the flesh showed some browning around the core and was otherwise of a woody texture after ripening. The external appearance of the fruit was entirely normal. Only after freezing for 14 days was it evident from external appearance after thawing that the fruit had been frozen.

Hardy pears withstood freezing in much the same manner. After 8 days all fruit was still of normal appearance when thawed. About 10 per cent of the fruit held in $25^{\circ}$ air longer than 72 hours, however, ripened with a slightly woody texture of the flesh. When held for 10 days and for 2 weeks under $25^{\circ}$ air, 50 per cent of the pears showed some discoloration of the flesh around the core upon thawing and a slight browuing of the vascular system in 25 per cent of the fruits after ripening. Other fruits ripened without any apparent injury and with normal quality.

From these tests and observations made on packed boxes of commercial shipments of Bartlett pears from the Sacramento River and Placerville districts and from Hardy pears from the latter district, pears evidently have an ability to overcome freezing injury not possessed by apricots, plums, or peaches. The fact that they do recover their normal condition after considerable freezing also materially reduces the risk of damage when precooling with, or when stored in air below $30^{\circ} \mathrm{F}$.

\section{HOLDING TESTS OF PRECOOLED AND NONPRECOOLED PEARS}

As a part of test 6 , three boxes of fruit were removed from P.F.E. 35403 after 30 hours of precooling, wrapped in heavy paper without removing the resistance thermometer points, transported to Davis where they were held for 10 days under transit temperatures.

After being held for this period, the fruit was observed for color and tested for firmness. The results are shown in table 19.

These boxes are believed to represent rather accurately the results obtained when pears are precooled to the temperatures given or when, with good maturity, nonprecooled fruit is carried in the upper part of a load moving under standard refrigeration. (When shipped, this fruit was light green in color and tested 16.5 pounds' pressure.) 
Besides these boxes, cooled as an integral part of an actual commercial shipment, other boxes of Bartlett and Hardy pears from commercial packing-houses in Newcastle, Suisun, and the Santa Clara Valley were precooled, held for 10 days, and observed in a similar manner

TABLE 19

Condition of Precooled and Nonprecooled Bartlett Pears After 10 Days Under Transit Temperatures

\begin{tabular}{|c|c|c|c|c|c|c|c|}
\hline Box & $\begin{array}{c}\text { Precooled } \\
\text { to }\end{array}$ & $\begin{array}{l}\text { Held } \\
\text { at }\end{array}$ & Color & Firmness & $\begin{array}{c}\text { Time } \\
\text { to } \\
\text { ripen }\end{array}$ & $\begin{array}{c}\text { Time } \\
\text { market- } \\
\text { able after } \\
\text { ripening }\end{array}$ & Remarks \\
\hline$A$ & $\begin{array}{l}\text { degrees } F \\
32-35^{*}\end{array}$ & $\begin{array}{r}\text { degrees } F \\
33-45 \dagger\end{array}$ & Light green & $\begin{array}{c}\text { pounds pressure } \\
15.0 \text { (hard) }\end{array}$ & $\begin{array}{c}\text { days } \\
5\end{array}$ & $\begin{array}{c}\text { days } \\
6\end{array}$ & \\
\hline B & $35-44$ & $40-53$ & Yellowish green & $15.0($ hard $)$ & 4 & 5 & $\begin{array}{l}\text { Although of the same } \\
\text { firmness as box A, } \\
\text { the fruit had notice- } \\
\text { ably more color }\end{array}$ \\
\hline $\mathrm{C}$ & $40-52$ & $45-53$ & Greenish yellow & 7.0 (firm) & 2 & 5 & $\begin{array}{l}\text { Fruit showed consid- } \\
\text { erable yellow color } \\
\text { and probably repre- } \\
\text { sented the appear- } \\
\text { ance of the riper } \\
\text { pears in the car upon } \\
\text { arrival }\end{array}$ \\
\hline D & $\begin{array}{c}\text { Non- } \\
\text { precooled }\end{array}$ & $65-53$ & Full yellow & 4.0 (firm-ripe) & 1 & 5 & $\begin{array}{l}\text { Fruit was in good con- } \\
\text { dition, but partially } \\
\text { ripe }\end{array}$ \\
\hline
\end{tabular}

* The temperatures of the second pear from the edge of the box when removed from the car and when received at Davis.

$\dagger$ Precooled fruit held under a rising temperature and nonprecooled (box D) under a decreasing temperature.

(table 20). Bartlett pears precooled to $34^{\circ} \mathrm{F}$ required, on the average, 5 days to ripen; those precooled to $40^{\circ}, 3$ days; and nonprecooled pears, 0.6 of a day. Precooled Hardy pears, though ripening more slowly, showed similar differences between precooled and nonprecooled fruit.

\section{SUMMARY OF PEAR PRECOOLING AND HOLDING TESTS}

When precooling in cars, with an air temperature of $32^{\circ} \mathrm{F}$ or below, pears in the outer portion of the boxes cool during the first 8-10 hours at an average rate of about $2.0^{\circ}-3.0^{\circ} \mathrm{F}$ an hour, subsequently this cool. ing rate declines to $2.0^{\circ}-1.0^{\circ}$ an hour. Some 16-20 hours, therefore, are usually necessary to reduce the fruit near the outer part of the package from $75^{\circ}$ to $40^{\circ}$ and $24-30$ hours to reduce it to $35^{\circ}$.

Fruit in the center of the boxes after 20-24 hours of cooling will vary from $45^{\circ}$ to $60^{\circ} \mathrm{F}$, according to its position in the load and the air temperature in contact with the boxes. Center temperatures of boxes in the center of the load may be reduced as little as $10^{\circ}$ in 20 hours (fig. 
TABLE 20

Comparative Condition and Period of Marketability of Precooled and Nonprecooled Pears AFTer Holding for 10 Days UNDER TRANSIT TeMPERATURES

\begin{tabular}{|c|c|c|c|c|c|c|c|c|}
\hline \multirow{2}{*}{ Place } & \multicolumn{2}{|c|}{ When harvested } & \multicolumn{2}{|c|}{ Temperature, } & \multicolumn{2}{|c|}{$\begin{array}{l}\text { After } 10 \text { days under } \\
\text { transit temperatures }\end{array}$} & \multirow{2}{*}{$\begin{array}{c}\text { Time } \\
\text { to } \\
\text { ripen }\end{array}$} & \multirow{2}{*}{$\begin{array}{l}\text { Time } \\
\text { market- } \\
\text { able } \\
\text { after } \\
\text { ripening }\end{array}$} \\
\hline & $\begin{array}{l}\text { Color } \\
\text { index }\end{array}$ & $\begin{array}{c}\text { Firm- } \\
\text { ness }\end{array}$ & $\begin{array}{l}\text { Pre- } \\
\text { cooled } \\
\text { to }\end{array}$ & $\underset{\text { at }}{\text { Held }}$ & $\begin{array}{l}\text { Color } \\
\text { index }\end{array}$ & General condition & & \\
\hline \multicolumn{9}{|c|}{ Bartlett } \\
\hline \multirow{4}{*}{ Santa Clara } & & pounds & degrees $F$ & degrees $F$ & & & days & days \\
\hline & & & $\int 34$ & $36-45$ & $21 / 2$ & Hard....... & 5 & 3 \\
\hline & $2-2 \frac{1}{2}$ & 18.2 & 40 & $40-50$ & $21 / 2$ & Firm..... & 3 & 5 \\
\hline & & & $\ldots \dagger$ & $60-53$ & $31 / 2-4$ & Ripe... & 0 & 3 \\
\hline \multirow{3}{*}{ San Jose......... } & & & 34 & $36-45$ & 2 & Hard & 6 & 2 \\
\hline & .2 & 15.0 & 40 & $40-50$ & $21 / 2$ & Firm to slightly spongy & 2 & 4 \\
\hline & & & $\ldots . t$ & $60-53$ & 2 & $\begin{array}{l}\text { Slightly spongy, nearly } \\
\text { ripe }\end{array}$ & 1 & 2 \\
\hline \multirow{2}{*}{ Alviso.............. } & $2+$ & 164 & 34 & $36-45$ & $21 / 2$ & Hard & 5 & 2 \\
\hline & $2+$ & 10.4 & $\ldots+. \dagger$ & $\begin{array}{l}40-50 \\
60-53\end{array}$ & $31 / 2-4$ & $\begin{array}{l}\text { Fim } \\
\text { Ripe. }\end{array}$ & $\begin{array}{l}3 \\
0\end{array}$ & $\begin{array}{l}2 \\
3\end{array}$ \\
\hline \multirow{3}{*}{ Suisun } & & & 34 & $36-45$ & $21 / 2$ & Hard to firm.... & 4 & 4 \\
\hline & $2+$ & 18.1 & 40 & $40-50$ & $21 / 2$ & Hard to firm.. & 3 & 4 \\
\hline & & & $\ldots \dagger$ & $60-53$ & 4 & Ripe.................... & 0 & 7 \\
\hline \multirow{3}{*}{ Newcastle.. } & & & 34 & $36-45$ & $21 / 2$ & Hard .. & 6 & 5 \\
\hline & 2 & 19.5 & 40 & $40-50$ & $21 / 2$ & Hard ... & 4 & 6 \\
\hline & & & $\ldots . \dagger$ & $60-53$ & $31 / 2$ & Firm & 2 & 7 \\
\hline \multirow{4}{*}{ Placerville } & & & 34 & $36-45$ & $2 \frac{1}{2}-3$ & Hard.... & 5 & 6 \\
\hline & $2+$ & 16.4 & 40 & $40-50$ & $2-3$ & Hard...... & 4 & 5 \\
\hline & & & 45 & $45-53$ & $31 / 2-4$ & Firm .................. & 2 & 5 \\
\hline & & & $\ldots . \dagger$ & $60-53$ & 6 & Firm ripe................ & 1 & 5 \\
\hline \multicolumn{9}{|c|}{ Hardy } \\
\hline \multirow{3}{*}{ Santa Clara } & & & 34 & $36-45$ & $2-3$ & Firm $\ldots \ldots$ & 10 & 7 \\
\hline & $2-3$ & 9.0 & 40 & $40-50$ & 3 & Firm & 8 & 7 \\
\hline & & & $\ldots . \dagger$ & $60-53$ & $21 / 2-3$ & Moderately firm..... & 6 & 6 \\
\hline \multirow{3}{*}{ Milpitas........ } & & & 34 & $36-45$ & $2-3$ & Firm & 11 & 7 \\
\hline & 2 & 10.3 & 40 & $40-45$ & 2 & Firm & 11 & 4 \\
\hline & & & $\ldots . \dagger$ & $60-53$ & $21 / 2-3$ & Slightly spongy........ & 8 & 5 \\
\hline \multirow{3}{*}{ Alviso............... } & & & 34 & $36-45$ & $1-2$ & Firm..... & 15 & 3 \\
\hline & $1 \frac{1}{2}-2$ & 9.0 & 40 & $40-45$ & 2 & Firm & 12 & 5 \\
\hline & & & $\ldots . \dagger$ & $60-53$ & 2 & 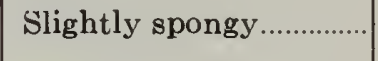 & 9 & 6 \\
\hline \multirow{3}{*}{ Alviso................. } & & & 34 & $36-45$ & 2 & Firm & 11 & 5 \\
\hline & $1 \frac{1}{2}-2$ & ......... & 40 & $40-50$ & 2 & Firm & 11 & 6 \\
\hline & & & $\ldots . \dagger$ & $60-53$ & $2-21 / 2$ & Firm to slightly spongy & 9 & 6 \\
\hline \multirow{3}{*}{ Davis.. } & \multirow{3}{*}{$2-2 \frac{1}{2}$} & \multirow{3}{*}{12.5} & 34 & $36-45$ & $2-31 / 2$ & Firm to slightly spongy & 9 & 4 \\
\hline & & & 40 & $40-50$ & $2-21 / 2$ & Slightly spongy ............... & 9 & 2 \\
\hline & & & $\ldots . \dagger$ & $60-53$ & $2-21 / 2$ & Slightly spongy................ & 7 & 5 \\
\hline
\end{tabular}

* No. 1, dark green No. 2, light green
No. 3, yellowish green No. 4, greenish yellow
No. 5 , light yellow No. 6, full yellow $\uparrow$ Nonprecooled. 
37, p. 95). Most tests, however, have shown that the temperature in such position will drop approximately $1^{\circ}$ an hour. Fruit having an initial temperature of $70^{\circ}-75^{\circ}$ will be close to $50^{\circ}$ after 24 hours. No very consistent difference in cooling rate existed between the tiers of fruit near the bunker and those near the center of the car.

Under high air temperatures pears near the edge of the box may approximate the temperature of the surrounding air after 16-20 hours and thus be prevented from further cooling. Cooling in the center of the boxes continues, but at a less rapid rate, until temperatures are uniform throughout the box.

Temperatures in the second pear from the edge of the box in standard and in heavily loaded cars show no differences in cooling rate. $\mathrm{Ob}$ viously, however, other factors being equal, the heavier load must cool somewhat more slowly.

Pears in the outer part of top boxes held in a nonprecooled car for 22 hours cooled only $10^{\circ} \mathrm{F}$, as compared with $30^{\circ}$ for the corresponding box in a precooled car.

Unwrapped pears, loose in lug boxes but tightly loaded in refrigerator cars, cooled in the center of the box at an average of $3^{\circ} \mathrm{F}$ an hour for the first 8-10 hours and at nearly $2^{\circ}$ an hour for the next 10 hours. This is two to three times the usual rate for precooling packed pears.

In precooling of individual boxes of pears in rapidly circulating air having a temperature of $25^{\circ} \mathrm{F}$, fruit temperatures in the center of boxes were reduced from $72^{\circ}$ to $40^{\circ}$ in 18 hours. When exposed to $32^{\circ}$ air in commercial storage rooms, center temperatures were $40^{\circ}-45^{\circ}$ after 24 hours. The time required to precool pears may thus be reduced from 25 to 40 per cent by the use of $25^{\circ}$ air circulating past the boxes at a rate not less than 250 feet a minute.

Packed Bartlett and Hardy pears with an initial temperature of $70^{\circ} \mathrm{F}$ or above may be precooled in $25^{\circ}$ air for $24-48$ hours without danger of freezing the more exposed fruits. In addition, should some freezing occur by a longer exposure to $25^{\circ}$ air, the above varieties are apparently able to fully recover their normal condition after thawing. After 48 hours in $25^{\circ}$ air fruit temperatures throughout the boxes were practically uniform.

Air temperatures at the top of the load of precooled cars while in transit fluctuated slightly above and below $50^{\circ} \mathrm{F}$. The temperatures in precooled cars shipped under modified icing were lower during the first half of the transit period to New York than those existing in nonprecooled cars moving under standard refrigeration. Upon arrival in New 
York after 10 days, the ice bunkers in the former were only about onefourth full and the temperature was some $5^{\circ}$ higher.

Bartlett pears from Placerville, precooled for 24 hours, with fruit temperatures in the outer part of the box reduced to $40^{\circ} \mathrm{F}\left(50^{\circ}-55^{\circ}\right.$ in the center), arrived in New York under one re-icing, and in several instances without re-icing, in satisfactory condition.

Bartlett pears in the center of 3 boxes precooled to $32^{\circ}, 35^{\circ}$, and $40^{\circ} \mathrm{F}$ required 5, 4, and 2 days respectively to ripen after being held for a 10-day transit period. Nonprecooled pears were eating-ripe after 1 day. Notable differences in the color of precooled and nonprecooled pears were also observed by the receivers on the New York market.

Hardy pears precooled to $34^{\circ} \mathrm{F}$ required 10-15 days to ripen; those precooled to $40^{\circ}, 8-12$ days; and nonprecooled pears, $6-9$ days.

\section{TESTS WITH APPLES}

Except for export, apples are rarely precooled. Tests were therefore confined to the rate of cooling in cold-storage rooms under different methods of packing, and with different temperatures and velocities of air.

\section{TEST 1}

In the first test, comparable lots of wrapped and unwrapped Yellow Newtown apples were cooled in three rooms where the temperature fluctuated only slightly from $32^{\circ}, 36^{\circ}$, and $46^{\circ} \mathrm{F}$ respectively. The initial temperature of each lot was only $62^{\circ}$. As figure 44 shows, to cool to $40^{\circ}$

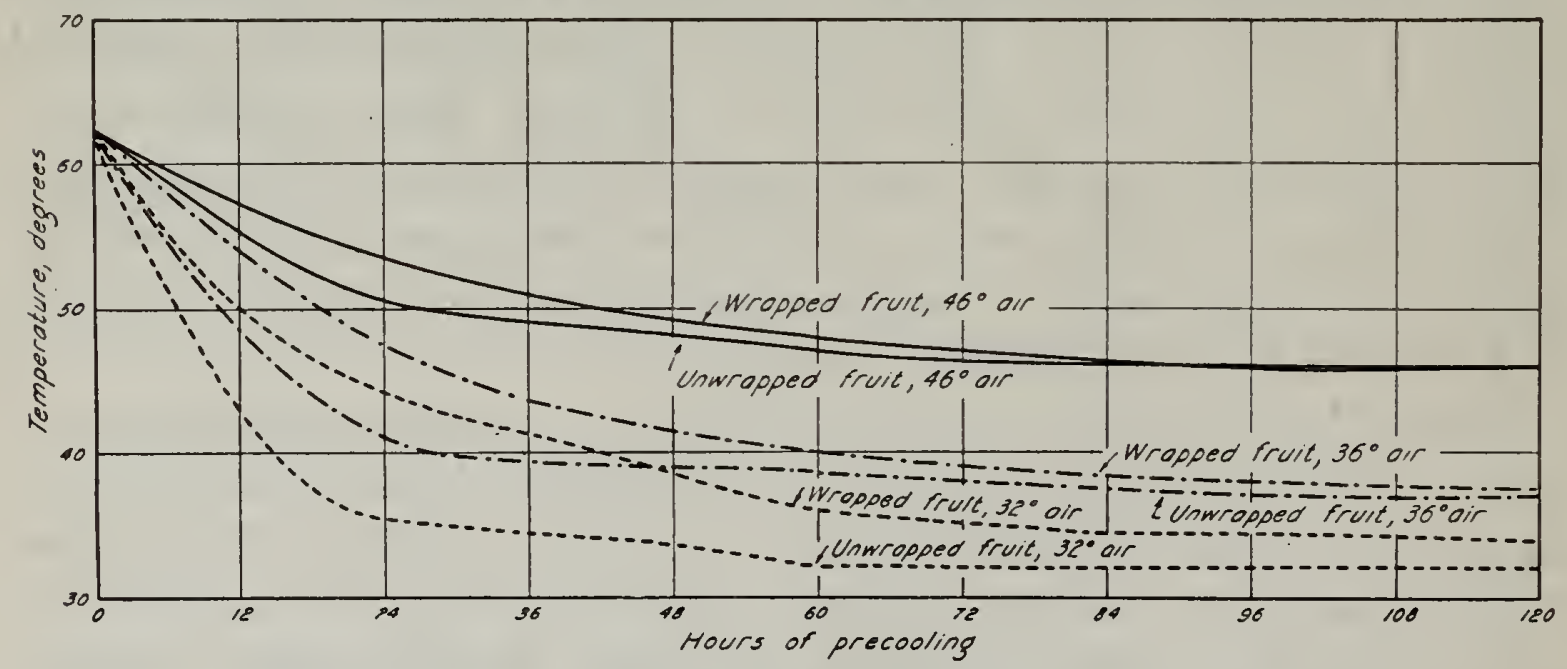

Fig. 44.-Precooling of wrapped and unwrapped Yellow Newtown apples, in air at $32^{\circ}, 36^{\circ}$, and $46^{\circ}$, University Farm cold storage. The chart represents core temperatures of fruit in the center of packages cooled with air moving at intervals.

the centers of the boxes of wrapped fruit required 60 hours in $36^{\circ}$ air and 42 hours in $32^{\circ}$ air. Approximately 84 hours were required in $32^{\circ}$ air to cool the centers of the boxes to $34^{\circ}$. This represents the approximate cooling rate in large storage rooms where considerable fruit is stacked together and cooled with only a slight movement of air. 
The maximum differences in the cooling rate of wrapped and unwrapped fruit cooled in $46^{\circ} \mathrm{F}$ air showed a difference of $3.5^{\circ}$; in $36^{\circ}$ air, $7.0^{\circ}$; and in $32^{\circ}$ air, $8.5^{\circ}$. These differences gradually disappeared; but, in the boxes cooled at the lowest temperature, the wrapped fruit still remained $1^{\circ}-2^{\circ}$ warmer than the unwrapped after 120 hours.

\section{TEST 2}

The second precooling test with apples was conducted with very warm fruit but under somewhat more favorable cooling conditions. Packed boxes of Gravenstein apples having a temperature of $85^{\circ}$ were

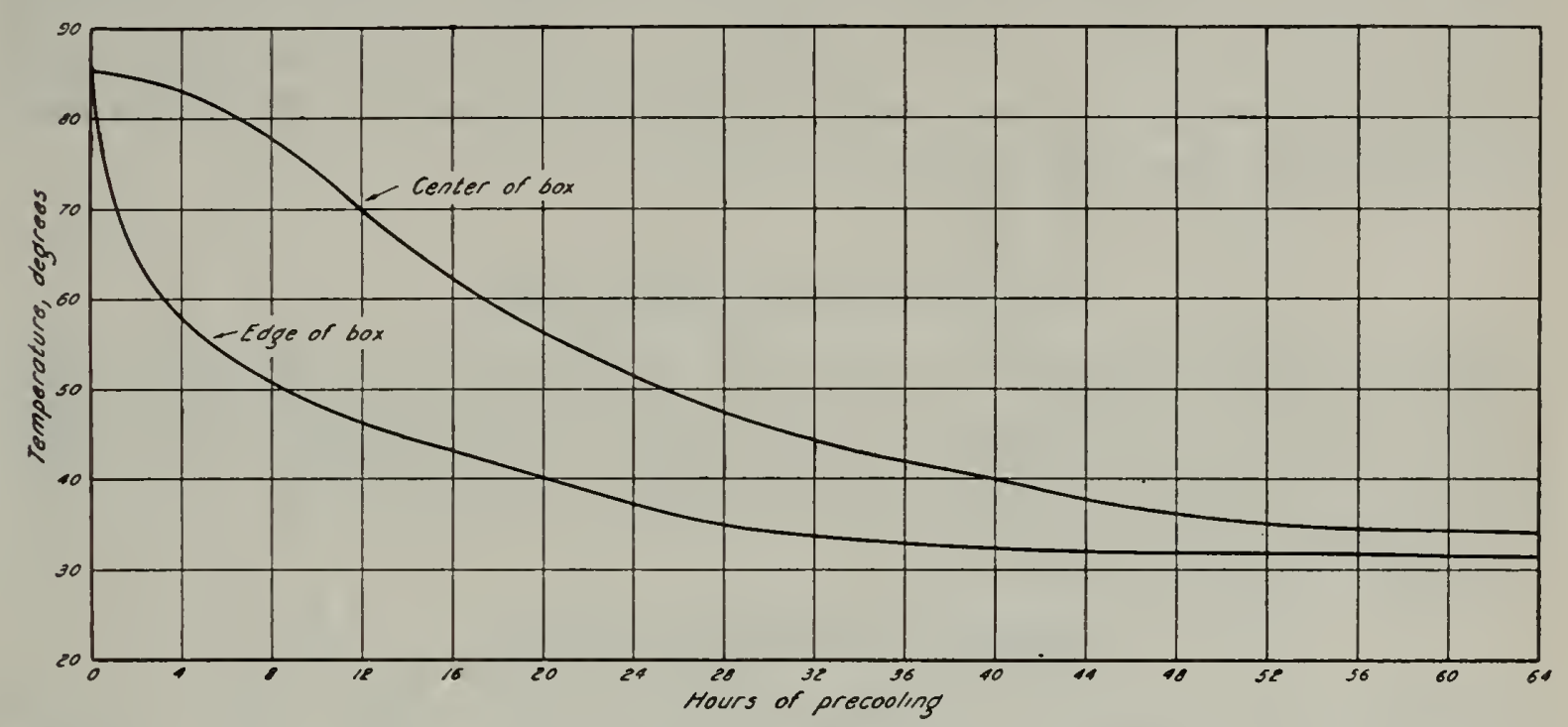

Fig. 45.-Precooling of Gravenstein apples, University Farm cold storage, July 22, 1933: comparative rate of cooling fruit in the center and near the edge of a box cooled in $32^{\circ}$ air moving at approximately 75 feet a minute.

cooled in $32^{\circ} \mathrm{F}$ air moving continuously at about 75 feet a minute. The center of this box, which was placed in a stack, showed little cooling for the first 6 hours, but after that time cooled more rapidly and reached $40^{\circ}$ in 40 hours, and $34^{\circ}$ after 56 hours. Cooling to $34^{\circ}$ was thus accomplished in two-thirds the time required under the same air temperatures in the previous test, in spite of the much higher initial temperature of the fruit in test 2 . Figure 45 illustrates this cooling rate and the much more rapid cooling of the outer fruit, caused by the large temperature difference between the apples and the air in contact with them. In this instance the maximum difference in different parts of the box occurred after $6-8$ hours, when it was as much as $27^{\circ}$. At the end of 20 hours, when the fruit near the edge of the box showed a temperature of $40^{\circ}$, the center fruit had cooled only to $56^{\circ}$.

\section{TEST 3}

In a third test, where the air temperature remained at $32^{\circ} \mathrm{F}$ and the velocity of the air was increased to 250 feet a minute, the center 
fruit reached $40^{\circ}$ in 24 hours and $33^{\circ}$ in 48 hours. By reducing the air temperature to $28^{\circ}-26^{\circ}$ after 12 hours, fruit in the center of the boxes cooled to $33^{\circ}$ in 36 hours.

\section{SUMMARY OF APPLE TESTS}

The time necessary to cool apples to $33^{\circ}-34^{\circ} \mathrm{F}$ in $32^{\circ}$ air was therefore, according to the tests, from 84 hours with little or no circulation of air to only 48 hours under an air circulation of 250 feet a minute. Further reduction in the time required for cooling the centers of the boxes to $34^{\circ}$ may be secured by the use of $25^{\circ}$ air. Air of this temperature circulated rapidly should result in at least a 40 per cent saving of the time over that usually considered necessary. Apples which were packed but unwrapped and cooled in $32^{\circ}$ air reached $35^{\circ}$ in 20 per cent less time than wrapped apples.

\section{TESTS WITH GRAPES}

Cooling records with grapes were taken in three cars, two of which were cooled with the bunker type of fans and the third with portable fans placed in the center of the load at the brace, blowing the air back to the top openings of the bunkers.

\section{GRAPE PRECOOLING TEST 1}

Refrigerator car P.F.E. 15660, Peltier, September 7, 1932. Loaded with 21 tiers of standard lugs placed 6 lugs wide and 7 high.

Purpose of Test.-To ascertain (1) the cooling rate of grapes, (2) the air temperature at the top of the load in transit, and (3) the general condition upon arrival.

Conditions of Loading and Precooling.-Practically an entire day was required for loading. At 5:00 p.m., when precooling began, the fruit in the bottom of the load near the ends of the car had cooled to $50^{\circ}$ $\mathrm{F}$, while that recently loaded near the doorway varied from $80^{\circ}$ to $90^{\circ}$. Re-icing and heavy salting, an hour before precooling, reduced these latter temperatures fairly rapidly. No additional ice was supplied during the 9 hours of cooling.

Temperatures Secured from Precooling.- The results, as recorded 2-3 inches from the edge of the lugs in the top and bottom of tiers 5, 4, and 11, appear in figure 46. Fruit in the center of the lug boxes in the top of the load cooled from $74^{\circ}$ to $38^{\circ} \mathrm{F}$ (a total of $36^{\circ}$ ) in 9 hours. Fruit in the bottom of the load, $10^{\circ}-12^{\circ}$ colder at the outset than that in the top, cooled only to $43^{\circ}$. Although air temperatures in the car remained rather high for the first 2 hours, they continued to decline throughout the precooling period and the general cooling rate was very uniform. 
Shipping Record and Condition of Fruit on Arrival.-This car was forwarded to Indianapolis under standard refrigeration plus 2 per cent salt at the first re-icing. Air temperature in transit at the top of the load at the brace varied between $42^{\circ}$ and $48^{\circ} \mathrm{F}$ and the shipping company reports that the car arrived in excellent condition.

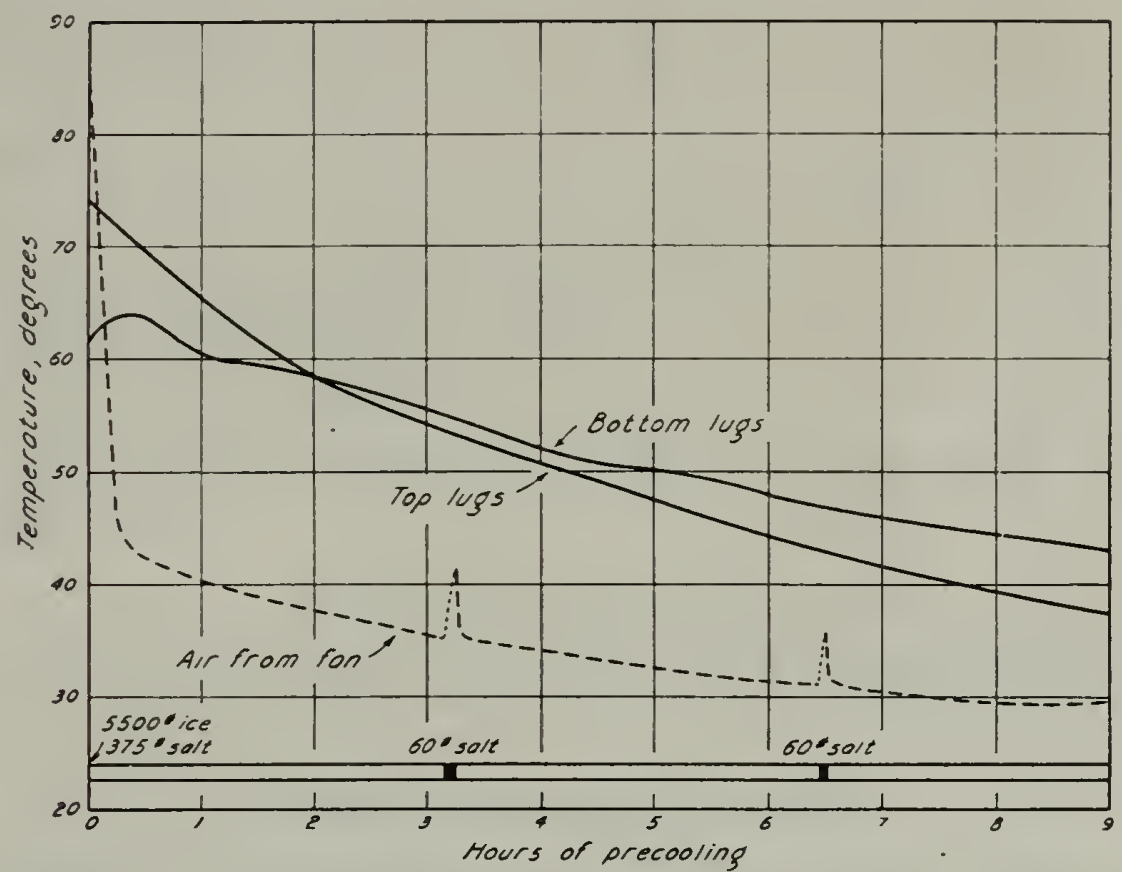

Fig. 46.-Precooling of grapes in P. F. E. 15660, Peltier, September 7, 1932: average fruit temperatures in the top and bottom lug boxes of tiers $1,2,4$, and 8 , and in top, center, and bottom lug boxes of tier 11 .

GRAPE PRECOOLING TEST 2

Refrigerator car P.F.E. 27284, St. Helena, September 28, 1932. Loaded with 1,170 22-pound lugs loaded crosswise of the car, stacks 5 wide and 9 high.

Purpose of Test.-To ascertain the extent of cooling, in 18 hours, of lug boxes loaded crosswise of the car.

Conditions of Loading and Precooling.-Although this was a high load, the fruit had been allowed to stand on the shipping platform overnight, and at time of loading the following morning had an average temperature of $60^{\circ} \mathrm{F}$. With the cars well iced at the beginning of precooling, no additional ice was placed in the bunkers during cooling.

Temperatures Secured from Precooling.-Temperatures were recorded in similar positions to those in test 1 , and after 9 hours were approximately the same. With the lugs placed, however, so that the solid ends of the boxes rather than the open sides were exposed to the air channels of the load and with a high load, the cooling rate was slightly less than in the previous test, where the initial fruit temperature was higher. Fruit in the top of the load changed from $62^{\circ}$ to $37^{\circ} \mathrm{F}$ (a total of $25^{\circ}$ ) in 10 hours. That in the center of the load cooled to $42^{\circ}$ in the 
same time. In the next 8 hours, fruit in the center boxes dropped only $11 / 2^{-31} 2^{\circ}$. During this period, however, the centers of these boxes were being cooled more than the curves in figure 47 would indicate. At the end of 18 hours the fruit throughout all the boxes was probably below $40^{\circ}$.

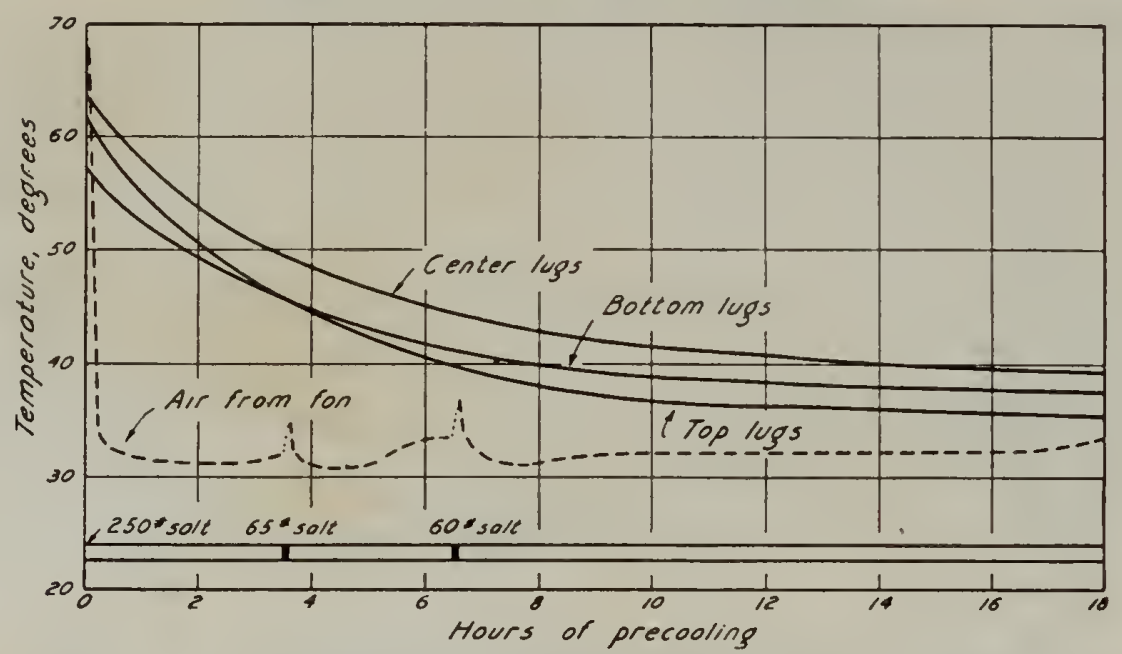

Fig. 47.-Precooling of grapes in P. F. E. 27284, St. Helena, September 28, 1932: average fruit temperatures in top, center, and bottom lug boxes in tiers 1, 8, and 13 .

\section{GRAPE PRECOOLING TEST 3}

Refrigerator car S. F. R. D. 17613, Lodi, September 13, 1933. Standard grape lugs loaded crosswise of car 7 tiers high; also 2 tiers of peaches in each end of the car.

Purpose of T'est.-To determine the rate of cooling when precooling fans were placed on top of the load at the doorway blowing the air back to the top openings of the ice bunkers.

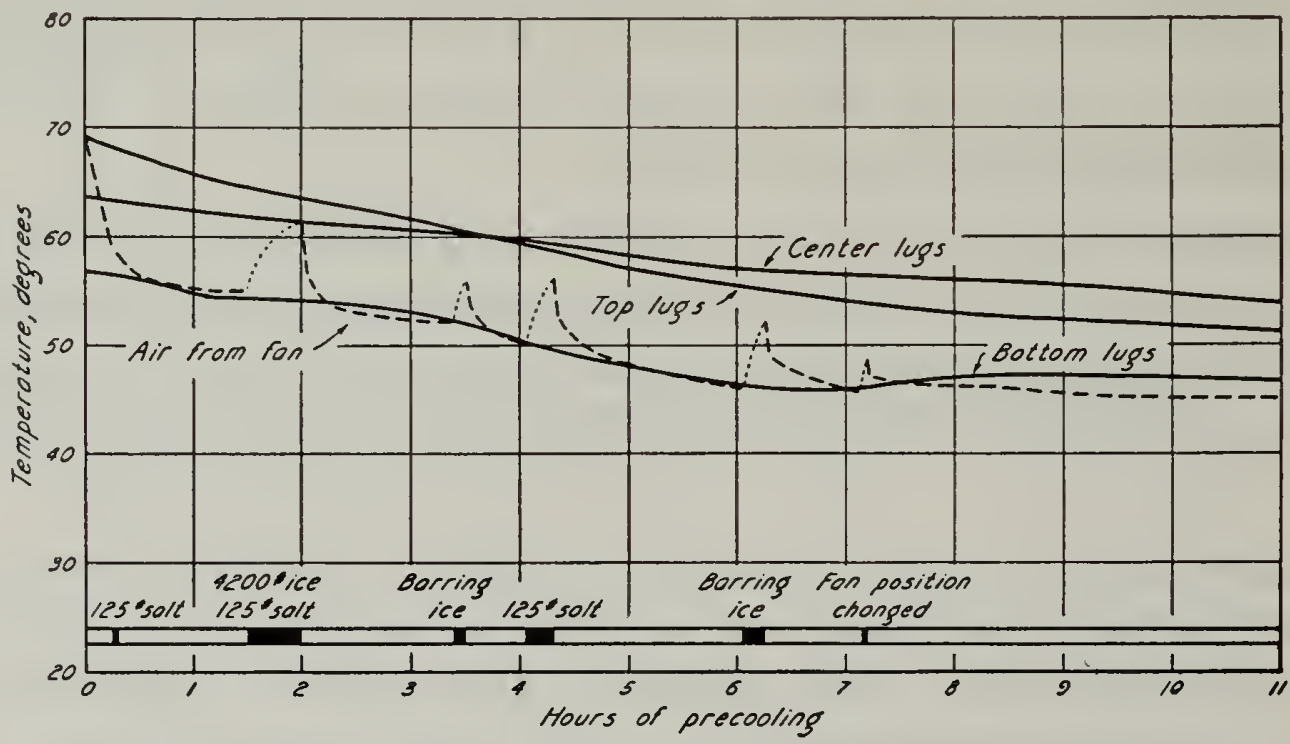

Fig. 48.-Precooling of grapes in S. F. R. D. 17613, Lodi, September 13-14, 1933: average fruit temperatures in the top, center, and bottom lug boxes in tiers 1, 5, and 13 .

Conditions of Loading and Precooling.-Loading extended over 8-10 hours, the fruit in the bottom of the load at the bunkers being allowed to 
cool considerably before precooling. Fruit in the top and center boxes averaged under $70^{\circ}$.

Temperatures Secured from Precooling.-In 11 hours the average temperature 2-3 inches from the edges of the boxes of peaches and grapes in tiers 1,5 , and 13 was reduced from $69^{\circ}$ to $51^{\circ} \mathrm{F}\left(18^{\circ}\right.$ of cooling); in the center boxes, from $64^{\circ}$ to $54^{\circ}$ ( $10^{\circ}$ of cooling); in the bottom boxes, from $57^{\circ}$ to $47^{\circ}$ (also $10^{\circ}$ ). (See fig. 48 .)

The method of cooling this car-merely speeding up the natural air circulation in the load-was of no greater success than numerous trials of former years. The cold air drawn directly from the bottom of the ice bunkers cooled the bottom of the load in a fairly successful manner but in the top and center, where maximum cooling is desired, the fruit cooled slowly because of the high temperature of the air $\left(55^{\circ}-45^{\circ} \mathrm{F}\right)$ circulated over and through it.

\section{SUMMARY OF GRAPE TESTS}

From the first two grape tests, where an air temperature approximating $32^{\circ} \mathrm{F}$ was maintained, cooling on the outer part of the lugs from $70^{\circ}$ to $40^{\circ}$ required 8-14 hours. No precooling tests were conducted with air at $25^{\circ}$, but as vinifera grapes are unlikely to freeze at this temperature, it is recommended for more rapid cooling. Precooling fans placed in the center of the car failed to reduce the air temperature at the top of the load below $45^{\circ}$ at any time.

Loading of the packages crosswise of the load so that the solid end of the lugs rather than the open sides are exposed to the air channels may retard cooling to a certain extent but this was not definitely determined.

\section{GENERAL DISCUSSION OF PRECOOLING IN WAREHOUSE ROOMS}

\section{TYPE OF ROOMS}

In most warehouses, precooling, or the rapid removal of heat from a product, is incidental or at least of secondary importance to more gradual cooling and the holding of commodities over a considerable period. For this reason the rooms in most warehouses have been designed primarily for storage and are usually of large size with ceilings as high as 14-20 feet and with insufficient refrigeration or air circulation to cool quickly any large volume of warm fruit.

In some instances cooling is by the direct expansion of ammonia in banks of coils swung from the ceiling or side walls. Such rooms have no air circulation except the small amount set up by the heat rising from the products in the room. Other rooms are cooled by blowing air over 
ammonia coils or through a brine spray in a bunker room and then directing it through air ducts to the storage room. This method, or some

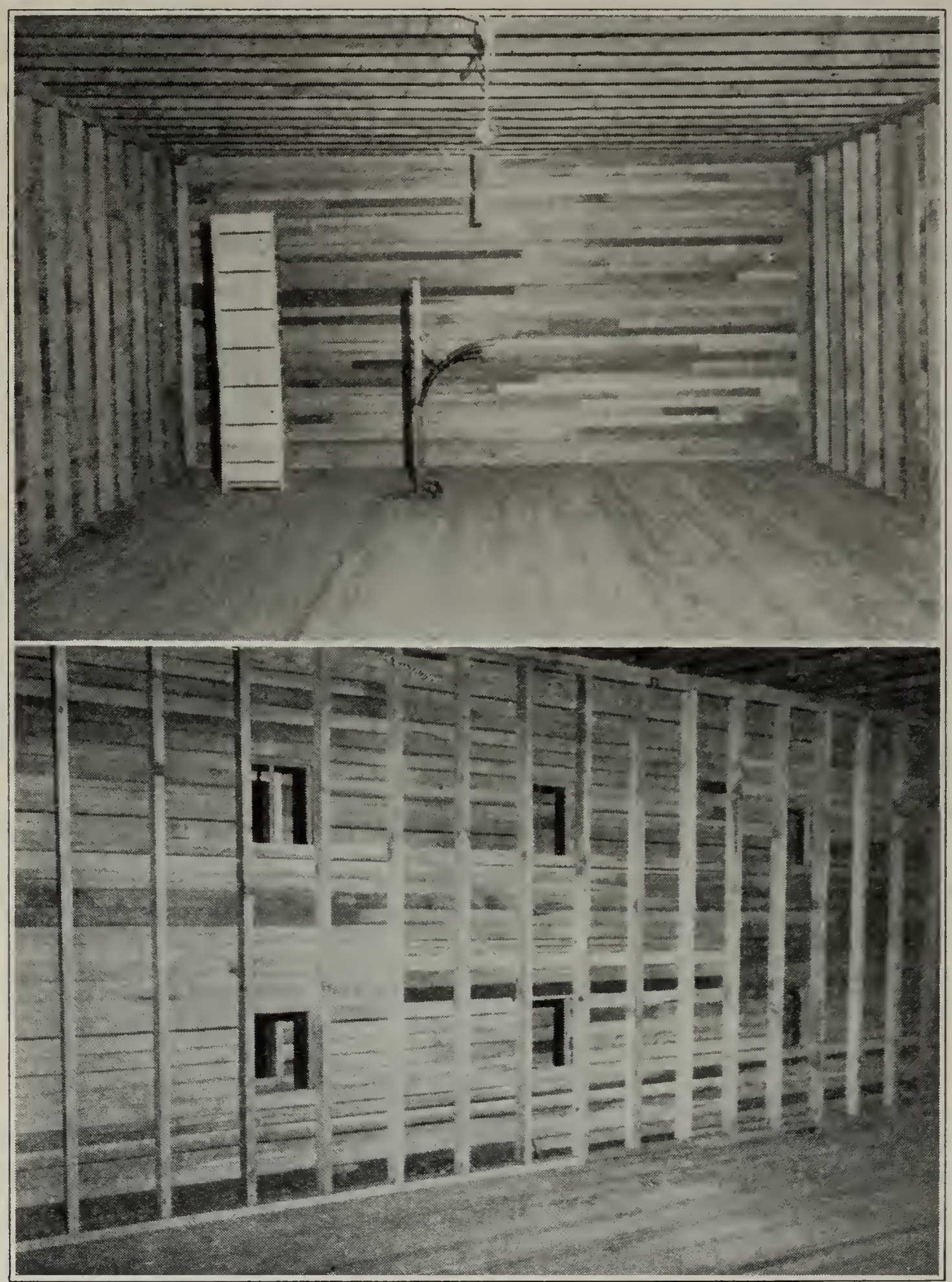

Fig. 49.-Interior views of a two-car-capacity precooling room. A unit of two such rooms is provided with 20 tons of refrigeration. Top view shows the low ceiling. With pear boxes stacked 8 high (one box higher than illustrated), all air must pass through the stacks rather than over the tops of the boxes as occurs in rooms with high ceilings. Lower view illustrates the air openings in one wall. Corresponding openings in the opposite wall permit a cross draft of air the narrow way of the room.

modification of it, where large quantities of cold air are circulated, is, for precooling, preferable to the coil room. By increasing the air velocity 
in many such rooms now being used for storage and for precooling, their efficiency for the latter purpose may be materially increased.

Where designed primarily for precooling, the rooms should preferably be of only such size as can normally be filled with fruit in from 4 to 8 hours. In some instances 6 to 8 -car capacity rooms will be satisfactory; in others, rooms of only 2-car capacity would be more desirable. Precool-

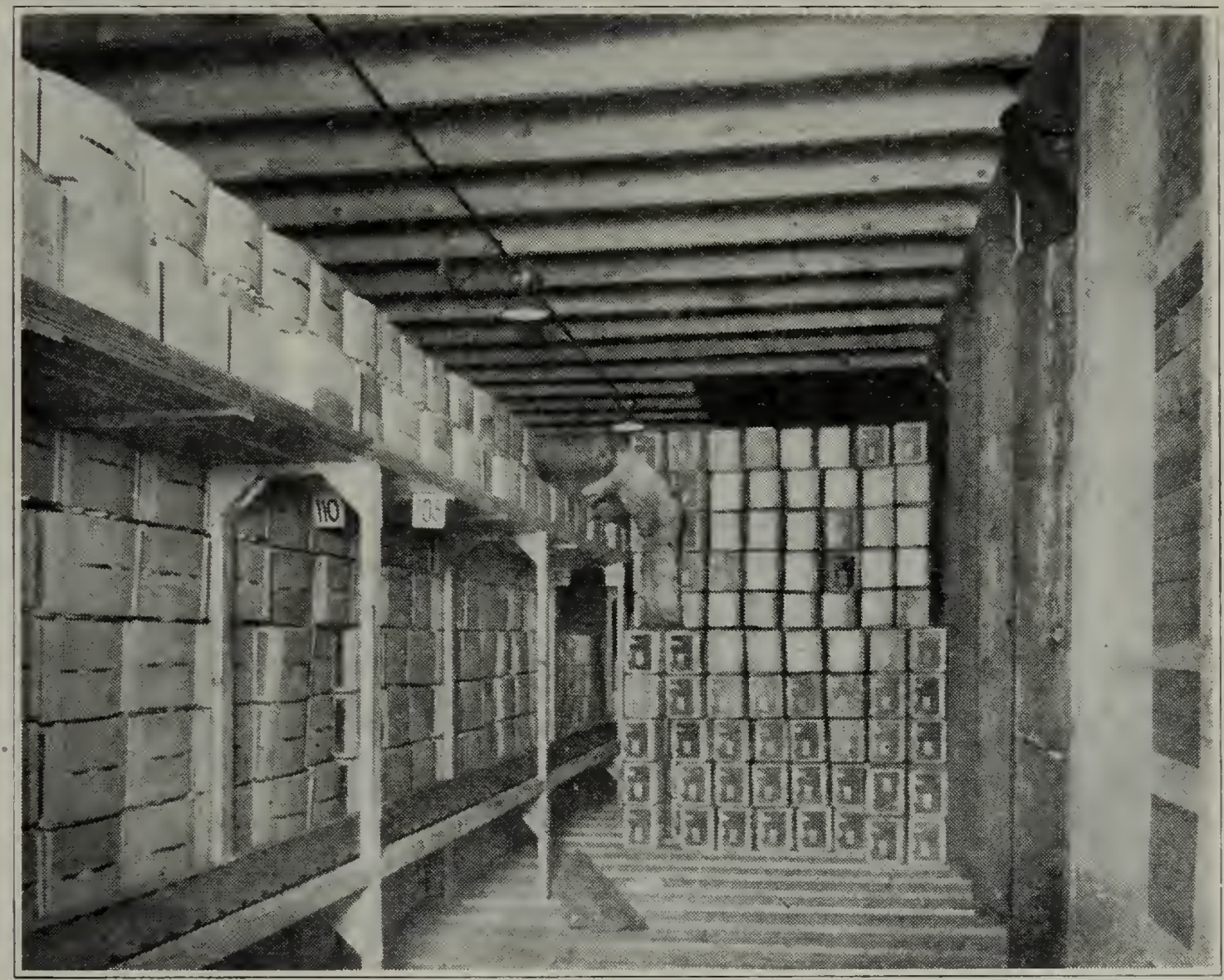

Fig. 50.-Interior view of an 8-car-capacity precooling and storage room $(11 \times 18 \times 60$ feet $)$ where the fruit is precooled by a down-draft circulation between the stacks. Two sets of conveyors down the center of the room are a permanent installation. (Illustration, courtesy of Southern Oregon Sales, Inc.)

ing rooms should also be designed with only 8 to 10 -foot ceilings in order that the fruit may occupy as large a percentage of the volume of the room as possible. With little space between the top boxes of fruit and the ceiling, a greater proportion of the circulating air is forced through the stacks.

Figure 49 illustrates a two-car room $30 \times 18 \times 10$ feet designed primarily for precooling cherries, apricots, and plums. This room, which is one of two in a precooling unit provided with 20 tons of refrigeration, has proved generally satisfactory, although more air openings in the wall would give greater uniformity in cooling. Figure 50 illustrates an 8-car pear precooling room where the cold air is introduced at the ceil- 
ing and is withdrawn at the floor. This system will be discussed under the following section.

\section{MOVEMENT OF AIR}

The value of rapid air movement in precooling is illustrated in a number of the graphs presented. Rasmussen ${ }^{32}$ also, filling two small rooms with apples-one room cooled with coils and the other by rapidly circulating air-found that 250 hours was necessary to cool the fruit in the center of the coil room to $30^{\circ} \mathrm{F}$, and only 40 hours to secure the same results in a blower room. Barger, ${ }^{33}$ working with oranges, likewise found that changing the air fifty times an hour, or nearly once each minute, cooled the fruit more uniformly and more rapidly than did changing only once in 2 minutes.

The rate of air flow through storage rooms during precooling is influenced by the capacity of the fans, the size of the air ducts, the size and number of the intakes and outlets, and the relative amount of space occupied by the fruit. Though the rate of movement in storage rooms is not easily measured, air-cooled rooms are usually designed so as to have a complete change of air every 2-4 minutes. When empty, such an air movement is little more than perceptible. Rooms designed for rapid precooling should have the air moving at a sufficient rate to make 1 to 2 complete changes a minute when empty. When filled with stacked fruit, the air space is reduced approximately one-half, which would result in 2 to 4 changes of air a minute during cooling.

In rooms with high ceilings and a cross direction of air flow, canvas baffles hung from the ceiling 10-15 feet in front of the intakes (fig. 10) force the air from the upper intakes downward, thus causing a greater percentage of the total volume to pass between the stacks. To prevent subsequent short-circuiting of air over other stacks at the outlet side of the room, top vents on this side are frequently closed. Although this practice may accomplish the intended purpose and may also actually increase the rate of air flow through certain stacks, it is of doubtful value unless the lower vents can be correspondingly enlarged. Otherwise, the closing of one-third to one-half of these outlets restricts or "pinches off" the total volume of the incoming air as much as though the same proportion of the inlets were closed. These intakes are usually closed only when the room temperature becomes too low or when, after the fruit has been precooled, it is desired to divert a greater volume of air to an adjacent room containing warm fruit. Where a single set of coils refrigerates two

32 Rasmussen, E. J. Cold-storage tests with McIntosh under forced air circulation. Amer. Soc. Hort. Sci. Proc. 28:568-571. 1931.

33 Barger, W. R. Orange refrigeration in ocean transport is best when fruit is precooled. U. S. Dept. Agr. Yearbook 1932:276-277. 1932. 
or more rooms, as is usually the case, this practice of shifting some cold air from one room to another lends considerable flexibility to the amount of refrigeration supplied to different rooms.

The rate of circulation, and indirectly the cooling rate, may also be increased in certain parts of the room by portable supplementary or "booster" fans, which are frequently placed at one end of a large block of fruit.

In rectangular rooms, a cross flow from one side to the other, or from center to sides, is considered preferable to having the air openings at the end. In the latter case, the air comes in contact with a larger amount of warm fruit, before being recooled, and cooling of the fruit is liable to be less uniform if not less rapid. The shortest distance for the air to travel in passing through the average cold-storage or precooling room is in the vertical direction. Instead of entering at the floor and being withdrawn at the ceiling, as in some of the earlier rooms, this movement of air in one of the newer precooling and storage plants (fig. 50) is reversed. Cold air enters at the ceiling and, after passing downward between all stacks of fruit, is withdrawn beneath a false floor. The down draft is sufficiently strong to overcome immediately any natural tendency of the warm air to rise; and, since there are no cross currents, warm fruit may be stacked adjacent to that which has been cooled without raising the air temperature around the stacks or depositing moisture on the cold fruit.

\section{HUMIDITY}

Under ordinary atmospheric conditions, fruit placed in a strong current loses moisture more rapidly than fruit allowed to remain for the same period in still or slightly moving air. If, however, the air is so moist that its vapor pressure equals or slightly exceeds that in the fruit, no moisture loss should occur with either high or low velocity. With a relative humidity of $85-90$ per cent in precooling rooms, little moisture is lost from fruit during precooling. With higher air velocities than those now used, a humidity of 90-95 per cent may perhaps be preferable. On the other hand, the precooling period is relatively short; and fruits requiring more than 24 hours of cooling are usually wrapped or otherwise closely packed so that a strong air current will not materially influence the rate of evaporation.

\section{COMMERCIAL HANDLING METHODS}

Actual handling in and ont of cold-storage rooms varies somewhat with different plants and with the kind of fruit. Often the packed boxes or crates are stacked on floor boards as received, and each stack is placed in the room without rehandling the boxes (fig. 10). In other instances, 
the stacks are built up in the room on timbers permitting free circulation of air beneath the bottom boxes. Stacks usually vary in height from about 4 feet for cherries to between 6 and 14 feet for other fruits and are separated by $2-4$ inch air spaces. Where the height of the cleats is not sufficient to separate each box from the one beneath or above it, or where the boxes are stacked on their sides, as with pears, strips may be

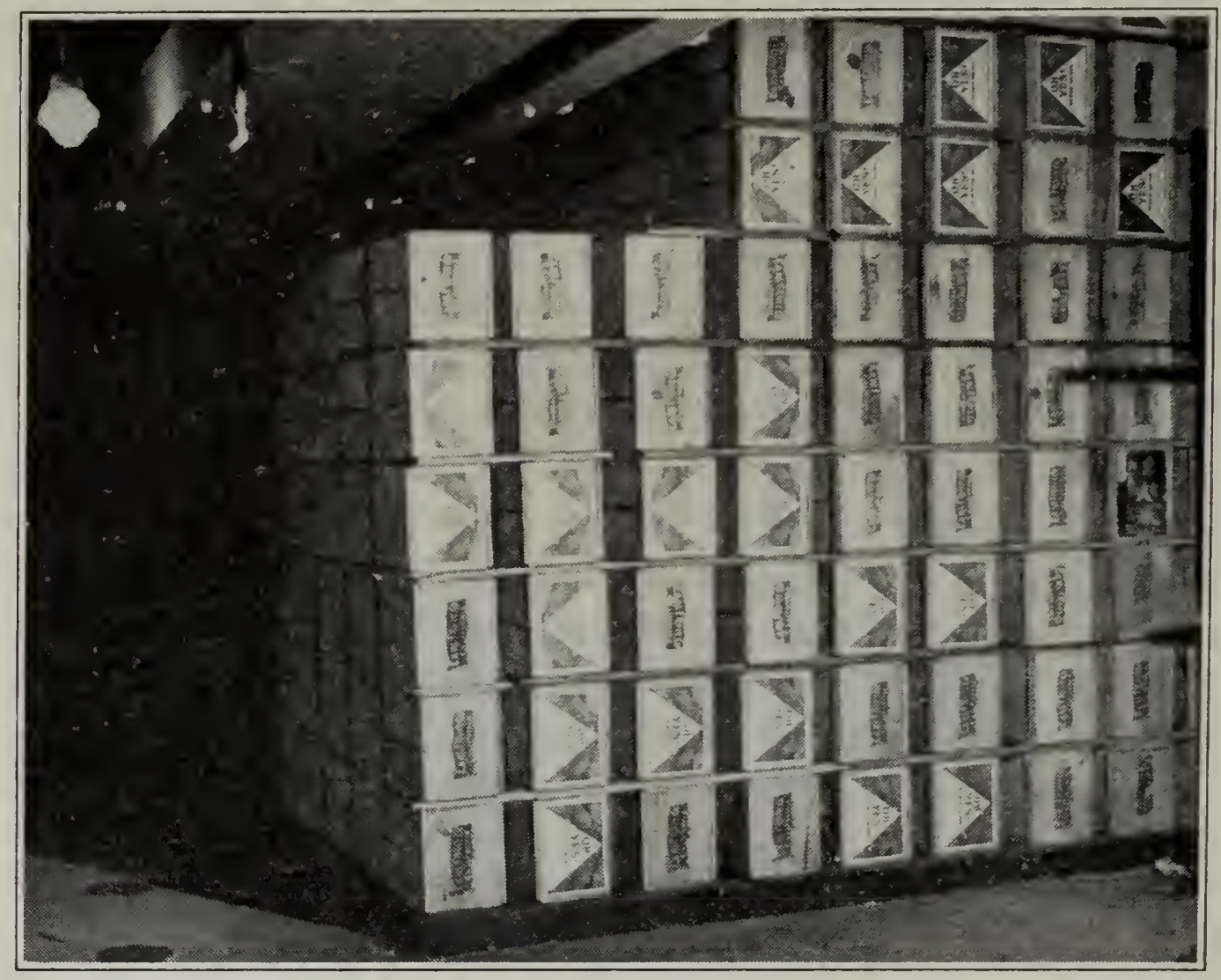

Fig. 51.-Precooling pears in a large storage room. Placing the bottom boxes off the floor, separating each row of boxes with a $3 / 4$-inch strip, and allowing a space of 2-4 inches between each stack permits free air circulation around the individual boxes and results in more rapid cooling. Cold-air ducts are shown at the left above.

used to allow a free circulation of air (fig. 51). Aisles are left to permit access to all lots of fruit; and, where space is abundant, different lots may be rather widely separated. Unpacked pears for canning, being usually stored for short periods, may be placed in rather large blocks with little or no air space between the individual stacks.

Fruit is reeeived for precooling at all hours and in various-sized lots. Thus, in large cold-storage rooms, operators are usually forced to place warm fruit with that which is at least partially precooled. As warehousemen realize, this practice is not ideal from the standpoint of most rapid cooling; and moisture is liable to be deposited upon the cold fruit. The latter danger is guarded against, however, by keeping the coldest fruit where the cold air will come in contact with it before passing over or through the stacks of warmer fruit. Where the air moves from one 
end or one side of the room to the other, the first fruit delivered is put near one or more air intakes, and no warm fruit is subsequently placed between the cooler fruit and the incoming air. Where the cold air is delivered to the center of the room through air ducts running lengthwise just beneath the ceiling (fig. 51) with the return ducts in a similar position near the side walls, cross aisles are left between stacks so that warm fruit may be placed behind that stacked along the center aisle. Occasionally certain lots remaining longer than others may have to be shifted from their original position or removed to another room for holding. As previously noted, the down-draft method of circulation permits warm fruit to be stacked in any part of the room.

\section{AIR TEMPERATURES IN PRECOOLING ROOMS}

With a precooling room containing only warm fruit, the incoming air may be considerably below $32^{\circ} \mathrm{F}$ until the fruit near the air intakes or in the colder section is in danger of freezing. Thereafter, or at least while any cold fruit remains near the air intakes, the temperature to which the air may be reduced is limited, even though additional warm fruit is placed in any position other than between the incoming air and the cold fruit. If all cold fruit is removed and the room refilled with warm, the air temperature may again safely be dropped to $29^{\circ}-30^{\circ}$ for stone fruits and to $25^{\circ}$ for pears. In rooms containing considerable warm fruit, the temperature of the air at the outlets may be several degrees warmer than at the air intakes. This difference is the "split" or "pick-up," representing the heat removed from the fruit. Fruit and air temperatures and air velocity are factors influencing this heat transfer. Because of the relatively large volume of air as compared with the quantity of the product to be cooled, this difference in warehouse rooms may be only $2^{\circ}-3^{\circ}$. Regardless of the amount of the pick-up as the air passes over the fruit, the refrigeration in the coils over which the air is drawn before returning to the room should be sufficient to remove this heat. Inability to maintain the incoming air at a constant temperature of $32^{\circ} \mathrm{F}$, or below, indicates insufficient refrigeration for precooling purposes. As previously pointed out, many rooms which contain ample refrigeration for storage purposes lack a sufficient amount for rapid precooling.

\section{GENERAL DISCUSSION OF PRECOOLING IN REFRIGERATOR CARS}

The results obtained from car precooling depend not only upon the equipment, but also upon the methods employed to maintain a low uniform air temperature, the period allotted for cooling, the time lost 
through interruptions in operating fans, and the size and temperature of the load. With a more liberal use of ice and salt, and more experience in operating the cooling equipment, the results obtained during the past season with heavy loads were in many instances equal to those first secured with much smaller loads.

\section{COOLING EQUIPMENT}

For cooling the upper part of the load, the portable fans drawing the cold air from the top of the ice bunkers and throwing it directly over the fruit have proved superior to any other equipment that the writers have tested. Portable fans are of two designs: one for placing inside the car proper at the top of the ice bunker, and the other in the top of the bunker itself.

In the latter case, they are suspended from the hatch opening, whence, after precooling, they are somewhat more easily removed than if placed inside the car. Two disadvantages, however, are that they must be removed while the ice is replenished or barred down and that the air must be forced through a grating, frequently containing only small perforations, before it comes in contact with the fruit.

The inside type of fans, when used, are most conveniently installed before the car is loaded. They should tilt slightly downward, but should be placed sufficiently high so that a good volume of air will be thrown to the center of the car. Insulated cables carrying the electric current to the motors are run along the inner wall of the car and out at the top of the door opening. When precooling is completed, the fans are removed, the operator bringing them out over the top of the load. To avoid damaging the boxes and the fruit itself, a wide board is laid over the load from the center of the car to each bunker. The operator should put these boards in position after loading and use them when placing thermometers before starting the fans.

\section{QUANTITIES AND METHODS OF HANDLING ICE AND SALT}

Where the cooling equipment used depends upon the ice in the car as the refrigerant, the quantities and methods of handling the ice, or the salt and ice mixture, are of primary importance. Where precooling consists only of placing fans in cars and allowing them to run, with no attention given to the source of cooling or to the air temperatures secured, the final results cannot compare with those possible when attention is given to these details. Formerly air temperatures of $40^{\circ}-50^{\circ} \mathrm{F}$ seem to have been accepted as about the minimum obtainable in refrigerator cars during the first 6-8 hours of precooling. Several of the accompanying figures illustrating the precooling of pears will show, 
however, that $34^{\circ}$ and even $30^{\circ}$ (fig. 37 , p. 95) can be reached in one hour. With sufficient ice and salt, moreover, and with close attention to precooling operations, $30^{\circ}$ air or that even lower may be maintained as long as desired (figs. 38, 39, 40, p. 96, 99, 101).

Rapid cooling is best secured by having the ice bunkers practically full at the outset and at least two-thirds full during the greater part of the process. In some instances early and late in the season, when fruit temperatures at loading time are not above $70^{\circ} \mathrm{F}$ and when other conditions favor rapid cooling, the ice bunkers are not replenished during a 9 to 18 -hour period (figs. 46 and 47 , p. 115, 116). Usually, however,

TABLE 21

Ice Consumed in Precooling Mixed Caris of Plums and Pears and of Standard Pear Loads

\begin{tabular}{|c|c|c|c|c|c|}
\hline \multirow{2}{*}{ Car No. } & \multirow{2}{*}{$\begin{array}{l}\text { Number of } \\
\text { packages }\end{array}$} & \multicolumn{2}{|c|}{$\begin{array}{l}\text { Fruit temperature, } \\
\text { degrees Fahrenehit }\end{array}$} & \multirow{2}{*}{$\underset{\text { precooled }}{\text { Hours }}$} & \multirow{2}{*}{$\begin{array}{l}\text { Ice consumed, } \\
\text { pounds }\end{array}$} \\
\hline & & $\begin{array}{l}\text { At beginning } \\
\text { of precooling }\end{array}$ & $\begin{array}{l}\text { At end of } \\
\text { precooling }\end{array}$ & & \\
\hline
\end{tabular}

Plums and pears (mixed load)

\begin{tabular}{|c|c|c|c|c|c|}
\hline 1002 & 541 & 57 & 31 & 26 & 5,600 \\
\hline 19697 & 567 & 53 & 32 & 24 & 5,800 \\
\hline 21681 & 557 & 70 & 32 & 24 & 8,400 \\
\hline Average & ......... & ........ & ......... & ........ & 7,325 \\
\hline
\end{tabular}

Pears (standard load)

\begin{tabular}{|c|c|c|c|c|c|}
\hline 9023 & 532 & 70 & 38 & 22 & 9,500 \\
\hline 36512 & 532 & 72 & 40 & 24 & 9,900 \\
\hline 70194 & 532 & 74 & 34 & 25 & 9,300 \\
\hline 16922 & 532 & 76 & 33 & 28 & 8,900 \\
\hline 23351 & 532 & 75 & 33 & 34 & 9,000 \\
\hline 15729 & 532 & 74 & 37 & 31 & 8,400 \\
\hline 14922 & 532 & 74 & 37 & 31 & 8,400 \\
\hline Average & ........ & ......... & ........ & $\ldots \ldots$ & 8,760 \\
\hline
\end{tabular}

Pears (heavy load)

\begin{tabular}{|c|c|c|c|c|c|}
\hline 27246 & 722 & 72 & 40 & 26 & 13,800 \\
\hline 2774 & 722 & 70 & 41 & 26 & 10,800 \\
\hline 22907 & 722 & 75 & 41 & 26 & 10,500 \\
\hline Average & .......... & ......... & ......... & ........ & 11,887 \\
\hline
\end{tabular}


this economy results in higher air temperatures and less cooling (figs. 17, 26, p. 42, 60). Heat removal, from the outer portion of the packages at least, is most rapid during the first half of the cooling period; and if the air removing the heat is to be recooled as it is drawn up through the ice before passing over the fruit again, the bunkers should be kept filled close to capacity. In general, therefore, even though at the outset a car contains enough ice, if entirely used, to cool the load, this method generally proves inefficient, and ice should be added as it is melted. After most of the heat has been removed, air temperatures can be maintained with less ice.

Cars of fruit vary somewhat in their optimum requirements. Cannon, ${ }^{34}$ cooling 46 cars of persimmons during October and November, added between 2,400 and 7,500 pounds of ice per car with an average of 4,995 pounds, or 2.5 tons. The time of cooling averaged 21 hours, and the fruit temperature was reduced from an average of $66^{\circ}$ to $31^{\circ} \mathrm{F}$. The average ice meltage in 13 cars of lug-packed apricots cooled for $7.5-8.0$ hours by one San Jose company was 4,700 pounds per car. The net amount of ice used in cooling the cars of apricots, plums and pears, and plums, shown in figures 17, 25, and 26 (p. 42, 57, and 60) was $5,700,6,760$ and 7,200 pounds respectively, while in cooling one 722 -box load of pears, 13,800 pounds of ice were melted. Other data on ice consumption in the commercial cooling of mixed cars of plums and pears, and of straight standard and heavy loads of pears are shown in table 21.

To increase the cooling surface and the rapidity of refrigeration, and also to prevent an undue amount of the salt scattered over the ice from dropping through into the bottom of the bunkers, the ice should be broken into approximately 50-pound lumps, except at the top of the bunkers, where it may be somewhat finer. Precaution should be taken, however, against having any considerable proportion of very fine ice, for the action of salt causes this to run together, so that the rapidly moving air passes through only the larger openings and is only partially cooled. When this condition occurs, and until it is corrected by again breaking up the ice into a uniform mass, the air temperature cannot easily be reduced to the desired point.

While the fans are operating, the warm air from the fruit is first brought in contact with the ice at the bottom of the bunkers, where it melts large cavities or pockets. This melting, with some unavoidable running together of the ice immediately above these pockets, again forces the air to pass largely around rather than through the ice. When these pockets occur-usually, in a car of warm fruit, after about 2 hours'

${ }_{34}$ Cannon, P. V. Savings in refrigerator charges on persimmons. Blue Anchor [California Fruit Exchange] 10(1):7. January, 1933. 
cooling - they should be filled by forcing a long icing bar down through the ice and working it from side to side, or with a circular motion, until the ice settles. (Frequently the top ice in the bunkers may drop 2 feet.) This treatment, known as "barring down," is very important in securing and maintaining low air temperatures and should be repeated as often as the air temperatures indicate that it is needed. Additional salt or ice may be added while the fans are stopped for this purpose.

Air leaving the fans at approximately $32^{\circ} \mathrm{F}$ and circulating over and through a high load of warm fruit may, during the first few hours, have its temperature increased as much as $25^{\circ}$. A difference of $10^{\circ}$ between the air leaving the ice bunker and that returning is typical of many cars. This difference in temperature obviously represents the heat absorbed from the fruit and the containers. Obviously, too, this heat now absorbed by the air should be removed from it as it passes through the ice bunkers. Since the air moves so rapidly, the bunkers of refrigerator cars would have to be materially enlarged if the ice alone were depended upon for a continuous supply of air approximating the temperature of the ice.

With addition of salt, however, the melting point of the ice is lowered, melting is expedited, and the rate of heat absorption from the air is increased. More rapid melting also absorbs a certain amount of heat from the ice and by producing lower temperatures in the ice bunkers cools the air passing through them to considerably below $32^{\circ} \mathrm{F}$. As a net result, more refrigeration is released within a given time.

$M_{a n n}{ }^{35}$ reports that with natural air circulation, air temperatures secured from various proportions of salt and ice were at the bottom of ice bunkers, approximately as follows:

Percentage of salt
2
5
10
15
20

Temperature of air, ${ }^{\circ} \mathrm{F}$

30

27

20

12

2

He adds that these temperatures are affected by the rate of supplying the heat to the mixture, by the fineness of the ice, and by the evenness of the mixture of salt. These factors become increasingly important in precooling operations; and, with the air circulating over a load of warm fruit several times a minute, more salt will be needed to secure the same temperatures during the first few hours.

In commercial practice the quantity of salt added during precooling

35 Mann, C. W. Refrigeration in transit. Blue Anchor [California Fruit Exchange] $1(9): 4-5$ and 26 . November, 1924. 
usually varies from 400 to 800 pounds, except in the case of heavy pear loads, which require from 800 to 1,200 pounds. With very warm fruit, some shippers believe equally good results are obtained, with less ice meltage, by operating the fans for about 2 hours before adding salt. In general, however, it is recommended that at least 250 pounds of salt be added immediately before starting the fans so as to release an extra amount of refrigeration at the outset. To reduce the air temperature further, or even maintain it at the desired level, a second salting of from 100 to 250 pounds should usually be given after 2 to 4 hours. Aside from the initial salting and the one closely following it, additional salt should be applied after re-icing or whenever, after barring down the ice, the air temperature cannot be maintained at the proper level. Examples are given on page 130, under "Air Temperatures During Precooling."

If the temperature during precooling has remained at $32^{\circ} \mathrm{F}$ or below, salting should be discontinued, and the air allowed to rise slightly for several hours before the fans are shut off. This procedure allows time for all the salt to dissolve and drain out and thus prevents any possible damage to the fruit from subfreezing temperatures which may occur at the bottom of the ice bunkers after the fans are stopped.

To avoid waste, the salt is best applied over the surface of the ice and worked in only slightly. It will gradually be carried down by subsequent barring of the ice.

\section{PLACING AND READING THERMOMETERS}

During precooling in refrigerator cars, fruit temperatures are usually taken in one or more boxes at the top of the load and also near the center at the brace. Air temperatures should preferably be taken at the fan and at the center of the car after the air blast has passed over the load. In some instances the temperatures may also be taken of the return air at the bottom of the bunkers. Unarmored fruit thermometers are best for securing fruit temperatures. Because it is impractical to secure these temperatures in the center of packages, the thermometers are inserted into the outer fruit to a depth of 1-2 inches, according to its size, or, for small fruits closely packed, are placed in the package to a depth of $21 / 2-3$ inches, passing between and through a number of fruits. Naturally, all readings recorded in such locations represent the minimum rather than the maximum fruit temperatures. Thermometers in fruits should be so placed that they may easily be read without removing or even loosening them from their original position. Otherwise, the wet bulb will be exposed to the air current, and the temperature will drop almost instantly. To prevent the air from influencing the reading while 
the thermometer is in the fruit, a small amount of cotton waste may be placed around the thermometer stem.

Air temperatures may be taken with easily read chemical thermom-

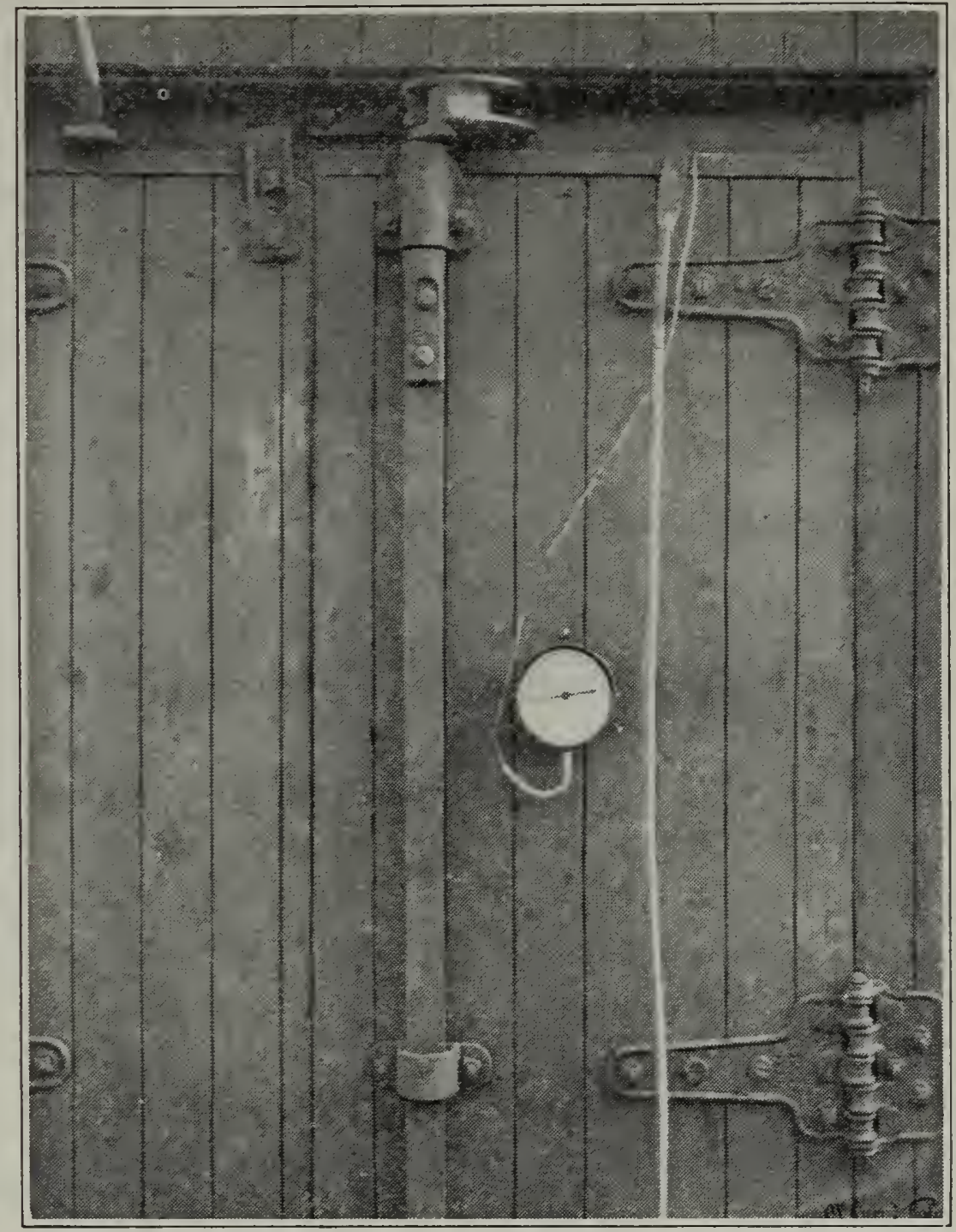

Fig. 52.-Extension type of dial thermometer on the door of a refrigerator car, showing the air temperature inside the car during precooling. The insulated cable, also passing into the car at the top of the door, furnishes the electric current to the precooling fans. (Courtesy of California Fruit Exchange.)

eters, swung on the protecting screen of the fan and above the load at the brace, or with extension dial thermometers having the bulb in these positions and the dial on the outside of the car (fig. 52). The latter arrangement has the advantage that the operator needs to enter the car less frequently; but it may be less accurate. All thermometers used, however, should previously be tested or calibrated for their accuracy, ${ }^{36}$ and

36 This is best determined by placing the thermometers in a cold-storage room of known temperature and allowing them to remain for some time before reading, or by placing them out of the sun or breeze in a container filled with finely crushed ice. In the latter case, if both container and ice are free from any salt mixture and the ice has not been held below $32^{\circ} \mathrm{F}$, the thermometers should read $32^{\circ}$. 
any corrections noted. Readings during precooling are taken at intervals of $1 / 2$ to 2 or 3 hours, according to the air and fruit temperatures at the previous reading and the general rate of cooling. ${ }^{37}$

Except when the fruit in the most exposed locations approaches $32^{\circ} \mathrm{F}$, little attention need be given fruit temperatures. The operator should, however, watch air temperatures closely, first to bring them down rapidly, second to determine when they start to rise and when the ice and salt mixture requires attention, and third to prevent any possibility of the air's becoming too cold. As previously pointed out, an air temperature as low as $25^{\circ}$ may safely be used for 18-24 hours with pears. Plums have withstood $25^{\circ}$ for 12 hours without injury but $29^{\circ}-30^{\circ}$ air is safer for this fruit, and also for cherries, apricots, and peaches.

\section{AIR TEMPERATURES DURING PRECOOLING}

The different figures presented show the air temperatures from the fans in the different cars. These vary rather widely. In some instances (figs. 33, 35, and 37 , p. 88, 92, and 95) the air blast was quickly reduced to $35^{\circ} \mathrm{F}$ or lower, while in others, through faulty management, it remained too high for rapid cooling. With the amount of salt supplied to P.F.E. 50473 (fig. 6, p. 24), lower air temperatures should have been secured. Failure to reduce the air to $32^{\circ}$ almost immediately was due to insufficient ice in the car and to improper barring down and application of the salt. After cooling for $73 / 4$ hours this car contained less than 1,000 pounds of ice. In P.F.E. 33160 (fig. 17, p. 42), replenishing the ice bunkers before starting the fans and the addition of more salt after $21 / 2$ hours, together with more frequent barring of the ice, would have produced lower air temperatures during the first $71 / 2$ hours. Failure to secure lower temperatures in P.F.E. 38444 (fig. 19, p. 44) was due to delayed re-icing and improper handling of the salt and ice mixture. With P.F.E. 36550 (fig. 34, p. 90) heavier initial salting plus approximately 100 pounds added at the last re-icing after 14 hours' cooling, would have lowered the temperature more quickly and have kept it more uniform. In P.F.E. 22693 (fig. 36, p. 94), more salt and more barring down were needed after 5 hours and ice should have been added earlier. When re-iced and salted after 15 hours, the air (and the fruit as well) showed a marked drop in temperature.

These examples illustrate differences in air-blast temperatures and show how the operator may control them. For rapid cooling, the air blast should be quickly reduced to $32^{\circ} \mathrm{F}$ and maintained at $32^{\circ}-30^{\circ} \mathrm{F}$ as nearly as possible for 18-20 hours during a 24-hour precooling

37 For convenience in getting in and out of cars to read thermometers during precooling, see "Miscellaneous Considerations," page 133. 
period. With pears, still faster cooling can be secured without danger of injury by dropping the air to $25^{\circ}$ and holding it between $25^{\circ}$ and $28^{\circ}$ until the exposed fruits reach $28^{\circ}-30^{\circ}$. Since time is an important factor in precooling and since no cold fruit is present in the load to prohibit the use of low air temperatures, their use seems highly desirable. Some, possibly, have been prejudiced against rapid cooling because fruit subjected to low temperatures for only a limited time is not thoroughly cooled and will subsequently show a rise in temperature.

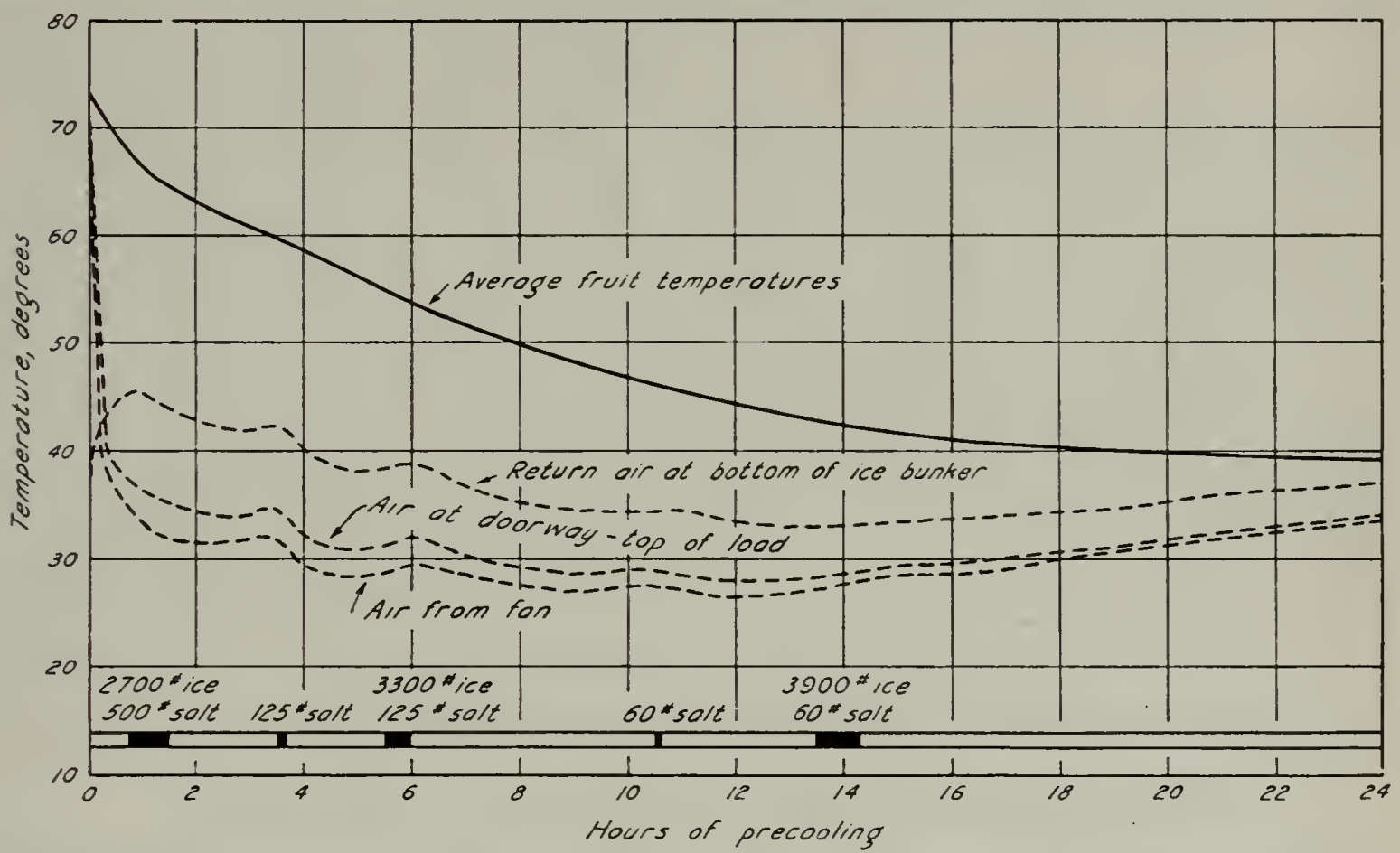

Fig. 53.-Precooling of Bartlett pears, P. F. E. 36612, Suisun, August 15-16, 1933: average fruit temperatures in nine positions of the load, together with the temperature of the air at the fan on leaving the top of the ice bunker, at the brace after passing orer the top of the load, and upon returning to the bottom of the ice bunker.

There appears, however, to be no evidence that rapid cooling is fundamentally harmful to deciduous fruits; and warm fruit wrapped and tightly packed can withstand subfreezing temperatures for a considerable period without freezing. It should be remembered that the rate of cooling in the center of a packed box is increased with a rapid cooling of the fruit near the edges.

Although the figures previously presented show only the temperatures of the air leaving the fans, thermometers were also placed in each car just above the load at the doorway and at the bottom of the bunkers where the warm air was returning to the ice. Smoothing out changes in temperature while the fans were not operating, figure 53 illustrates air temperatures in these three positions in a standard load of pears. The air moves over the top of the load so rapidly that after 10 hours of cooling its temperature at the brace is only about $2^{\circ} \mathrm{F}$ higher than 
at the fan. Even in high loads, this difference has been found not to exceed $4^{\circ}$ after a few hours of cooling, nor $2^{\circ}$ after $18-20$ hours. Since these differences are small, the operator may determine approximately the temperature of the fan blast by reading a thermometer in the doorway; and if a dial extension thermometer is placed at this point, with the dial on the outside of the door, considerable going in and out of the car may be obviated.

With heavy loads of warm fruit, differences in the air temperature above the load at the brace and at the bottom of the bunker, where air returns to the ice for recooling, are greater than the differences between temperature at the fan and at the brace. The reason for this is that the air has to travel farther and comes in contact with a greater surface of packages as it filters back through the load. The total temperature difference between the air when entering the car at the top of the bunker and when returning to the bottom represents the split or pick-up, as in a storage room. As previously mentioned, in a 722-box load of pears, where the fruit occupies a greater proportion of the air space in the car, this pick-up during the first $8-10$ hours of precooling is sometimes as high as $25^{\circ} \mathrm{F}$.

In all cars cooled by reversing the natural circulation, the coldest air is first brought in contact with the warmest fruit and vice versa, so that the entire load reaches a relatively uniform temperature.

\section{FRUIT TEMPERATURES SECURED IN PRECOOLING}

Rates of cooling the fruit in the outer parts of packages in different positions in the load are given under individual car tests, and the relation between these outer temperatures and those in the center of the packages is illustrated in several of the storage-room tests. The general results are summarized under each fruit.

When close attention is paid to securing and maintaining a good air temperature, the cooling rate is approximately the same in refrigerator cars as in a storage room. Considerable variation, however, may exist by either method. The primary factors determining the results are the velocity of the air circulating over or through the packages, the difference in temperature between the air and fruit, and the length of time cooling continues. The rapid circulation of cold air has been emphasized. Important though this is, at least 24 hours and usually $30-48$, as indicated by an extension of the cooling curves in figures 35,36 , and 37 , are necessary to reduce the fruit temperatures in the center of a packed box of pears to $40^{\circ} \mathrm{F}$. Cooling of a heavy load of fruit may demand little more time than that necessary for a standard load, provided the air flow is not materially restricted and the same air temperature 
is maintained in both cars. If, however, no extra refrigeration is provided for the heavier load, the air temperature will eventually become higher, and the rate of cooling slower.

Unwrapped fruit in open packages, such as plum crates, requires one-third to one-fourth the time, and unpacked pears in lug boxes about one-third the time required for packed pears. The influence of liners upon the rate of cooling has not been definitely determined. It is reasonable to expect them to have some retarding influence, although where the fruit is tightly packed, and especially if it is individually wrapped, their influence is probably slight.

In loading refrigerator cars, one should remember the desirability of unobstructed air circulation during precooling. In mixed cars (those containing more than one kind of fruit, or type and size of package) some of the air channels running lengthwise of the car are necessarily blocked. Repeated tests under uniform conditions would be required to determine accurately how much this method of loading affects the cooling rate. It is believed, however, that a lengthwise blocking will have less effect on cooling with the bunker type of precooling fans than would a blocking in the vertical direction.

\section{MISCELLANEOUS CONSIDERATIONS}

Loads of most deciduous fruits contain in one end of the car, known as the "heavy end," an additional tier of crates or boxes which usually blocks one-half of the door openings. Where fruit is to be precooled in refrigerator cars and temperature readings must be taken inside the car, this extra tier of fruit should be placed so as to block the door on the left, which after loading is rarely opened. The brace of the load will then be opposite the right-hand door, which always opens first, and it will be unnecessary for the precooling operator to climb over a stack of fruit in order to enter. In instances where the car is moved after loading and before precooling, and the platform from which the precooling operator must work comes on the opposite side of the car from which it was loaded, the position of this tier of fruit with reference to the doors should be reversed.

Since portable equipment permits the precooling of fruit in cars at any loading point, the results obtained often depend largely upon one or more miscellaneous factors. Suitable electric current must be available for the fans, and a reserve supply of ice and salt must always be on hand or quickly obtainable. Since much of the work is carried out at night, lighting facilities are necessary, and sufficient helpers available for re-icing cars and reading thermometers: Though some inexperienced workers may be used, at least the operator in charge should 
be a reliable man, trained for the work in hand. Fans may frequently have to be disconnected because of switching. The coöperation of the railroad in moving cars as little as possible and replacing them without undue delay is essential. Figure 54 furnishes an example of a car where cooling of a 722-box load of pears was retarded by switching and by delay in re-icing. $\mathrm{Had}$ a $30^{\circ}$ air temperature been secured in 1-2 hours instead of after 10 hours, cooling of the outer fruit, followed by that in the center of the box, would have been considerably more rapid.

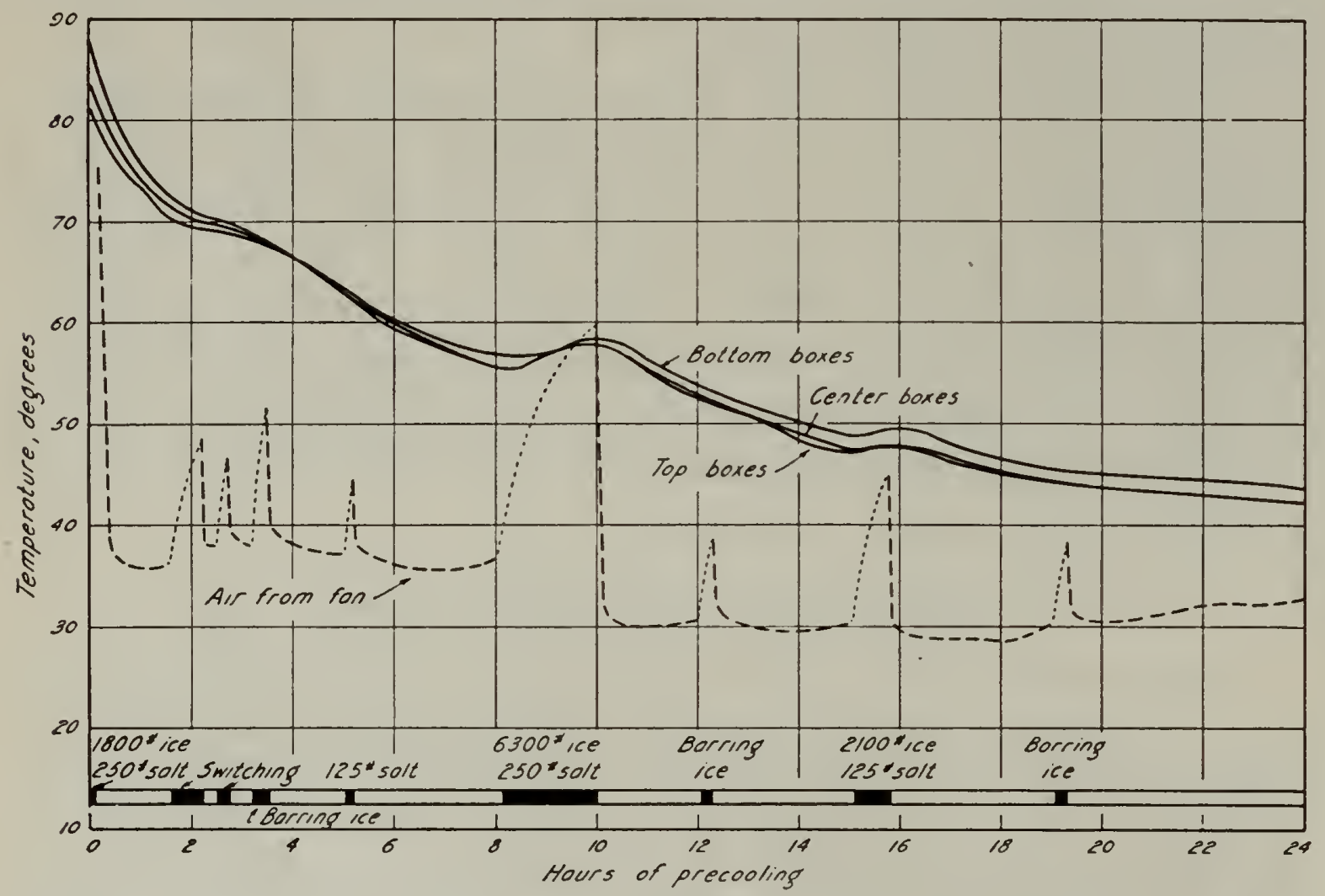

Fig. 54.-Precooling of pears in P. F. E. 17456, Placerville, August 24-25, 1933. The air temperature in this 722-box load of pears was reduced to $36^{\circ}$ in 1 hour but could not be maintained or lowered until after 10 hours on account of movement of the car and a delay in re-icing. After re-icing, which in itself required 2 hours, the temperature was reduced to $30^{\circ} \mathrm{F}$. The fruit temperature taken near the edges of boxes in the top, center, and bottom of tiers 1, 5, and 10 show uniform but rather slow cooling. The initial fruit temperatures, however, were high.

\section{CAR VERSUS WAREHOUSE COOLING}

Car cooling has been designed to supply precooling facilities to centers of production or to shipping points where, because of the limited shipping season or volume of fruit handled, precooling warehouses could not be economically maintained. Its chief purpose, therefore, has been to fill a need not otherwise supplied, although at present, with the large increase in precooled shipments, it also supplements warehouse cooling.

The latter has generally been preferred to car cooling because it was quicker and more thorough. These tests, however, conducted in storage 
rooms and in refrigerator cars containing cooling equipment, fail to show, if the equipment is properly operated, any essential or consistent difference in the rate of cooling. With a sufficient and properly managed supply of the salt and ice mixture, air temperatures in refrigerator cars during precooling may be reduced as low, and in many instances lower, than is possible under the usual system of management of the present type of warehouse rooms. In addition, the air in cars is brought over the load with considerable force and, being confined in a very limited space, circulates more rapidly than in warehouse rooms.

The thoroughness of cooling under the two systems is fundamentally dependent upon the time available. Since track facilities are definitely limited, precooling in cars is usually limited to 24 hours or less. Unwrapped fruits in open-type containers should be well cooled within this time but fruits difficult to cool, such as pears, are rarely brought to an average temperature lower than $40^{\circ}$, even after 36 hours. Thorough precooling of pears to approximately $32^{\circ}$ will require from 48 to 72 hours. Where precooling for this period of time is desirable, warehouse cooling is considered preferable to car cooling. In addition, where shipments are to be assembled gradually or must be prorated between growers or between districts, precooling often extends into a short storage period, and it is in this connection that cold-storage warehouses have their main advantage.

\section{METHODS OF SHIPPING PRECOOLED FRUIT}

Fruit shipped by rail may be forwarded under various traffic rules or icing schedules. These are subject to frequent changes but, since the present schedules have a very important bearing upon precooling and shipping methods, they merit brief discussion.

\section{STANDARD REFRIGERATION}

Under standard refrigeration, cars are usually ordered pre-iced. After loading, the service calls for re-icing at the first icing station in transit and refilling the bunkers to capacity at each regular station en route. With 8-10 such stops between California and the eastern markets, loads of warm fruit may consume some 20,000 pounds of ice in transit. Standard refrigeration, as the name implies, has long been used for most nonprecooled deciduous fruits, and is still to be recommended with some transcontinental shipments which have been precooled. Highly perishable fruits, or those moving during the warmest weather, particularly if well advanced in maturity and only partially precooled, can be shipped by this method with the minimum risk of 
arriving overripe. Precooling and forwarding under standard refrigeration also offers the possibility of having many early shipments of greater maturity (plum test 1 ), ripening with better quality.

The present cost of standard refrigeration to New York is $\$ 94.50$ a car, plus $\$ 4.72$ to $\$ 11.81$ if salt is to be added with the ice. The expense of this service is a rather large item; and for this reason growers and shippers are interested in the possible savings which may be made by precooling and shipping under more limited icing schedules.

\section{RULE 247: INITIAL ICING AND ONE RE-ICING IN TRANSIT}

This original modified icing schedule providing for only one re-icing in transit has been largely replaced by Rule 254 , which permits an additional re-icing after loading and before shipping.

\section{RULE 254: INITIAL ICING, ICE REPLENISHED, AND ONE RE-ICING IN TRANSIT}

As indicated, this service calls for a pre-iced car, for re-icing after loading and before shipping, and one re-icing in transit; the charge for which is $\$ 67.00$ to New York, or $\$ 28.50$ less than for standard refrigeration. This service, first obtained in 1933, is a distinct concession from the carriers, and has created a greater interest in precooling and modified icing than any other tariff. Growers and shippers felt not only that the difference in the two refrigeration rates would cover the cost of precooling but that many shipments of precooled fruit could be made under this schedule and be delivered in better condition than nonprecooled shipments re-iced daily.

While there have been some exceptions, precooling with modified icing has generally been highly successful. Detailed reports concerning the condition of the fruit on arrival in New York with only one re-icing in transit are shown in apricot test 3 , page 41 , plum test 4 , page 61 , and pear tests 5 and 6 , pages 93 and 95 , respectively. Several of these pear loads not only contained 722 boxes but were precooled only to a temperature of between $40^{\circ}$ and $50^{\circ}$; in addition the cars encountered high outside temperatures in transit.

Air-temperature records secured at the top of the load at the doorway while the cars were in transit were considerably lower for several days than in nonprecooled cars under standard refrigeration and were quite similar for 6-8 days to standard-refrigeration shipments which had been precooled. As the ice in the bunkers becomes low there will necessarily be some rise in temperature within the car. With fruit well advanced in maturity, uniformly low temperatures are desired throughout the transit period, but with the usual maturity of most shipments 
a slight temperature increase during the last 2 or 3 days may not be serious. In any event a gradually rising temperature for several days as the car approaches destination is less serious than the slow cooling of nonprecooled loads duiring the first 4-6 days. Under present icing tariffs, a continuation of precooling with less ice supplied in transit is therefore to be expected.

As possible objections to limited icing, it may be that cars arriving at destination too late in the week to sell at auction until the following Monday may have to be re-iced after arrival. This may also be true with cars which are diverted from their original destination. Some shippers also feel that in certain private-sale markets the buyers, accustomed to seeing full ice bunkers, may be prejudiced against a car arriving with little ice. In some instances he may also wish to hold the car several days before unloading and may therefore demand re-icing.

\section{RULE 240: INITIAL ICING ONLY}

In contrast to replenishing the ice in the car each 24 hours, as called for under standard refrigeration, or once in transit as provided by Rule 254, Rule 240 specifies, "Do not re-ice." Initial icing may be either by the carrier or the shipper. In the former case, the charge to New York is $\$ 39.55$, or slightly less than half that for standard refrigeration. If the shipper chooses to ice the car, so that it may be full of ice after loading, he must pay $\$ 21.00$ for this privilege.

Obviously, if fruit is warm when loaded and is to travel any distance, this service is inadequate. With precooled shipments, however, its use is increasing. Shipment of the more rapidly ripening fruits, such as apricots, plums, and peaches, may be successfully carried for a period of 24-48 hours, while pears, precooled only to between $40^{\circ}$ and $50^{\circ} \mathrm{F}$, have carried to New York in a firm condition. Pear test 2, page 88, is a comparative test of a precooled load shipped without re-icing by the Placerville Fruit Growers' Association in September, 1932, with a nonprecooled car shipped standard refrigeration. This test and similar shipments of Bosc pears are also more fully discussed by Read. ${ }^{38}$ Pear tests 8 and 9 (p. 98 and 100, respectively), give the condition of other cars shipped to New York during the months of July and August, 1934, without receiving any ice in transit. Both of these loads were car-cooled for 26 hours, reducing the temperature of the fruit to approximately $45^{\circ}$. Upon arrival in New York little ice remained in the cars. The air temperature at the top of the load had gradually climbed during transit to $60^{\circ}$. All the fruit was reported firm to hard with slight color.

38 Read, F. W. A test of new types of refrigeration and precooling service. Blue Anchor [California Fruit Exchange] 9(12):4, 30, 32, and 35. December, 1932. 
In pear test 10 , page 102 , the air temperatures in transit and the comparative condition of the fruit on arrival are shown for three cars; a nonprecooled load receiving standard refrigeration, and two precooled loads, one shipped with one re-icing and one without re-icing. After the fifth day the latter car carried at a slightly higher temperature than the load re-iced in transit, but under a lower average temperature than the nonprecooled load re-iced daily. Upon arrival in New York corresponding differences were noted in the color of the fruit. The precooled load with one re-icing showed the least color change. Precooled fruit shipped without re-icing showed somewhat more color change but less than the nonprecooled load under standard refrigeration, where the icing charges were more than twice as great.

In these tests of pears, where the fruit was only precooled to $40^{\circ} \mathrm{F}$ and was shipped during the warmest part of the summer, ripening was somewhat greater than is desirable. With more thorough cooling, however, and perhaps with the use of block ice, which would melt less rapidly, this limited icing service for pears may be used even with the heavier loads. Successful shipments of this nature have been made for two years from the Antelope Valley. Upon arrival in New York ice bunkers were reported to be one-half full and the fruit temperature from $44^{\circ}$ to $48^{\circ}$. A large share of the precooled shipments of fall and winter pear varieties from the Rogue River district of Oregon are shipped without re-icing in transit. Fisher ${ }^{39}$ reports similar shipments from the Northwest, while Cannon ${ }^{40}$ reports substantial savings in refrigeration by not re-icing persimmons shipped during October and November.

In general, this limited system of icing is, of course, suitable only for precooled fruit or that shipped during cold weather; also the same objections may apply to some shipments as mentioned in connection with Rule 254. On the other hand, growers and shippers are intent on reducing costs and, with precooling now much more general than formerly, this method of shipment is likely to increase.

\section{HEAVY LOADING}

Freight rates for deciduous fruits have long been based on a minimum load of 26,000 pounds. In 1933 , however, a 10 per cent reduction (from $\$ 1.73$ a hundred pounds to $\$ 1.55$ ) was granted for shipments east of Chicago for minimum loads of 36,000 pounds. In 1934 the same reduction applied to 30,000-pound loads. To secure these minimum

\footnotetext{
39 Fisher, D. F. Economics in improved refrigeration of fruits in transit. U. S. Dept. Agr. Yearbook 1933:352-354. 1933.

40 Cannon, P. V. Savings in refrigeration charges on persimmons. Blue Anchor [California Fruit Exchange] 10(1):7. January, 1933.
} 
weights, especially the former, fruit must be loaded relatively close to the top of the car (using a brace load) and without precooling they are impracticable. With precooled shipments, however, heavy loading has proved not only practicable but advantageous.

Among the earlier shipments of Bartlett pears during the summer months, Schorr ${ }^{41}$ reports numerous 722-box loads which carried satisfactorily and only a few which did not. Mallison and Powell ${ }^{42}$ report as good results in shipping heavy loads from the Northwest as from standard loads. Pear tests 5 and 6 (p. 93 and 95) in this report, made in 1933, and test 8 (p. 98) made in 1934, give the results of heavy-load shipments made by the Placerville Fruit Growers' Association. In addition to the savings made in these shipments by heavier loadings, they were also shipped under modified icing.

Heavy loading of other fruits has been more limited than those with pears. Some shippers, however, have employed the 30,000-pound load successfully with plums (see plum tests 4 and 6, p. 61 and 64) and with continued improvement in methods and more thorough precooling, 30,000 pounds for plums, apricots, and peaches should be as successful as 36,000-pound loads for pears.

The success of the heavier loads largely depends upon the extent of precooling, the methods of loading, and the temperature conditions the car encounters in transit. Heavy loads of well-precooled fruit loaded into well-cooled and well-insulated cars, without exposure to outside air, should carry under a lower temperature for a greater distance than lighter loads. With thorough precooling the "squeeze" pack as used with citrus loads may also prove an advantage over present methods of loading with a brace between the doorways. A closely packed load but with a space between the cold fruit and the side walls of the car is planned by one of the larger pear associations this year. This system has already been used here to some extent commercially and, in the test shipments of Mallison and Powell, has given slightly better results than braced loads.

\section{GENERAL SUMMARY AND CONCLUSIONS}

The general value of precooling perishable fruit for long-distance shipments has been recognized for many years; but the absence, in many localities, of suitable facilities, together with the expense involved, has been a retarding factor in its general adoption.

\footnotetext{
41 Schorr, B. K. Precooling deciduous fruits in 1933. Blue Anchor [California Fruit Exchange] 10(11):2, 3, 19. November, 1933.

42 Mallison, E. D., and C. L. Powell. Refrigerated transportation of Bartlett pears from the Pacific Northwest. U. S. Dept. Agr. Tech. Bul. 434:1-30. 1934.
} 
Recent development of efficient portable car-cooling equipment, reduced refrigeration charges for limited icing services in transit, and a 10 per cent saving in freight charges by heavier loading of cars, have all greatly increased the interest in precooling during the past three years, and are bringing about changes in methods of handling and shipping California deciduous fruits. During the past three years a larger percentage of interstate shipments of the fruits studied, namely, cherries, apricots, plums, peaches, nectarines, pears, and grapes, were precooled, and many of these cars shipped under the lower freight and refrigeration rates.

In addition to the financial savings which thus result from precooling, precooled fruit reaches the eastern markets in a more uniform condition of maturity, firmer, and with less color development than nonprecooled. Thorough precooling also offers the possibility of certain fruits' being allowed to become somewhat more mature before harvesting and thus to gain in dessert quality when finally ripe. Some of the results upon rate of ripening and the period of marketability of precooled and nonprecooled fruit are shown.

Precooling tests were conducted both in warehouse rooms and in refrigerator cars. Car precooling has been found to offer a service to growers and shippers who prefer it or who do not have access to warehouses. Newer types of car equipment and their operation were studied, together with the general rate and uniformity of cooling. In some shipments air temperatures were not only recorded during precooling, but throughout the period of transit.

Samples of precooled and nonprecooled fruit were held in storage for a 10-day transit period under shipping temperatures and then observed for differences in ripeness and for the length of time the fruit remained marketable. Reports on carload lots were also received from shippers' representatives in the eastern markets. In practically all instances the value of precooling is apparent.

For rapid and uniform cooling in refrigerator cars, where ice is used as the refrigerant, the portable precooling fans which fasten inside the car at the top opening of the ice bunkers, drawing the cold air from the top of the bunkers and forcing it over the load, are the most efficient yet tested. This type of equipment cools the top of the load more rapidly than the bottom-a desirable result, in that under natural air flow in a refrigerator car, top fruit cools more slowly and never becomes so cold as that in the bottom. With proper attention given to the ice and the addition of suitable quantities of salt, air temperatures in refrigerator cars during precooling may be comparable to those in commercial cold-storage rooms. 
Unwrapped fruit in relatively open containers, or that which is of relatively low temperature when loaded, may be cooled in refrigerator cars to a satisfactory carrying temperature by the addition of $350-500$ pounds of salt to the ice remaining in the car bunkers after loading. With most shipments, however, when the precooling period is longer than 4-6 hours, additional ice should be supplied. Lower air temperatures are secured and more rapid cooling accomplished by keeping the ice bunkers two-thirds full at all times.

In cooling wrapped and tightly packed fruit, and particularly the heavier loads of pears, three to four re-icings are recommended during a 24-hour precooling period. To secure and maintain a temperature of $32^{\circ} \mathrm{F}$ or below during this time will require the melting of some 5 tons of ice and the use of $800-1,000$ pounds of salt. Failure to secure or maintain a low air temperature after operating the precooling fans for 3-4 hours indicates the need for more ice or salt (or both), or that the ice should be barred down to fill the large air pockets which may have formed at the bottom of the bunkers.

Operators of car-precooling equipment should appreciate the fact that ice must be melted in order to secure cooling and that the rate of melting and the amount of ice consumed is a measure of the heat being absorbed. Suggestions for securing the best results for car precooling are given under the general discussion of car cooling.

As previously intimated, the rate of cooling in refrigerator cars may be equal to, or even more rapid than that in cold-storage warehouse rooms, many of which lack sufficient reserve refrigeration and air velocity for most rapid cooling. Rooms of large size may also contain both warm and cold fruit, the latter preventing the use of most desirable air temperatures for the rapid removal of heat. To offset this disadvantage, which is being corrected in some plants and avoided in the new constructions, the use of refrigerator cars for precooling is usually limited to 24 hours or less on account of insufficient track space for holding. To thoroughly precool wrapped and closely packed fruit, such as pears, this period of time is insufficient. Thus where a considerable period is necessary for obtaining low fruit temperatures, warehouse cooling offers the most feasible if not also the most economical means of accomplishing the desired results.

Aside from the original temperature and how the fruit is packed, the primary factors in cooling of fruit whether in a refrigerator car or in a warehouse room are two in number: (1) the temperature of the air, and (2) its velocity past and around the packages. Increasing the air velocity from practically still air to that moving past the fruit at 250 feet a minute may reduce the time required for cooling by 30-50 per 
cent. A similar reduction in cooling time may be secured by the use of minimum air temperatures. Air at $25^{\circ} \mathrm{F}$ may be safely employed in precooling warm packed pears for approximately 24 hours, and little injury has occurred where it was used for 48 hours. The air used in precooling plums and other stone fruits may be maintained at $25^{\circ}-26^{\circ}$ for 8-10 hours, after which it should be raised to approximately $30^{\circ}$. Since vinifera grapes held in storage at a temperature of $28^{\circ}$ have not been injured, $28^{\circ}$ air may be safely used as long as necessary. Cooling of the different fruits under varying air temperatures and velocities are given in the summary for each individual fruit.

The newer and less expensive icing services, together with reduced freight rates for heavier loads, made possible through precooling, have effected large savings in transportation charges.

Under modified icing services, commercial shipments of precooled fruit have arrived at their destination in better condition than nonprecooled fruit shipped under standard refrigeration and in some instances in as good condition as precooled shipments so forwarded. The air-temperature records secured in a number of cars in transit to New York show little difference between those receiving standard refrigeration and those re-iced only once. With the less perishable fruits at least, which have been thoroughly precooled, daily re-icing of the cars in transit appears to be an unnecessary expense.

\section{ACKNOWLEDGMENTS}

As a large number of the tests comprising these investigations have been with commercial shipments, the authors here wish to express their appreciation to many individuals and to no less than twenty-five shipping and sales organizations, ice companies, storage warehousemen, precooling companies, refrigerator car companies, and canneries interested in precooling, who have provided the opportunity to work under commercial conditions, and who have made possible this report, through their coöperation in making the necessary arrangements for the tests; in supplying recording instruments accompanying shipments to the eastern markets; in supplying fruit and arranging for its inspection at destination; and in furnishing various storage, shipping, and transportation information. 